ALEXANDRE BELETTI FERREIRA

TÉCNICAS DE PROGRAMAÇÃO E AVALIAÇÃO DE DESEMPENHO DE SOLVERS DE SISTEMAS DE EQUAÇÕES LINEARES EM SISTEMAS COMPUTACIONAIS DE ALTO DESEMPENHO 
ALEXANDRE BELETTI FERREIRA

TÉCNICAS DE PROGRAMAÇÃO E AVALIAÇÃO DE DESEMPENHO

DE SOLVERS DE SISTEMAS DE EQUAÇÕES LINEARES EM SISTEMAS COMPUTACIONAIS DE ALTO DESEMPENHO

Tese apresentada à Escola Politécnica da Universidade de São Paulo para obtenção do título de Doutor em Engenharia.

SÃO PAULO

2014 
ALEXANDRE BELETTI FERREIRA

\section{TÉCNICAS DE PROGRAMAÇÃO E AVALIAÇÃO DE DESEMPENHO DE SOLVERS DE SISTEMAS DE EQUAÇÕES LINEARES EM SISTEMAS COMPUTACIONAIS DE ALTO DESEMPENHO}

Tese apresentada à Escola Politécnica da Universidade de São Paulo para obtenção do título de Doutor em Engenharia.

Área de Concentração:

Engenharia de Estruturas

Orientador: Professor Dr. Paulo de Mattos Pimenta 
Este exemplar foi revisado e corrigido em relação à versão original, sob responsabilidade única do autor e com a anuência de seu orientador.

São Paulo, 8 de janeiro de 2014.

Assinatura do autor

Assinatura do orientador

\section{FICHA CATALOGRÁFICA}

\section{Ferreira, Alexandre Beletti}

Técnicas de programação e avaliação de desempenho de solvers de sistemas de equações lineares em sistemas computacionais de alto desempenho / A.B. Ferreira. -- versão corr. -São Paulo, 2014.

$169 \mathrm{p}$.

Tese (Doutorado ) - Escola Politécnica da Universidade de São Paulo. Departamento de Engenharia de Estruturas e Geotecnica.

1. Análise não linear de estruturas 2. Sistemas lineares 3. Programação paralela I. Universidade de São Paulo. Escola Politécnica. Departamento de Engenharia de Estruturas e Geotécnica II. t. 


\section{DEDICATÓRIA}

Dedico este trabalho a Célia Maria Beletti Ferreira. 


\section{AGRADECIMENTOS}

Agradeço a Deus pela vida e a Jesus Cristo pelo exemplo de conduta.

Agradeço profundamente ao professor Paulo de Mattos Pimenta por ter possibilitado a realização de meu doutorado na Escola Politécnica da USP e por sua orientação técnica, além de ter colaborado com o processo de aquisição da bolsa de estudos e, principalmente, por possibilitar meu estágio no LBNL em Berkeley.

Agradeço ao pesquisador Osni Marques, do Lawrence Berkeley National Laboratory, por ter me recebido, direcionado o trabalho e por ter fornecido acesso aos recursos computacionais do referido laboratório.

Agradeço também ao professor João Batista Aparecido da UNESP, por ter despertado a consciência acadêmica em meu ser durante os anos de realização de meu trabalho de mestrado.

Agradeço aos colegas do JAC-LMC pelo apoio técnico: Fernando Gonçalves, Jorge Carvalho Costa e Paulo Nigro.

Agradeço também aos demais colegas do JAC-LMC: Leonardo Lago, Eduardo Simões, Henrique Campello, Eduardo Campello e Marcelo Teixeira.

Agradeço aos funcionários da USP: Wandréa, Juliana e Janete.

Agradeço aos familiares e amigos: Célia M. Beletti Ferreira, Edson R. Ferreira, Alessandra V. Basseti, Silvia M. Beletti, Alice V. Ferrreira, Dulce Basseti, Rui Silvestrin, Marcos Arias, Ricardo Lahuerta, Paulo Ribeiro, Guilherme S. Roxo, Luiz Alexandre, Bonney, Max e Luiz H. Gazeta.

Agradeço ainda à Fatec por ter concedido afastamento de parte de minhas atividades e a Capes pelo apoio financeiro.

Agradeço por fim a todos aqueles que contribuíram direta ou indiretamente para a realização deste trabalho.

Muito obrigado a todos. 


\section{RESUMO}

Os problemas de engenharia atualmente têm aumentado a sua ordem de grandeza, por conta de diversos fatores. A modelagem em ambiente computacional dos mesmos esbarra em limitações, como grandes quantidades de tempo de processamento gastos com diversas simulações da modelagem e a pouca quantidade de memória disponível para alocar propriamente os problemas.

A resolução de grandes sistemas de equações lineares, comumente abordado nos problemas atuais de engenharia, necessita da exploração das duas situações mencionadas anteriormente.

A subárea computacional que permite explorar a redução do tempo e a possibilidade de alocação na memória de tais problemas é chamada de computação de alto desempenho.

O objetivo deste trabalho é ilustrar o uso de softwares de resolução de sistemas de equações lineares, chamados de solvers, projetados para os ambientes computacionais de alto desempenho, testando-os e avaliando-os em um conjunto de matrizes conhecido, bem como abordar os detalhes computacionais envolvidos em tais procedimentos.

Palavras-chave: solver, computação de alto desempenho, sistema de equações lineares. 


\begin{abstract}
Engineering problems today have increased their order of magnitude, due to several factors. Modeling these problems with computers brings up certain limitations, as the amount of processing time needed for several simulations and the lack of available memory to properly allocate them.

The resolution of large systems of linear equations, commonly discussed in current engineering problems, needs the exploration of the two situations mentioned above.

The subarea that allows exploring the computational time reduction and the possibility of allocating memory in such problems is called high performance computing.

The aim of this paper is to illustrate the use of software to solve systems of linear equations, called solvers, designed for high performance computing environments, to test and evaluate them for a set of matrices as well as to address the computational details involved in such procedures.
\end{abstract}

Palavras: solver, high performance computing, systems of linear equations. 


\section{LISTA DE ILUSTRAÇÕES}

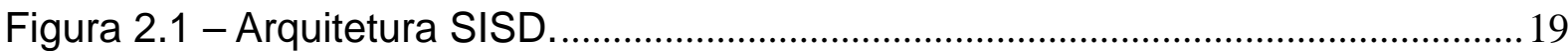

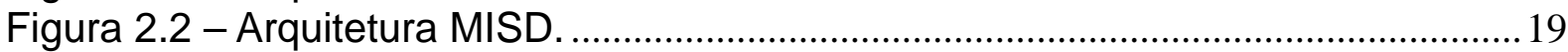

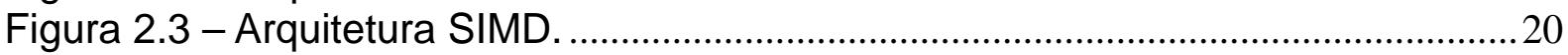

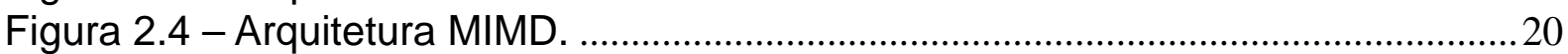

Figura 2.5 - MIMD de Memória Compartilhada.............................................................21

Figura 2.6 - MIMD de Memória Distribuída. …………….........................................22

Figura 2.7 - UCP, variáveis e pilha acessadas por único processo..............................26

Figura 2.8 - Quatro transições entre processos. ............................................................2

Figura 2.9 - Três processos com linha de controle e contador de programa..............28

Figura 2.10 - Um processo com três linhas de controle e contador de programa.....28

Figura 3.1 - Bloco cíclico e estrutura que armazena o bloco local de coluna de L.....57

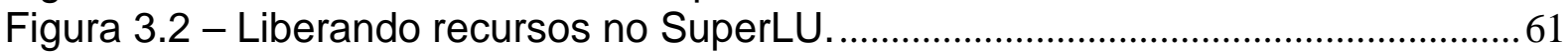

Figura 3.3 - Trecho de código com exemplo do uso de "job". .......................................65

Figura 3.4 - Trecho de código com exemplo da fase de análise do MUMPS..............68

Figura 3.5 - Trecho de código com exemplo da fase de fatoração do MUMPS.........69

Figura 3.6 - Trecho de código com exemplo da fase de fatoração do MUMPS.........70

Figura 3.7 - Trecho de código com exemplo da fase de fatoração do MUMPS.........70

Figura 3.8 - Rotinas de manipulação de vetores do PETSc............................................72

Figura 3.9 - Rotinas de manipulação de matrizes do PETSc..........................................73

Figura 3.10 - Rotinas de resolução de sistemas do solver PETSc. ……………….......75

Figura 4.1 - Matrizes Diagonais........................................................................................... 78

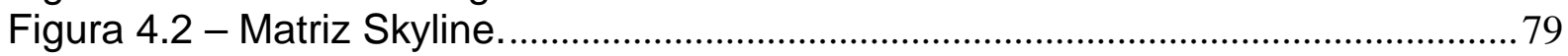

Figura 4.3 - Perfil Skyline. ........................................................................................ 79

Figura 4.4 - Matrizes Diagonais: (a) bcsstm02, (b) bcsstm22, (c) bcsstm08, (d)

bcsstm25 e (e) bcsstm39.

Figura 4.5 - Matrizes Diagonais: solvers PETSc e MUMPS.........................................82

Figura 4.6 - Matrizes Esparsas com Diagonais Densas: (a) LFAT5, (b) mhdb416, (c)

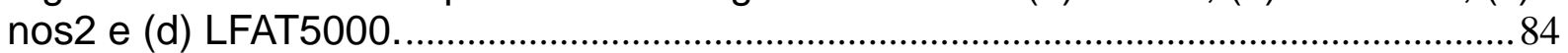

Figura 4.7 - Matrizes Esparsas com Diagonais Densas: solvers PETSc e MUMPS.. 86 Figura 4.8 - Matrizes Diagonais com Elementos Próximos a Diagonal: (a) nos4, (b) nos5, (c) nos6, (d) nos7 e (e) nos3.

Figura 4.9 - Matrizes Esparsas com Elementos Não Nulos Próximos a Diagonal

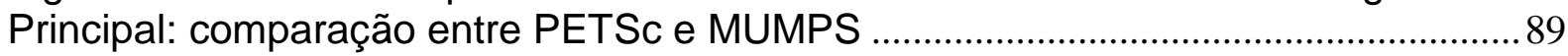

Figura 4.10 - Elementos não nulos da matriz "parabolic_fem".......................................90

Figura 4.11 - Tempos de execução da matriz "parabolic_fem". ...................................92

Figura 4.12 - Elementos não nulos da matriz "G3_circuit"...............................................93

Figura 4.13 - Tempos de execução da matriz "G3_circuit". ..............................................94

Figura 4.14 - Elementos não nulos da matriz "thermal2".............................................95

Figura 4.15 - Tempos de execução da matriz "thermal2".................................................96

Figura 4.16 - Elementos não nulos da matriz "ecology2"...............................................97

Figura 4.17 - Tempos de execução da matriz "ecology2". ..............................................98

Figura 4.18 - Elementos não nulos da matriz "apache2". .................................................99

Figura 4.19 - Tempos de execução da matriz "apache2". .............................................. 101

Figura 4.20 - Elementos não nulos da matriz "af_shell8"...........................................102

Figura 4.21 - Tempos de execução da matriz "af_shell8". .............................................103

Figura 4.22 - Elementos não nulos da matriz "tmt_sym"................................................104

Figura 4.23 - Tempos de execução da matriz "tmt_sym"...............................................105

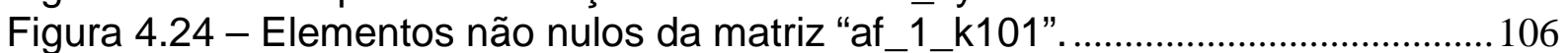

Figura 4.25 - Tempos de execução da matriz "af_1_k101".........................................107 
Figura 4.26 - Matriz "parabolic_fem" - Speedup dos solvers...................................... 110

Figura 4.27 - Matriz "parabolic_fem" - Eficiência dos solvers....................................... 111

Figura 4.28 - Matriz "G3_circuit" - Speedup dos solvers........................................... 112

Figura 4.29 - Matriz "G3_circuit" - Eficiência dos solvers............................................. 113

Figura 4.30 - Matriz "thermal2" - Speedup dos solvers. ............................................. 114

Figura 4.31 - Matriz "thermal2" - Eficiência dos solvers. ............................................. 114

Figura 4.32 - Matriz "ecology2" - Speedup dos solvers............................................... 115

Figura 4.33 - Matriz "ecology2" - Speedup do solvers: MUMPS (a) e SuperLU (b). 116

Figura 4.34 - Matriz "ecology2" - Eficiência dos solvers.............................................. 117

Figura 4.35 - Matriz "apache2" - Speedup dos solvers. ............................................. 117

Figura 4.36 - Matriz "apache2" - Eficiência dos solvers. .............................................. 118

Figura 4.37 - Matriz "af_shell8" - Speedup dos solvers............................................... 119

Figura 4.38 - Matriz "af_shell8" - Speedup do solvers: MUMPS (a) e SuperLU (b). 119

Figura 4.39 - Matriz "af_shell8" - Eficiência dos solvers................................................ 120

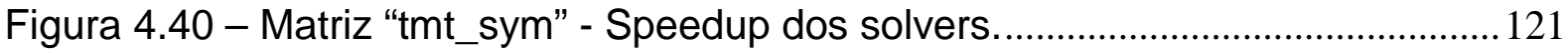

Figura 4.41 - Matriz "af_shell8" - Eficiência dos solvers..............................................121

Figura 4.42 - Matriz "af_1_k101" - Speedup dos solvers. ...........................................122

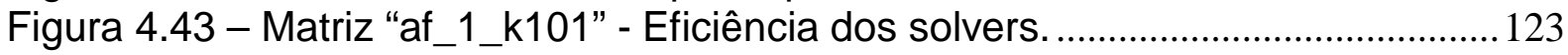

Figura 4.44 - Matriz "parabolic_fem" - Volume MPI..................................................... 124

Figura 4.45 - Matriz "G3_circuit" - Volume MPI........................................................... 125

Figura 4.46 - Matriz "thermal2" - Volume MPI. ............................................................. 126

Figura 4.47 - Matriz "ecology2" - Volume MPI.............................................................. 127

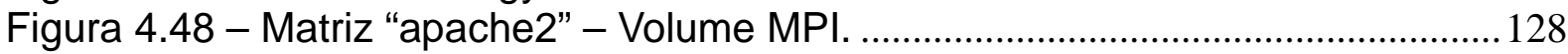

Figura 4.49 - Matriz "af_shell8" - Volume MPI......................................................... 129

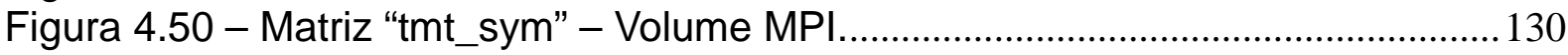

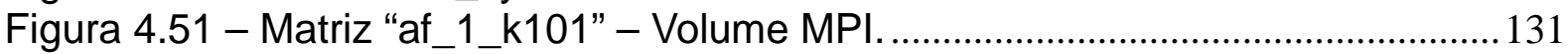

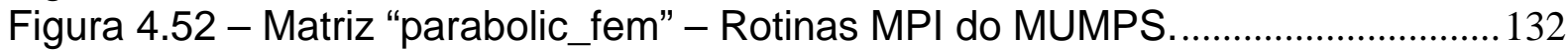

Figura 4.53 - Matriz "parabolic_fem" - Rotinas MPI do SuperLU............................... 133

Figura 4.54 - Matriz "parabolic_fem" - Rotinas MPI do PETSc. .................................. 134

Figura 4.55 - Matriz "G3_circuit" - Rotinas MPI do MUMPS...................................... 135

Figura 4.56 - Matriz "G3_circuit" - Rotinas MPI do SuperLU...................................... 136

Figura 4.57 - Matriz "G3_circuit" - Rotinas MPI do PETSc. ........................................ 137

Figura 4.58 - Matriz "thermal2" - Rotinas MPI do MUMPS. ....................................... 138

Figura 4.59 - Matriz "thermal2" - Rotinas MPI do SuperLU. ...................................... 138

Figura 4.60 - Matriz "thermal2" - Rotinas MPI do PETSc............................................ 139

Figura 4.61 - Matriz "ecology2" - Rotinas MPI do MUMPS ......................................... 140

Figura 4.62 - Matriz "ecology2" - Rotinas MPI do SuperLU....................................... 140

Figura 4.63 - Matriz "ecology2" - Rotinas MPI do PETSc. .......................................... 141

Figura 4.64 - Matriz "apache2" - Rotinas MPI do MUMPS........................................... 142

Figura 4.65 - Matriz "apache2" - Rotinas MPI do SuperLU.......................................... 143

Figura 4.66 - Matriz "apache2" - Rotinas MPI do PETSc. .......................................... 143

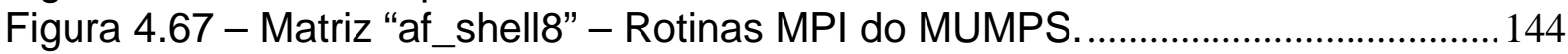

Figura 4.68 - Matriz "af_shell8" - Rotinas MPI do SuperLU....................................... 145

Figura 4.69 - Matriz "af_shell8" - Rotinas MPI do PETSc. .......................................... 145

Figura 4.70 - Matriz "tmt_sym" - Rotinas MPI do MUMPS ......................................... 146

Figura 4.71 - Matriz "tmt_sym" - Rotinas MPI do SuperLU......................................... 147

Figura 4.72 - Matriz "tmt_sym" - Rotinas MPI do PETSc. ........................................... 148

Figura 4.73 - Matriz "af_1_k101" - Rotinas MPI do MUMPS. .................................... 149

Figura 4.74 - Matriz "af_1_k101" - Rotinas MPI do SuperLU. .................................... 149

Figura 4.75 - Matriz "af_1_k101" - Rotinas MPI do PETSc....................................... 150 


\section{LISTA DE TABELAS}

Tabela 2.1 - Configurações do supercomputador Hopper. .....................................22

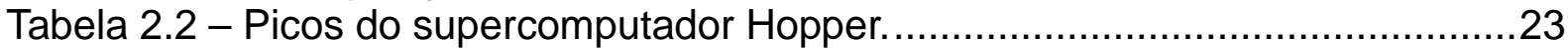

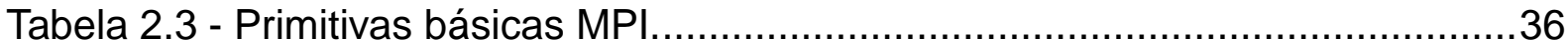

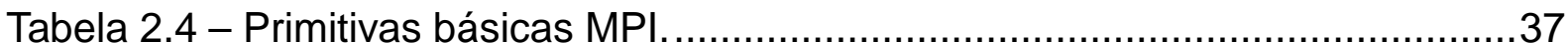

Tabela 2.5 - Equivalência de tipos de dados MPI com C, C++ e Fortran. .................37

Tabela 2.6 - Declaração de "status" MPI com C, C++ e Fortran...............................40

Tabela 2.7 - Parâmetros da rotina MPI_Reduce.................................................41

Tabela 2.8 - Declaração de "status" MPI com C, C++ e Fortran. .............................42

Tabela 3.1 - Estrutura da SuperMatrix no SuperLU. ............................................58

Tabela 3.2 - Esquema ordenado por colunas do SuperLU....................................58

Tabela 3.3 - Estrutura de vetor no SuperLU. ....................................................59

Tabela 3.4 - Opções de configurações do SuperLU. ...............................................59

Tabela 3.5 - Parâmetros da rotina "pdgssvv" do SuperLU.......................................60

Tabela 3.6 - Parâmetro "job" do solver MUMPS. .................................................65

Tabela 3.7 - Trecho de código com exemplo do uso de "job". ..................................66

Tabela 3.8 - Estrutura da matriz montada no processador host. ............................67

Tabela 3.9 - Estrutura do vetor montado no processador host. ..............................67

Tabela 3.10 - Parâmetro "icntl[6]" do solver MUMPS............................................68

Tabela 3.11 - Parâmetros da rotina VecSetValues do PETSc. ……………….........73

Tabela 3.12 - Parâmetros da rotina VecSetValues do PETSc. ...............................74

Tabela 3.13 - Parâmetros da rotina VecSetValues do PETSc. …............................75

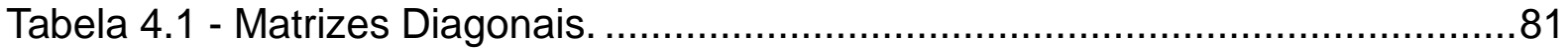

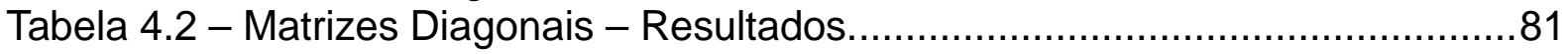

Tabela 4.3 - Matrizes Esparsas com Diagonais Densas.....................................85

Tabela 4.4 - Matrizes Esparsas com Diagonais Densas - Resultados....................85

Tabela 4.5 - Matrizes Esparsas com Elementos Próximos a Diagonal Principal.......88

Tabela 4.6 - Matrizes Esparsas com Diagonais Densas - Resultados......................89

Tabela 4.7 - Características da matriz "parabolic_fem". ........................................91

Tabela 4.8 - Tempos de execução da matriz "parabolic_fem".................................91

Tabela 4.9 - Características da matriz "G3_circuit"............................................93

Tabela 4.10 - Tempos de execução da matriz "G3_Circuit”. ....................................93

Tabela 4.11 - Características da matriz "thermal2". ..............................................96

Tabela 4.12 - Tempos de execução da matriz "thermal2" .....................................96

Tabela 4.13 - Características da matriz "ecology2"...........................................97

Tabela 4.14 - Tempos de execução da matriz "ecology2"....................................98

Tabela 4.15 - Características da matriz "apache2". .........................................100

Tabela 4.16 - Tempos de execução da matriz "apache2". ....................................100

Tabela 4.17 - Características da matriz "af_shell8"............................................102

Tabela 4.18 - Características da matriz "af_shell8"...........................................102

Tabela 4.19 - Características da matriz "tmt_sym". .........................................104

Tabela 4.20 - Tempos de execução da matriz "tmt_sym".....................................105

Tabela 4.21 - Características da matriz "af_1_k101".......................................106

Tabela 4.22 - Tempos de execução da matriz "af_1_k101". ................................106

Tabela 4.23 - Principais rotinas MPI utilizadas por cada solver.............................132 


\section{SUMÁRIO}

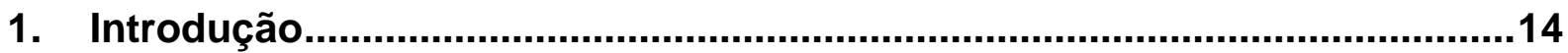

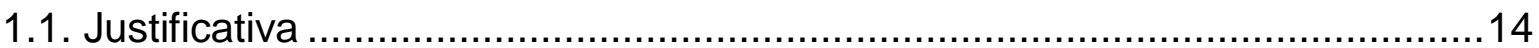

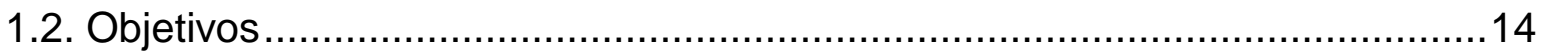

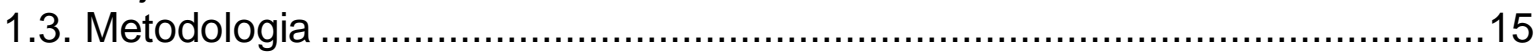

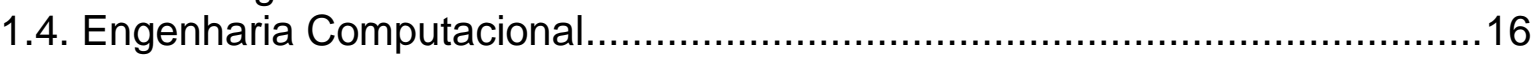

1.5. Estrutura dos Capítulos do Trabalho ................................................. 17

2. Aspectos Computacionais .....................................................................18

2.1. Arquiteturas de Computadores .................................................... 18

2.1.1. SISD - Single Instruction Single Data ........................................... 18

2.1.2. MISD - Multiple Instruction Single Data ................................................ 19

2.1.3. SIMD - Single Instruction Multiple Data .............................................. 19

2.1.4. MIMD - Multiple Instruction, Multiple Data .........................................20

2.1.4.1. MIMD - Memória Compartilhada ................................................21

2.1.4.2. MIMD - Memória Distribuída ........................................................21

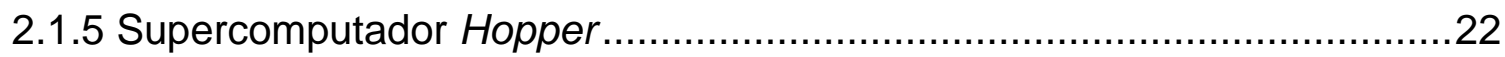

2.1.5.1. Hopper - Configuração .....................................................22

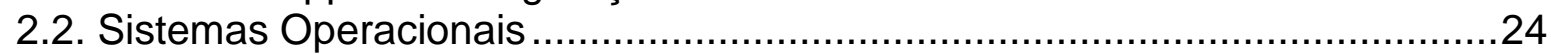

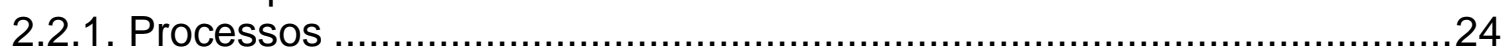

2.2.1.1. Modelo de Processos Sequenciais ........................................... 25

2.2.1.2. Hierarquia e Estados de Processos em Sistemas UNIX ...................26

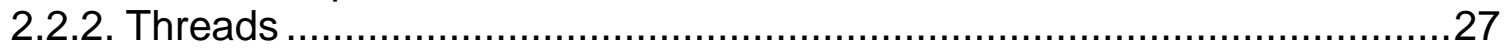

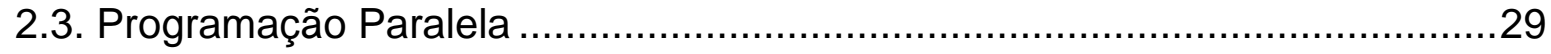

2.3.1. Programação MIMD - Memória Compartilhada .....................................29

2.3.1.1. Thread e Memória Compartilhada ...................................................29

2.3.1.2. Criação de Thread .............................................................. 30

2.3.1.3. Finalização de Thread .......................................................... 31

2.3.1.4. Junção de Thread................................................................ 31

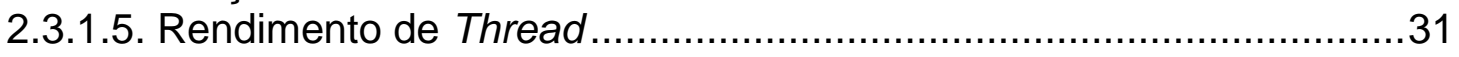

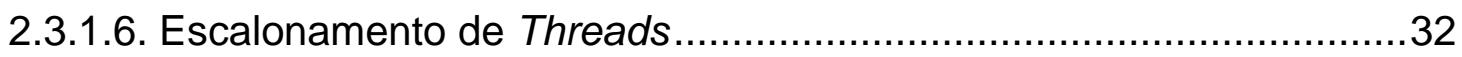

2.3.1.7. HT - Hyper Threading Tecnology ............................................ 33

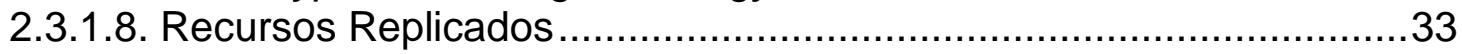

2.3.1.9. Recursos Particionados ............................................................. 33

2.3.1.10. Recursos Compartilhados .....................................................33

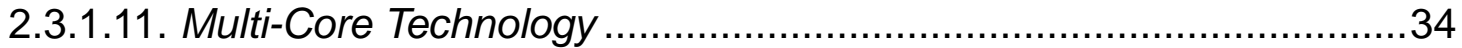

2.3.2. Programação MIMD - Memória Distribuída .............................................34

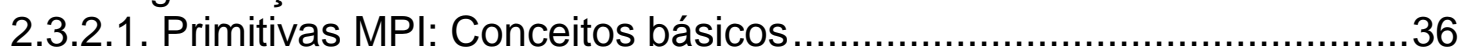

2.3.2.2. Primitivas MPI: MPI_Init..................................................... 38

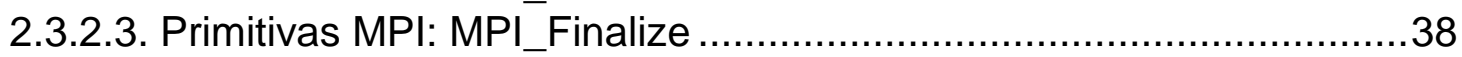

2.3.2.4. Primitivas MPI: MPI_Send ................................................ 39

2.3.2.5. Primitivas MPI: MPI_Recv .................................................. 39

2.3.2.6. Primitivas MPI: MPI_Bcast.................................................. 40

2.3.2.7. Primitivas MPI: MPI_Reduce .................................................... 41

2.3.2.8. Primitivas MPI: MPI_Allreduce............................................... 42

2.3.2.9. Primitivas MPI: MPI_Wait ..................................................... 42

2.3.2.10. Primitivas MPI: MPI_Barrier.................................................... 43

3. Resolução de Sistemas de Equações Lineares ..........................................44 


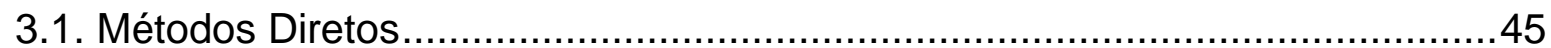

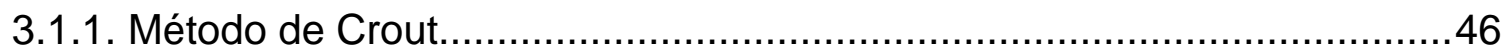

3.1.2. Método de Cholesky......................................................................4

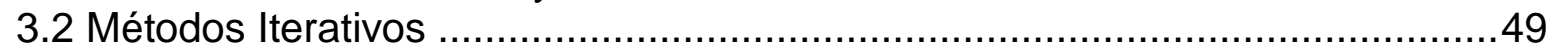

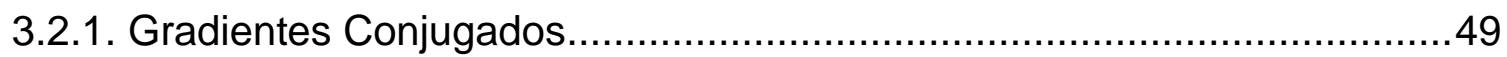

3.2.2. Gradientes Conjugados Pré-Condicionados ........................................50

3.3. Softwares para Resolução de Sistemas de Equações Lineares.....................52

3.3.1. BLAS (Basic Linear Algebra Subprograms) ......................................52

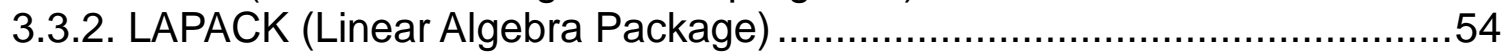

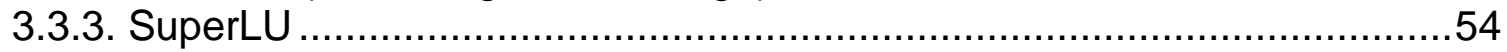

3.3.3.1. SuperLU - Programação Básica ...................................................56

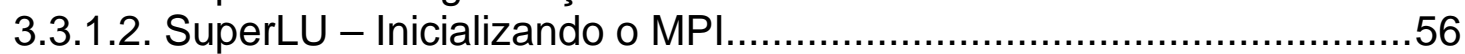

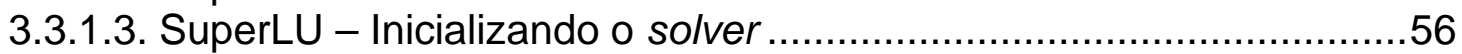

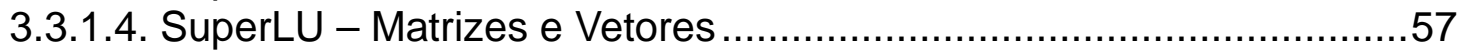

3.3.1.5. SuperLU - Configurando as opções .............................................59

3.3.1.6. SuperLU - Resolvendo o sistema ...............................................60

3.3.1.7. SuperLU - Liberando recursos alocados......................................60

3.3.1.8. SuperLU - Finalizando o solver ....................................................61

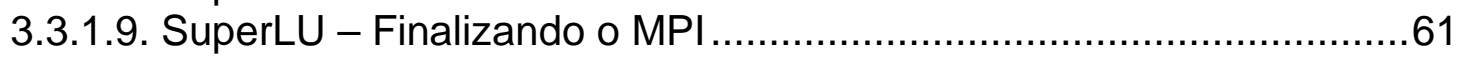

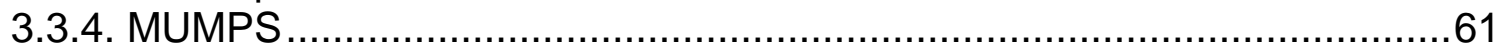

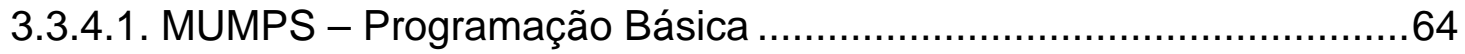

3.3.4.2. MUMPS - Controlando as Fases de Trabalho ...............................64

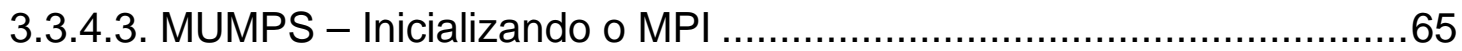

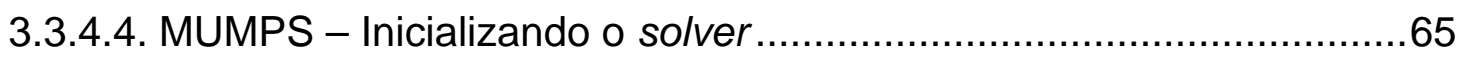

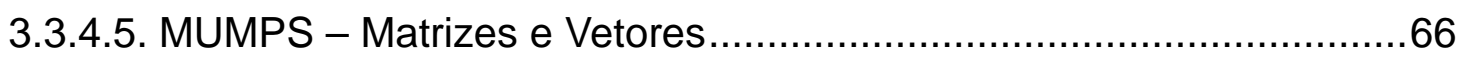

3.3.4.6. MUMPS - Fase de Análise do Sistema ........................................68

3.3.4.7. MUMPS - Fase de Fatoração do Sistema ......................................69

3.3.4.8. MUMPS - Fases de Solução do Sistema.........................................69

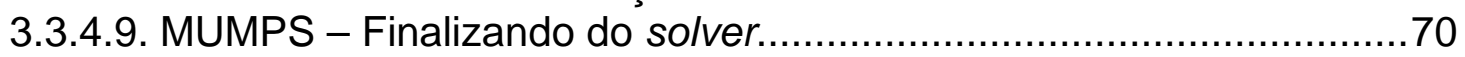

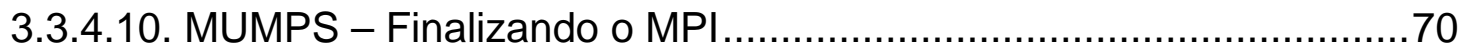

3.3.5. PETSC - Programação Básica ………………..................................... 70

3.3.5.1. PETSc - Inicializando o solver e o MPI ........................................71

3.3.5.2. PETSc - Matrizes e Vetores ......................................................72

3.3.5.3. PETSc - Resolução de Sistemas de Equações Lineares .................74

3.3.5.4. PETSc - Finalizando o solver e o MPI .........................................76

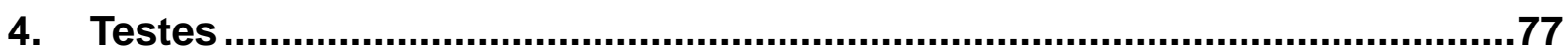

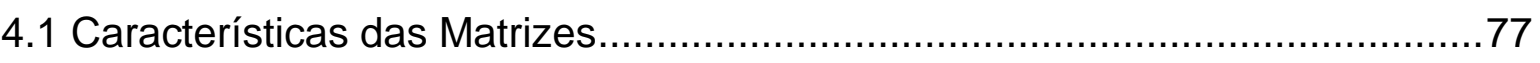

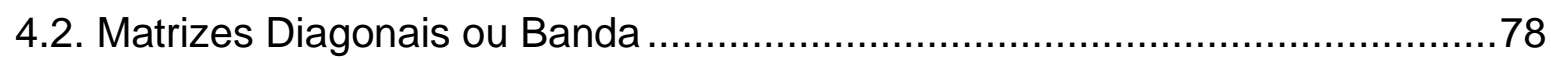

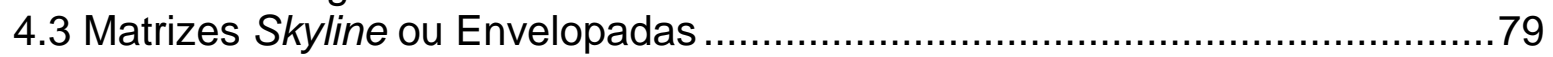

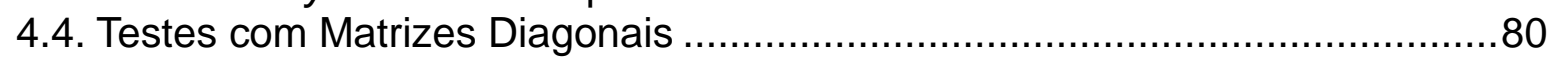

4.4. Testes com Matrizes Esparsas - Diagonais Densas ....................................83

4.5. Testes com Matrizes Esparsas - Elementos Próximos da Diagonal...............86

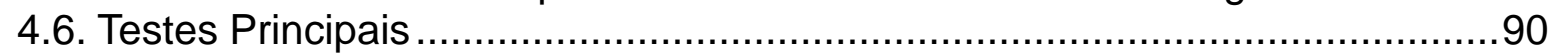

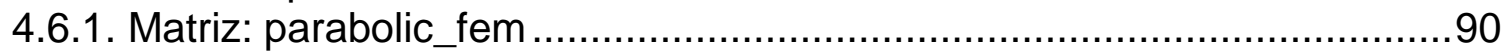

4.6.2. Matriz: G3_circuit ...................................................................

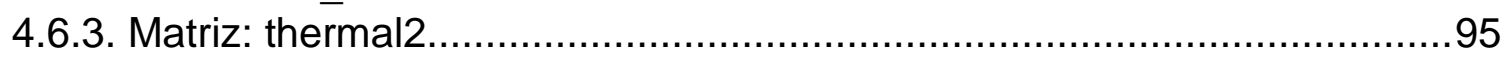

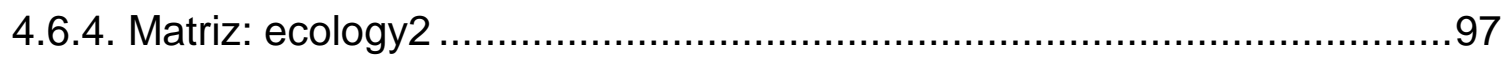

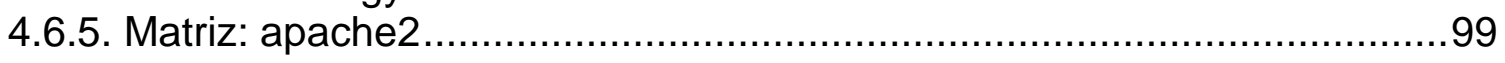

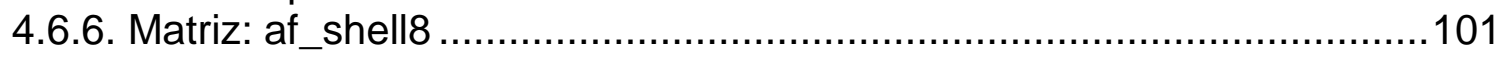




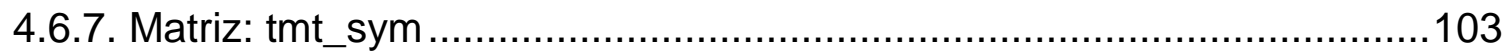

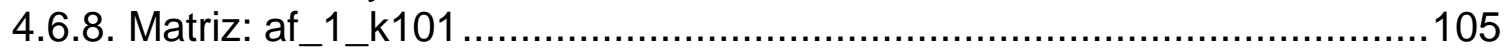

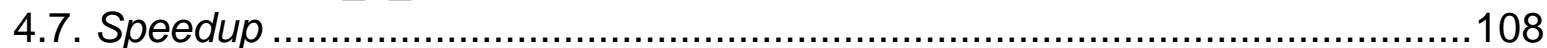

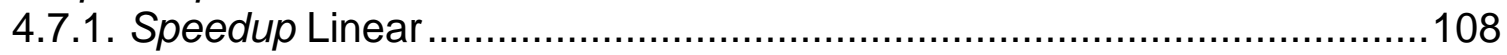

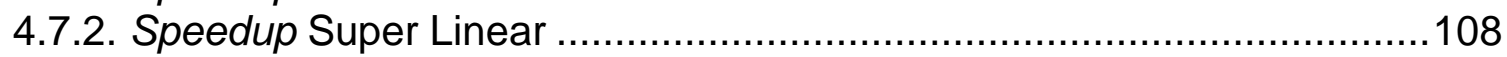

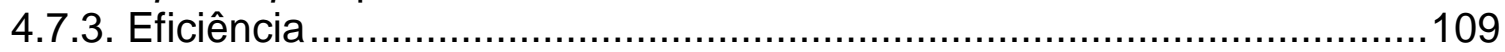

4.7.4. Testes de Speedup e Eficiência ..................................................... 110

4.7.4.1. Speedup e Eficiência - Matriz: parabolic_fem............................... 110

4.7.4.2. Speedup e Eficiência - Matriz: G3_circuit..................................... 111

4.7.4.3. Speedup e Eficiência - Matriz: thermal2 .................................... 113

4.7.4.4. Speedup e Eficiência - Matriz: ecology2 ...................................... 115

4.7.4.5. Speedup e Eficiência - Matriz: apache2 …................................. 117

4.7.4.6. Speedup e Eficiência - Matriz: af_shell8 ...................................... 118

4.7.4.7. Speedup e Eficiência - Matriz: tmt_sym......................................120

4.7.4.8. Speedup e Eficiência - Matriz: af_1_k101 …..............................122

4.8. Testes de Volume MPI ..................................................................124

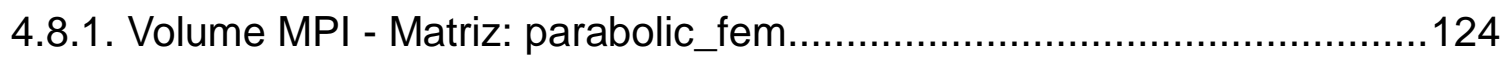

4.8.2. Volume MPI - Matriz: G3_circuit..................................................125

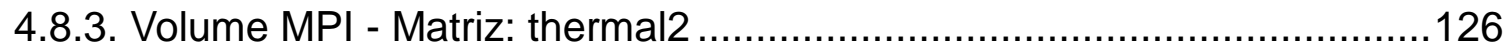

4.8.4. Volume MPI - Matriz: ecology2 .................................................127

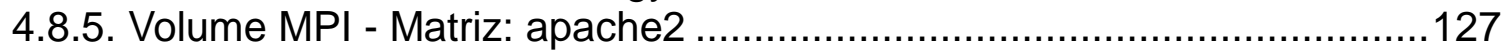

4.8.6. Volume MPI - Matriz: af_shell8 ...................................................128

4.8.7. Volume MPI - Matriz: tmt_sym..................................................129

4.8.8. Volume MPI - Matriz: af_1_k101 …………..............................130

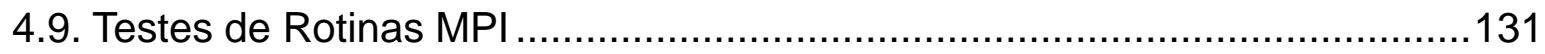

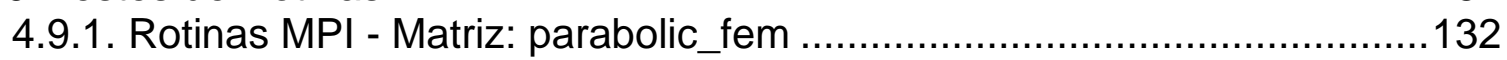

4.9.2. Rotinas MPI - Matriz: G3_circuit....................................................135

4.9.3. Rotinas MPI - Matriz: thermal2 …...............................................137

4.9.4. Rotinas MPI - Matriz: ecology2 ………………............................139

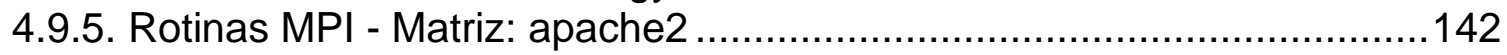

4.9.6. Rotinas MPI - Matriz: af_shell8 …………...................................144

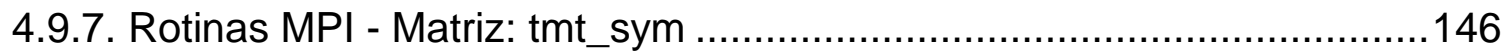

4.9.8. Rotinas MPI - Matriz: af_1_k101 …………..............................148

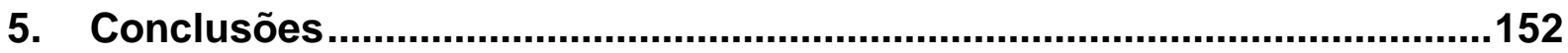

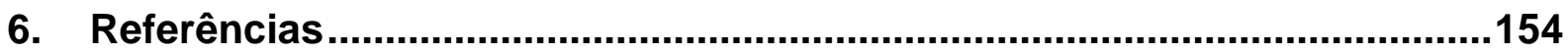

Apêndice A - Operacionalizando a estrutura paralela......................................160

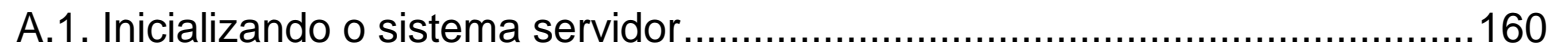

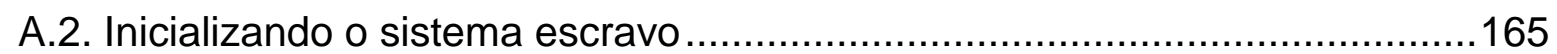

A.3. Localizando os nós escravos no servidor .............................................167 


\section{Introdução}

Neste primeiro capítulo serão feitas explicações básicas sobre o trabalho desenvolvido e explicitado ao longo dos próximos capítulos, bem como a contextualização do ambiente de trabalho, no que tange aos aspectos de organização física e lógica, como poderá ser observado nos próximos itens desta introdução.

\subsection{Justificativa}

As áreas de engenharia em geral tem cada vez mais aumentado a ordem de grandeza dos problemas a serem resolvidos, por conta de sua complexidade, entre outros fatores [1].

Problemas que, ao serem modelados em ambientes computacionais, ocupam espaço na memória principal e secundária, além de necessitarem de um determinado poder computacional dos processadores e componentes que o auxiliam nos cálculos, como os registradores e a unidade de ponto flutuante [2].

Alguns trabalhos do passado tratavam de pequenos modelos, ou representações em menor proporção, por não ser possível, em uma abordagem computacional, resolver problemas maiores. A busca por economia, eficiência, e durabilidade se faz necessária, no entanto, a análise de modelos mais bem descritos, mais detalhados e consequentemente mais próximos da realidade também é algo indispensável [3].

Neste trabalho, o problema considerado é a resolução de sistemas de equações lineares, tendo em vista que essa é uma das questões a ser explorada nos trabalhos de engenharia que, se tratada de maneira correta, permitirá explorar problemas cada vez maiores e em um tempo considerado viável [4].

\subsection{Objetivos}

Os engenheiros se deparam com problemas que não cabem na memória principal de um computador ou que consomem muito tempo para serem resolvidos, sendo necessário um mecanismo de viabilizar a resolução de tais problemas. Nesses casos surgem os profissionais da área de engenharia computacional, que desenvolvem mecanismos para realizar a interface entre a computação e a 
engenharia, viabilizando o uso de um ambiente computacional paralelo.

Quando se opta por utilizar o ambiente paralelo, pode ser basicamente por duas razões principais. A primeira razão é que o problema que se pretende resolver não cabe na memória principal, ou RAM (Random Access Memory), do computador e precisa ser dividido. A segunda é que o tempo gasto para resolver o problema é considerado muito grande, portanto espera-se uma diminuição do tempo utilizando um ambiente paralelo.

Mais uma vez cabe explicitar que o ambiente paralelo e as técnicas de programação paralela serão utilizados para realizar de maneira distribuída, ou paralela, a resolução de sistemas de equações lineares, sendo esse o objetivo principal do trabalho.

Pode-se dizer também que o presente trabalho não tem como objetivo principal otimizar especificamente o tempo de resolução dos sistemas de equações lineares, mas sim indicar mecanismos que viabilizem ao engenheiro computacional, termo que será discutido mais a frente, paralelizar seus programas, por questões de memória ou de tempo.

\subsection{Metodologia}

Para desenvolver o presente trabalho, primeiramente será pesquisado 0 ambiente da estrutura paralela a ser utilizada, tendo em vista que existem inúmeras possibilidades de ambientes paralelos atualmente [5]. Tais ambientes são descritos de forma aprofundada por [2] e serão considerados neste texto, porém de uma forma não tão aprofundada.

Também serão pesquisados os ambientes que os sistemas operacionais fornecem para operacionalizar o hardware, pois sem esse software básico seria inviável o uso dos hardwares criados sobre os modelos de arquiteturas citados no parágrafo anterior e descritos em [6].

A computação distribuída ou paralela vem para lidar com questões computacionais que necessitam de alto poder de processamento e que os computadores pessoais, por mais sofisticados que sejam, não conseguem atender a essa demanda de processamento.

Existem técnicas distintas para elaborar a computação de alto desempenho, que envolvem mecanismos físicos e lógicos também distintos, mas que, no contexto 
lógico ou de programação, acabam sendo muito semelhantes.

Existirão duas abordagens de programação paralela ao longo do desenvolvimento do texto, porém será dada ênfase àquela capaz de lidar melhor com os ambientes paralelos criados para supercomputadores de alto desempenho.

É também necessário um estudo básico sobre os métodos diretos e iterativos para resolução de sistemas de equações lineares, tendo em vista que os ambientes paralelos e as técnicas de programação distribuídas serão utilizados para paralelizar, em partes, a resolução de tais sistemas.

Note que não haverá uma abordagem matemática aprofundada neste trabalho, pois esse não é o escopo, além do que serão abordados pacotes de solvers (softwares utilizados para resolução de sistemas de equações lineares), que dispensam certos conhecimentos matemáticos e dependem mais de conhecimentos computacionais para o uso das ferramentas, pois não serão feitas modificações no código fonte dos solvers.

Posteriormente, serão escolhidos alguns problemas prontos, disponíveis em uma base de dados de matrizes, que representam obviamente sistemas de equações lineares, para testar as técnicas de paralelismo dos solvers escolhidos para os testes do trabalho.

Ao final, serão discutidas as conclusões e os próximos passos.

\subsection{Engenharia Computacional}

A engenharia computacional pode ser definida como ciência, ou área de trabalho, que permite aos engenheiros, juntamente a profissionais de computação e matemáticos, desenvolver suas pesquisas utilizando recursos computacionais aliados a recursos matemáticos.

O ambiente de engenharia computacional é muito comum nos locais de pesquisa onde existe computação de alto desempenho, pois os engenheiros precisam simular seus modelos utilizando técnicas computacionais criadas por pesquisadores da área da computação.

Por outro lado, as ferramentas da computação precisam ser aplicadas em algumas situações, então os matemáticos aperfeiçoam seus métodos para se utilizarem de tais recursos fornecidos pela computação.

Um exemplo a ser citado é o caso do LBNL (Lawrence Berkeley National 
Laboratory), vinculado à Universidade da Califórnia, pertencente ao Departamento de Energia dos Estados Unidos da América [7].

Nesse laboratório encontram-se engenheiros civis, mecânicos, elétricos, da computação, físicos e matemáticos, trabalhando em conjunto para criar softwares e utilizar a infraestrutura de alto desempenho disponibilizada ao laboratório para fins de simulação numérica.

A Universidade Federal de Juiz de Fora já oferece a formação específica em Engenharia Computacional, fazendo da computação não um fim, mas um meio de realizar a ciência nos dias atuais [8].

\subsection{Estrutura dos Capítulos do Trabalho}

O presente trabalho está organizado, considerando a divisão dos capítulos, da seguinte forma:

O capítulo um, chamado de Introdução, ilustra a organização do trabalho, considerando a justificativa, os objetivos e sua metodologia de desenvolvimento.

No capítulo dois serão abordadas as questões dos fundamentos de arquitetura de computadores, sejam eles ou não de grande porte, bem como as técnicas de programação distribuída ou paralela para ambientes distintos de arquiteturas paralelas.

Nesse mesmo capítulo serão discutidas questões de sistemas operacionais necessárias para entender as técnicas de programação paralela, sem as quais o processo de codificação dos programas seria muito mais difícil.

O capítulo três irá discutir os métodos diretos e iterativos para a resolução de sistemas de equações lineares, bem como os solvers utilizados nos testes do capítulo seguinte.

No capítulo quatro são demonstrados os testes realizados com um conjunto de matrizes escolhidos para o presente trabalho, utilizando um ou mais processadores, abordando questões de escalabilidade dos métodos e de desempenho dos solvers.

Ao final, são apresentadas as conclusões do texto, considerando os testes realizados e comparando-os com a literatura existente. 


\section{Aspectos Computacionais}

Neste capitulo serão discutidos alguns aspectos computacionais essenciais para a compreensão do presente trabalho. Os principais tópicos que abrangem este capítulo são:

- Arquitetura de Computadores;

- Sistemas Operacionais;

- Programação Paralela ou Distribuída.

A ideia deste capítulo não é esgotar nenhum dos assuntos mencionados anteriormente, somente abordar da forma mais precisa possível tais itens, facilitando a leitura e o entendimento de um leitor que não tenha formação específica em computação, porém precisa conhecer a área brevemente para fazer uso de seus recursos. O leitor mais interessado poderá consultar [9] para as questões de Arquitetura de Computadores, [6] para as questões de Sistemas Operacionais ou ainda [5] para as questões de Programação Distribuída.

\subsection{Arquiteturas de Computadores}

Arquitetura de Computadores é uma área da computação que estuda a maneira como os computadores são projetados e organizados, conteúdo básico dos cursos de computação. Sua discussão se faz necessária para o entendimento dos conceitos de Sistemas Operacionais.

Para dar andamento em qualquer conceito de Sistemas Operacionais é necessário o entendimento básico da organização da máquina onde tal software básico será executado, por isso cabe essa abordagem no presente trabalho.

Segundo [10] [11], existem classificações de arquiteturas de computadores seguindo o número de fluxo de dados e de instruções capazes de processar em cada instante, produzindo quatro classes distintas de arquiteturas.

\subsubsection{SISD - Single Instruction Single Data}

Esta é a arquitetura primordial e mais simples, na qual o equipamento é considerado sequencial, pois ele consegue executar fisicamente apenas uma instrução por vez. Utiliza-se o termo fisicamente, pois logicamente é possível 
simular certa ideia de simultaneidade via software básico, ou seja, através de um sistema operacional multitarefa, capaz de alternar rapidamente entre os processos que está executando, dando uma ideia de processamento simultâneo. Os microcomputadores pessoais que não possuem múltiplos núcleos (cores) se enquadram nessa categoria, como pode ser visto na Figura 2.1.

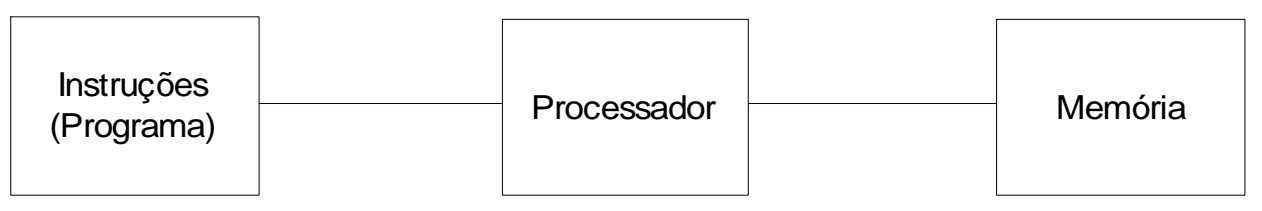

Figura 2.1 - Arquitetura SISD.

\subsubsection{MISD - Multiple Instruction Single Data}

Tal arquitetura é hipotética [11], imaginando uma situação em que várias instruções processariam um único dado. Não existe nenhuma implementação prática dessa estrutura (Figura 2.2).

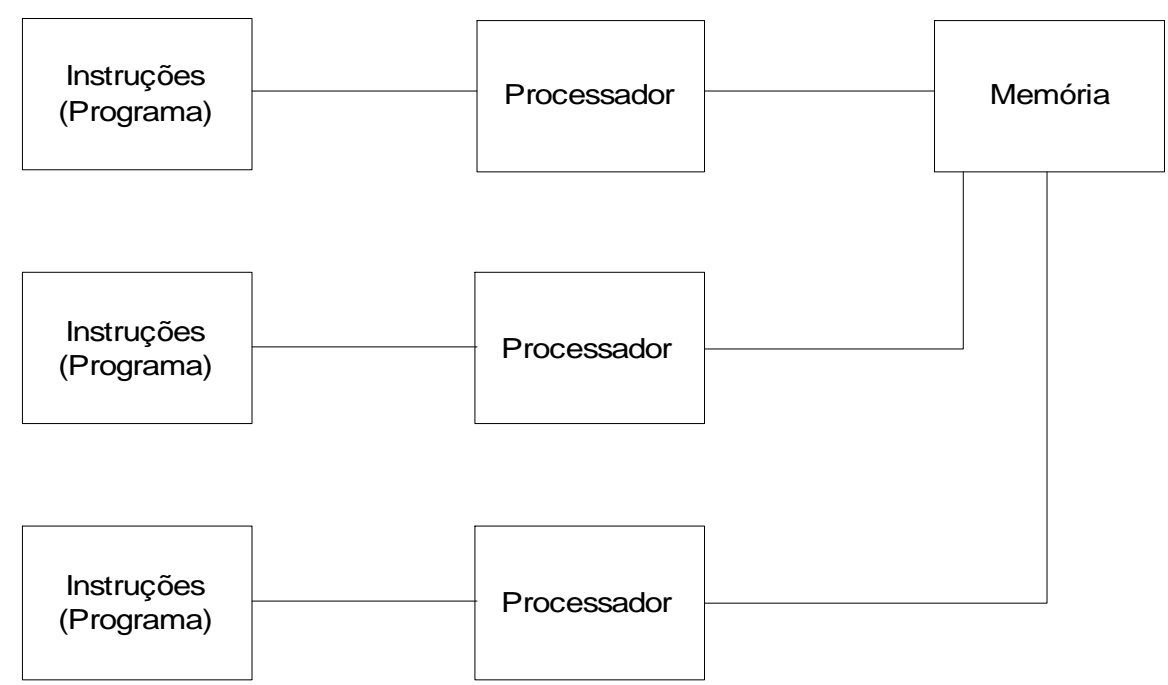

Figura 2.2 - Arquitetura MISD.

\subsubsection{SIMD - Single Instruction Multiple Data}

Esta é considerada a estrutura que utiliza fisicamente a técnica de paralelismo de dados (lógica), na qual há apenas um processo com vários dados distintos executando simultaneamente de maneira síncrona. Os processadores MMX (MultiMedia eXtension) utilizam essa técnica no processamento gráfico no Pentium ${ }^{\circledR}$ 200 Mhz e 233 Mhz.

Nessa estrutura existe menos hardware, menos memória e um hardware específico para essa arquitetura (Figura 2.3). 


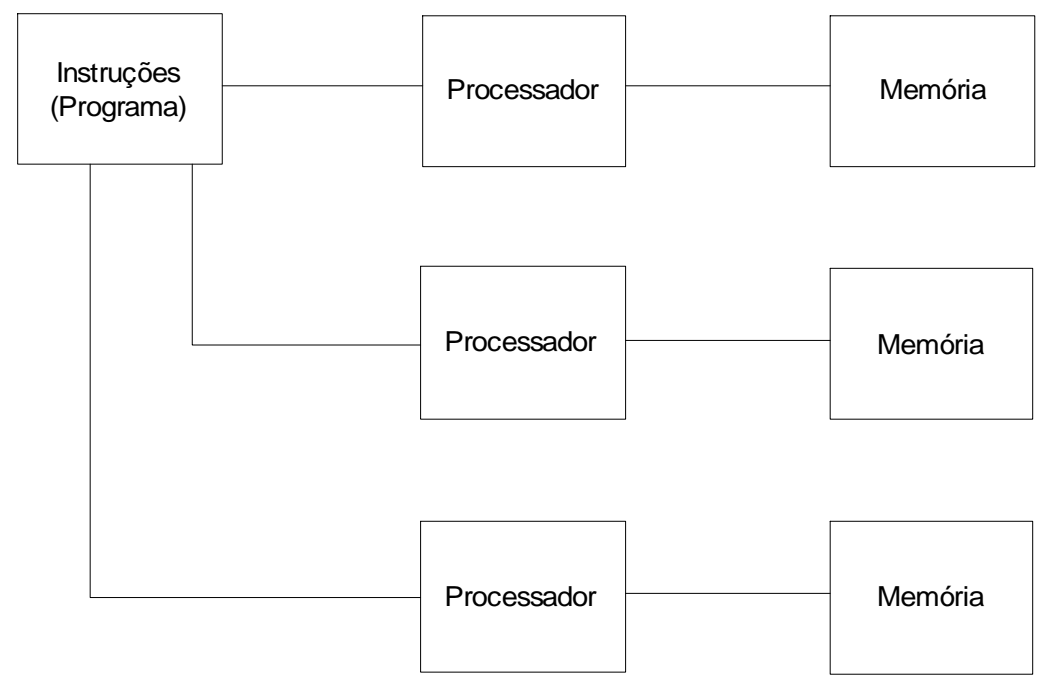

Figura 2.3 - Arquitetura SIMD.

\subsubsection{MIMD - Multiple Instruction, Multiple Data}

Considerado o modelo de execução paralelo, na qual cada processador está trabalhando em uma estrutura independente, existindo fluxos múltiplos de instruções e dados, como se fossem um conjunto de arquiteturas SISD (Figura 2.4). As máquinas paralelas de maneira geral se encaixam nessa categoria, os clusters e os sistemas MPP (Massive Parallel Processors).

Pode-se utilizar aqui um hardware heterogêneo ou homogêneo, memória compartilhada ou distribuída, estrutura de rede dedicada ou compartilhada, criando diversas divisões que Flynn não contemplou em sua modelagem inicial e derivam duas possibilidades de MIMD [10].

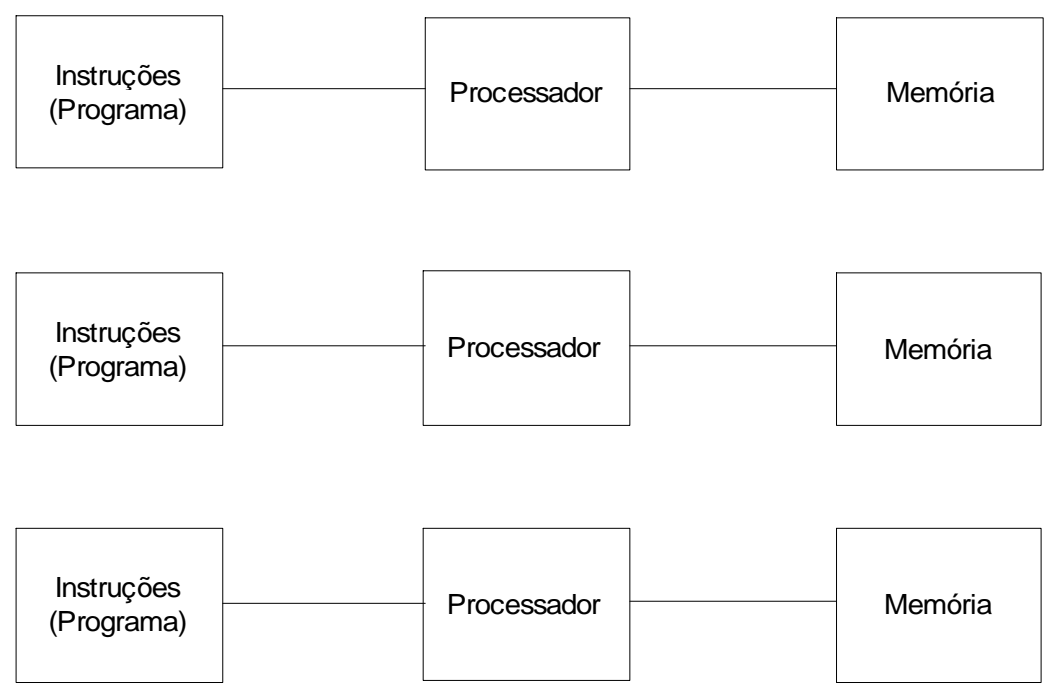

Figura 2.4 - Arquitetura MIMD. 


\subsubsection{MIMD - Memória Compartilhada}

Essa estrutura de $M I M D$ abrange todas as máquinas que possuem múltiplos processadores ou ainda múltiplos núcleos (multiple cores) em um único processador, mas que acessam uma memória em comum.

Um exemplo desse tipo de implementação é a estrutura SMP. Tal arranjo permite que múltiplos processadores executem diferentes instruções independentes. O acesso a um banco comum de memória permite uma rápida comunicação entre os processos, porém, dando vez a questões de conflitos de acesso, que podem ser reduzidas via cache ou ainda via escalonamento do sistema operacional que será instalado nessa estrutura. Os dados precisam ser constantemente copiados das caches para um acesso a uma memória principal pelo software que esteja fazendo uso dessas estruturas (Figura 2.5).

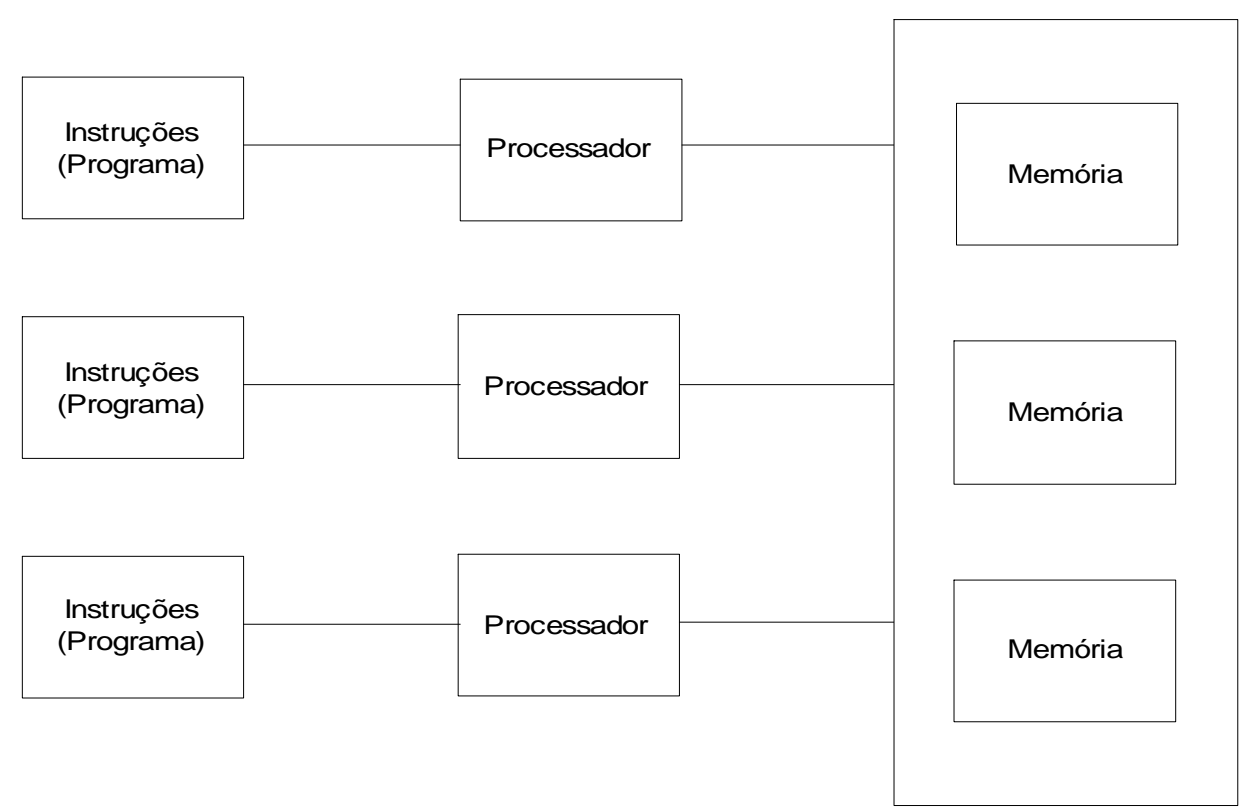

Figura 2.5 - MIMD de Memória Compartilhada.

\subsubsection{MIMD - Memória Distribuída}

Aqui estão inclusas todas as estruturas paralelas que são compostas por unidades processadoras [10], cada um com sua memória e seu próprio barramento de comunicação. Em um cluster essa unidade processadora recebe o nome de nó ou node.

Não existe memória comum nessas estruturas, apenas a comunicação dos dados, que é feita via dispositivos físicos que conectam essas estruturas 
independentes, como hubs ou switches (concentradores de rede), como pode ser observado na Figura 2.6.

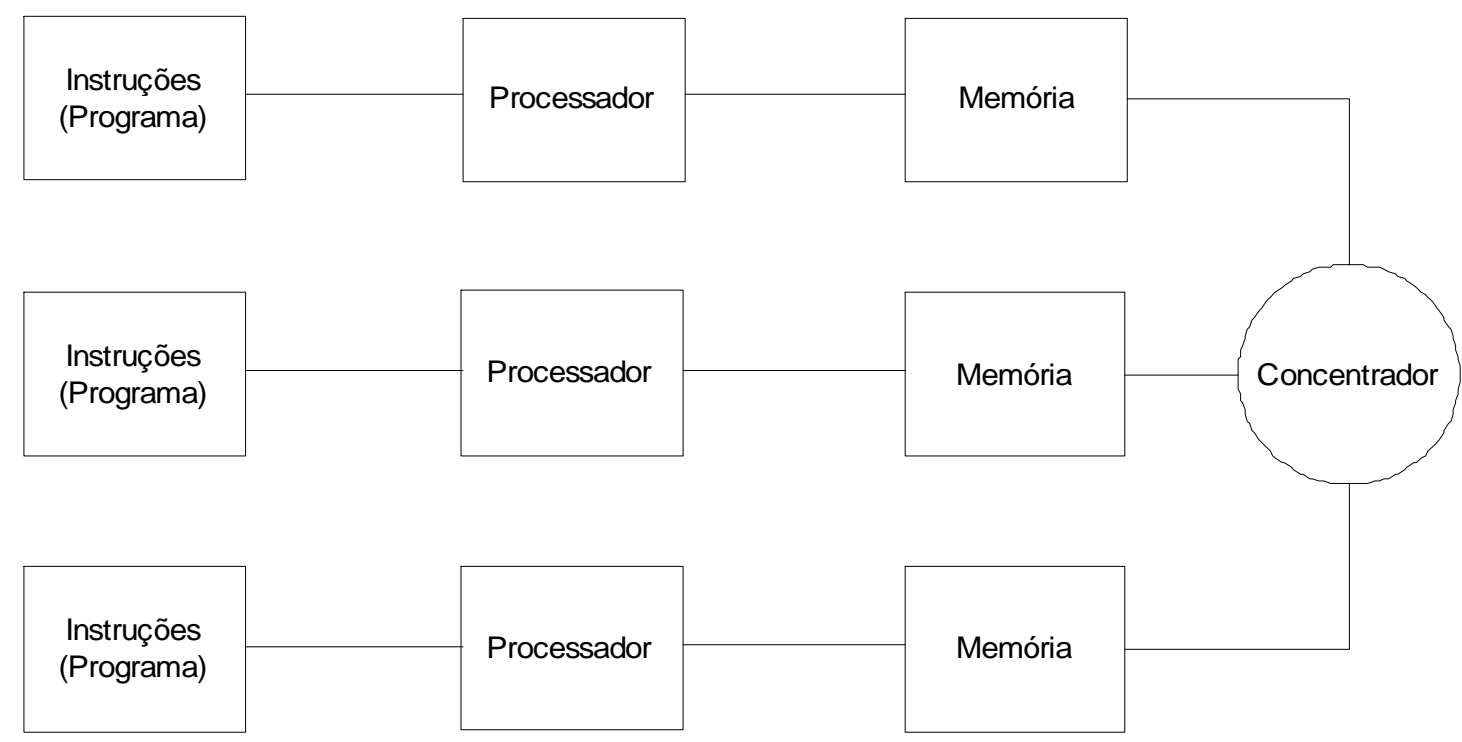

Figura 2.6 - MIMD de Memória Distribuída.

\subsubsection{Supercomputador Hopper}

O Hopper é um dos supercomputadores pertencentes ao NERSC (National Energy Research Scientific Computing Center), sendo o primeiro sistema do laboratório a operar na faixa de peta-flops (número de operações de ponto flutuante por segundo), com um pico de performance de 1.28 Petaflops [7].

No início do trabalho com o Hopper, em janeiro de 2012, ele era o oitavo supercomputador mais rápido do mundo, porém, ao término desta pesquisa, ele já estava na décima sexta posição.

\subsubsection{Hopper - Configuração}

Para se ter uma ideia clara das configurações do Hopper, observe a Tabela 2.1, contendo os detalhes de sua configuração.

Tabela 2.1 - Configurações do supercomputador Hopper.

\begin{tabular}{|l|l|}
\hline Supercomputador & Hopper \\
\hline Nós & 6.384 \\
\hline Processador & 2 processadores AMD 'MagnyCours' 2.1-GHz \\
\hline Núcleos por Nó & 24 núcleos \\
\hline Total de núcleos & 153.216 \\
\hline RAM por Nó & 32 GB (6000 nós) / 64 GB (384 nós) - DDR3 1333 Mhz \\
\hline Total de RAM & 217 Terabytes \\
\hline Espaço em Disco & 2 Petabytes \\
\hline
\end{tabular}


Como pôde ser notado, essa máquina possui 153.216 núcleos de processamento, também chamados de cores, 217 Terabytes de memória principal (RAM) e 2 Petabytes de memória secundária (armazenamento não volátil) [7].

Um fato interessante é que existem 384 nós com o dobro de memória RAM, comparando-os aos outros 6000 nós do supercomputador, mas geralmente esses 384 nós não são acessíveis, portanto as aplicações acabam tendo um ambiente totalmente homogêneo para desenvolver as aplicações paralelas.

A Tabela 2.2 ilustra os picos do supercomputador Hopper, considerando um núcleo, um nó e a máquina toda.

Tabela 2.2 - Picos do supercomputador Hopper.
\begin{tabular}{|l|l|}
\hline Processadores & Picos (em flops) \\
\hline Núcleo & 8.4 Gflops \\
\hline Nó & 201.6 Gflops \\
\hline Hopper & 1.28 Peta-flops \\
\hline
\end{tabular}

O responsável por sua fabricação e manutenção é a Cray Supercomputers, fabricante de alguns dos computadores mais potentes do mundo. A versão do Hopper é um Cray XE6.

Como observado na Tabela 2.1, esse supercomputador é formado pela união de máquinas que possuem localmente dois processadores, cada um deles com doze núcleos, totalizando vinte e quatro núcleos locais, ou seja, por nó do supercomputador.

Então, pode-se dizer que cada nó do supercomputador pode ser acessado localmente como uma estrutura MIMD de memória compartilhada, com 32 ou 64 GB de memória. Para ser acessado como um todo é preciso pensar em um ambiente MIMD de memória distribuída, ou seja, ele é um ambiente híbrido, que deve ser programado de forma também híbrida para obter um melhor desempenho, porém essa não é a única forma de programá-lo. Esse assunto será retomado posteriormente neste mesmo capítulo.

A descrição feita evidencia que cada nó constitui localmente uma estrutura MIMD de memória compartilhada. Globalmente, precisa ser interpretado como um ambiente MIMD de memória distribuída, já que cada nó possui seu próprio banco de memória. Dessa forma, um melhor desempenho será extraído do sistema se for pensado e programado como um ambiente híbrido, similar ao mencionado em [12]. 
No entanto, essa não é a única opção de uso, conforme será descrito logo mais.

\subsection{Sistemas Operacionais}

Após a compreensão das possíveis estruturas de organização de um computador, faz-se necessário o entendimento do software básico que operacionaliza uma dessas estruturas.

Em princípio, o sistema operacional precisa ser escrito para reconhecer a arquitetura de hardware disponibilizada para ele, caso contrário o usuário do sistema poderá ter um recurso de hardware que o software não reconhece.

Um exemplo prático disso é o fato de que os primeiros processadores de arquitetura de 64 bits foram lançados na família Pentium® IV e o sistema operacional da época não reconheciam os 64 bits da arquitetura, pois não foi desenvolvido para esse ambiente. Por questões de compatibilidade, o sistema operacional executava mesmo assim nesses processadores, porém trabalhava como se estivesse em uma arquitetura de 32 bits, perdendo muito em desempenho.

Outra questão que pode ser citada é o fato do usuário possuir um processador com mais de um núcleo, por exemplo, a máquina dita dual core ou quad core, com dois ou quatro núcleos respectivamente, porém o sistema operacional não reconhece os núcleos e não consegue fazer uso de todos eles, mais uma vez perdendo muito em desempenho.

Para o entendimento mais preciso deste trabalho, dois conceitos básicos de sistemas operacionais precisam ser abordados: processos e threads, que serão discutidos na sequência.

\subsubsection{Processos}

Segundo [6], um processo é uma abstração de um programa em execução, toda explicação de processos é baseado nisso e esse entendimento é imprescindível.

Complementando tal conceito, pode ser dito que um programa corresponde a um código de máquina gerado para uma determinada arquitetura e, possivelmente, para um determinado sistema operacional. Quando solicitamos ao programa para que o mesmo entre em execução, ele passa a ser um processo, assumindo o controle de uma UCP, dos registradores, da memória, entre outros itens, mesmo que 
temporariamente [9].

Os computadores modernos têm habilidade de desenvolver diversas atividades simultaneamente, ou seja, é possível editar um texto enquanto ouve-se uma música, ou ainda enquanto um programa executa um cálculo e muitas outras possibilidades.

Em um sistema com uma única Unidade Central de Processamento (UCP ou CPU), caso da arquitetura SISD, ocorre a alternância entre os processos através de técnicas de escalonamento de processos, que são capazes de dedicar fatias de tempo para cada um dos programas em execução em um mesmo instante.

Note que a definição de execução em um mesmo instante não é correta, pois se tem tal impressão como usuários do computador, quando na verdade está ocorrendo a concorrência entre os processos pela UCP dentro de um espaço de tempo. Alguns autores classificam esse fato como um pseudoparalelismo, justificando que o paralelismo real não existe nestas estruturas.

Em sistemas com mais de uma UCP ou ainda, de certa forma, em sistemas com a UCP tendo mais de um núcleo, caso da arquitetura MIMD, ocorre o paralelismo real, em que um ou mais processos podem realmente executar simultaneamente.

\subsubsection{Modelo de Processos Sequenciais}

Esse modelo é uma forma de desenvolver a lógica de processos em um computador. Todos os programas do computador e, quase sempre, o sistema operacional é organizado dessa maneira, no qual cada processo tem, virtualmente, sua própria UCP.

Em tal estrutura, o processo consegue acessar seus próprios registradores, variáveis e pilha, sendo responsabilidade do sistema operacional preservar esses valores quando ocorre a alternância entre um processo e outros, gerando o que se conhece como multiprogramação [6].

Deve ficar claro que para o processo em si, ele acredita ter o controle total da UCP, variáveis e pilha, se tratando do modelo conceitual, mas no sistema real de multiprogramação somente um processo está ativo em um dado instante de tempo, como pode ser visto na Figura 2.7. 


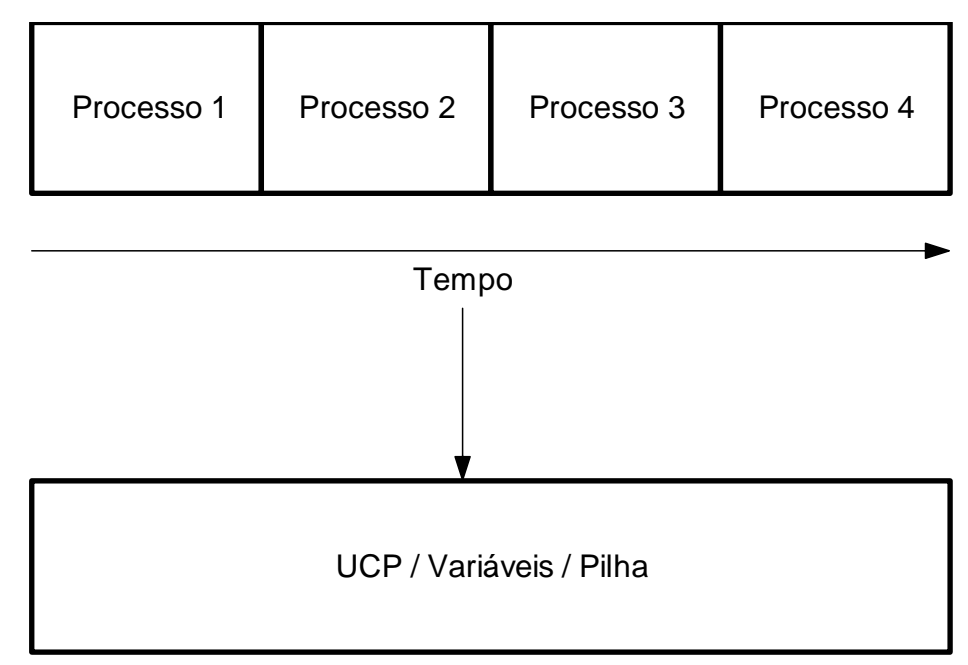

Figura 2.7 - UCP, variáveis e pilha acessadas por único processo.

Nessa estrutura de acesso à UCP e seus recursos, faz-se necessário adotar mecanismos para alternar entre os processos, criando uma agenda com critérios para dividir o tempo nos acessos dos processos, sabendo que esse controle todo depende do sistema operacional.

\subsubsection{Hierarquia e Estados de Processos em Sistemas UNIX}

Nos sistemas baseados em Unix, como o Minix e as distribuições Linux, os processos possuem mecanismos de gerenciamento para que possam, basicamente, serem criados e destruídos.

Em tais estruturas, os processos são criados pela chamada de sistema FORK [6], que cria uma cópia idêntica do processo que fez a chamada. Dessa forma, o processo filho também pode executar uma chamada FORK, criando o que é conhecido como o conceito de árvore de processos.

Dentro desse contexto, é sabido então que os processos são independentes entre si, como mencionado no modelo conceitual descrito anteriormente, porém existe a necessidade de utilizar-se de técnicas de sincronização para que um processo possa interagir com outro quando isso for necessário como em um ambiente de impressão, que fica aguardando trabalhos para direcioná-los à interface da impressora.

Para implementar a comunicação dos processos, eles precisam possuir estados que os classificam da seguinte forma: executando, pronto e bloqueado.

O estado de executando classifica aquele processo que realmente faz uso da UCP em um dado instante. O estado de pronto é utilizado para classificar um 
processo que é executável, porém está parado para permitir que algum outro processo execute. Por fim, o estado de bloqueado para classificar um processo que não pode ser executado até que algo aconteça.

Note que nos dois primeiro casos os programas podem executar, porém no caso de pronto não existe UCP disponível para ele e então ele é forçado a esperar. No terceiro caso, de bloqueado, pode-se observar o exemplo do ambiente de impressão, que fica aguardando a chegada de dados para serem impressos.

Ainda segundo [6], existem quatro possibilidade de transição entre os processos, como pode ser observado na Figura 2.8.

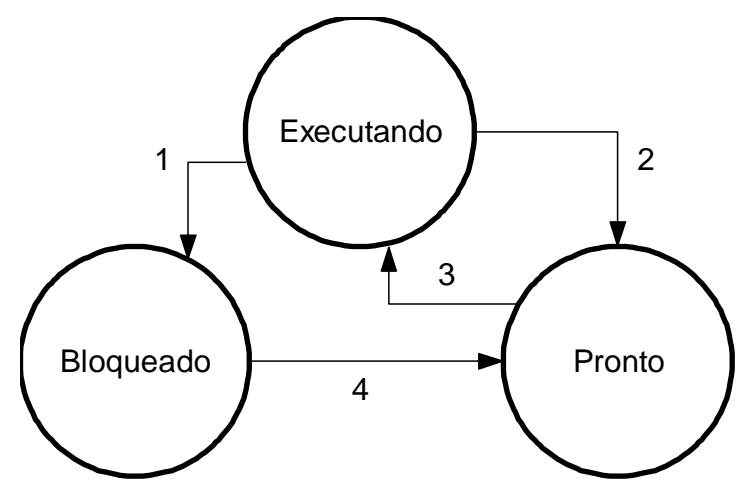

Figura 2.8 - Quatro transições entre processos.

A transição de número 1 ocorre quando um processo verifica que não pode mais executar por alguma razão e realiza uma chamada de sistema denominada BLOCK, ou no caso do ambiente de impressão em que o bloqueio ocorre automaticamente. As transições de número 2 e 3 ocorrem pelo escalonador ou agendador de processos do sistema operacional. Por fim, a transição de número 4 ocorre quando um processo que aguardava por algo já pode entrar em execução, então ele passa ao estado de pronto para que o agendador decida quando ele será executado realmente.

\subsubsection{Threads}

Em um processo tradicional, como os que foram discutidos anteriormente, existe apenas uma linha de controle, um único contador de programa, um único estado para cada registrador, e a área de memória é também única. Existem alguns sistemas operacionais nos quais existe a possibilidade de múltiplas linhas de controle dentro de um único processo, geralmente chamadas de threads ou processos leves [6]. 
A Figura 2.9 ilustra três processos, cada um com uma linha de controle e ainda com um contador de programa (indicado pela seta) exclusivos.

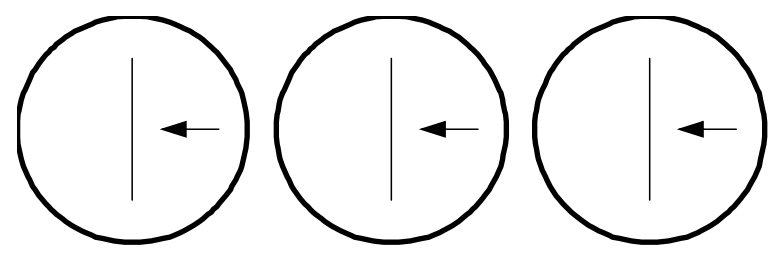

Figura 2.9 - Três processos com linha de controle e contador de programa.

Esse modelo tradicional mostra que cada processo trabalha com um único thread, ou seja, possui sua linha de controle, seu contador de programa e seu espaço de endereço. A outra possibilidade é a ilustrada pela Figura 2.10.

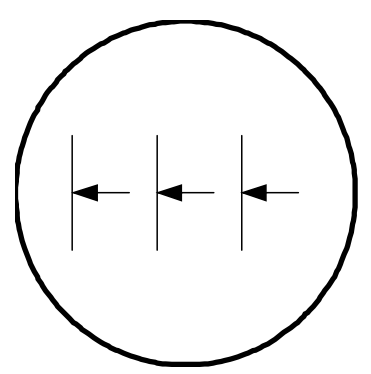

Figura 2.10 - Um processo com três linhas de controle e contador de programa.

Nesse caso, o processo possui três threads, três linhas de controle, mas todos os threads acessam o mesmo espaço de endereço, embora os contadores de programa sejam distintos.

Existe ainda a questão de que o gerenciamento dos threads pode ocorrer no nível do usuário ou ainda no nível do sistema operacional. Isso quer dizer que alguns sistemas operacionais não reconhecem threads, e o usuário tem que controlar tais procedimentos via comandos, como ocorre na biblioteca Pthreads [6].

Nos sistemas operacionais em que existe o reconhecimento dos threads (quando um thread, por exemplo, bloqueia), ele sabe que deve colocar outro em execução, do mesmo ou de outro processo. Para o escalonador ou agendador do sistema operacional, existe o controle de threads tanto quanto existe o controle de processos.

Ainda segundo [6], a alternância entre os threads no nível do usuário é muito mais rápida, por outro lado, quando algum thread de um processo bloqueia, o sistema operacional para o processo todo, pois ele desconhece a existência de threads. 


\subsection{Programação Paralela}

Programação paralela ou distribuída é a área que compreende o desenvolvimento de softwares para ambientes de alto desempenho, definida por [5] como Sistema Distribuído Computacional.

Existem duas abordagens de programação paralela ou distribuída: programar para ambiente de memória compartilhada, fornecido pela arquitetura MIMD de memória compartilhada e programar para ambiente de memória distribuída, fornecido pela arquitetura MIMD de memória distribuída.

Há ainda a possibilidade de um ambiente híbrido, formado pela união da arquitetura MIMD de memória compartilhada com a arquitetura MIMD de memória distribuída.

\subsubsection{Programação MIMD - Memória Compartilhada}

Esse item trata dos conceitos que norteiam o ambiente de programação em memória compartilhada, sendo necessário definir alguns conceitos básicos relacionados a processos "leves", ou threads, bem como os conceitos de criação, junção, finalização e escalonamento.

Além disso, alguns mecanismos físicos foram implementados pelos fabricantes de hardware para reconhecer e trabalhar melhor com as threads, migrando o contexto originário de sistemas operacionais para o ambiente de arquitetura de computadores.

Cabe dizer que nesse item não se abordarão os aspectos práticos da programação de memória compartilhada, basicamente por duas razões. A primeira é o fato de que memória compartilhada não é o escopo deste trabalho. A segunda é que as rotinas de programação distribuída, que serão abordadas posteriormente neste capítulo, funcionam também como mecanismos de programação de memória compartilhada, porém geralmente não são tão eficazes quanto às rotinas específicas para ambiente de memória compartilhada, sendo ideal em um ambiente híbrido, comentado no item anterior deste mesmo capítulo.

\subsubsection{Thread e Memória Compartilhada}

Segundo [13], a definição básica de thread é um mecanismo que existe onde um processo se divide em outros processos menores que irão concorrer pelo uso do 
processador, compartilhando fatias de tempo do mesmo, como ocorre com os processos em geral em qualquer sistema operacional multitarefa.

A existência de thread depende da implementação do mecanismo pelo próprio sistema operacional, chamado de Kernel Level Thread (KLT) ou por bibliotecas desenvolvidas especificamente para essa finalidade, técnica denominada de User Level Thread (ULT).

Por exemplo, em um processador com um núcleo, enquanto o processo de uma calculadora concorre com o processo de um editor de texto em um ambiente de um sistema operacional multitarefa, os recursos de hardwares utilizados são distintos, por isso o sistema operacional pode escalonar os processos e simular uma execução simultânea, típica dos sistemas com ambiente de janelas. Se o processador em questão tivesse mais de um núcleo, as threads poderiam realmente executar simultaneamente.

Deve-se também levar em consideração o fato de que a memória principal (RAM) utilizada por esses processos é única no hardware hospedeiro, ou seja, precisa ser implementado algum mecanismo de proteção das áreas de código e variáveis, para que uma thread não destrua a outra.

Cada linha de execução de uma thread pode:

- Criar uma thread (thread-create);

- Sincronizar com uma thread (join;)

- Abandonar o uso da UCP (thread-yield);

- Replicar-se somente na parte essencial do código.

Além disso, as linhas de execução da thread podem ter os seguintes estados:

- Criação (o processo pai cria uma thread e entra na fila de prontos);

- Execução (tomando para si o uso da UCP);

- Pronto (entra na fila de prontos);

- Bloqueado (o processo é interrompido para aguardar algo);

- Término (processo finalizado).

\subsubsection{Criação de Thread}

O conceito básico de criação de thread é que uma linha de execução pode ser dividida em outras duas linhas, ou seja, são executadas simultaneamente. 
A thread que cria outra thread é chamada de thread pai e a thread que é gerada no processo de criação é chamada de thread filho. Depois de criada essa thread, ambas concorrem para o uso do processador, alternando suas tarefas e, se outras threads fossem criadas, ocorreria o mesmo.

\subsubsection{Finalização de Thread}

Após terminar o seu trabalho, a thread precisa ser finalizada, ou seja, se um trabalho é dividido em porções menores, a cada término de uma pequena porção (thread filho), o trabalho da thread pai vai se completando até que todas as threads filho dentro dessa thread pai terminem.

Via de regra, quando uma thread pai cria uma thread filho, todas as suas variáveis ficam acessíveis para a thread filho, que as manipula segundo sua necessidade. Dessa forma precisa haver um cuidado ao finalizar uma thread pai, pois se ela for finalizada antes de uma thread filho, a thread filho também será finalizada, tendo em vista que perde o acesso às variáveis disponibilizadas pela thread pai.

Uma thread pode ser finalizada quando termina seu processo ou quando encontra um comando de saída (pthread_exit) ou ainda de cancelamento (pthread_cancel).

\subsubsection{Junção de Thread}

Essa situação ocorre no caso em que o trabalho de uma thread pai depende de um retorno específico de uma thread filho, por exemplo, na situação em que está sendo executado um cálculo de média de nota de um aluno, levando em consideração duas notas de avaliações, a thread pai calcula a média, mas depende do fornecimento da nota das avaliações por um thread filho.

No caso anterior, o que ocorre é que a thread pai precisa fazer um join (junção) com a thread filho, que irá fornecer as notas das avaliações, para não ficar ociosa aguardando o retorno da thread filho.

\subsubsection{Rendimento de Thread}

Muitas vezes ocorrem situações indesejadas no escalonamento de processos realizado pelo sistema operacional, levando a situações em que alguns processos 
monopolizam recursos por um tempo indeterminado, ou ainda, deixando outros recursos sob sua "responsabilidade", no entanto não está fazendo uso dos mesmos.

Quando se desenvolve um código que faz uso de técnicas de threading, o controle sobre a alternância das threads está nas mãos do programador, ou seja, no desenvolvimento do código ele pode fazer uso do mecanismo de thread yield que libera a UCP para outra thread, criando um escalonamento pelo próprio programador, considerando sistemas operacionais que não reconheçam threads.

\subsubsection{Escalonamento de Threads}

O escalonamento corresponde ao fato de alternar entre os processos ou entre as threads de maneira muito rápida, criando a sensação de que vários trabalhos são executados simultaneamente em máquinas com um único processador ou núcleo.

Nas questões de programação com threads, precisam ser consideradas aqui duas situações: o escalonamento de threads no nível do usuário e o escalonamento de threads no nível do núcleo do sistema operacional.

Em se tratando de threads no nível do usuário, o controle do que irá ocorrer está por conta do programador, ou seja, o sistema operacional desconhece as threads do processo, ele apenas realiza o escalonamento dos processos e não das threads. Se a fatia de tempo destinada ao processo que cria threads se der por encerrada, o controle passará para outro processo e, somente quando o sistema operacional retornar o controle para o processo que está criando as threads, ocorrerá o escalonamento interno das threads implementado pelo programador.

No caso de threads no nível do núcleo do sistema operacional, o próprio sistema consegue visualizar as threads filho de cada thread pai e escalona essas threads de acordo com a prioridade atribuída a ela, ou seja, as threads de duas threads pais estão concorrendo simultaneamente, diferentemente do que ocorre com as threads no nível do usuário. Como o controle fica a cargo do sistema operacional e não do programador, as decisões tomadas se tornam mais "genéricas" e não específicas para cada situação a ser resolvida, tornando assim o uso das threads no nível do sistema operacional um processo mais lento do que o das threads no nível do usuário. 


\subsubsection{HT - Hyper Threading Tecnology}

Essa tecnologia foi desenvolvida para melhorar a performance dos processadores da linha IA-32 quando são utilizados em sistemas operacionais e softwares que utilizam técnicas de multi-threading ou ainda em aplicações do tipo single-threading executando em ambientes de multitarefas. Essa tecnologia possibilita que um único processador físico execute mais de um código (thread) concorrentemente utilizando recursos de execução compartilhada [14].

Os processadores da linha chamada de IA-32 utilizam essa técnica como forma de implementar multi-threading, diferenciando-se dos processadores que possuem múltiplos núcleos ou ainda de máquinas com mais de um processador fisicamente.

Processadores com HT (alguns membros da família Intel Pentium $4 \circledast$ e $X e o n \AA)$ possuem um ambiente de execução compartilhado, ou seja, seriam dois núcleos lógicos, que não existem fisicamente, apenas compartilhando os recursos de um único núcleo do processador físico.

\subsubsection{Recursos Replicados}

Segundo [15], o estado de arquitetura consiste nos registradores (gerais, controle, flags, entre outros) que são utilizados pelo sistema operacional e softwares para controlar a execução e o armazenamento dos dados. No caso de processadores com a tecnologia $\mathrm{HT}$, esse estado de arquitetura é replicado para cada processador lógico disponível na estrutura.

\subsubsection{Recursos Particionados}

Recursos particionados são buffers compartilhados devido à limitação do uso por cada processador lógico, existindo para que determinadas operações de um processador lógico possam desconsiderar operações de outro processador lógico que pode estar paralisado. Além disso, o uso de tais recursos possibilita a igualdade de operação dos processadores.

\subsubsection{Recursos Compartilhados}

Muitos recursos do processador físico são totalmente compartilhados para possibilitar uma utilização dinâmica, incluindo a cache e todas as unidades de 
execução. Alguns recursos compartilhados são endereçados de maneira linear, incluindo um bit de identificação, para saber qual processador lógico está manipulando uma dada entrada.

A cache L1 pode operar de dois modos de acordo com o contexto do bit de identificação mencionado anteriormente. Uma das formas é a cache L1 totalmente compartilhada por dois processadores lógicos, a outra é o modo adaptativo em que os acessos à memória usando uma área paginada são mapeados de forma idêntica através de processadores lógicos compartilhando os dados da cache L1.

\subsubsection{Multi-Core Technology}

Essa é outra forma de muti-threading [14] dos processadores da linha IA32, implementando dois ou mais núcleos físicos em uma única pastilha de processador. O processador Intel Pentium Extreme Edition $\Theta$ introduziu essa técnica, além de possuir tecnologia $\mathrm{HT}$, ou seja, ele possuía dois núcleos e cada núcleo possuía tecnologia $\mathrm{HT}$, fornecendo quatro processadores lógicos em uma única pastilha física de processador.

No caso do Intel Pentium $D \AA$, o processador possuía apenas dois núcleos, mas não tinha tecnologia $H T$, nesse caso fornecia dois processadores lógicos, vinculados cada um a um núcleo específico e seus recursos, em uma única pastilha física de processador.

Ainda na linha da Intel $\AA$, analisando o Intel Core $2 \AA(X e o n \AA 3000$ e 5100 e Core Duo $\left.\AA^{\circledR}\right)$, o processador contém dois núcleos que compartilham a cache de segundo nível (L2), que permite compartilhamento eficiente de dados ente dois núcleos para reduzir o tráfego de memória para o barramento do sistema.

Por fim, o Intel Xeon $\AA 5300$, o Intel Core 2 Extreme Quad $\AA$ e o Intel Core 2 Quad ${ }^{\circledR}$ suportam a tecnologia de quatro núcleos, porém o primeiro possui um sistema duplo de barramento independente, já os dois últimos possuem um sistema único de barramento.

\subsubsection{Programação MIMD - Memória Distribuída}

A programação distribuída é adequada ao ambiente dos clusters e grids, sejam eles ou não supercomputadores, existindo vários tipos de programação distribuída, umas mais e outras menos utilizadas por uma série de questões, que 
não são o escopo deste trabalho.

Segundo [5], quando houve o crescimento dos multicomputadores de alto desempenho, os pesquisadores e desenvolvedores, precisavam de um ambiente de troca de mensagens para facilitar a escrita de códigos paralelos para esses sistemas.

Tal ambiente deveria ser composto por primitivas de trocas de mensagens com um nível conveniente de abstração, diferentemente do uso de sockets que suportam somente as primitivas send e receive e trabalham em uma pilha de protocolos de rede generalizados, algo que não é conveniente para o ambiente paralelo em questão, específico por necessitar de uma estrutura transparente que facilite 0 alto desempenho.

As redes de alta velocidade presentes nos supercomputadores precisam de um ambiente de troca de mensagens que favoreçam o seu uso, caso contrário existirá um "gargalo" gigantesco de rede.

A maioria dos desenvolvedores de supercomputadores criaram bibliotecas de comunicação proprietárias que conseguiam aproveitar o ambiente paralelo com eficiência, porém as bibliotecas de um supercomputador não eram compatíveis com as bibliotecas de outro supercomputador, gerando dificuldades com 0 desenvolvimento de softwares, pois todos tinham uma portabilidade muito baixa.

Por conta dessas questões, em um determinado momento foi necessário pensar na criação de um ambiente homogêneo de troca de mensagens, que recebeu o nome de MPI (Message Passing Interface) [16].

O ambiente MPI consiste em uma tentativa de padronização para ambientes de programação via troca de mensagens, sem ter que se preocupar com a arquitetura do ambiente paralelo em si, permitindo altíssima portabilidade aos códigos escritos com essa interface.

Segundo [16], o processo de criar o padrão MPI envolveu 80 pessoas, provenientes de 40 organizações americanas e europeias, sendo que os principais fabricantes de computadores paralelos participaram do desenvolvimento de tal interface, bem como laboratórios e centros de pesquisa.

A ideia básica era obter padronização e portabilidade, através de um conjunto de rotinas adaptadas a qualquer ambiente paralelo. A existência de distintas arquiteturas de computadores gera certa complexidade na implementação de tais rotinas, reescritas para cada uma das arquiteturas, para manter a portabilidade dos 
códigos.

A primeira versão do MPI é datada de 1992, versão essa sem um padrão, pois sua especificação é datada de 1993, dando origem a versão escrita seguindo tal padrão, datada de 1994 (MPI 1.0). Posteriormente surgiu a versão 1.1, que é datada de 1995 [11].

A interface MPI trabalha com o conceito de que a comunicação ocorre por grupo de processos, sendo que cada grupo recebe um identificador. Cada processo também tem o seu identificador dentro do grupo. O par identificador do grupo e identificador do processo forma o endereço de um processo, usado nas primitivas de comunicação de envio e recebimento. Pode existir mais de um grupo de processos trabalhando em um mesmo serviço de computação [5].

Existem algumas primitivas básicas que podem ser comentadas brevemente, como pode ser visto na Tabela 2.3.

Tabela 2.3 - Primitivas básicas MPI.

\begin{tabular}{|l|l|}
\hline Primitiva & Descrição Resumida \\
\hline MPI_Init & Inicializa a interface MPI. \\
\hline MPI_Send & Envia uma mensagem e espera a cópia para o buffer. \\
\hline MPI_Recv & Recebe uma mensagem e bloqueia caso não haja nenhuma. \\
\hline MPI_Bcast & Envia de um processo para todos os outros. \\
\hline MPI_Reduce & Um processo recebe de todos os outros. \\
\hline MPI_Finalize & Finaliza a interface MPI. \\
\hline
\end{tabular}

Para compreender melhor o funcionamento do mecanismo de troca de mensagens, serão explicadas com mais detalhes essas seis primitivas do padrão MPI, começando pelos conceitos básicos.

Devido aos solvers utilizados nos testes deste trabalho, também serão descritas ao final deste capítulo mais três primitivas não tão usuais: MPI_Allreduce, MPI_Wait e MPI_Barrier.

\subsubsection{Primitivas MPI: Conceitos básicos}

Alguns parâmetros que precisam ser definidos com mais clareza, por isso foi criada a Tabela 2.4 com os itens presentes em várias primitivas de comunicação MPI. 
Tabela 2.4 - Primitivas básicas MPI.

\begin{tabular}{|l|l|}
\hline Parâmetro & Descrição \\
\hline id_origem & Identificador do processo remetente. \\
\hline id_destino & Identificador do processo destinatário. \\
\hline tipo_dado & Tipo do dado a ser enviado ou recebido. \\
\hline vetor_dados & Vetor com os dados a serem enviados ou recebidos. \\
\hline quantidade & Quantidade de dados a serem enviados ou recebidos. \\
\hline tag & Rótulo para diferenciar tipos de mensagens. \\
\hline comunicador & Indica um grupo de processos, geralmente único no software. \\
\hline
\end{tabular}

Os parâmetros "id_origem" e "id_destino" são valores do tipo inteiro e podem possuir valores entre 0 e $\mathrm{N}-1$, onde $\mathrm{N}$ indica o número total de processos envolvidos no cálculo que estiver sendo realizado. Tal informação independe da linguagem utilizada, seja ela $\mathrm{C}, \mathrm{C}++$ ou Fortran.

O "tipo_dado" em MPI pode assumir uma série de valores, sendo que tais valores possuem seus correspondentes em cada linguagem de programação disponível pelas variantes de bibliotecas do MPI. A Tabela 2.5 ilustra as principais equivalências dos tipos de dados em $\mathrm{C}, \mathrm{C}++$ e Fortran.

Tabela 2.5 - Equivalência de tipos de dados MPI com C, C++ e Fortran.

\begin{tabular}{|l|l|l|l|}
\hline MPI & C & C++ & Fortran \\
\hline MPI_CHAR & signed char & signed char & - \\
\hline MPI_INT & signed int & signed int & INTEGER \\
\hline MPI_FLOAT & float & float & REAL \\
\hline MPI_DOUBLE & double & double & DOUBLE PREC. \\
\hline
\end{tabular}

O parâmetro "vetor_dados" contém todos os elementos que serão enviados em uma única mensagem, sendo que todos os elementos devem estar armazenados em um vetor e, obviamente, os valores devem ser todos de um mesmo tipo de dado, possivelmente um dos valores ilustrados na Tabela 2.5.

Apenas como complemento ao parágrafo anterior, cabe dizer que o parâmetro "quantidade" faz referência ao tamanho do "vetor_dados", com relação ao número de elementos que compõem tal vetor, tendo em vista que as informações sempre são enviadas ou recebidas em buffer de vetor.

O valor "tag" é do tipo inteiro e pode ser utilizado como um rótulo para 
diferenciar vários tipos de mensagens, porém tradicionalmente as mensagens possuem sempre o mesmo "tag", sendo que o par de mensagens de envio e recebimento deve sempre possuir o mesmo "tag", senão a mensagem não será recebida pelo destinatário.

Já o parâmetro "comunicador", o mesmo possibilita criar um grupo de processos e, também tradicionalmente, possui sempre o mesmo valor dentro de um software, para que todos os processos dentro desse mesmo software possam se comunicar sem maiores dificuldades, pois, por padrão, somente processos de um mesmo "comunicador" podem se comunicar diretamente. O valor do comunicador padrão é "MPI_COMM_WORLD”.

\subsubsection{Primitivas MPI: MPI_Init}

Essa primitiva permite iniciar a interface MPI e deve ser chamada antes de qualquer outra rotina MPI [16].

Códigos escritos em linguagem $\mathrm{C} / \mathrm{C}++$ permitem passar parâmetros para manipular variáveis do ambiente MPI, porém isso é desaconselhável. Por questões de portabilidade, recomenda-se chamar a rotina sem nenhum parâmetro ou colocando valor NULL.

No caso de códigos escritos em linguagem Fortran, não é possível passar qualquer tipo de parâmetro, sendo assim a portabilidade é mantida naturalmente.

\subsubsection{Primitivas MPI: MPI_Finalize}

Essa rotina deve ser chamada por cada processo antes dele terminar seu código, pois ela limpa todo o ambiente MPI criado. Após ser chamada essa rotina, nenhuma outra rotina MPI pode ser chamada [16].

Se o processo tiver mais algum código para executar localmente, sem participar de qualquer outra comunicação MPI, ele poderá continuar sem maiores dificuldades, mas não poderá retomar nenhum procedimento MPI.

Todo processo deverá finalizar as comunicações MPI antes de chamar a rotina de finalização, ou então deverá abortar qualquer rotina pendente, pois a rotina MPI_Finalize não assegura as comunicações pendentes que não foram completadas. 


\subsubsection{Primitivas MPI: MPI_Send}

A rotina MPI_Send pode ser considerada uma das mais utilizadas, pois realiza um envio bloqueante de mensagem em uma comunicação utilizando a interface MPI.

O formato dessa rotina é o seguinte:

MPI_Send(vetor_dados, quantidade, tipo_dado, id_destino, tag, comunicador)

Por ser uma rotina que necessita de parâmetros, os campos utilizados nessa rotina foram descritos na Tabela 2.1.

Cabe dizer que todos os parâmetros dessa rotina são parâmetros de entrada, nenhum deles será modificado pela rotina em questão.

A comunicação dita bloqueante é também chamada de standard-mode, indicando que a finalização do send não necessariamente indica que o seu par de receive iniciou em outro processo, e nenhuma suposição deve ser feita no software sobre os dados de saída ter ou não sido armazenados no buffer de destino pelo MPI.

Sobre os parâmetros da rotina, cabe dizer mais uma vez que o valor informado em "quantidade" refere-se exatamente a quantidade de itens no parâmetro "vetor_dados", e não faz qualquer alusão a quantidade de bytes ou bits do tipo do dado. Dessa forma, tendo um vetor de dados com 5 elementos do tipo inteiro ou real, o parâmetro "quantidade" será 5 para os dois casos.

\subsubsection{Primitivas MPI: MPI_Recv}

A rotina MPI_Recv também pode ser considerada uma das mais utilizadas, pois realiza um recebimento bloqueante de mensagem em uma comunicação utilizando a interface MPI.

O formato dessa rotina é o seguinte:

MPI_Recv(vetor_dados, quantidade, tipo_dado, id_origem, tag, comm, status)

Mais uma vez, a comunicação aqui é dita bloqueante e em modo standard, situação já explicada no item anterior deste mesmo capítulo.

Os parâmetros dessa rotina estão também expostos na Tabela 2.1, exceto pelo parâmetro "status", que é um parâmetro de saída, sendo que seu valor será modificado conforme o ocorrido no processamento da rotina. 
A Tabela 2.6 ilustra como deve ser declarada a variável "status" nas linguagens $\mathrm{C}, \mathrm{C}++$ e Fortran.

Tabela 2.6 - Declaração de "status" MPI com C, C++ e Fortran.

\begin{tabular}{|l|l|l|}
\hline C & C++ & Fortran \\
\hline MPI_Status & MPI::Status & INTEGER(3) \\
\hline
\end{tabular}

Os valores retornados em "status" podem indicar possíveis erros ocorridos com a origem (processo "remetente"), com a "tag" ou outro erro qualquer, sendo que existem valores para cada tipo de erro [16].

O parâmetro "vetor_dados", nessa rotina, é um parâmetro de entrada e não de saída, pois irá receber os valores provenientes da mensagem MPI. Esse vetor deverá ter tamanho suficiente para armazenar todos os valores esperados pela mensagem, especificado pelo parâmetro "quantidade". O buffer de recebimento especificado pelo "vetor_dados" pode ser maior do que a quantidade de valores esperados, pois os valores recebidos serão preenchidos na sequência do buffer, começando pelo primeiro endereço do mesmo, no caso o primeiro endereço do vetor, sendo a posição 0 em linguagem $C$ e $\mathrm{C}++$ e a posição 1 em linguagem Fortran. Sugere-se a leitura de [16] para um melhor entendimento dessa rotina e o tratamento de possíveis erros.

\subsubsection{Primitivas MPI: MPI Bcast}

A rotina MPI_Bcast é largamente utilizada nos programas paralelos, pois facilita o desenvolvimento em uma série de casos, evitando excesso de linhas de códigos pelos desenvolvedores.

O formato dessa rotina é o seguinte:

MPI_Bcast(vetor_dados, quantidade,tipo_dado,id_origem,comm)

Essa rotina envia uma mensagem que parte do processo especificado pelo parâmetro "id_origem" para todos os outros processos do grupo, incluindo ele próprio [16].

O valor "id_origem" deve ser o mesmo em todos os processos que irão receber essa comunicação, por isso, geralmente, essa rotina é colocada de forma "explícita” no código, ou seja, não está dentro de nenhuma condição de código exclusiva de determinado processo. 
Todos os processos envolvidos na comunicação devem ter as mesmas variáveis de parâmetros declaradas para que seja possível o funcionamento correto dessa rotina.

\subsubsection{Primitivas MPI: MPI_Reduce}

A rotina MPI_Reduce realiza uma operação de redução como soma e valor máximo, com todos os processos membros de um mesmo grupo.

O formato dessa rotina é o seguinte:

MPI_Reduce(vetor_envio, ventor_rec, quantidade, tipo_dado, operação,id_proc, comm)

Nessa rotina cabem algumas explicações sobre cada um dos parâmetros necessários para seu funcionamento, pois ela tem um comportamento um pouco mais complexo do que as outras rotinas descritas até agora. Observe a Tabela 2.7 na para uma breve descrição dos parâmetros dessa rotina.

Tabela 2.7 - Parâmetros da rotina MPI_Reduce.

\begin{tabular}{|l|l|}
\hline Parâmetro & Descrição \\
\hline vetor_envio & Vetor com os dados a serem enviados por todos os processos. \\
\hline vetor_rec & Vetor com os dados a serem recebidos de todos os processos. \\
\hline quantidade & Quantidade de dados a serem enviados ou recebidos. \\
\hline tipo_dado & Tipo do dado a ser enviado ou recebido. \\
\hline operação & Operação de redução. \\
\hline id_proc & Identificador do processo destinatário. \\
\hline comunicador & Indica um grupo de processos, geralmente único no software. \\
\hline
\end{tabular}

O parâmetro "vetor_envio" faz referência ao nome do buffer onde estão os dados que serão enviados para o processador destinatário, identificado pelo parâmetro "id_proc", do tipo inteiro. O processador destinatário receberá todos os valores no "vetor_rec", respeitando sempre a quantidade de elementos especificada pelo parâmetro "quantidade", contendo a dimensão do buffer, ou vetor, de envio e recebimento.

Os parâmetros "tipo_dado" e "comunicador" já foram explicados anteriormente, e seguem as mesmas respectivas definições.

A operação de redução, especificada pelo parâmetro "operação", pode ser uma das listadas na Tabela 2.8, e também poderá ser uma operação definida pelo 
usuário.

Tabela 2.8 - Declaração de "status" MPI com C, C++ e Fortran.

\begin{tabular}{|l|l|}
\hline Operação & Descrição \\
\hline MPI_MAX & Retorna o valor máximo. \\
\hline MPI_MIN & Retorna o valor mínimo. \\
\hline MPI_SUM & Retorna a soma dos valores. \\
\hline MPI_PROD & Retorna o produto dos valores. \\
\hline
\end{tabular}

Existem outras operações não menos importantes, porém estão sendo destacadas algumas das mais utilizadas nos códigos de programação paralela em geral.

\subsubsection{Primitivas MPI: MPI_Allreduce}

Essa rotina é muito similar a rotina MPI_Reduce, exceto pelo fato de que o resultado da operação de redução, descrita anteriormente, não se restringe apenas a um único processo, ou seja, o resultado irá para todos os processos pertencentes ao comunicador informado na rotina.

O formato dessa rotina é o seguinte:

MPI_Allreduce(vetor_envio,vetor_rec, quantidade, tipo_dado, operação, comm)

Note que, nesse caso não existe o campo "id_proc" descrito no item anterior, pois o mesmo não é necessário, tendo em vista que todos os processos recebem o resultado da redução.

\subsubsection{Primitivas MPI: MPI_Wait}

A rotina MPI_Wait é utilizada para completar operações de requisição de envio e recebimento não bloqueantes. Por exemplo, a finalização de uma requisição de envio indica que a operação de envio associada completou-se, assim os dados foram copiados do buffer de envio. O remetente fica livre para acessar o buffer de envio. O mesmo ocorre com uma operação de recebimento não bloqueante.

$O$ formato dessa rotina é o seguinte: 
Uma chamada à rotina MPI_Wait retorna quando a operação identificada pelo campo "requisição" tiver sido finalizada. Esse campo não foi descrito ao longo do trabalho, pois está diretamente relacionado com as rotinas de envio e recebimento não bloqueantes, que não terão suas respectivas descrições cobertas por este texto. O campo "requisição" está ligado sempre a um equivalente a esse, vindo de uma rotina de envio ou recebimento não bloqueantes.

Com relação ao campo "status", cabe dizer que ele equivale ao explicitado no item que descreveu a rotina MPI_Recv e os respectivos retornos podem ser vistos em [16].

\subsubsection{Primitivas MPI: MPI_Barrier}

Com essa rotina é possível sincronizar um grupo inteiro de processos que pertencem a um mesmo comunicador.

O formato dessa rotina é o seguinte:

\section{MPI_Barrier(comm)}

O campo "comm" indica o comunicador onde os processos estão agrupados, como já foi descrito anteriormente neste trabalho.

O funcionamento dessa rotina é bem simples, ela bloqueia todos os processos que a chamaram, até que todos a tenham chamado, garantindo sincronismo em casos onde há real necessidade. 


\section{Resolução de Sistemas de Equações Lineares}

Os problemas da mecânica computacional frequentemente recaem na resolução de sistemas lineares, um dos principais métodos numéricos desta área do conhecimento. Inúmeros são as formulações matemáticas e algoritmos para resolução dessa classe de problemas.

A resolução de sistemas lineares de equações algébricas pode basicamente ser dividida em dois grupos de métodos: os métodos diretos e os iterativos. Os métodos diretos são aqueles em que é possível determinar previamente o número de operações matemáticas necessárias para obter a resolução do sistema. Entre os principais métodos diretos destacam-se o método da eliminação de Gauss e os métodos baseados na prévia decomposição da matriz dos coeficientes por um produto de matrizes, entre eles citamos o método de Crout, o método de Doolitle e o método de Cholesky. Já os métodos iterativos são aqueles baseados em processos iterativos, como o próprio nome diz, que consistem em calcular uma sequência de aproximações da solução do sistema linear, condicionados a uma aproximação inicial e uma tolerância desejada da solução do sistema. Sendo assim, para os métodos iterativos não se pode prever o número de operações matemáticas para obtenção da solução. Entre os principais métodos iterativos destacam-se o método de Gauss-Seidel, o método de Gauss-Jacobi, o método dos gradientes conjugados e o método dos gradientes biconjugados [17,18].

Considere-se o sistema linear $\mathbf{A x}=\mathbf{b}$, que pode ser representado na seguinte forma matricial $[19,20]$ :

$$
\mathbf{A x}=\mathbf{b} \Rightarrow\left[\begin{array}{ccccc}
a_{1,1} & a_{1,2} & a_{1,3} & \cdots & a_{1, n} \\
a_{2,1} & a_{2,2} & a_{2,3} & \cdots & a_{2, n} \\
a_{3,1} & a_{3,2} & a_{3,3} & \cdots & a_{3, n} \\
\vdots & \vdots & \vdots & \ddots & \vdots \\
a_{n, 1} & a_{n, 2} & a_{n, 3} & \cdots & a_{n, n}
\end{array}\right]\left[\begin{array}{c}
x_{1} \\
x_{2} \\
x_{3} \\
\vdots \\
x_{n}
\end{array}\right]=\left[\begin{array}{c}
b_{1} \\
b_{2} \\
b_{3} \\
\vdots \\
b_{n}
\end{array}\right]
$$

Nesse sistema o determinante da matriz A não pode ser nulo, garantindo solução única.

Resolver tal sistema consiste em determinar um vetor $\overline{\mathbf{x}}$ que satisfaça todas as equações do sistema linear em questão.

Se o sistema $\mathbf{A x}=\mathbf{b}$ apresenta ao menos uma solução, ele é dito 
consistente, caso contrário ele é dito inconsistente.

Além disso, se no sistema $\mathbf{A x}=\mathbf{b}$ todos os elementos do vetor $\mathbf{b}$ forem nulos, o sistema é dito homogêneo, e a solução do sistema é o próprio vetor $\mathbf{b}$.

Pretende-se neste trabalho resolver sistemas cuja solução não seja nula, utilizando-se de métodos diretos ou iterativos.

\subsection{Métodos Diretos}

Os métodos diretos servem para calcular o vetor solução $\overline{\mathbf{x}}$ caracterizados por fornecerem solução de um sistema próxima a exata, devido aos erros gerados por questões computacionais.

Seja o sistema linear de equações algébricas, descrito em sua forma matricial por:

$$
\mathbf{A x}=\mathbf{b},
$$

onde A é a matriz dos coeficientes das equações algébricas, $\mathbf{x}$ é o vetor das incógnitas e b é o vetor dos termos independentes.

Fazendo uma decomposição multiplicativa da matriz $\mathbf{A}$ em:

$$
\mathbf{A}=\mathbf{L D U},
$$

sendo a matriz $\mathbf{L}$ triangular inferior de diagonal unitária, a matriz $\mathbf{D}$ diagonal e a matriz $\mathbf{U}$ triangular superior de diagonal unitária. Assim, o novo sistema a ser resolvido terá a seguinte forma:

$$
\mathbf{L D U x}=\mathbf{b} .
$$

Esse sistema pode ser resolvido, utilizando as três etapas descritas abaixo:

1. $\mathbf{L y}=\mathbf{b} \quad$ (substituição descendente ou progressiva)

2. $\mathbf{D z}=\mathbf{y} \quad$ (substituição diagonal)

3. $\mathbf{U x}=\mathbf{z} \quad$ (substituição ascendente ou regressiva).

Os vetores $\mathbf{y}$ e $\mathbf{z}$ são apenas auxiliares no processo.

Note que, utilizando a decomposição LDU, necessita-se que a matriz não seja singular e o elemento $a_{1,1}$ deve ser diferente de zero. Quando trabalhamos com matrizes simétricas, o sistema pode ser simplificado utilizando para decomposição 
$\mathbf{U}=\mathbf{L}^{T}$, tendo assim a decomposição $\mathbf{L D L}^{T}$, que reduz significativamente o número de operações matemáticas para resolver sistemas com matriz simétrica.

Dessa metodologia derivam vários métodos clássicos para resolução de sistemas, fazendo combinações das matrizes decompostas.

a) Método de Crout

Quando se faz $\overline{\mathbf{L}}=\mathbf{L D}$ e utiliza-se a decomposição $\overline{\mathbf{L}}$ para resolver o sistema sem a etapa de substituição diagonal o método denomina-se Método de Crout. Esse método não necessita que a matriz seja simétrica.

b) Método de Doolitle

Quando se faz $\overline{\mathbf{U}}=$ DU e utiliza-se a decomposição $\mathbf{L} \overline{\mathbf{U}}$ para resolver o sistema sem a etapa de substituição diagonal o método denomina-se Método de Doolitle. Esse método não necessita que a matriz seja simétrica.

c) Método de Cholesky

Quando se faz $\tilde{\mathbf{L}}=\mathbf{L} D^{1 / 2}$ e utiliza-se a decomposição $\tilde{\mathbf{L}} \tilde{\mathbf{L}}^{T}$ para resolver o sistema sem a etapa de substituição diagonal o método denomina-se Método de Cholesky. Esse método necessita que a matriz seja simétrica positivo definida.

\subsubsection{Método de Crout}

O método Crout é um dos mais divulgados métodos diretos para a solução de sistemas de equações lineares. Nesse caso, a matriz não precisa ser simétrica e sua decomposição ocorre da seguinte maneira:

$\mathbf{A}=\mathbf{L U}$

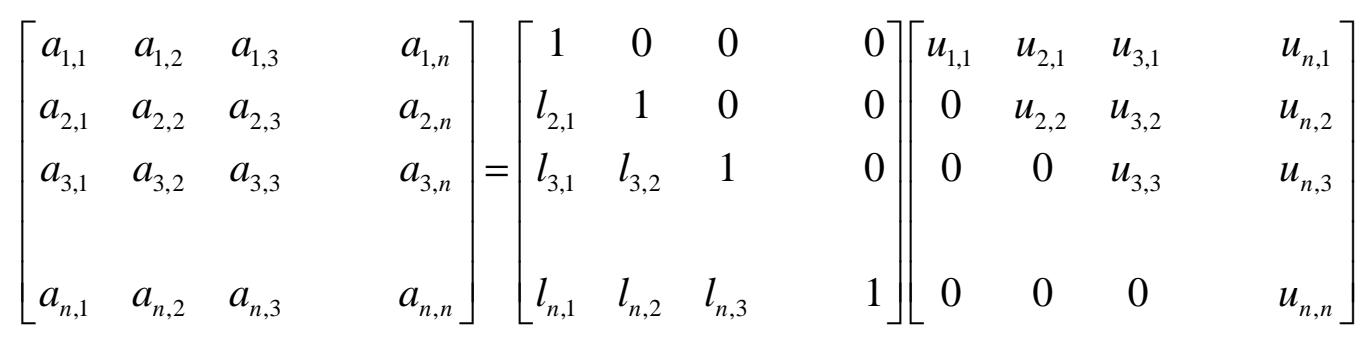

Como pode ser visto, a matriz $L$ é triangular inferior e todos elementos da diagonal possuem valor unitário e a matriz $\mathrm{U}$ é triangular superior.

Para resolver o sistema $\mathbf{A x}=\mathbf{b}$, será feito o seguinte: 


$$
\begin{aligned}
& u_{i j}=\left(a_{i j}-\sum_{k=1}^{i-1} l_{i k} u_{k j}\right) i, j=1, \ldots, n, i \leq j \\
& l_{i j}=\frac{\left(a_{i j}-\sum_{k=1}^{j-1} l_{i k} u_{k j}\right)}{u_{j j}} i, j=1, \ldots, n, i \leq j
\end{aligned}
$$

Após obter as matrizes $U$ e $L$, a resolução do sistema $\mathbf{A x}=\mathbf{b}$ é dada com a resolução dos sistemas triangulares:

$$
\begin{aligned}
& A x=b \\
& L U x=b \quad \longrightarrow \quad L y=b
\end{aligned}
$$

Substituição Progressiva

$$
\mathbf{L y}=\mathbf{b} \Rightarrow\left[\begin{array}{ccccc}
l_{1,1} & 0 & 0 & 0 \\
l_{2,1} & l_{2,2} & 0 & 0 \\
l_{3,1} & l_{3,2} & l_{3,3} & 0 \\
l_{n, 1} & l_{n, 2} & l_{n, 3} & l_{n, n}
\end{array}\right]\left[\begin{array}{l}
y_{1} \\
y_{2} \\
y_{3} \\
y_{n}
\end{array}\right]=\left[\begin{array}{l}
b_{1} \\
b_{2} \\
b_{3} \\
\\
b_{n}
\end{array}\right]
$$

Substituição Regressiva

$$
\mathbf{U x}=\mathbf{y} \Rightarrow\left[\begin{array}{cccc}
u_{1,1} & u_{2,1} & u_{3,1} & u_{n, 1} \\
0 & u_{2,2} & u_{3,2} & u_{n, 2} \\
0 & 0 & u_{3,3} & u_{n, 3} \\
& & & \\
0 & 0 & 0 & u_{n, n}
\end{array}\right]\left[\begin{array}{l}
x_{1} \\
x_{2} \\
x_{3} \\
x_{n}
\end{array}\right]=\left[\begin{array}{l}
y_{1} \\
y_{2} \\
y_{3} \\
y_{n}
\end{array}\right]
$$

Feitas as substituições Progressiva $(\mathbf{L y}=\mathbf{b})$ e Regressiva $(\mathbf{U x}=\mathbf{y})$ obtêmse finalmente o vetor $\overline{\mathbf{x}}$.

\subsubsection{Método de Cholesky}

Um dos métodos diretos mais conhecidos e utilizados é o método de Cholesky, utilizado para resolver sistemas lineares em que a matriz A seja simétrica e positiva definida: 


$$
\mathbf{A}=\mathbf{G G}^{\mathbf{T}}
$$

$$
\left[\begin{array}{ccccc}
a_{1,1} & a_{1,2} & a_{1,3} & a_{1, n} \\
a_{2,1} & a_{2,2} & a_{2,3} & a_{2, n} \\
a_{3,1} & a_{3,2} & a_{3,3} & a_{3, n} \\
a_{n, 1} & a_{n, 2} & a_{n, 3} & a_{n, n}
\end{array}\right]=\left[\begin{array}{cccc}
g_{1,1} & 0 & 0 & 0 \\
g_{2,1} & g_{2,2} & 0 & 0 \\
g_{3,1} & g_{3,2} & g_{3,3} & 0 \\
& & & \\
g_{n, 1} & g_{n, 2} & g_{n, 3} & g_{n, n}
\end{array}\right]\left[\begin{array}{cccc}
g_{1,1} & g_{2,1} & g_{3,1} & g_{n, 1} \\
0 & g_{2,2} & g_{3,2} & g_{n, 2} \\
0 & 0 & g_{3,3} & g_{n, 3} \\
& & & \\
0 & 0 & 0 & g_{n, n}
\end{array}\right] \text { (3.9) }
$$

Como pode ser visto a matriz $\mathrm{G}$ é triangular inferior com elementos da diagonal estritamente positivos.

Para resolver o sistema $\mathbf{A x}=\mathbf{b}$, será feito o seguinte:

$$
\begin{aligned}
& g_{k k}=\left(a_{k k}-\sum_{i=1}^{k-1} g_{k k}^{2}\right)^{1 / 2} \\
& g_{j k}=\frac{1}{g_{k k}}\left(a_{j k}-\sum_{i=1}^{k-1} g_{j i} g_{k i}\right)
\end{aligned}
$$

Após obter o fator $\mathrm{G}$, a resolução do sistema $\mathbf{A x}=\mathbf{b}$ é dada com a resolução dos sistemas triangulares:

$\mathbf{A x}=\mathbf{b}$

$$
G^{\mathrm{T}} x=b \stackrel{G^{\mathrm{T}} x=y}{\longrightarrow} \quad G y=b
$$

Substituição Progressiva

$$
\mathbf{G y}=\mathbf{b} \Rightarrow\left[\begin{array}{cccc}
g_{1,1} & 0 & 0 & 0 \\
g_{2,1} & g_{2,2} & 0 & 0 \\
g_{3,1} & g_{3,2} & g_{3,3} & 0 \\
& & & \\
g_{n, 1} & g_{n, 2} & g_{n, 3} & g_{n, n}
\end{array}\right]\left[\begin{array}{l}
y_{1} \\
y_{2} \\
y_{3} \\
y_{n}
\end{array}\right]=\left[\begin{array}{l}
b_{1} \\
b_{2} \\
b_{3} \\
\\
b_{n}
\end{array}\right]
$$

Substituição Regressiva

$$
\mathbf{G}^{\mathbf{T}} \mathbf{x}=\mathbf{y} \Rightarrow\left[\begin{array}{cccc}
g_{1,1} & g_{2,1} & g_{3,1} & g_{n, 1} \\
0 & g_{2,2} & g_{3,2} & g_{n, 2} \\
0 & 0 & g_{3,3} & g_{n, 3} \\
0 & 0 & 0 & g_{n, n}
\end{array}\right]\left[\begin{array}{l}
x_{1} \\
x_{2} \\
x_{3} \\
x_{n}
\end{array}\right]=\left[\begin{array}{c}
y_{1} \\
y_{2} \\
y_{3} \\
y_{n}
\end{array}\right]
$$


Feita as substituições Progressiva $(\mathbf{G y}=\mathbf{b})$ e Regressiva $\left(\mathbf{G}^{\mathbf{T}} \mathbf{x}=\mathbf{y}\right)$, obtêmse finalmente o vetor $\overline{\mathbf{x}}$.

\subsection{Métodos Iterativos}

Segundo [17], os métodos iterativos fornecem uma sequencia de soluções aproximadas, em que cada solução aproximada é obtida baseada na anterior, aplicando $n$ vezes um mesmo procedimento.

Tais métodos consideram a transformação do sistema original $\mathbf{A x}=\mathbf{b}$ para $\mathbf{a}$ forma equivalente $\mathbf{x}=\mathbf{H x}+\mathbf{g}$. Partindo dessa forma equivalente e de um vetor $\mathbf{x}_{0}$, que é a solução inicial aproximada do sistema, pode-se determinar uma sequência de soluções aproximadas $\mathbf{x}^{(\mathbf{k}+\mathbf{1})}=\mathbf{H} \mathbf{x}^{(\mathbf{k})}+\mathbf{g} \quad \mathrm{k}=0,1,2, \ldots$, onde $\mathbf{H}$ é matriz iterativa e g é um vetor.

Pode-se então perceber que, partindo de uma aproximação inicial $\mathbf{x}_{0}$ para a solução exata do sistema $\mathbf{A x}=\mathbf{b}$, denominada $\overline{\mathbf{x}}$, tem-se uma sequência de soluções aproximadas armazenadas nos vetores $\mathbf{x}^{(1)}, \mathbf{x}^{(2)}, \mathbf{x}^{(3)}, \ldots, \mathbf{x}^{(n)}$, que se espera serem convergentes para a solução $\overline{\mathbf{x}}$.

\subsubsection{Gradientes Conjugados}

O método dos Gradientes Conjugados utiliza alguns itens do método do Maior Decréscimo e do conceito de direções A-conjugadas, porém não serão feitas provas e demonstrações desses outros itens, por não serem o escopo deste trabalho [21].

Considerando o sistema linear seguinte:

$$
\mathbf{A x}=\mathbf{b} .
$$

A matriz $\mathbf{A} \in R^{\mathrm{nxn}}$ deve ser simétrica e definida positiva. $\mathrm{O}$ vetor $\mathbf{b} \in R^{\mathrm{n}} \mathrm{e}$ pode-se calcular $\mathbf{x} \in R^{\mathrm{n}}$.

Antes de dar início ao algoritmo propriamente dito, alguns procedimentos são realizados: 


$$
\begin{aligned}
& k=0 \\
& \text { escolha de } \mathbf{x}_{0} \\
& \mathbf{r}_{0}=\mathbf{b}-\mathbf{A} \mathbf{x}_{0} \\
& \mathbf{p}_{0}=-\mathbf{r}_{0} \\
& \text { escolha de } \boldsymbol{\varepsilon}>0
\end{aligned}
$$

Os cálculos utilizados no método de Gradientes Conjugados são exibidos no seguinte algoritmo:

$$
\begin{gathered}
\alpha_{k}=\frac{\mathbf{r}_{k}^{T} \mathbf{p}_{k}}{\mathbf{p}_{k}^{T} \mathbf{A} \mathbf{p}_{k}} \\
\mathbf{x}_{k+1}=\mathbf{x}_{k}+\alpha_{k} \mathbf{p}_{k} \\
\mathbf{r}_{k+1}=\mathbf{r}_{k}-\alpha_{k} \mathbf{A} \mathbf{p}_{k} \\
\beta_{k}=\frac{\mathbf{p}_{k}^{T} \mathbf{A} \mathbf{r}_{k+1}}{\mathbf{p}_{k}^{T} \mathbf{A} \mathbf{p}_{k}} \\
\mathbf{p}_{k+1}=\mathbf{r}_{k+1}+\beta_{k} \mathbf{p}_{k}
\end{gathered}
$$

O algoritmo do método dos Gradientes Conjugados segue a sequência das equações anteriores, após isso é feito seguinte cálculo: $\left\|\mathbf{r}_{k+1}\right\|<\varepsilon\|\mathbf{b}\|$.

Se a condição anterior for satisfeita, o algoritmo é encerrado, caso contrário retorna-se à primeira equação e novamente são realizados os cálculos do algoritmo.

Teoricamente o método dos Gradientes Conjugados deveria convergir em $n$ passos, porém devido aos erros de arredondamento, a convergência não ocorre dessa forma finita.

Em matrizes grandes e esparsas a convergência pode ser lenta [22], mas existe o tratamento dessa questão através de Pré-Condicionamento, por exemplo, com o uso do método de Cholesky Incompleto.

\subsubsection{Gradientes Conjugados Pré-Condicionados}

Como mencionado no item anterior, o Método dos Gradientes Conjugados tem a convergência lenta para matrizes esparsas, inclusive em alguns casos seu desempenho é inferior se comparado com os métodos diretos. A convergência pode ser melhorada se o sistema linear for pré-condicionado. 
Esse pré-condicionamento equivale a multiplicar a matriz original do sistema por outra, de modo que o resultado desse produto esteja mais próximo da matriz identidade, obtendo, assim, uma matriz dita bem condicionada [21].

Considere o sistema linear seguinte: $\mathbf{A x}=\mathbf{b}$.

A matriz $\mathbf{A} \in R^{\text {nxn }}$ deve ser simétrica e definida positiva. $\mathrm{O}$ vetor $\mathbf{b} \in R^{\mathrm{n}} \mathrm{e}$ pode-se calcular $\mathbf{x} \in R^{\mathrm{n}}$. A ideia básica do pré-condicionamento é construir uma transformação que tenha efeito na matriz $\mathbf{A}$, sendo que existem diversos tipos de pré-condicionadores. Nos testes do próximo capítulo o pré-condicionador adotado é o Cholesky Incompleto.

Considere a matriz de pré-condicionamento definida por $\mathbf{B} \in R^{\mathrm{nxn}}$, sendo assim, o início do algoritmo ocorre da seguinte forma:

$$
\begin{aligned}
& k=0 \\
& \text { escolha de } \mathbf{x}_{0} \\
& \mathbf{r}_{0}=\mathbf{b}-\mathbf{A} \mathbf{x}_{0} \\
& \mathbf{p}_{0}=-\mathbf{z}_{0}=-\mathbf{B}^{-1} \mathbf{r}_{\mathbf{0}} \\
& \text { escolha de } \boldsymbol{\varepsilon}>0
\end{aligned}
$$

Os cálculos do método de Gradientes Conjugados Pré-Condicionados são os exibidos no seguinte algoritmo:

$$
\begin{gathered}
\boldsymbol{\alpha}_{k}=-\frac{\mathbf{r}_{k}^{T} \mathbf{p}_{k}}{\mathbf{p}_{k}^{T} A p_{k}} \\
\mathbf{x}_{k+1}=\mathbf{x}_{k}+\boldsymbol{\alpha}_{k} p_{k} \\
r_{k+1}=r_{k}-\alpha_{k} A p_{k} \\
\mathbf{z}_{k+1}=B^{-1} r_{k+1} \\
\beta_{k}=\frac{\mathbf{r}_{k+1}^{T} \mathbf{z}_{k+1}}{r_{k}^{T} \mathbf{z}_{k}} \\
\mathbf{p}_{k+1}=-\mathbf{z}_{k+1}+\beta_{k} p_{k}
\end{gathered}
$$

Após a realização dos cômputos anteriores, calcula-se $\left\|\mathbf{r}_{k+1}\right\|<\varepsilon\|\mathbf{b}\|$.

Se a condição anterior for satisfeita o algoritmo é encerrado, caso contrário, volta-se ao primeiro cálculo e procede-se novamente até que ela seja satisfeita.

Note que este texto não tem como objetivo tratar esse assunto de forma 
aprofundada, apenas explicar brevemente como funciona tal método, pois o mesmo está implementado dentro de um dos softwares que será utilizado nos testes do trabalho.

\subsection{Softwares para Resolução de Sistemas de Equações Lineares}

Para trabalhar com a resolução de sistemas de equações descritas anteriormente, faz-se necessário entender alguns dos softwares que são a base para as implementações mais específicas, descritas neste mesmo capítulo.

Os softwares básicos devem realizar funções básicas de álgebra linear, 0 caso do BLAS e de suas variantes, bem como a resolução de sistemas de equações densos, como no caso do LAPACK e ScaLAPACK.

Após o entendimento básico desses softwares, torna-se possível fazer uma apresentação dos solvers utilizados nesta pesquisa. Os solvers diretos utilizados e apresentados neste trabalho são o SuperLU e o MUMPS. O solver iterativo utilizado nesta pesquisa é o PETSc. Esses softwares são comumente utilizados em pesquisas que envolvem ambiente computacional de alto desempenho [23,3].

\subsubsection{BLAS (Basic Linear Algebra Subprograms)}

O pacote BLAS é uma biblioteca escrita em linguagem Assembly, para ser utilizada em programas feitos na linguagem Fortran, composta por um conjunto de funções que executam operações básicas de álgebra linear, como multiplicação de vetores e matrizes. A primeira versão da biblioteca é datada de 1973 [24].

Esta biblioteca é muito utilizada em computação de alto desempenho, e existem variantes das mesmas desenvolvidas pela Intel, AMD, entre outros.

Segundo [24], a biblioteca BLAS existe devido a algumas razões:

- Pode servir como uma ajuda conceitual, tanto na concepção como na codificação de um esforço de programação, considerando uma operação como o produto vetorial, por exemplo:

- Implementa a qualidade de auto documentação do código para identificar uma operação como o produto vetorial, por exemplo, através de um único "mnemônico";

- Partindo do fato de que uma quantidade significante do tempo de execução em complexos programas que utilizam álgebra linear pode ser gasto em pequenas 
operações de baixo nível, a redução desse tempo pode refletir na economia do tempo de execução do programa como um todo, sendo assim, a codificação em linguagem Assembly influencia muito em boa parte dos casos [25];

- A programação de algumas dessas operações de baixo nível envolvem certas sutilezas no algoritmo e implementação que geralmente são ignoradas em ambientes típicos de programação.

Cada operação presente na biblioteca, originalmente eram 38 funções, é identificada por um nome "raiz". Esse nome "raiz" recebe um prefixo de uma ou mais letras: I, S, D, C ou Q, identificando operações com inteiros, precisão simples, precisão dupla, complexo de precisão simples ou tipo estendido de dados, respectivamente. Para programas que envolvem o uso de mais de um tipo de dados, o "output" da função é indicado pela letra mais à esquerda que precede o nome da função.

Essa primeira versão da biblioteca foi escrita em Assembly para o IBM 360/67, CDC 6600/7600 e para o UNIVAC 1108. Exceto no caso do código para o IBM 360/67, o código escrito em Assembly mostrou-se muito mais rápido na execução do que os escritos em Fortran [24].

Em [26] está descrito que o BLAS mostrou-se ineficiente em algumas máquinas, principalmente naquelas que possuíam arquitetura vetorial, capazes de executar instruções do tipo SIMD não comportadas pela atual implementação do BLAS.

Em 1984, durante uma série de encontros científicos ficou decidido a implementação de uma continuação do BLAS, com mais rotinas e com mais poder computacional. O BLAS criado por [24] passou então a ser conhecido como Nível 1 do BLAS e o novo conjunto estendido de instruções foi chamado de Nível 2 do BLAS.

Nesse Nível 2 do BLAS, é possível obter o produto de uma matriz por um vetor, resolver sistemas de equações, entre outros itens.

Em 1990 foi proposto por [27] o terceiro e último nível do BLAS, responsável por operações com matrizes, como produtos de matrizes, multiplicação de uma matriz por uma matriz triangular e solução de sistemas de equações.

Atualmente, o BLAS é composto então por esses três níveis, que podem ser utilizados por chamadas das rotinas com os tipos de dados específicos desejados, desde que suportados pela rotina em questão. 


\subsubsection{LAPACK (Linear Algebra Package)}

O software LAPACK (Linear Algebra Package) é uma biblioteca originalmente composta por sub-rotinas para Fortran 77 para resolver os problemas mais comuns de álgebra linear numérica. Foi projetado para ser eficiente nos computadores de alto desempenho [28,29].

A biblioteca é composta por rotinas de driver aptas a resolver tipos de problemas tradicionais, rotinas computacionais para realizar tarefas computacionais distintas e rotinas auxiliares para realizar certas sub tarefas ou cálculos comuns. Cada rotina de driver geralmente chama uma sequência de rotinas computacionais, que podem realizar uma gama de rotinas cobertas pelas rotinas de driver. Muitas das rotinas auxiliares podem ser usadas para análise numérica ou por desenvolvedores de softwares.

A alta eficiência do LAPACK está condicionada a sua execução em processadores vetoriais, workstations de alta performance, e processadores com memória compartilhada, tendo também uso satisfatório em computadores pessoais e mainframes. Existem versões especiais do LAPACK capazes de trabalhar com arquiteturas paralelas ou ainda com arquiteturas SIMD.

As rotinas do LAPACK foram escritas para, sempre que possível, chamar as rotinas do BLAS, pois existem implementações específicas do BLAS para computadores modernos de alto desempenho. O BLAS não é uma parte estrita do LAPACK, podendo ser utilizado de forma independente, mas sua cópia acompanha a distribuição do LAPACK.

$O$ código de comunicação entre o LAPACK e o BLAS é chamado de implementação modelo, que não possui grande desempenho, mas permite que usuários executem o LAPACK em máquinas que não oferecem nenhuma implementação do BLAS.

\subsubsection{SuperLU}

Segundo [30], o pacote SuperLU é uma biblioteca com um conjunto de rotinas responsáveis por resolver sistemas de equações lineares esparsos, no formato $\mathbf{A X}=\mathbf{B}$, onde $\mathbf{A}$ é uma matriz quadrada $n x n$, não singular, esparsa, e $\mathbf{X}$ e $\mathbf{B}$ são densos, podendo ser de ordem $n \times$ nrhs, onde $n r h s$ é o número de vetores $\mathbf{b}$ e $\mathbf{x}$, ilustrados na equação 3.2 , possuindo geralmente valor unitário. As rotinas de 
fatoração LU podem lidar com matrizes que não sejam quadradas.

A matriz exposta na equação $\mathbf{A X}=\mathbf{B}$ não precisa ser simétrica ou positiva definida, pois o SuperLU foi desenvolvido para lidar particularmente com matrizes que possuam estrutura não simétrica, no entanto, existem testes comparando-o com outros solvers [23].

Foram escritas três versões do SuperLU, uma para processadores únicos, chamada de versão sequential, outra para processadores de memória compartilhada, chamada de shared memory, e a versão apresentada neste trabalho, que foi desenvolvida para processadores com memória distribuída, chamada de distributed memory [31].

Todas as versões mencionadas anteriormente usam variações da eliminação de Gauss otimizada para poder aproveitar de forma apropriada cada uma das arquiteturas disponíveis [32], pois os recursos disponíveis são distintos, como já ilustrados no capítulo que trata dos aspectos computacionais.

Cabe também salientar que as três versões do SuperLU foram escritas em linguagem C, usando Pthreads e OpenMP na versão shared memory, e MPI na versão distributed memory. Junto ao pacote é fornecida a interface para uso da biblioteca em linguagem Fortran.

Com relação aos tipos de dados disponíveis, a biblioteca trabalha com dados reais e complexos, de precisão simples e dupla, exceto na versão distributed memory, que permite apenas dados reais e complexos com precisão dupla.

A versão utilizada neste trabalho foi desenvolvida para trabalhar no modelo MIMD, descrito no capítulo de aspectos computacionais, tendo sido testada em várias plataformas, incluindo IBM SP, Cray XT, SGI Altrix e diversos clusters executando Linux.

As matrizes A e $\mathbf{B}$, citadas anteriormente, podem ser distribuídas para todos os processadores, desde que exista memória suficiente local por processador para comportar tal procedimento. Segundo [30], esse método é mais rápido que o descrito na sequência, pois o outro método necessita de uma redistribuição de dados em diferentes estágios do algoritmo.

A segunda possibilidade é distribuir as matrizes A e B pelos processadores, baseando-se em uma distribuição por blocos de linhas, onde cada processador possui um bloco de linhas consecutivas de $\mathbf{A}$ e $\mathbf{B}$. 


\subsubsection{SuperLU - Programação Básica}

Serão discutidas aqui as questões pertinentes aos aspectos básicos de programação relativos ao solver SuperLU, porém será considerada apenas a versão desenvolvida para memória distribuída, por conta dos objetivos descritos anteriormente no início da tese.

Por outro lado, os aspectos aqui discutidos podem aplicar-se as outras versões do solver, no entanto recomenda-se a leitura do manual do software para dirimir eventuais dúvidas [30].

\subsubsection{SuperLU - Inicializando o MPI}

A primeira coisa a ser feita antes de qualquer procedimento envolvendo ambientes de memória distribuída é inicializar a comunicação MPI, através de sua rotina básica que informa o nome do grupo de processos ("MP_Init").

Não será discutida aqui a sintaxe para inicializar o MPI, pois depende da linguagem de programação que o desenvolvedor estiver utilizando.

\subsubsection{SuperLU - Inicializando o solver}

O processo de inicialização do solver SuperLU é um tanto quanto detalhista, pois são abordados aspectos que não são necessários nos outros dois solvers discutidos neste texto.

Uma questão que surge inicialmente é que o SuperLU trabalha com o conceito de um grid de processos, uma malha que permite organizar os cálculos que serão distribuídos aos processadores envolvidos no processamento.

O SuperLU utiliza a distribuição tradicional de bloco cíclico para o grid, que pode ser vista na Figura 3.1. 
Global Matrix

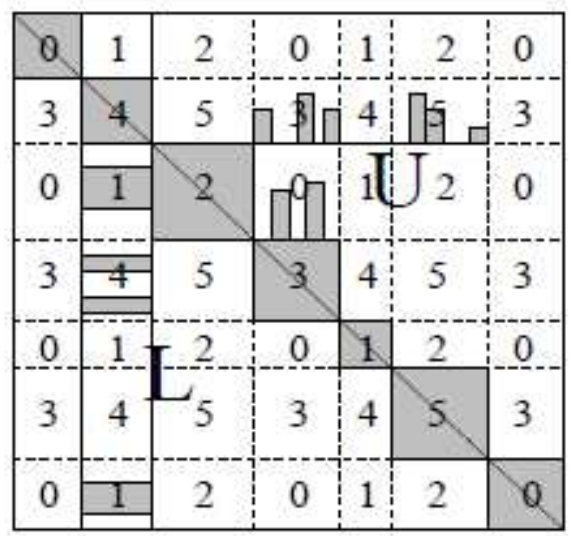

\begin{tabular}{|c:c:c|}
\hline 0 & 1 & 2 \\
\hdashline 3 & 4 & 5 \\
\hline
\end{tabular}
Storage of block column of $\mathrm{L}$

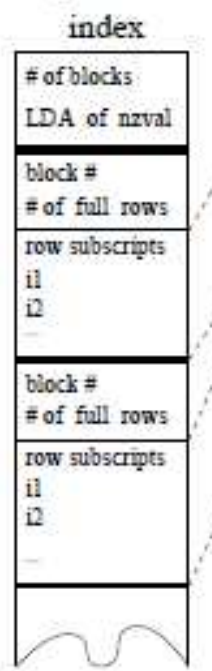

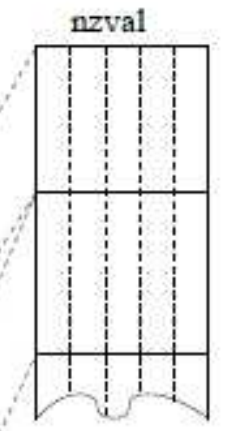

Figura 3.1 - Bloco cíclico e estrutura que armazena o bloco local de coluna de L. Fonte: [30]

Para compreender de forma um pouco mais aprofundada o procedimento descrito e ilustrado anteriormente, recomenda-se a leitura de [30,33].

A rotina de inicialização precisa ser chamada da seguinte maneira:

superlu_gridinit(MPI_COMM_WORLD, nprow, npcol, \&grid);

Observando-se os parâmetros de entrada dessa rotina, nota-se primeiramente a passagem do comunicador padrão para os processos MPI. O segundo parâmetro, "nprow", indica o número de linhas do grid de processos. O terceiro parâmetro, "npcol", indica o número de colunas do grid de processos. Por fim, o parâmetro "\&grid" faz referência a uma estrutura que contém informações sobre os processos.

A estrutura de "\&grid" não será discutida aqui, mas pode ser obtida no manual do solver [30].

\subsubsection{SuperLU - Matrizes e Vetores}

Para resolver o sistema de equações lineares, é preciso informar a matriz " $A$ ", o vetor " $b$ ", para que o solver possa fornecer o resultado do sistema em um vetor " $x$ ".

O solver SuperLU utiliza uma estrutura para armazenar as matrizes densas e esparsas criadas por ele próprio, chamada de SuperMatrix, que contém dois níveis 
de campos da estrutura da mesma. O primeiro nível contempla as propriedades da matriz, sendo essas informações independentes da maneira de como a matriz é armazenada na memória. As três propriedades são: o tipo de esquema de armazenamento, o tipo dos dados dos elementos da matriz e algumas propriedades matemáticas. O segundo nível aponta para o local de armazenamento real da matriz.

A estrutura principal da SuperMatrix pode ser vista na Tabela 3.1.

Tabela 3.1 - Estrutura da SuperMatrix no SuperLU.

\begin{tabular}{|l|l|}
\hline Parâmetro & Descrição \\
\hline Stype & Tipo de esquema de armazenamento. \\
\hline Dtype & Tipo dos dados dos elementos. \\
\hline Mtype & Propriedades matemáticas. \\
\hline nrow & Número de linhas. \\
\hline ncol & Número de colunas. \\
\hline *Store & Ponteiro para o local de armazenamento. \\
\hline
\end{tabular}

Os campos "nrow" e "ncol" são do tipo inteiro e servem para informar respectivamente o número de linhas e colunas da matriz. O último campo é um ponteiro, contendo o endereço de armazenamento da matriz.

A primeira estrutura, "Stype", pode assumir várias possibilidades, discutidas em [30]. O principal esquema de armazenamento está ilustrado na Tabela 3.2, chamado de esquema ordenado por colunas ou ainda de Harwell Boeing [34].

Tabela 3.2 - Esquema ordenado por colunas do SuperLU.

\begin{tabular}{|l|l|}
\hline Parâmetro & Descrição \\
\hline nnz & Número de não zeros da matriz. \\
\hline${ }^{*}$ nzval & Ponteiro para o vetor dos valores não nulos. \\
\hline${ }^{*}$ rowind & Ponteiro para o vetor dos índices de linhas dos não nulos. \\
\hline${ }^{*}$ colptr & Ponteiro para o vetor de início de colunas. \\
\hline
\end{tabular}

Note que essa estrutura possui, além do campo "nnz" do tipo inteiro, outros três ponteiros para vetores que contêm as informações da matriz, todos eles do tipo inteiro.

A estrutura "Dtype" pode assumir uma das quatro possibilidades de tipo de valores: ponto flutuante de precisão simples, ponto flutuante de precisão dupla, valor 
complexo de precisão simples e valor complexo de precisão dupla.

A estrutura "Mtype" contém algumas propriedades matemáticas que não serão discutidas neste texto, mas que estão disponíveis no manual do software [30].

Os vetores no SuperLU são armazenados tradicionalmente da forma ilustrada na Tabela 3.3.

Tabela 3.3 - Estrutura de vetor no SuperLU.

\begin{tabular}{|l|l|}
\hline Parâmetro & Descrição \\
\hline Ida & Dimensão do vetor. \\
\hline${ }^{*}$ nzval & Ponteiro para o vetor dos valores não nulos. \\
\hline
\end{tabular}

O primeiro campo, "Ida", tradicionalmente possui valor um, exceto nos casos de sistemas com mais de um vetor " $b$ ". O segundo campo é um ponteiro para um vetor denso, contendo todos os valores dos elementos do vetor "b".

\subsubsection{SuperLU - Configurando as opções}

O próximo passo antes de resolver um sistema de equações utilizando o SuperLU é configurar o comportamento da biblioteca através de suas opções.

As opções do solver foram criadas no SuperLU como, mais uma vez, uma estrutura de dados, característica comum em diversos programas escritos em linguagem C. As principais opções do SuperLU estão descritas na Tabela 3.4.

Tabela 3.4 - Opções de configurações do SuperLU.

\begin{tabular}{|l|l|}
\multicolumn{2}{l}{ Tabela 3.4 - Opções de configurações do SuperLU. } \\
\hline Opções & Descrição \\
\hline Fact & Forma fatorada da matriz é ou não fornecida na entrada. \\
\hline Equil & Equilibrar ou não o sistema. \\
\hline ColPerm & Como permutar as colunas da matriz. \\
\hline RowPerm & Como permutar as linhas da matriz. \\
\hline Trans & Resolver o sistema transposto. \\
\hline IterRefine & Refinamento iterativo. \\
\hline PrintStat & Exibir as estatísticas do solver. \\
\hline
\end{tabular}

Não serão descritos neste texto os detalhes de cada uma das opções e caso o usuário deseje se aprofundar nas características de cada uma, recomenda-se a leitura de [30].

Uma das possibilidades para não se aprofundar nas configurações do solver é 
utilizar a rotina "set_default_options_dist()", que possibilita a configuração automática para dos parâmetros de opções para valores mais comumente utilizados.

\subsubsection{SuperLU - Resolvendo o sistema}

Depois de inicializar o solver, definir o sistema a ser resolvido e configurar suas opções de execução, falta somente o procedimento de solicitar a resolução do sistema de equações lineares.

Tal procedimento pode ser feito através da chamada a rotina "pdgssvx", que possui uma lista de parâmetros, apresentados na Tabela 3.5, salientando que esses parâmetros estão na ordem em que devem ser especificados, sempre separados por vírgula.

Tabela 3.5 - Parâmetros da rotina "pdgssvx" do SuperLU.

\begin{tabular}{|l|l|}
\hline Opções & Descrição \\
\hline \&options & Estrutura de opções. \\
\hline \&A & Matriz do sistema. \\
\hline \&ScalePermstruct & Estrutura de vetores de transformações de "A". \\
\hline $\mathrm{b}$ & Vetor "b" do sistema. \\
\hline Idb & Dimensão do vetor "b". \\
\hline nrhs & Número de vetores "b". \\
\hline \&grid & O grid de processadores. \\
\hline \&LUstruct & Estrutura que armazena "L" e "U". \\
\hline \&SOLVEstruct & Estrutura de uso interno do solver. \\
\hline berr & Erro relativo da solução. \\
\hline \&stat & Estrutura com estatísticas de tempo de execução. \\
\hline \&info & Estrutura com informações sobre o solver. \\
\hline
\end{tabular}

Observe que, os parâmetros que possuem o nome precedido por um " $\&$ " indicam um ponteiro, porém somente quando os códigos estão escritos em linguagem $\mathrm{C}$ ou $\mathrm{C}++$. No caso dos códigos em Fortran, são variáveis tradicionais, mas é necessária uma consulta ao manual [30] para verificar os detalhes de cada um dos parâmetros da rotina em questão.

\subsubsection{SuperLU - Liberando recursos alocados}

Após realizar todos os cálculos com o solver é necessário finalizar o ambiente de processamento, liberando os recursos e o grid de processadores utilizados. 
Observe a Figura 3.2, contendo as rotinas para liberar os recursos.

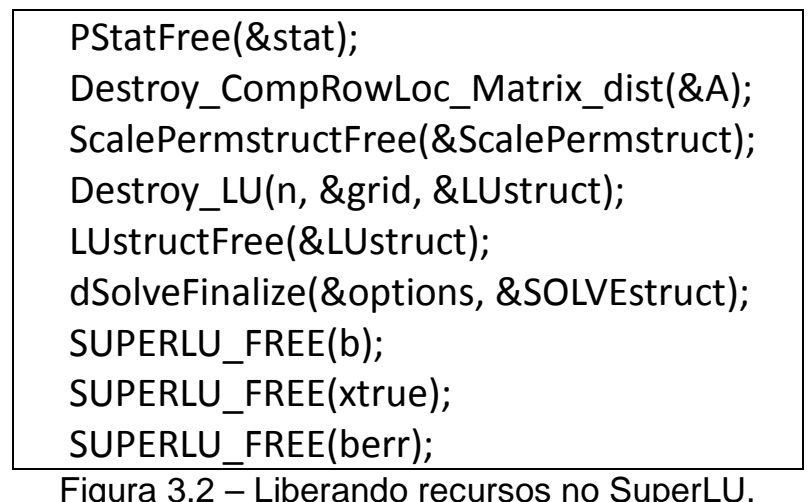

Note que algumas rotinas são necessárias para liberar os recursos alocados pelo solver. Por exemplo, a rotina "PStatFree" libera o espaço de memória utilizado pela estrutura de dados de estatística do solver SuperLU. A rotina "Destroy_CompRowLoc_Matriz_dist" libera o espaço da matriz "A" distribuída por todos os processadores do grid.

As demais instruções ilustradas na figura anterior seguem a mesma linha de raciocínio das duas rotinas descritas anteriormente, e, para mais detalhes a respeito delas, é necessária à leitura de [30].

\subsubsection{SuperLU - Finalizando o solver}

Depois de liberar os recursos alocados pelo SuperLU para a resolução do sistema, é necessário liberar o grid de processadores envolvidos no cálculo.

Esse procedimento é feito através da rotina "superlig_gridexit(\&grid)", que tem como único parâmetro o endereço do grid de processos criado na inicialização do solver.

\subsubsection{SuperLU - Finalizando o MPI}

Ao final de todos os procedimentos do solver é necessário chamar a rotina de finalização do MPI, descrita anteriormente neste trabalho, chamada de "MPI_Finalize".

Lembre-se também que a sintaxe da mesma depende da linguagem de programação utilizada com o solver, que pode variar entre C, $\mathrm{C}++$ e Fortran.

\subsubsection{MUMPS}

Segundo [35], o MUMPS (Multifrontal Parallel Solver) é um pacote para 
resolução de sistemas de equações lineares na forma $\mathbf{A x}=\mathbf{b}$, onde $\mathbf{A}$ é uma matriz quadrada esparsa que pode ser não simétrica, simétrica positiva definida, ou simétrica geral, pois o MUMPS implementa um método direto, baseado em uma aproximação multifrontal que realiza uma fatoração direta:

$$
\mathbf{A}=\mathbf{L} \mathbf{U} \text {. }
$$

$\mathrm{Na}$ equação 3.17, a matriz $\mathbf{L}$ é a matriz triangular inferior e $\mathbf{U}$ é a matriz triangular superior. Se a matriz for simétrica então a fatoração ocorre na forma:

$$
\mathbf{A}=\mathbf{L D L}^{\mathbf{T}} \text {. }
$$

$\mathrm{Na}$ equação 3.18, é dito que $\mathbf{D}$ é a matriz diagonal. A documentação do software em questão deixa claro se o mesmo explora o paralelismo proveniente da esparsidade da matriz A e proveniente também do núcleo denso da fatoração.

Dentre as principais funcionalidades do MUMPS, podem-se destacar a solução de sistemas transpostos, análise de erro, refinamento iterativo, capacidade de processamento fora do núcleo (processador), análise de paralelismo, detecção de pivôs nulos, estimativa básica de deficiência de rank e base de espaço nulo para matrizes simétricas, entre outros itens.

O pacote oferece também alguns algoritmos de ordenação de matrizes disponibilizados como funcionalidade nativa, além de interface para outros pacotes externos, como PORD, SCOTCH e METIS, sendo este último fortemente recomendado. MUMPS está disponível para vários tipos de aritmética, como real ou complexa, com precisão simples ou dupla.

A versão original desse pacote foi escrita em Fortran 90, porém existe a interface para uso em linguagem $\mathrm{C}$, bem como interfaces para uso com o Matlab, Octave e Scilab, porém nesses últimos três casos somente para a versão sequencial (fazendo uso de apenas um único processador).

Por ser destinado a ambientes de paralelismo, o software precisa de alguma versão do MPI instalada no ambiente paralelo, além do uso das bibliotecas BLAS, BLACS e ScaLAPACK (versão de memória distribuída do LAPACK). A versão sequencial necessita somente do BLAS.

Ainda segundo [35], o pacote tem sido executado em máquinas distintas, bem como em compiladores e sistemas operacionais distintos, porém a experiência da maioria dos ambientes resume-se a máquinas baseadas em Unix, rodando em computadores da SGI, Cray, IBM, bem como diversos clusters. 
Quando um trabalho é submetido ao MUMPS, ele distribui as tarefas pelos processadores, mas um processo master (geralmente de rank $=0$ ) é necessário na fase de análise, para distribuir a matriz de entrada para os outros processadores (chamados de slaves) nos casos onde a matriz é centralizada e para receber a solução ao final. O sistema $\mathbf{A x}=\mathbf{b}$ é resolvido em três fases principais: Análise, Fatoração e Solução.

$\mathrm{Na}$ fase de Análise é realizado o pré-processamento que inclui a ordenação da matriz baseada no padrão simétrico de $\mathbf{A}+\mathbf{A}^{\mathbf{T}}$ e também é realizada a fatoração simbólica. Tanto a versão paralela quanto sequencial da fase de análise está disponível no pacote. Nessa fase também é feita uma estimativa do número de operações e memória necessárias para a fatoração e solução.

$\mathrm{Na}$ fase de Fatoração, é feita a fatoração da matriz no formato da equação 3.17 para matrizes não simétricas, ou no formato da equação 3.18 , para matrizes simétricas, sendo definido pela fase de análise. A matriz é então distribuída entre os processadores de acordo com o gráfico de mapeamento de dependência da fatoração (gerado na fase de análise), chamado de "árvore de eliminação". A fatoração numérica é a sequencia de fatoração densa nas chamadas matrizes frontais.

A árvore de eliminação também expressa a independência entre as tarefas e permite que ocorram processos simultâneos, este procedimento recebe o nome de "aproximação multifrontal". Após essa fase, as matrizes são mantidas distribuídas para serem utilizadas na fase de solução.

$\mathrm{Na}$ fase de solução, ocorre a substituição, baseado no tipo de matriz detectada na fase de análise, como será descrito posteriormente neste capítulo.

O vetor b é primeiramente pré-processado e então é enviado via broadcast pelo processo master para os processos slaves. A substituição progressiva e a substituição regressiva são então realizadas usando os fatores computados durante a fase de fatoração (que estão distribuídos pelos processos), e que permitirão obter o vetor $\mathbf{x}$. A solução contida no vetor $\mathbf{x}$ é então pós-processada para obter a solução única do sistema original, onde $\mathbf{x}$ pode ser montado no processo master ou, ainda, permanecer distribuído nos outros processos (slaves).

As três fases descritas acima podem ser chamadas separadamente ou ainda de uma única vez, dependendo das necessidades do usuário da biblioteca MUMPS, 
que também permite a participação ou não do processo master nas fases de fatoração e solução.

Para os algoritmos usados no MUMPS [35], tanto o simétrico quanto o não simétrico, foi escolhida uma abordagem totalmente assíncrona, utilizada para permitir sobreposição entre as comunicações e os cálculos, com um agendamento dinâmico das tarefas computacionais, inicialmente escolhido para acomodar a ordenação numérica gerada na fatoração, porém também por ser auto adaptável ao tempo de execução para remapear o trabalho e os dados aos processadores mais apropriados.

\subsubsection{MUMPS - Programação Básica}

Este item é dedicado as técnicas de programação utilizadas para manusear o solver direto MUMPS, sendo que serão abordados as estruturas, os comandos e demais tópicos necessários.

Neste trabalho, apesar do MUMPS ter sido escrito originalmente em linguagem Fortran, o código do driver desenvolvido para testes com as matrizes foi escrito em linguagem $\mathrm{C}$ e $\mathrm{C}++$ (a parte básica de programação em $\mathrm{C}$, porém foi utilizada linguagem $\mathrm{C}++$ para a implementação das classes para as matrizes, vetores e alguns outros itens).

Ao longo do texto haverá uma explicação genérica do funcionamento das rotinas, ou seja, a explicação serve para as linguagens $C, C++$ e Fortran, porém, na eventualidade de algum exemplo do código desenvolvido, será escrito em $\mathrm{C}$ e $\mathrm{C}++$.

\subsubsection{MUMPS - Controlando as Fases de Trabalho}

O solver MUMPS precisa ser informado, através de um parâmetro de entrada, sobre qual é a ação que deverá realizar. Dependendo da ação informada, outros parâmetros relacionados podem ser necessários.

Essas fases de trabalho são informadas através do parâmetro chamado "job" que deve possuir um dos valores da Tabela 3.6. 
Tabela 3.6 - Parâmetro "job" do solver MUMPS.

\begin{tabular}{|l|l|}
\hline JOB & Descrição \\
\hline-1 & Inicializa a instância do MUMPS. \\
\hline-2 & Destrói a instância do MUMPS. \\
\hline 1 & Realiza a fase de Análise do solver. \\
\hline 2 & Realiza a fase de Fatoração do solver. \\
\hline 3 & Realiza a fase de Solução do solver. \\
\hline 4 & Realiza as fases de Análise e Fatoração. \\
\hline 5 & Realiza as fases de Fatoração e Solução. \\
\hline 6 & Realiza as fases de Análise, Fatoração e Solução. \\
\hline
\end{tabular}

Com cada valor repassado para o parâmetro "job", o solver terá um comportamento diferente, como será verificado nos próximos itens.

\subsubsection{MUMPS - Inicializando o MPI}

A primeira coisa ao iniciar um código de programação que irá utilizar as rotinas do MUMPS é inicializar o ambiente de MPI, comentado no capítulo dois deste texto. A rotina que deverá ser chamada para inicialização é: MPI_Init.

A sintaxe dessa rotina depende da linguagem de programação utilizada, sendo possível o uso nas linguagens $\mathrm{C}, \mathrm{C}++$ e Fortran.

\subsubsection{MUMPS - Inicializando o solver}

Como já foi mencionado no item 3.3.4.1, para utilizar o solver é preciso informar qual é o trabalho ("job") que ele deverá realizar, sendo assim deve-se informar primeiramente o trabalho para que incialize.

Observe o trecho de código da Figura 3.3, ilustrando uma inicialização da instância de trabalho do MUMPS.

Figura 3.3 - Trecho de código com exemplo do uso de "job".

DMUMPS_STRUC_C id;
id.job = -1;
id.par = 1;
id.sym = 1;
dmumps_c(\&id);


Note que, antes de tudo, foi criada uma estrutura chamada "id", do tipo "DMUMPS_STRUCT_C", que é uma estrutura padrão fornecida pela biblioteca com os campos necessários para servirem de parâmetros para o solver.

No caso da inicialização da interface, o valor de "id.job" é -1, como já foi ilustrado na Tabela 3.6 do item anterior, porém outros parâmetros básicos são necessários para esse primeiro procedimento

Essa rotina deve ser chamada em todos os processos pertencentes ao código com os mesmos parâmetros em todos os processos, algo similar ao comentado no item sobre programação distribuída, no capítulo dois.

Os outros dois parâmetros são "par" e "sym", representados aqui respectivamente por "id.par" e "id.sym". Ambos são do tipo numérico inteiro.

O parâmetro "par" indica que o processo host, ou master, não irá participar das fases de fatoração e resolução, quando configurado com valor 0 (zero). Se for configurado com o valor 1 (um), indica que o processo irá participar das fases de fatoração e resolução.

O parâmetro "sym" indica como é a matriz "A" que será resolvida, seguindo os valores da Tabela 3.7.

Tabela 3.7 - Trecho de código com exemplo do uso de "job".

\begin{tabular}{|l|l|}
\hline SYM & Estrutura \\
\hline 0 & Não simétrica. \\
\hline 1 & Simétrica Positivo Definida \\
\hline 2 & Simétrica Geral \\
\hline
\end{tabular}

No driver desenvolvido neste trabalho, o parâmetro "sym" ficou com o valor fixo 1 (um), pois todas as matrizes utilizadas no testes possuem essa mesma característica.

\subsubsection{MUMPS - Matrizes e Vetores}

Depois de inicializado o ambiente MPI, é necessário informar o sistema de equações que se pretende resolver, ou seja, a matriz " $A$ " e ao menos um vetor " $b$ ", para que o solver possa encontrar então o vetor " $x$ ".

Observe a Tabela 3.8 com as informações sobre a matriz "A". 
Tabela 3.8 - Estrutura da matriz montada no processador host.

\begin{tabular}{|l|l|}
\hline Parâmetro & Descrição \\
\hline $\mathrm{N}$ & Ordem da matriz. \\
\hline $\mathrm{NZ}$ & Número de elementos não nulos. \\
\hline IRN & Vetor de tamanho NZ com os índices das linhas. \\
\hline JCN & Vetor de tamanho NZ com os índices das colunas. \\
\hline A & Valor real do elemento na matriz. \\
\hline
\end{tabular}

Esse é o armazenamento tradicional do MUMPS para matrizes esparsas, sempre lembrando que a posição do elemento "A[i]" é especificada por "IRN[i]", com relação à linha e "JCN[i]", com relação a coluna.

Esses parâmetros devem ser especificados na estrutura antes da fase de análise do solver, exceto pelo parâmetro do vetor "A", que precisa estar presente antes da fase de fatoração.

Note que essa estrutura préssupõe que a matriz A está centralizada em um processador master e será distribuída automaticamente pelo próprio solver, o que neste trabalho foi o ideal, já que nenhuma das matrizes utilizadas nos testes extrapolavam a quantidade de memória RAM definida no processo master, não sendo necessário utilizar o formato de matriz do sistema distribuída por mais outro processo.

O fato da matriz do sistema não estar distribuída entre os processadores, não implica que o cálculo não será realizado em paralelo, somente que a matriz está alocada toda no processo master, que fará sua distribuição.

Como já dito anteriormente, no caso da matriz estar distribuída, por exemplo pela falta de memória RAM, os parâmetros são um pouco diferentes, porém isso não será abordado neste texto, bastando o leitor verificar no manual do software como proceder [35].

Para armazenar o vetor "b", o procedimento é bem mais simples, pois ele é armazenado de maneira densa, como pode ser observado na Tabela 3.9.

Tabela 3.9 - Estrutura do vetor montado no processador host.

\begin{tabular}{|l|l|}
\hline Parâmetro & Descrição \\
\hline RHS & Vetor com os valores reais \\
\hline NRHS & Número de vetores b (opcional), geralmente 1 (um). \\
\hline LRHS & Dimensão do vetor b, no caso de NRHS maior que 1 (um). \\
\hline
\end{tabular}


Cabe dizer também que existe a possibilidade de armazená-lo de maneira esparsa, porém essa técnica não será abordada neste texto, bastando o leitor consultar o manual do software.

Os parâmetros relacionados ao vetor $b$ devem ser especificados na estrutura antes da fase de solução do solver.

\subsubsection{MUMPS - Fase de Análise do Sistema}

Após a inicialização do solver MUMPS com os parâmetros básicos comentados anteriormente, a próxima fase do solver é a análise.

A Figura 3.4 ilustra o trecho de código que faz a chamada da rotina de análise do solver e o seu único parâmetro obrigatório.

Figura 3.4 - Trecho de código com exemplo da fase de análise do MUMPS.

$$
\begin{aligned}
& \text { id.icntl[6] = 5; } \\
& \text { id.job = } 1 ; \\
& \text { dmumps_c(\&id); }
\end{aligned}
$$

Com relação ao parâmetro "job”, esse já havia sido comentado anteriormente, porém com relação ao parâmetro "icntl[6]", deve ser feita ainda uma explicação, tendo em vista sua obrigatoriedade.

O parâmetro em questão faz alusão ao tipo de ordenação, como pode ser observado na Tabela 3.10.

Tabela 3.10 - Parâmetro "icnt|[6]" do solver MUMPS.

\begin{tabular}{|l|l|}
\hline IcntI[6] & Descrição da Ordenação \\
\hline 0 & Approximate Minimum Degree (AMD). \\
\hline 1 & Configurado pelo usuário. \\
\hline 2 & Approximate Minimum Fill (AMF). \\
\hline 3 & SCOTCH. \\
\hline 4 & PORD. \\
\hline 5 & METIS. \\
\hline 6 & Approximate Minimum Degree - Quase Dense (QAMD). \\
\hline 7 & Escolha automática pela fase de análise. \\
\hline
\end{tabular}

Esse parâmetro é acessado pelo processo master e somente na fase de 
análise, e seu valor padrão é 7. As opções 3, 4 e 5 somente estarão disponíveis se os respectivos pacotes de software tiverem sido instalados previamente.

Uma importante observação a ser feita é que o parâmetro "icntl[6]", por tratarse de uma posição de um vetor da estrutura do MUMPS, segue a numeração padronizada de cada linguagem de programação. Como as linguagens $\mathrm{C}$ e $\mathrm{C}++$ começam a numeração dos índices dos vetores na posição 0 (zero), o parâmetro fica sendo "icntl[6]", mas, na verdade, o valor real na biblioteca MUMPS é a posição 7 do vetor parâmetro "icntl".

\subsubsection{MUMPS - Fase de Fatoração do Sistema}

Depois do procedimento de análise, é possível realizar a fase de fatoração do sistema, como pode ser observado na Figura 3.5.

Figura 3.5 - Trecho de código com exemplo da fase de fatoração do MUMPS.

id.job = 2
id.icntl[13] = 20;
dmumps_c(\&id);

Como pode ser notado no código da Figura 3.5, além do parâmetro "job" já explicado anteriormente, foi feito uso do parâmetro opcional "icntl[13]", que é utilizado tanto na fase de fatoração quanto de análise.

O seu valor corresponde à porcentagem de aumento estimado no espaço de trabalho do solver, sendo que, quando o fill-in (preenchimento) da matriz for considerado significativo, o aumento desse parâmetro pode ajudar no correto funcionamento do solver. O valor padrão é 20 , que corresponde a um aumento de $20 \%$. Em alguns casos foi necessário ajustar o valor para 70 , para matrizes em que a fatoração gerou uma quantidade maior de elementos não nulos.

Cabe ressaltar que na linguagem Fortran a posição real do vetor de configuração "icntl" é 14, por conta de seus índices começarem em 1 (um) e não em 0 (zero), fato já comentado anteriormente.

\subsubsection{MUMPS - Fases de Solução do Sistema}

Depois do procedimento de fatoração, é possível realizar a fase de solução do sistema, como pode ser observado na Figura 3.6. 
Figura 3.6 - Trecho de código com exemplo da fase de fatoração do MUMPS.

id.job = 3 ;
dmumps_c(\&id);

Nessa fase nenhum parâmetro extra é obrigatório, além do tradicional parâmetro "job" já explicado anteriormente. Nenhum outro parâmetro opcional foi utilizado durante as pesquisas.

\subsubsection{MUMPS - Finalizando do solver}

Para finalizar a instância do MUMPS é necessário chamar mais uma vez o solver com o valor do parâmetro "job" configurado para -2 (Figura 3.7), conforme ilustrado na Tabela 3.6.

Figura 3.7 - Trecho de código com exemplo da fase de fatoração do MUMPS.

id.job = $-2 ;$
dmumps_c(\&id);

\subsubsection{MUMPS - Finalizando o MPI}

Ao final do código do uso das rotinas do MUMPS, é necessário finalizar o ambiente de programação de passagem de mensagens, inicializado no começo da codificação do programa.

Como já explicado no capítulo referente a parte de programação distribuída, para finalizar o ambiente paralelo é necessário chamar a rotina "MPI_Finalize".

Mais uma vez, a sintaxe da rotina depende da linguagem de programação que está sendo utilizada.

\subsubsection{PETSC - Programação Básica}

Este item é dedicado a ilustrar os aspectos básicos de programação com o solver iterativo PETSc, porém apenas com seu uso básico, pois o mesmo possui várias possibilidades de uso, inclusive para a resolução de sistemas de equações lineares [36].

O PETSc fornece um conjunto de ferramentas para uso na computação científica, tanto em códigos paralelos ou ainda seriais. Através dessa biblioteca é possível resolver sistemas de equações não lineares e lineares, fazendo uso de 
técnicas do método de Newton e métodos do subespaço de Krylov. Além disso, existem diversas possibilidades de armazenamento de matrizes e também um conjunto de pré-condicionadores.

Ao longo desta pesquisa, foi utilizado somente o método iterativo dos Gradientes Conjugados, além dos pré-condicionadores que realizam a fatoração Cholesky incompleta.

O código de programação do driver para os testes realizados neste trabalho foi escrito em linguagem $\mathrm{C}$ e $\mathrm{C}++$, seguindo a própria linguagem de desenvolvimento do PETSc, escrito em linguagem $\mathrm{C}_{++}$, porém com mecanismos de acesso a suas rotinas muito similares a uma linguagem estruturada, facilitando o uso pelo desenvolvedor em linguagem C, similar ao mencionado em [37].

Os exemplos de trechos de código pertencentes a esse item estão todos escritos em linguagem $\mathrm{C}$ e $\mathrm{C}++$, porém existe a possibilidade de uso do PETSc em Fortran [38], com um driver de comunicação, conforme a própria documentação do PETSc [39].

Uma das grandes facilidades do PETSc é permitir ao usuário informar, como um parâmetro do executável, determinadas opções, sem ter de fazer qualquer tipo de alteração no código já compilado.

Outra questão que ficará evidente ao longo do desenvolvimento desse item é que raramente o usuário terá de utilizar diretamente rotinas MPI, porém ele precisa ter conhecimentos sobre o ambiente MPI para entender o funcionamento das rotinas do PETSc.

\subsubsection{PETSc - Inicializando o solver e o MPI}

Todo programa que utiliza as rotinas do solver PETSc deve iniciar com a seguinte rotina:

PetscInitialize (int argc, char ***argv, char * file, char *help);

Essa rotina inicializa tanto o solver quanto o ambiente de $\mathrm{MPI}$, não sendo necessário realizar as duas coisas separadamente. Os argumentos "argc" e "argv" são argumentos permitidos pelas linguagens $\mathrm{C}$ e $\mathrm{C}++$ para passar parâmetros a uma determinada rotina em linha de comando, no momento de chamar o executável do programa. 
O argumento "file" permite passar configurações para o solver PETSc baseadas no conteúdo de um arquivo de texto, além da opção "help", que retorna as informações sobre o uso básico do solver na saída padrão de vídeo.

\subsubsection{PETSc - Matrizes e Vetores}

Para declarar um vetor no PETSc observe primeiramente o código ilustrado na Figura 3.8, com algumas rotinas básicas que serão explicadas na sequência.

Figura 3.8 - Rotinas de manipulação de vetores do PETSc.

VecCreate(MPI_Comm comm, Vec *x);
VecSetSizes(Vec x, int m, int M);
VecSet(Vec x, PetsScalar valor);
VecSet(Vec x, int n, int *índices, PetsScalar *valores, operação);

A primeira rotina apresentada na Figura 3.8 cria o vetor de nome " $x$ " dentro do comunicador especificado (explicações sobre o comunicador foram dadas no capítulo dois, no item de programação distribuída).

A segunda rotina permite definir a dimensão do vetor " $x$ ", sendo "M" a sua ordem e "m" um parâmetro opcional que define o tamanho do vetor localmente em um processo. Nesse caso do valor de "m", como em alguns outros ao longo deste texto, pode-se utilizar a opção "PETSC_DECIDE”, que deixa a escolha do tamanho local por conta do próprio solver.

A terceira rotina permite definir um mesmo valor para todos os elementos do vetor, facilitando muito no aspecto de programação, evitando o uso explícito de uma rotina de laço de repetição. O valor "PetscScalar" equivale a um valor do tipo real de precisão dupla.

A quarta rotina permite definir valores específicos para um conjunto de elementos do vetor, conforme pode ser observado na Tabela 3.11. 
Tabela 3.11 - Parâmetros da rotina VecSetValues do PETSc.

\begin{tabular}{|l|l|}
\hline Parâmetro & Definição \\
\hline $\mathrm{x}$ & Vetor a ser manipulado. \\
\hline $\mathrm{n}$ & Quantidade de elementos da operação. \\
\hline${ }^{*}$ índices & Vetor com os índices do elementos. \\
\hline${ }^{*}$ valores & Vetor com os valores dos elementos. \\
\hline operação & Tipo da operação (inserir, alterar e excluir). \\
\hline
\end{tabular}

A Tabela 3.11 mostra o significado dos parâmetros da rotina "VecSetValues", que permite manipular os valores de um vetor. Note que uma sequência de valores pode ser manipulada simultaneamente, bastando especificar a quantidade de valores com o parâmetro "n", e suas posições e valores dentro dos vetores "índices" e "valores", lembrando que a posição especificada por "índices[i]" corresponde ao valor especificado pelo vetor "valores[i]".

Para manipular matrizes com o PETSc, observe a Figura 3.9, com as rotinas básicas de acesso as matrizes.

Figura 3.9 - Rotinas de manipulação de matrizes do PETSc.

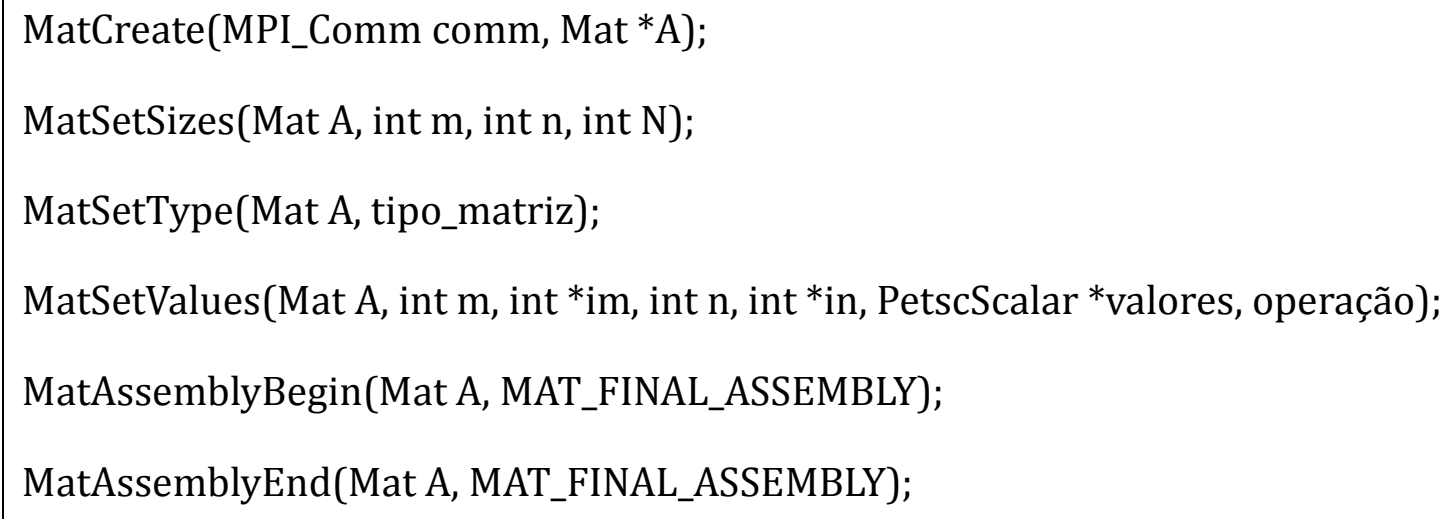

A primeira rotina cria a matriz "A" dentro do comunicador especificado no primeiro parâmetro da rotina (mais informações sobre o comunicador podem ser encontradas no capítulo dois deste trabalho).

A segunda rotina permite definir o número de linhas da matriz " $A$ ", especificados pelo parâmetro "M", e o número de colunas, especificado pelo parâmetro "N". Caso o usuário opte por definir a dimensão da matriz localmente em um processador, ele pode fazer uso dos parâmetros opcionais "m" e " $n$ ", que correspondem respectivamente ao número de linhas e colunas. O padrão é utilizar a 
opção "PETSC_DECIDE", e permitir que o solver escolha o tamanho ideal.

A terceira rotina, "MatSetType", permite definir o tipo da matriz, especificado pelo parâmetro "matriz_tipo", podendo receber um dos valores descritos na Tabela 3.12 .

Tabela 3.12 - Parâmetros da rotina VecSetValues do PETSc.

\begin{tabular}{|l|l|}
\hline Tipo da Matriz & Descrição \\
\hline MATSEQBAIJ & Compressão por blocos de linhas - sequencial. \\
\hline MATMPIBAIJ & Compressão por blocos de linhas - paralela. \\
\hline MATSEQAIJ & Alocação esparsa sequencial. \\
\hline MATMPIAIJ & Alocação esparsa paralela. \\
\hline MATSEQDENSE & Alocação de matriz densa. \\
\hline
\end{tabular}

Neste trabalho foi utilizada a alocação esparsa paralela, permitindo a resolução do sistema em um ambiente distribuído.

A rotina "MatSetValues" tem como parâmetros os seguintes itens: a matriz "A" que será modificada, o valor "m", contendo o número de linhas, o valor "n", contendo o número de colunas, os vetores "im" e "in" armazenam os índices da linha e da coluna do vetor "valores", que possui o valor real de cada um dos elementos da matriz. Por exemplo, o valor de "im[i]" e de "in[i]" são o número da linha e da coluna do elemento "valor[i]".

As duas últimas rotinas, "MatAssemblyBegin" e "MatAssemblyEnd", devem sempre ser chamadas ao final dos procedimentos de criação e manipulação dos valores de uma matriz, não sendo necessário nenhum parâmetro extra, somente o nome da matriz.

\subsubsection{PETSc - Resolução de Sistemas de Equações Lineares}

O solver PETSc trabalha com o conceito de criar o contexto para o solver, que corresponde à criação e passagem de parâmetros para informar ao software como ele deverá resolver o sistema.

Neste trabalho serão abordadas apenas as opções utilizadas durante a pesquisa, tendo em vista que a lista de opções é extensa e está disponível no manual de uso do software com cada um de seus detalhes [39].

Observe a Figura 3.10, ilustrando algumas das rotinas de funcionamento do 
solver do software PETSc .

Figura 3.10 - Rotinas de resolução de sistemas do solver PETSc.

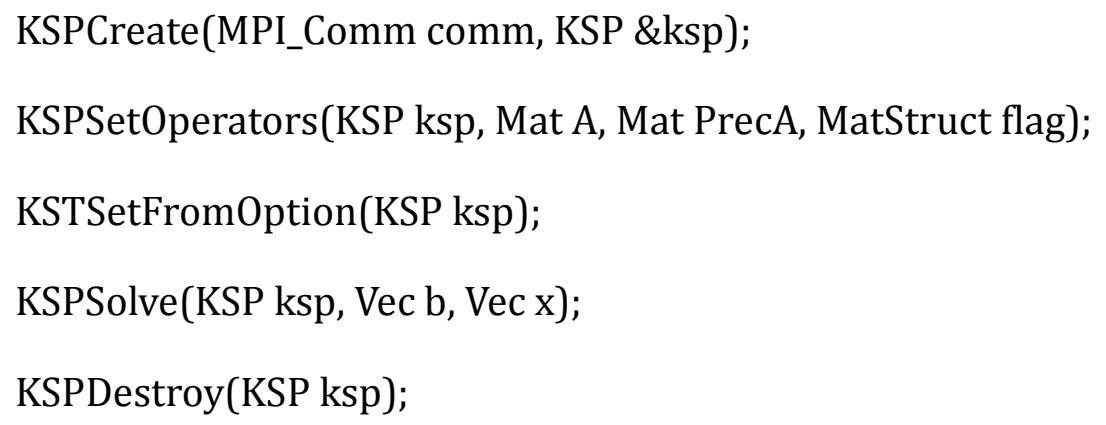

A primeira rotina é responsável pela criação do contexto do solver PETSc e tem como parâmetros o comunicador MPI dos processos, comentado com mais detalhes no capítulo dois, e também o parâmetro informando o nome do contexto que será utilizado pelas próximas rotinas do solver.

A segunda rotina é responsável por configurar os operadores associados com o sistema, como a matriz a ser resolvida, representada pelo parâmetro " $A$ " e, opcionalmente, uma matriz pré-condicionada, representada pelo parâmetro "PrecA". Nota-se também que existe o primeiro parâmetro que informa o nome do contexto do solver criado pela rotina anterior e também um parâmetro chamado "flag", que pode informar algumas características especificas da matriz. Esse último item não será abordado neste trabalho.

A terceira rotina apresentada na Figura 3.10 é uma das mais interessantes disponibilizadas pelo solver PETSc, pois através dela é possível que o usuário configure diversas opções do solver em tempo de execução, na própria linha de comando do executável criado pelo usuário. Observe a Tabela 3.13 contendo algumas das possibilidades de opções a serem configuradas em tempo de execução.

Tabela 3.13 - Parâmetros da rotina VecSetValues do PETSc.

\begin{tabular}{|l|l|}
\hline Opção em Tempo Execução & Descrição \\
\hline ksp_type & Informa o solver que será utilizado. \\
\hline ksp_max_it & Número máximo de iterações. \\
\hline pc_type & Informa o pré-condicionador. \\
\hline
\end{tabular}

As operações em tempo de execução, ou em linha de comando, 
apresentadas na Tabela 3.13 foram utilizadas ao longo desta pesquisa com êxito, evitando ter de recompilar o programa em algumas situações de testes deste trabalho.

A quarta rotina, ilustrada na Figura 3.10, é a responsável direta pela resolução do sistema, baseado nas opções configuradas pelas rotinas anteriores a esta, também ilustradas na mesma figura.

Quando um usuário informa uma opção em tempo real, ela é absorvida pela terceira rotina, "KSPSetFromOptions", que foi executada antes da rotina de solução do sistema, "KSPSolve", portanto, sempre os parâmetros informados em tempo de execução serão absorvidos pela rotina principal de solução do sistema de equações lineares.

\subsubsection{PETSc - Finalizando o solver e o MPI}

A última rotina ilustrada na Figura 3.10 é responsável por destruir o contexto do solver PETSc e sempre deverá ser executada ao final de todas as outras rotinas. Cabe dizer que ela própria irá finalizar o ambiente de programação distribuída do MPI, não sendo necessário nenhum outro procedimento de finalização por parte do usuário. 


\section{Testes}

Para realizar os testes deste trabalho, foram utilizadas matrizes do conjunto de matrizes de Tim Davis, da Universidade da Flórida [40], muito utilizado para testes de softwares que realizam a resolução de sistemas de equações lineares.

Esse conjunto de matrizes é descrito como uma grande e ativa base de dados de matrizes esparsas oriundas de problemas reais. Tal coleção tem seu uso muito difundido na comunidade em que trabalha, utilizando álgebra linear numérica para o desenvolvimento de aplicativos e teste de performance de códigos escritos para trabalharem principalmente com matrizes esparsas.

O conjunto em questão permite testes robustos, por conta dos dados das matrizes serem de problemas reais e ainda permite a repetição e comparação de experimentos, tendo em vista que as matrizes estão disponíveis em diversos formatos de armazenamento.

Cabe ainda dizer que as matrizes cobrem um largo espectro de domínios, incluindo aqueles decorrentes de problemas em geometria 2D ou 3D, como casos de engenharia estrutural.

Para aqueles que desejam utilizar esse conjunto, existem diversos formatos disponíveis no site, além de softwares que facilitam o uso das matrizes em Matlab, Mathematica, Fortran e $\mathrm{C}$, bem como aplicativos online dentro do próprio site.

\subsection{Características das Matrizes}

As matrizes escolhidas para os testes deste trabalho possuem algumas características comuns $[41,42,43,44,45]$, que são as seguintes:

- Possuem estrutura simétrica $\left(\mathbf{a}_{\mathbf{i}, \mathbf{j}}, \mathbf{a}_{\mathbf{j}, \mathbf{i}}\right.$ são diferentes de zero);

- Possuem simetria de valores $\left(\mathbf{a}_{\mathbf{i}, \mathbf{j}}=\mathbf{a}_{\mathbf{j}, \mathbf{i}}\right)$;

- São Positivo Definidas;

- São Esparsas (a maioria dos elementos da matriz possui valor nulo).

A justificativa de escolha de matrizes com tais características está descrita em [46], onde é explicado que, em geral, quando o método dos Elementos Finitos é aplicado para a solução de problemas de engenharia, torna-se necessário resolver 
um sistema de equações lineares em que a matriz dos coeficientes possui as características descritas anteriormente.

Com relação à esparsidade das matrizes escolhidas, a maioria delas tem menos de $1 \%$ de seus elementos não nulos (ou $1 \%$ de densidade), ou seja, são matrizes consideradas muito esparsas.

\subsection{Matrizes Diagonais ou Banda}

Segundo [47], as matrizes podem ser diagonais, sendo nomeadas de acordo com a Figura 4.1.

\begin{tabular}{|l|c|c|}
\hline Denominação & Banda inferior & Banda Superior \\
\hline Diagonal & 0 & 0 \\
\hline Triangular Superior & 0 & $\mathrm{n}-1$ \\
\hline Triangular Inferior & $\mathrm{n}-1$ & 0 \\
\hline Tridiagonal & 1 & 1 \\
\hline Bidiagonal Superior & 0 & 1 \\
\hline Bidiagonal Inferior & 1 & 0 \\
\hline
\end{tabular}

Figura 4.1 - Matrizes Diagonais.

Note que, na Figura 4.1, o termo "banda" faz referência ao número de diagonais abaixo ou acima da diagonal principal. A matriz que possui somente elementos não nulos na sua diagonal principal $\left(\mathbf{a}_{\mathbf{i}, \mathbf{i}} \neq \mathbf{0}\right)$ recebe o nome de matriz diagonal.

A matriz que possui somente elementos não nulos na sua diagonal principal e na diagonal imediata superior e inferior à diagonal principal é chamada de matriz tridiagonal.

No caso de uma matriz que possui somente elementos não nulos na sua diagonal principal e na diagonal imediata superior ou inferior à diagonal principal é chamada de matriz bidiagonal.

Este trabalho irá utilizar matrizes diagonais em alguns dos testes iniciais, principalmente com matrizes consideradas pequenas, somente utilizadas para validar os solvers utilizados nesta pesquisa. 


\subsection{Matrizes Skyline ou Envelopadas}

Segundo [48], existe outra classificação de matrizes, chamadas skyline. $\mathrm{Na}$ verdade, a nomenclatura skyline é proveniente da estrutura de dados utilizada no armazenamento de matrizes que, geralmente, possuem elementos não nulos muito próximos a sua diagonal principal, como pode ser visto na Figura 4.2.

$$
\mathbf{K}=\left[\begin{array}{cccccc}
K_{11} & 0 & K_{13} & 0 & 0 & K_{16} \\
& K_{22} & 0 & K_{24} & 0 & 0 \\
& & K_{33} & K_{34} & 0 & 0 \\
& & & K_{44} & 0 & K_{46} \\
& & & & K_{55} & K_{56} \\
\text { symm } & & & & & K_{66}
\end{array}\right]
$$

Figura 4.2 - Matriz Skyline.

FONTE: [48].

Como a matriz da Figura 4.2 é simétrica, somente a parte superior dela está sendo exibida. Para definir o envelope, também chamado de perfil ou modelo skyline, basta verificar em cada elemento da diagonal qual é o último elemento não nulo presente na coluna atual, desse elemento da diagonal. Sendo assim, pode-se verificar o perfil skyline na Figura 4.3.

$$
\mathbf{K}=\left[\begin{array}{cccccc}
K_{11} & & K_{13} & & & K_{16} \\
& K_{22} & 0 & K_{24} & & 0 \\
& & K_{33} & K_{34} & & 0 \\
& & & K_{44} & & K_{46} \\
& & & & K_{55} & K_{56} \\
\text { symm } & & & & & K_{66}
\end{array}\right]
$$

Figura 4.3 - Perfil Skyline.

FONTE: [48].

Observando-se a Figura 4.3, verifica-se que os elementos nulos dentro do perfil skyline de cada coluna são também armazenados, portanto, elementos muito distantes da diagonal principal desfavorecem 0 uso de tal técnica de armazenamento de estrutura de dados. Cabe também dizer que, durante o processo de fatoração, geralmente os elementos nulos presentes no envelope tornar-se-ão elementos não nulos. 


\subsection{Testes com Matrizes Diagonais}

Para os primeiros testes, foram escolhidas matrizes diagonais de ordens diversas, todas do conjunto de matrizes de Tim Davis [40], sempre respeitando as características expostas no item 4.1 deste capítulo. A Figura 4.4 mostra os elementos não nulos do conjunto de matrizes selecionadas.

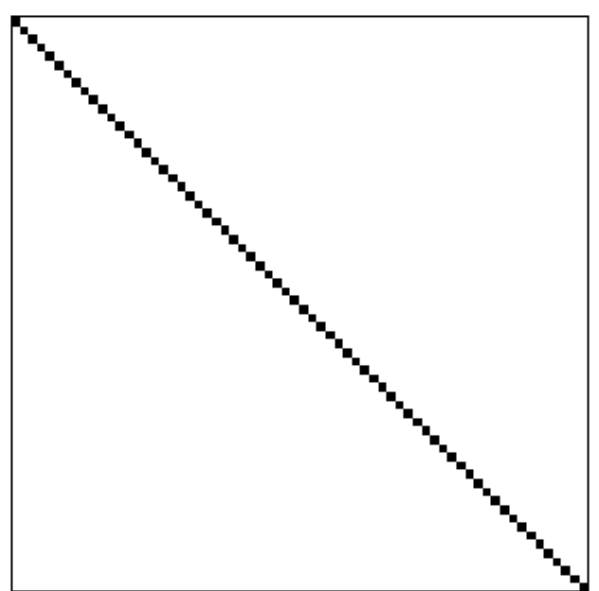

(a)

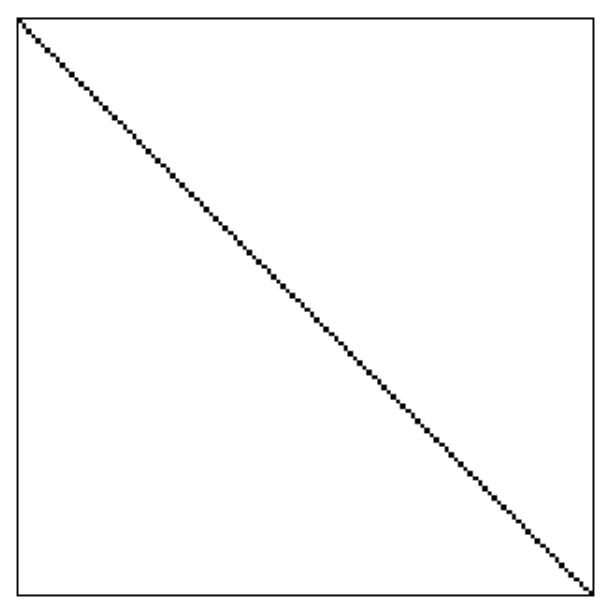

(c)

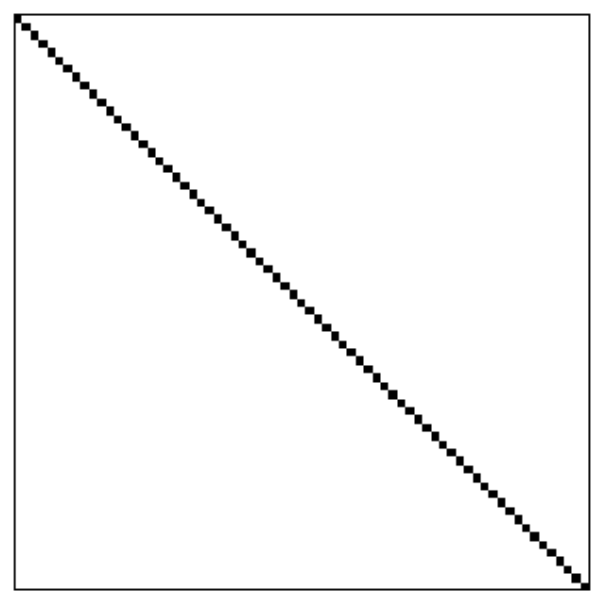

(b)

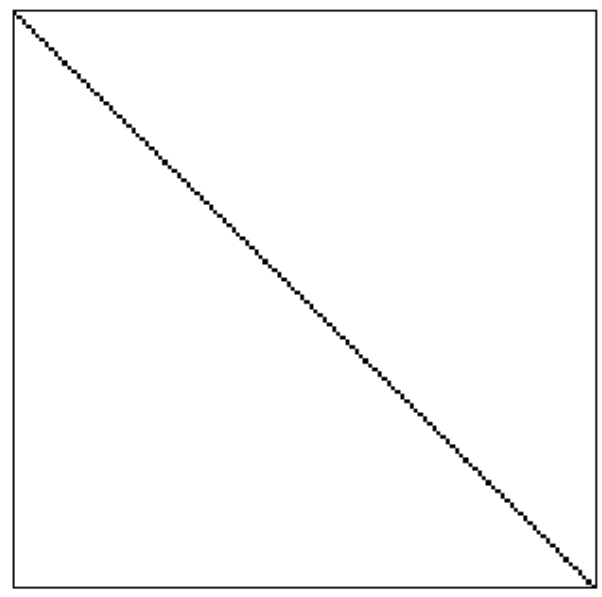

(d)

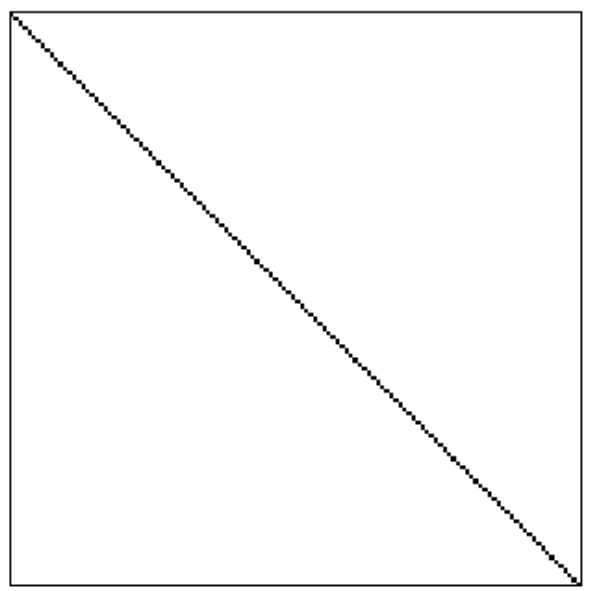

(e)

Figura 4.4 - Matrizes Diagonais: (a) bcsstm02, (b) bcsstm22, (c) bcsstm08, (d) bcsstm25 e (e) bcsstm39. 
Para se ter uma ideia clara da ordem das matrizes, bem como da quantidade de elementos não nulos e a porcentagem, foi criada a Tabela 4.1, contendo tais valores.

Tabela 4.1 - Matrizes Diagonais.

\begin{tabular}{|l|r|r|r|}
\hline Matriz & Ordem & Não Nulos & Densidade (\%) \\
\hline bcsstm02 & 66 & 66 & 1,515 \\
\hline bcsstm22 & 138 & 138 & 0,725 \\
\hline bcsstm08 & 1074 & 1074 & 0,093 \\
\hline bcsstm25 & 15439 & 15439 & 0,006 \\
\hline bcsstm39 & 46772 & 46772 & 0,002 \\
\hline
\end{tabular}

Como pode ser notado, os valores não nulos correspondem exatamente aos valores da diagonal, ou seja, a quantidade de valores não nulos deve ser igual à ordem da matriz, no caso de matrizes ditas diagonais.

Para os primeiros testes, foram escolhidos dois solvers paralelos. O MUMPS foi escolhido como sendo o representante dos solvers diretos e o PETSc foi escolhido como o representante dos solvers iterativos.

O método iterativo escolhido para o PETSc foi o Gradientes Conjugados, usando como pré-condicionador a fatoração incompleta Cholesky.

Como as matrizes escolhidas possuem ordem muito pequena, se comparadas às maiores matrizes disponíveis no conjunto de matrizes utilizado neste trabalho, esses testes foram realizados com um único processador, porém ambos solvers foram escritos utilizando rotinas MPI, questão discutida no capítulo anterior.

O ambiente de testes utilizado foi a máquina Hopper, um Cray XT4, tendo sua estrutura sido explicada em capítulo anterior deste mesmo trabalho. Os resultados obtidos estão expressos na Tabela 4.2.

Tabela 4.2 - Matrizes Diagonais - Resultados.

\begin{tabular}{|l|c|r|r|r|}
\hline Matriz & MUMPS (s) & PETSc (s) & Iterações & SVD \\
\hline bcsstm02 & 0,000789880 & 0,000935 & 1 & 1 \\
\hline bcsstm22 & 0,001044750 & 0,000998 & 1 & 1 \\
\hline bcsstm08 & 0,004074100 & 0,002017 & 1 & 1 \\
\hline bcsstm25 & 0,048908300 & 0,020429 & 1 & 1 \\
\hline bcsstm39 & 0,148723900 & 0,061574 & 1 & 1 \\
\hline
\end{tabular}

Com relação aos campos da Tabela 4.2, os valores expressos nas colunas MUMPS e PETSc, correspondem ao tempo em segundos que cada solver utilizou na sua respectiva fase de resolução do sistema de equações lineares. 
O campo iterações, faz referência ao número de iterações que o solver PETSc levou para convergir ao resultado, considerando a configuração com uma tolerância de $10^{-5}$.

Segundo [46], os valores singulares medem a inversibilidade de matriz, sendo que o menor valor singular obtido por uma dada iteração representa a distância que a matriz está de se tornar singular. Além disso, a razão entre o maior e o menor valor singular de uma dada iteração representa a dificuldade em inverter tal matriz. Esse valor está representado na Tabela 4.2 pelo campo SVD e é comumente referenciado como número de condição da matriz.

Para se obter uma ideia exata do ocorrido foi gerada a Figura 4.5, que ilustra graficamente o desempenho de ambos os solvers em relação ao tempo de execução da fase de resolução do sistema de equações lineares.

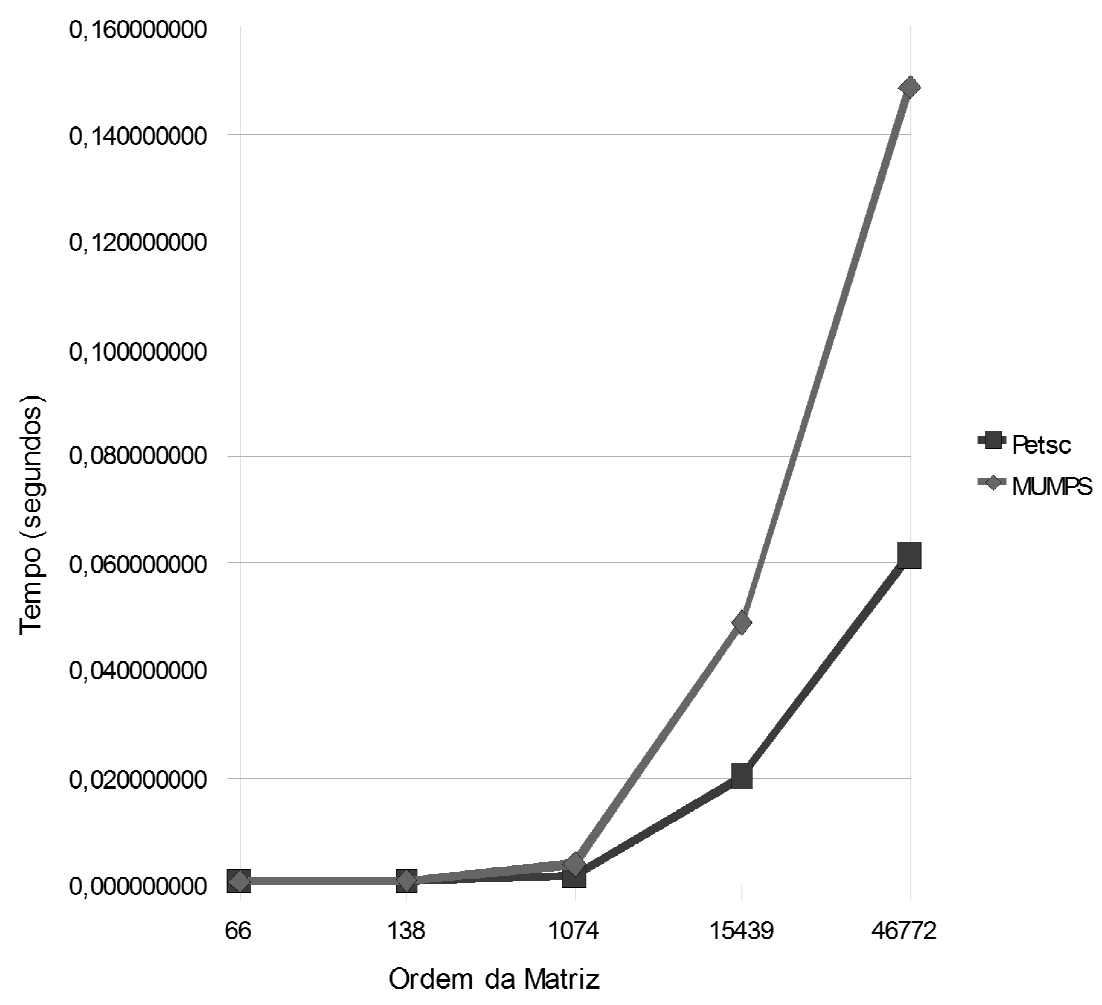

Figura 4.5 - Matrizes Diagonais: solvers PETSc e MUMPS.

Como pode ser observado na Figura 4.5, com matrizes de ordem até 1000, os dois solvers mostraram-se bastante similares em relação ao tempo de execução, porém, desse ponto em diante, o solver PETSc mostrou-se superior, obtendo tempos bem inferiores com relação ao MUMPS [49]. 
Buscando um maior entendimento do ocorrido, deve-se considerar os dados expostos na Tabela 4.2, que mostra que o solver iterativo convergiu em apenas uma iteração, não permitindo que a matriz se tornasse singular, como pode ser visto no campo SVD de cada uma das matrizes em estudo.

Cabe também dizer que o condicionamento das matrizes foi testado antes e todas se mostraram mal condicionadas, portanto o pré-condicionador mostrou-se eficaz para o PETSc nesse caso [50].

\subsection{Testes com Matrizes Esparsas - Diagonais Densas}

Dando andamento nos testes, foram escolhidas algumas matrizes esparsas, de ordens diversas, que têm como características comuns, diagonais densas próximas à diagonal principal. Mais uma vez, foram respeitadas as características expostas no item 4.1 deste capítulo.

As matrizes desse item provêm de diversos problemas, o que influencia em seus valores não nulos das mesmas, porém, o que está sendo considerado aqui é a posição dos elementos não nulos da matriz e não especificamente seus valores.

Novamente foi criada uma representação gráfica dos elementos não nulos presentes nas quatro matrizes estudadas neste tópico, como pode ser visto na Figura 4.6. 


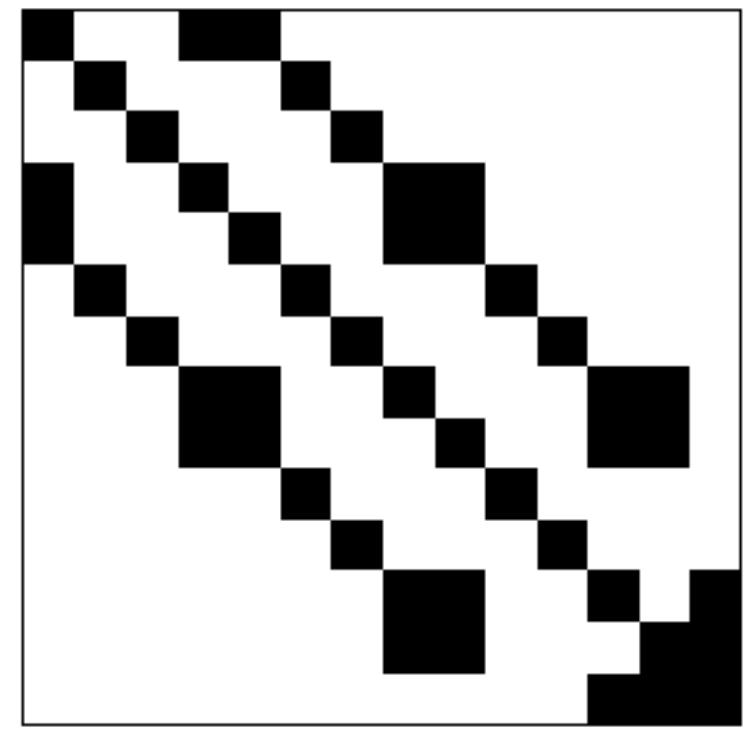

(a)

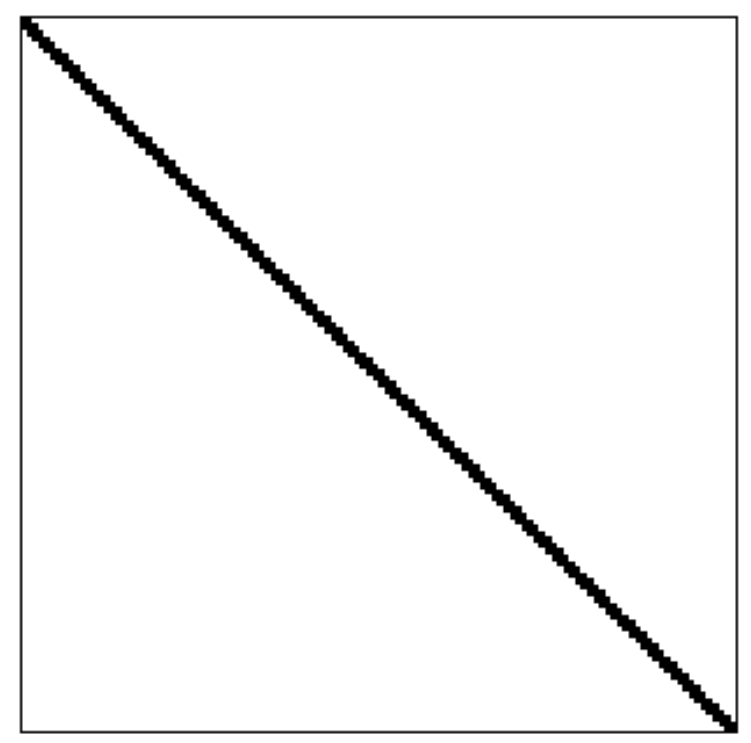

(c)

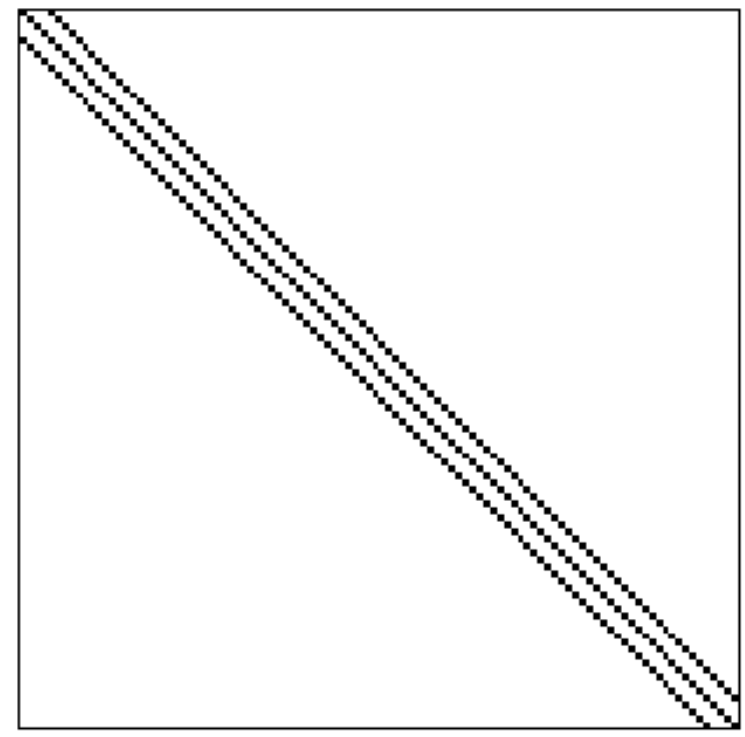

(b)

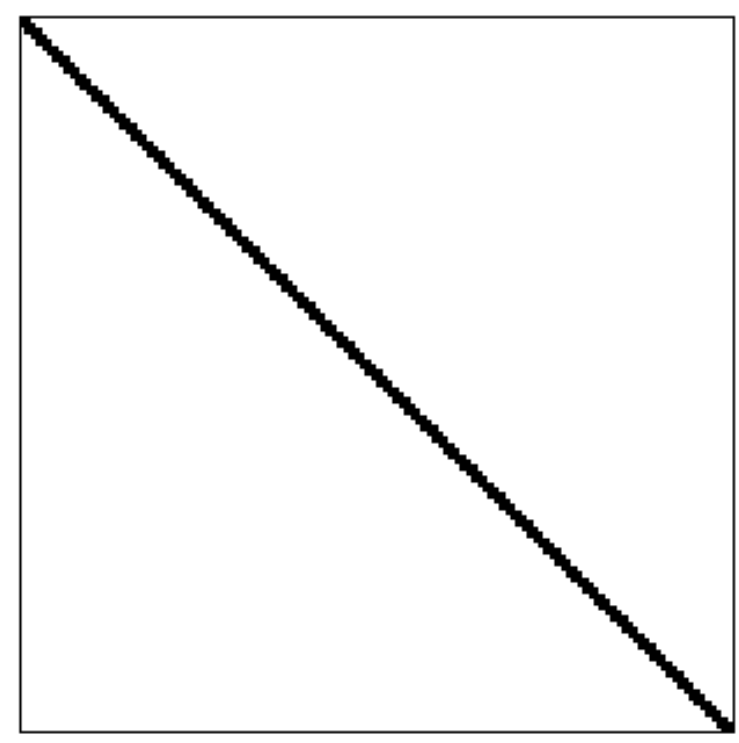

(d)

Figura 4.6 - Matrizes Esparsas com Diagonais Densas: (a) LFAT5, (b) mhdb416, (c) nos2 e (d) LFAT5000.

Como observado na Figura 4.6, as matrizes "nos2" e "LFAT5000" são muito parecidas, possuem os elementos muito próximos à diagonal principal, quase formando uma matriz tridiagonal [47].

A matriz "mhdb416" possui também uma linha diagonal de elementos não nulos paralelos à diagonal principal, porém não é considerada uma matriz de banda, tendo em vista que os elementos não estão na diagonal imediatamente posterior e anterior à diagonal principal.

A matriz "LFAT5" assemelha-se muito à matriz "mhdb416", exceto pelo fato de ter alguns elementos não nulos fora das diagonais paralelas à diagonal principal. 
Para ter uma ideia clara da ordem das matrizes, bem como da quantidade de elementos não nulos e a porcentagem, foi criada a Tabela 4.3, contendo tais valores.

Tabela 4.3 - Matrizes Esparsas com Diagonais Densas.

\begin{tabular}{|l|r|r|r|r|}
\hline Matriz & Ordem & Não Nulos & Densidade (\%) & Skyline \\
\hline LFAT5 & 14 & 46 & 23,47 & 5 \\
\hline mhdb416 & 416 & 2312 & 1,34 & 18 \\
\hline nos2 & 957 & 4137 & 0,45 & 4 \\
\hline LFAT5000 & 19994 & 79966 & 0,02 & 5 \\
\hline
\end{tabular}

O campo Skyline foi adicionado na Tabela 4.3 para ilustrar o tamanho máximo do envelope utilizado em um possível armazenamento utilizando tal técnica de estrutura de dados, exposta no início deste capítulo.

Outro detalhe é que a matriz "LFAT5" é a matriz mais densa utilizada ao longo desta pesquisa, e foi escolhida apenas pela questão de semelhança da posição de seus elementos não nulos com relação às outras desse mesmo conjunto.

Da mesma forma que foram realizados os testes do tópico anterior a este, também foram feitos os mesmos testes para as matrizes esparsas com elementos não nulos próximos a diagonal principal, como pode ser visto na Tabela 4.4.

Tabela 4.4 - Matrizes Esparsas com Diagonais Densas - Resultados.

\begin{tabular}{|l|c|r|c|c|}
\hline Matriz & MUMPS (s) & PETSc (s) & Iterações & SVD \\
\hline LFAT5 & 0,000755071 & 0,001006 & 1 & 1 \\
\hline Mhdb416 & 0,002055167 & 0,001792 & 1 & 1 \\
\hline nos2 & 0,005026820 & 0,002414 & 1 & 1 \\
\hline LFAT5000 & 0,092969900 & 0,036530 & 1 & 1 \\
\hline
\end{tabular}

De forma similar aos testes do tópico anterior, o solver iterativos mostrou-se mais eficiente em quase todos os casos executados, inclusive mantendo o mesmo padrão de resolver o sistema em uma única iteração.

Pode-se observar também que, conforme a ordem da matriz aumenta, os tempos de execução do solver iterativo tornam-se melhores ainda do que o solver direto. O teste do solver iterativo com as duas primeiras matrizes, "LFAT5" e "mhdb416", utilizou metade do tempo com relação ao solver direto. No caso do matriz "nos2", a resolução com um solver iterativo executou em 1/3 do tempo do solver direto, fato similar ao ocorrido no último teste com a matriz "LFAT5000", que executou o solver iterativo em 1/4 do tempo do solver direto. 
Para se ter uma ideia exata do ocorrido foi gerada a Figura 4.7, que ilustra graficamente o desempenho de ambos os solvers com relação ao tempo de execução da fase de resolução do sistema de equações lineares.

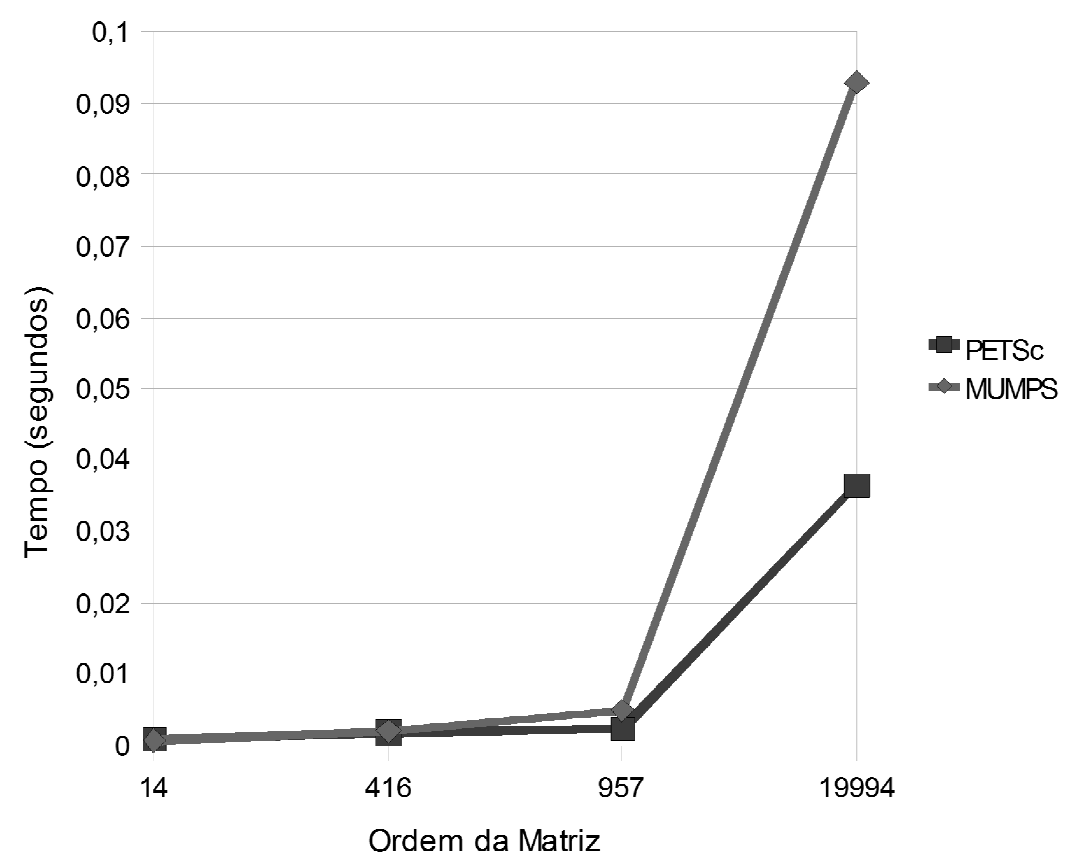

Figura 4.7 - Matrizes Esparsas com Diagonais Densas: solvers PETSc e MUMPS.

Com relação ao gráfico da Figura 4.7, fica evidente o desempenho superior do solver iterativo, principalmente quando a ordem da matriz aumenta, fato comprovado anteriormente pelos testes realizados com as matrizes diagonais, do tópico anterior [51].

Pode-se também dizer, mediante os testes dos dois tópicos, que o desempenho do solver iterativo é evidentemente melhor quando a matriz possui ordem superior a 1000, e que os elementos estejam próximos à diagonal principal.

\subsection{Testes com Matrizes Esparsas - Elementos Próximos da Diagonal}

Prosseguindo com os testes, foram escolhidas algumas matrizes esparsas, de ordens diversas, que têm como características comuns elementos próximos de sua diagonal principal, respeitando sempre as características expostas no item 4.1 deste capítulo. A Figura 4.8 representa os elementos não nulos presentes em cada uma das matrizes escolhidas. 


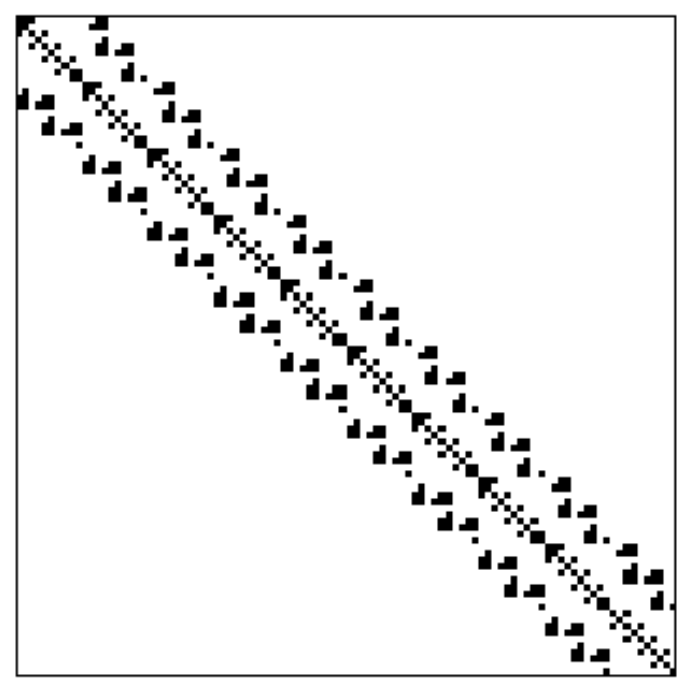

(a)

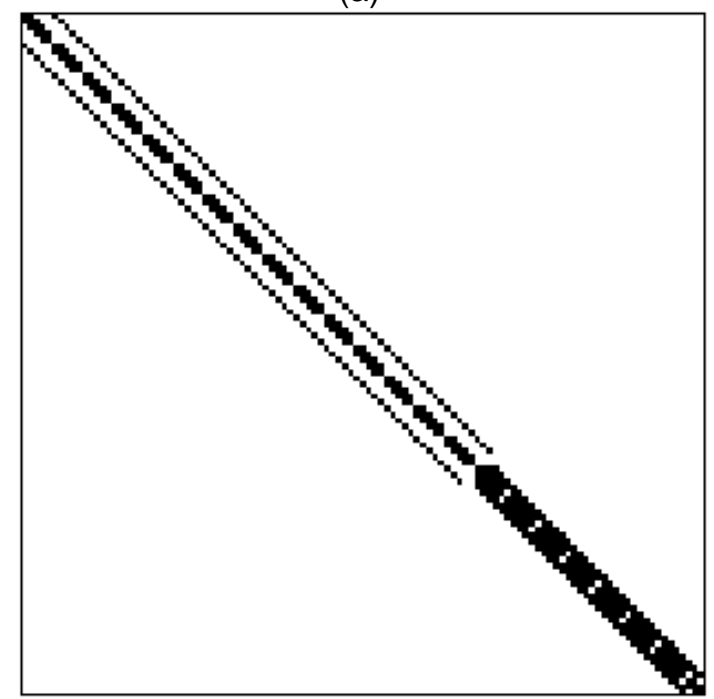

(c)

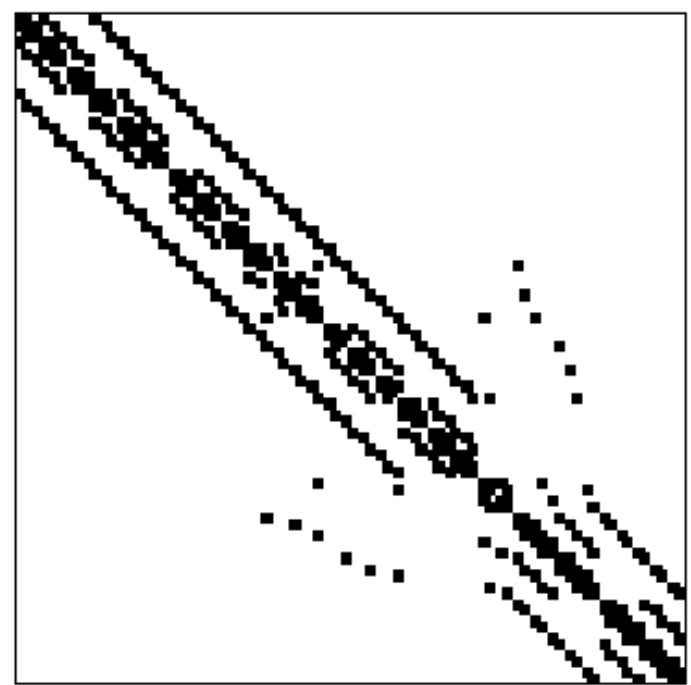

(b)

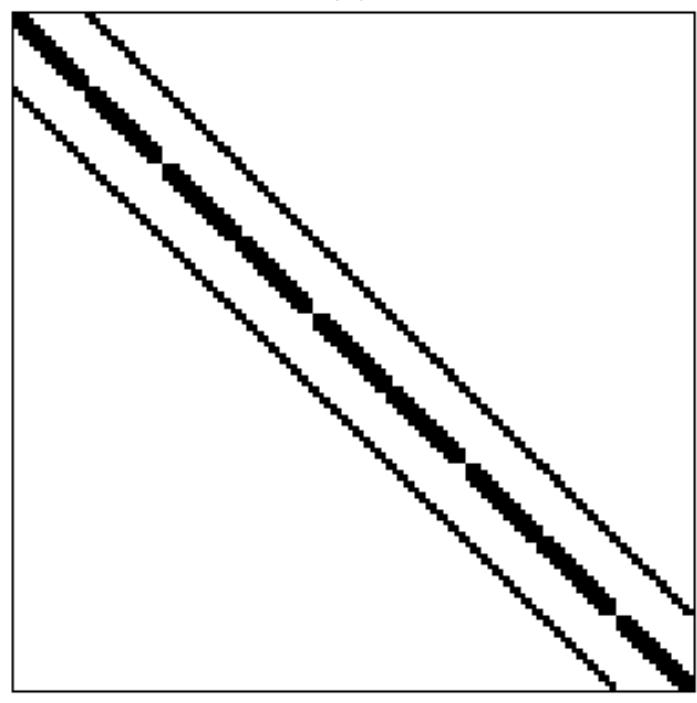

(d)

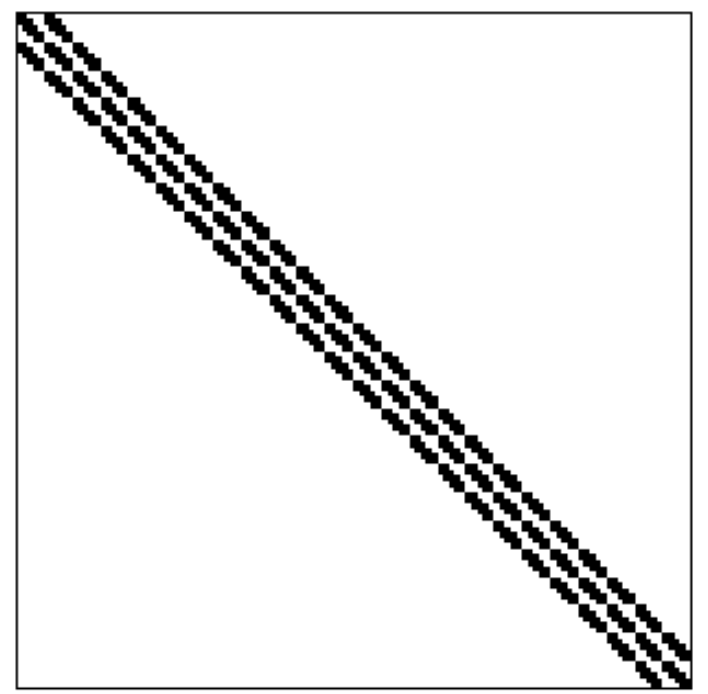

(e)

Figura 4.8 - Matrizes Diagonais com Elementos Próximos a Diagonal: (a) nos4, (b) nos5, (c) nos6, (d) nos7 e (e) nos3. 
Algumas considerações podem ser feitas sobre o conjunto de matrizes da Figura 4.8, começando pelo fato de que todas pertencem a um mesmo grupo disponível no conjunto de Matrizes de Tim Davis [40].

A matriz "nos4" possui elementos próximos à diagonal, mas que não formam diagonais paralelas continuas, além da presença de somente alguns elementos não nulos em determinadas diagonais, quase que totalmente composta por valores nulos.

A matriz "nos5" possui elementos próximos à diagonal, mas não chegam a formar diagonais densas paralelas à diagonal principal, além da existência de alguns elementos únicos em determinadas diagonais.

Já as matrizes "nos6" e "nos7" são relativamente semelhantes, considerando que existem diagonais muito densas paralelas à diagonal principal, como as matrizes ilustradas no tópico anterior, sendo necessário retomar a discussão posteriormente ainda neste mesmo tópico.

A matriz "nos3" assemelha-se visualmente às figuras "nos6" e "nos7", mas existe a questão do skyline, que não fica visível na Figura 4.8.

A Tabela 4.5 possui o nome das matrizes, a ordem, a quantidade de elementos não nulos, a densidade de cada matriz, bem como o campo Skyline, importante para a compreensão dos resultados posteriormente exibidos.

Tabela 4.5 - Matrizes Esparsas com Elementos Próximos a Diagonal Principal.
\begin{tabular}{|l|r|r|r|r|}
\hline Matriz & Ordem & Não Nulos & Densidade (\%) & Skyline \\
\hline nos4 & 100 & 594 & 5,94 & 13 \\
\hline nos5 & 468 & 5172 & 2,36 & 178 \\
\hline nos6 & 675 & 3255 & 0,71 & 30 \\
\hline nos7 & 729 & 4617 & 0,87 & 81 \\
\hline nos3 & 960 & 15844 & 1,72 & 43 \\
\hline
\end{tabular}

Observando as matrizes da Tabela 4.5, nota-se que possuem densidade similar às do tópico anterior, porém o tamanho máximo do envelope, ou skyline, é bem superior se comparadas às matrizes com valores de ordem próximos e isso reflete nos resultados, como pode ser notado na Tabela 4.6. 
Tabela 4.6 - Matrizes Esparsas com Diagonais Densas - Resultados.

\begin{tabular}{|l|r|r|r|r|}
\hline Matriz & MUMPS (s) & PETSc (s) & Iterações & SVD \\
\hline nos4 & 0,001222133 & 0,001418 & 11 & 17,291 \\
\hline nos5 & 0,004980084 & 0,022170 & 87 & 385,984 \\
\hline nos6 & 0,004383088 & 0,003425 & 14 & 92141,7 \\
\hline nos7 & 0,007783888 & 0,004840 & 15 & $3,33 E+006$ \\
\hline nos3 & 0,007241965 & 0,016186 & 27 & 701,613 \\
\hline
\end{tabular}

Com relação à afirmação anterior, a primeira comparação a ser feita é entre a matriz "mhdb416", de ordem 416 com densidade de 1,34\% e skyline máximo de 18, e a matriz "nos5", de ordem 468 com densidade 2,36\% e skyline máximo de 178 . O solver direto teve um desempenho superior no caso da matriz "nos5", diferentemente do caso da matriz "mhdb416", devido ao valor de skyline máximo.

O mesmo ocorreu com relação à matriz "nos2", de ordem 957 densidade 0,45\% e skyline máximo de 4 , e a matriz "nos3", de ordem 960 , com densidade $1,72 \%$ e skyline máximo de 43 (esse skyline não é perceptível na visão da Figura 4.7). Mais uma vez o solver direto teve um desempenho para o caso da matriz "nos3", novamente devido ao valor de skyline máximo da mesma.

Para uma visualização melhor dos resultados obtidos, foi gerado o gráfico ilustrado pela Figura 4.9.

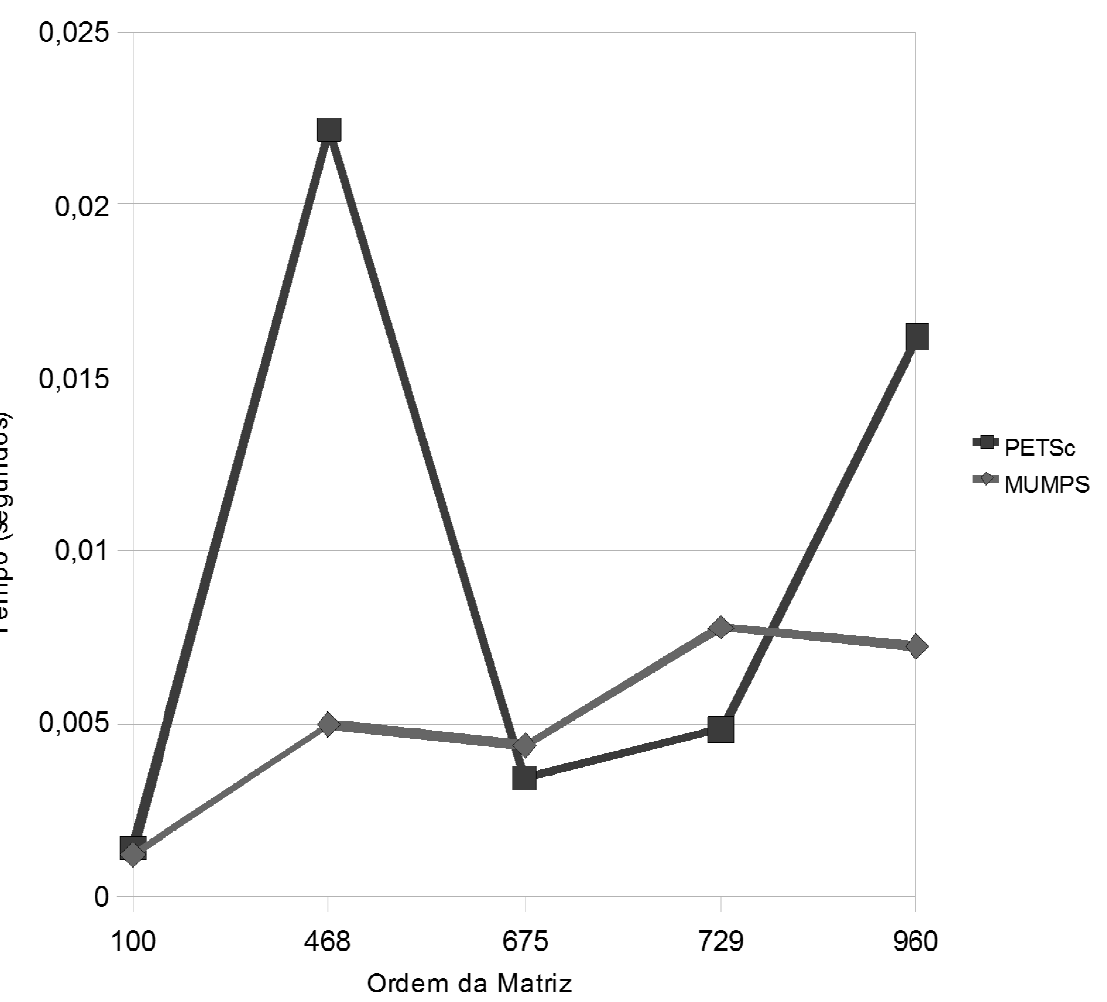

Figura 4.9 - Matrizes Esparsas com Elementos Não Nulos Próximos a Diagonal Principal: comparação entre PETSc e MUMPS 
A Figura 4.9 deixa claro que a combinação "densidade e valor máximo de skyline" influencia muito o desempenho do solver iterativo, deixando o tempo de resolução do sistema muito distante do tempo de resolução do solver direto [52].

As matrizes "nos6" e "nos7" foram resolvidas mais rapidamente com o solver iterativo, devido ao fato da existência de diagonais muito densas próximas à diagonal principal, explicado no item anterior deste mesmo capítulo, tornando o fator do skyline secundário nesse caso, porém os tempos foram muito próximos entre os dois solvers.

Com relação à matriz "nos4", pelo fato de ser muito pequena, os dois solvers tiveram tempo de resolução muito próximos.

\subsection{Testes Principais}

Prosseguindo com os testes, foram escolhidas algumas matrizes esparsas, de ordens diversas, porém bem maiores do as matrizes utilizadas até então, variando a ordem de 500.000 até 1.500 .000 , sempre respeitando as características expostas no item 4.1 deste capítulo.

\subsubsection{Matriz: parabolic_fem}

Considere então a matriz da Figura 4.10, mais uma vez com a representação dos elementos não nulos da matriz "parabolic_fem".

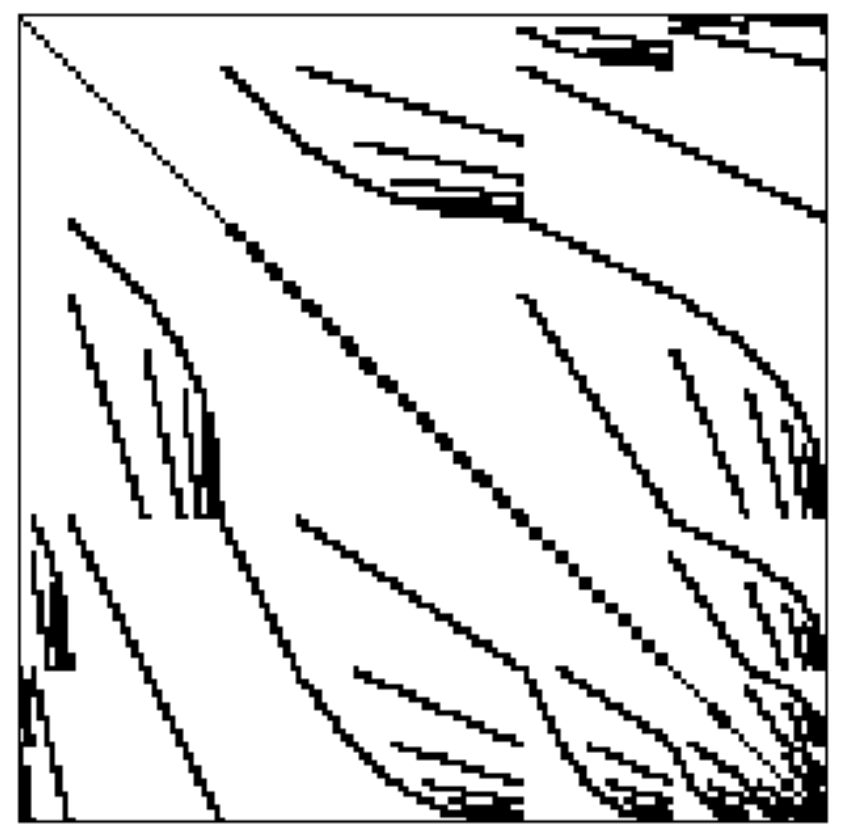

Figura 4.10 - Elementos não nulos da matriz "parabolic_fem". 
A matriz "parabolic_fem" é um caso em que os elementos estão distantes da diagonal principal e bem dispersos, não criando linhas densas paralelas a diagonal principal.

Por outro lado, existem alguns elementos próximos à diagonal principal, assemelhando-se aos casos do item 4.5, fato esse que possivelmente reflete nos resultados que serão exibidos na sequência deste item.

A matriz "parabolic_fem" possui as características expostas na Tabela 4.7.

Tabela 4.7 - Características da matriz "parabolic_fem".

\begin{tabular}{|l|r|r|r|}
\hline Matriz & Ordem & Não Nulos & Densidade (\%) \\
\hline parabolic_fem & 525.825 & 3.674 .625 & 0,00132 \\
\hline
\end{tabular}

Como pode ser verificada, a matriz "parabolic_fem" é considerada muito esparsa, ressaltando que os elementos não nulos indicados nessa tabela fazem referência aos elementos da parte superior e inferior, que são idênticos, somando-se ainda a quantidade de elementos da diagonal principal.

Para os testes seguintes foram utilizados até 256 processadores do supercomputador Hopper, permitindo analisar com mais detalhes o comportamento do paralelismo dos três solvers utilizados: SuperLU, MUMPS e PETSc. Os tempos, em segundos, gastos na resolução dos sistemas podem ser vistos na Tabela 4.8.

Tabela 4.8 - Tempos de execução da matriz "parabolic_fem".

\begin{tabular}{|l|r|r|r|r|r|r|r|}
\hline Solver/Procs. & $\mathbf{4}$ & $\mathbf{8}$ & $\mathbf{1 6}$ & $\mathbf{3 2}$ & $\mathbf{6 4}$ & $\mathbf{1 2 8}$ & $\mathbf{2 5 6}$ \\
\hline \hline PETSc (s) & 63,456909 & 37,113102 & 21,218710 & 13,261823 & 8,028948 & 8,027692 & 7,852432 \\
\hline \hline MUMPS (s) & 2,159963 & - & 1,262736 & 1,006205 & 1,107565 & 1,359979 & 1,704042 \\
\hline SuperLU (s) & 4,000000 & 3,080000 & 2,610000 & 2,900000 & 4,590000 & 5,640000 & 9,120000 \\
\hline
\end{tabular}

Como pode ser notado na tabela anterior, os tempos do solver iterativo PETSc são bem superiores se comparados aos outros dois solvers diretos, porém quando o número de processadores aumenta, principalmente até 32 processadores, o tempo cai de maneira considerável, mostrando a alta escalabilidade $[53,54]$ do método dos gradientes conjugados [46].

O solver SuperLU teve um bom desempenho no início, mas o aumento dos processadores a partir de 64, mostrou ser um fator prejudicial a essa matriz, e 0 método não mostrou ser competitivo com o seu concorrente direto, principalmente pela questão óbvia de não ter sido escrito especificamente para matrizes simétricas.

Com relação aos tempos do solver direto MUMPS, foi demonstrado um excelente desempenho se comparado aos outros dois solvers, mostrando ser uma 
boa escolha para matrizes com estrutura de elementos não nulos esparsos, próximos ou não da diagonal principal.

Outra questão a ser considerada é o fato de que o MUMPS não executou com 8 processadores, mesmo aumentando o tempo de execução, possivelmente por alguma falha do software. Algumas tentativas foram feitas sem sucesso e até a conclusão deste texto não foi possível obter tal tempo.

Como feito nos itens anteriores deste capítulo, para uma visão mais clara do comportamento dos três solvers, foi gerada a Figura 4.11.

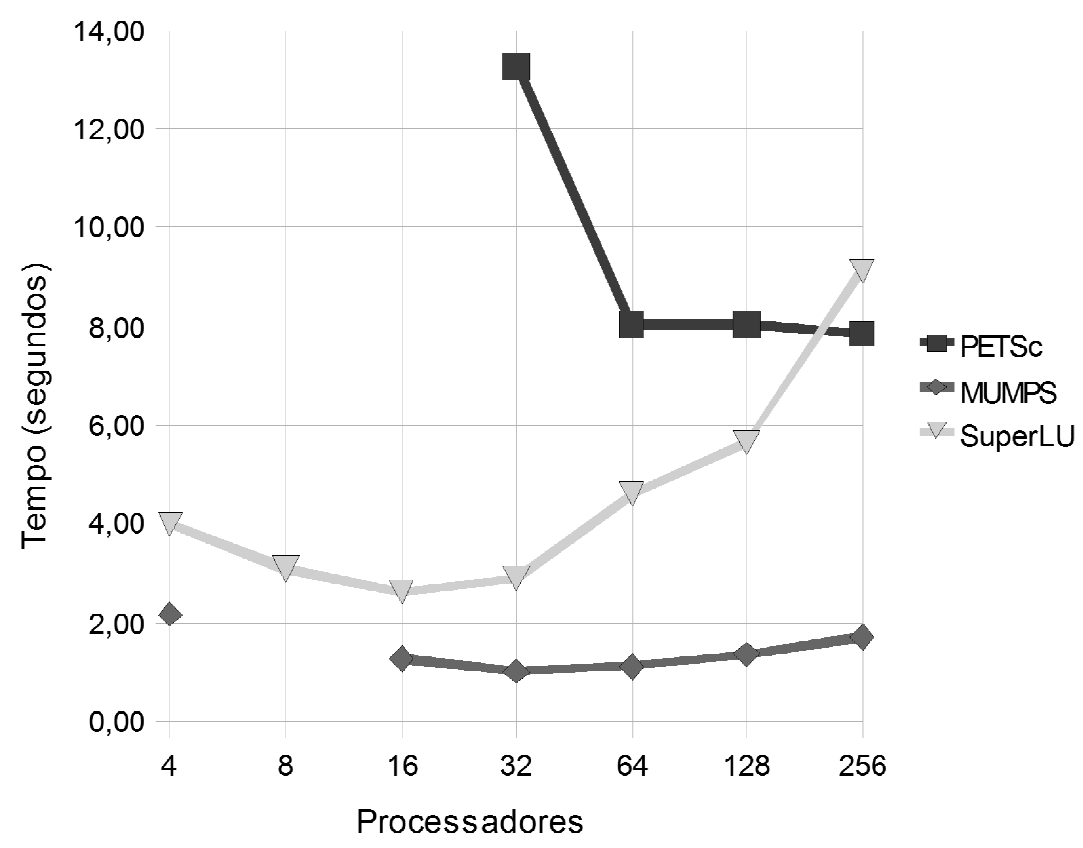

Figura 4.11 - Tempos de execução da matriz "parabolic_fem".

Como já explicado anteriormente, não existe o tempo de execução com 8 processadores para o solver MUMPS, por isso não existe o respectivo ponto de execução em sua curva na Figura 4.11.

Foram omitidos dessa figura os tempos com 4, 8 e 16 processadores do solver PETSc, devido ao fato de estarem muito distantes dos outros valores e tornariam a apresentação da do gráfico expresso na figura muito menos proveitosa.

\subsubsection{Matriz: G3_circuit}

Para esse teste, será obervada a matriz "G3_circuit", ilustrada na Figura 4.12, que contém a representação dos elementos não nulos da matriz em questão. 


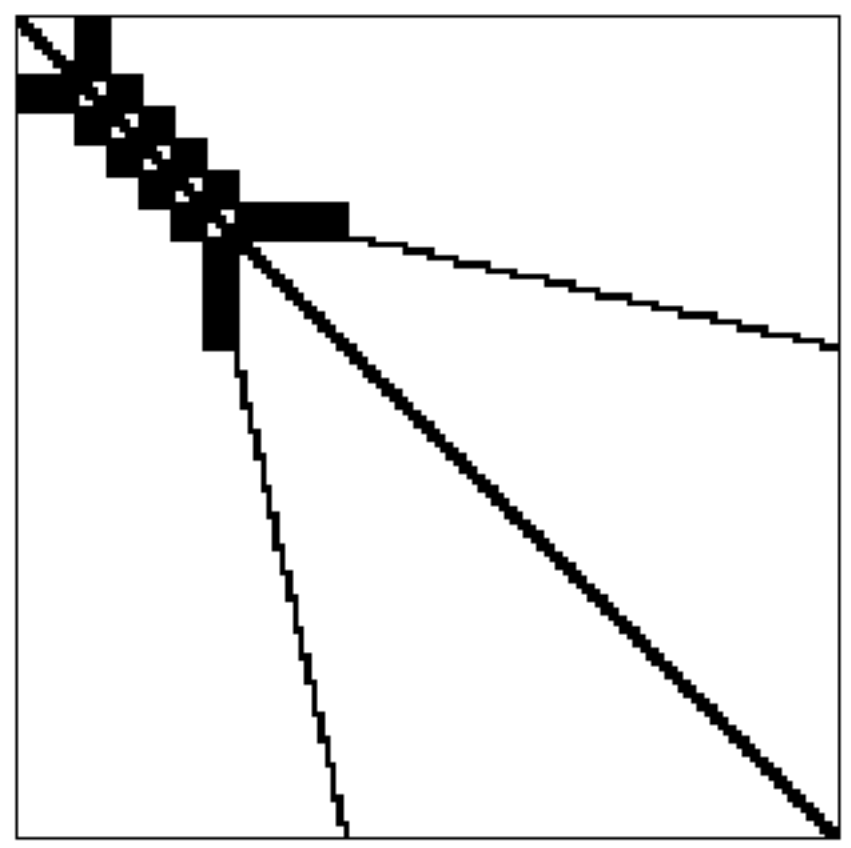

Figura 4.12 - Elementos não nulos da matriz "G3_circuit".

A matriz da Figura 4.12 tem uma estrutura densa de elementos que não formam linhas paralelas à diagonal principal, mas formam blocos contínuos próximos à diagonal e uma linha densa contínua.

Para averiguar melhor a estrutura da matriz, a Tabela 4.9 mostra a ordem da matriz, a quantidade de elementos não nulos e sua densidade.

\begin{tabular}{|l|r|r|r|}
\hline \multicolumn{1}{|c|}{ Tabela 4.9 - Características da matriz "G3_circuit". } \\
\begin{tabular}{|l|r|r|r|}
\hline Matriz & Ordem & Não Nulos & Densidade (\%) \\
\hline G3_circuit & 1.585 .478 & 7.660 .826 & 0,000340 \\
\hline
\end{tabular}
\end{tabular}

Cabe dizer que a matriz "G3_circuit" é a de maior ordem deste trabalho, porém é também a matriz menos densa.

Para os testes com essa matriz foram utilizados, inicialmente, 4 processadores, mas os testes estenderam-se até 2048 processadores, para verificar possíveis mudanças no comportamento dos solver utilizados, como pode ser observado na Tabela 4.10.

Tabela 4.10 - Tempos de execução da matriz "G3 Circuit".

\begin{tabular}{|l|r|r|r|r|r|r|r|r|r|r|}
\hline Solver/Procs, & $\mathbf{4}$ & $\mathbf{8}$ & $\mathbf{1 6}$ & $\mathbf{3 2}$ & $\mathbf{6 4}$ & $\mathbf{1 2 8}$ & $\mathbf{2 5 6}$ & $\mathbf{5 1 2}$ & $\mathbf{1 0 2 4}$ & $\mathbf{2 0 4 8}$ \\
\hline \hline PETSc (s) & 41,68 & 25,97 & 14,84 & 9,59 & 5,21 & 3,11 & 3,23 & 4,12 & 8,73 & 25,60 \\
\hline \hline MUMPS (s) & 9,34 & 6,08 & 4,27 & 2,78 & 2,33 & 2,19 & 2,48 & 4,12 & & - \\
\hline \hline SuperLU (s) & - & 15,31 & - & 10,57 & - & 16,01 & 20,48 & 18,43 & 36,70 & 36,33 \\
\hline
\end{tabular}

Com relação à Tabela 4.10 e o solver SuperLU, é possível observar que com 4, 16 e 64 processadores o solver não conseguiu resolver o sistema, sendo 
diagnosticada uma falha do software e nada pôde ser feito, por não se tratar de um ajuste de parâmetros da ferramenta computacional, pois a solução de tal falha não faz parte do escopo deste trabalho.

O mesmo pode ser dito em relação ao solver direto MUMPS, que apresentou falha com 1024 e 2048 processadores, porém, nesse caso, não ficou claro se foi uma falha do software ou um erro nos parâmetros de ajuste da memória RAM, o fato é que esses tempos não influenciariam em nada as conclusões, pois o menor tempo de resolução do sistema, comparando-se os três solvers, já havia sido obtido com um número inferior de processadores, que é o caso do teste com 128 processadores do solver MUMPS.

Para analisar melhor o comportamento dos solvers com essa matriz, foi criada a Figura 4.13, contendo as curvas dos tempos de execução para cada solver considerando os testes de 4 até 2048 processadores.

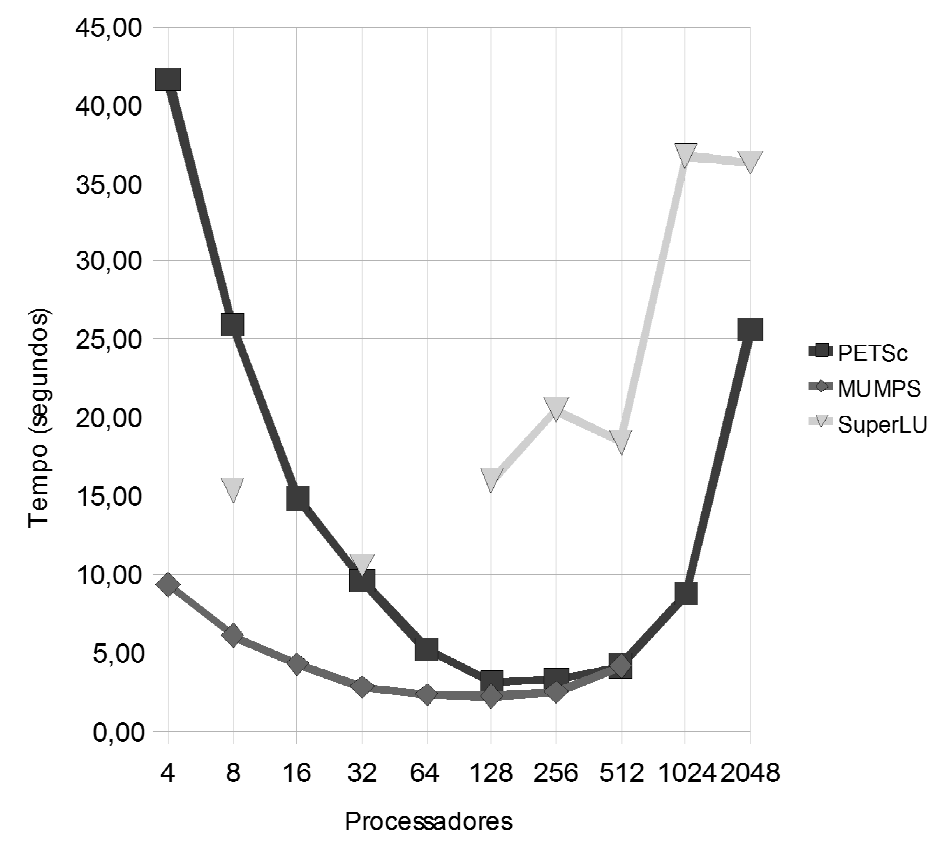

Figura 4.13 - Tempos de execução da matriz "G3_circuit".

Analisando-se a Figura 4.13 e os dados da Tabela 4.11, pode-se dizer que 0 solver SuperLU não demonstrou ser eficiente para os testes, algo que já era esperado, pois não foi escrito especificamente para matrizes com características como as deste trabalho. Note também que a curva está incompleta por conta da ausência dos testes com 4, 16 e 64 processadores, comentados anteriormente neste mesmo item.

Já os testes com o solver MUMPS mostraram um comportamento já esperado, com baixa escalabilidade e seu melhor tempo de execução foi com 128 
processadores que, diga-se de passagem, foi o melhor tempo entre os três solvers utilizados nesse teste.

Com relação ao solver iterativo PETSc, pode-se dizer que o mesmo demonstrou alta escalabilidade e mostrou-se competitivo a partir do uso de 128 processadores, porém não conseguiu ser superior em termos do tempo de resolução do sistema se comparado ao solver direto MUMPS.

\subsubsection{Matriz: thermal2}

Para esse próximo teste foi escolhida a matriz "thermal2", tendo sua estrutura de elementos não nulos representada na Figura 4.14.

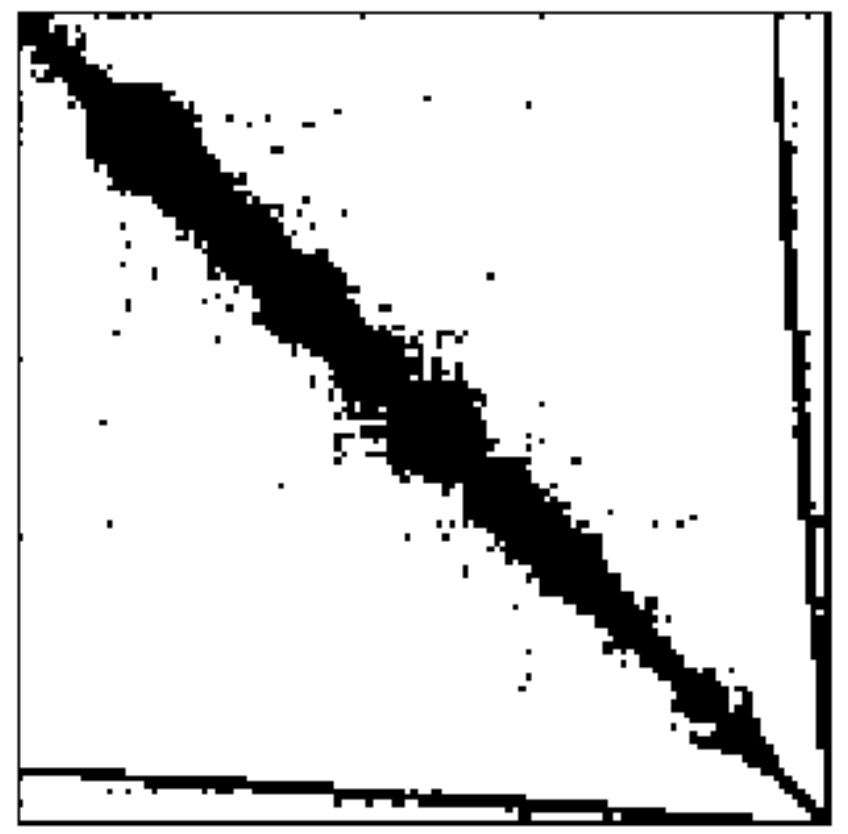

Figura 4.14 - Elementos não nulos da matriz "thermal2".

Pode-se observar que essa matriz possui muitos elementos próximos à diagonal principal, mas não chega a ter uma estrutura de linhas densas paralelas à diagonal principal. Além disso, ela possui um bloco denso que parte de uma de suas últimas colunas, formando uma estrutura de "escada" pelas colunas subsequentes, continuando até a última linha da matriz.

Para poder avaliar de maneira correta a estrutura da matriz, observe a Tabela 4.11, contendo a ordem, o número de elementos não nulos e a densidade da matriz "thermal2". 
Tabela 4.11 - Características da matriz "thermal2".

\begin{tabular}{|l|r|r|r|}
\hline Matriz & Ordem & Não Nulos & Densidade (\%) \\
\hline thermal2 & 1.228 .045 & 8.580 .313 & 0,000568 \\
\hline
\end{tabular}

A matriz "thermal2" é a segunda maior dos testes realizados neste trabalho, porém é mais densa do que a maior matriz utilizada, que é a de nome "G3_circuit".

Os testes seguintes utilizaram até 2048 processadores, considerando os tempos dos três solvers escolhidos, como pode ser visto na Tabela 4.12.

Tabela 4.12 - Tempos de execução da matriz "thermal2".

\begin{tabular}{|l|r|r|r|r|r|r|r|r|r|r|}
\hline Solver/Procs. & $\mathbf{4}$ & $\mathbf{8}$ & $\mathbf{1 6}$ & $\mathbf{3 2}$ & $\mathbf{6 4}$ & $\mathbf{1 2 8}$ & $\mathbf{2 5 6}$ & $\mathbf{5 1 2}$ & $\mathbf{1 0 2 4}$ & $\mathbf{2 0 4 8}$ \\
\hline \hline PETSc (s) & 186,02 & 114,53 & 61,96 & 32,61 & 19,29 & 12,17 & 13,46 & 32,47 & 110,26 & 145,02 \\
\hline \hline MUMPS (s) & 4,46 & 3,41 & 2,66 & 1,80 & 1,91 & 2,32 & 2,94 & 4,86 & 7,62 & 19,20 \\
\hline \hline SuperLU (s) & 8,79 & 6,87 & 5,95 & 5,84 & 8,21 & 9,56 & 12,46 & 11,46 & 27,04 & 32,90 \\
\hline
\end{tabular}

Note que, para esse caso, o solver iterativo mostrou-se muito ineficiente quando comparado aos solvers diretos, principalmente com relação ao MUMPS. Se forem considerados os três primeiros e os dois últimos valores do PETSc, notar-se-á que os tempos estão muito acima dos tempos de seus concorrentes.

$\mathrm{Na}$ Figura 4.15 foram omitidos os tempos citados no parágrafo anterior, para gerar um gráfico mais simples de ser observado pelo leitor.

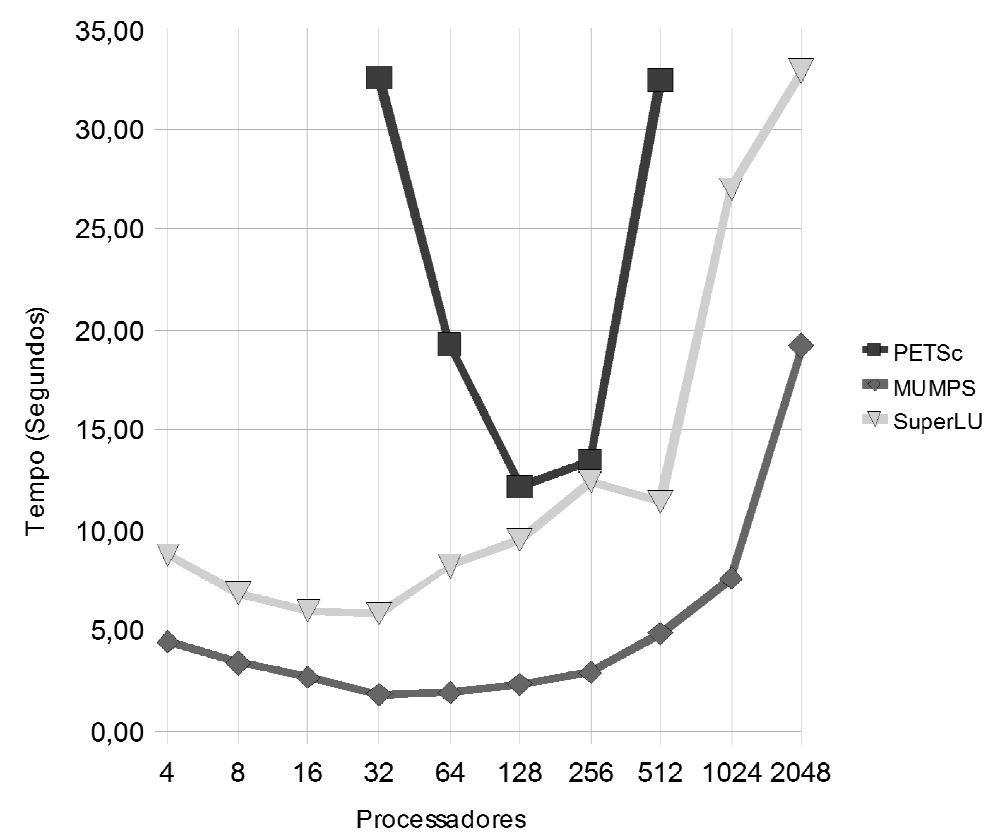

Figura 4.15 - Tempos de execução da matriz "thermal2".

Com relação à figura anterior, como já foi comentado, os tempos do solver PETSc foram omitidos nos testes com 4, 8, 16, 1024 e 2048 processadores e o gráfico gerado mostrou pouca escalabilidade, tendo seu melhor tempo no teste com 
128 processadores. O solver MUMPS mostrou um bom desempenho, tendo seu melhor tempo no teste com 32 processadores. O solver SuperLU também obteve seu melhor tempo no teste com 32 processadores e, além disso, seu desempenho foi inferior ao MUMPS, mas quase sempre superior ao PETSc.

Os testes com a matriz "thermal2" demonstraram um comportamento atípico do solver PETSc, pois mostrou-se pouco eficiente, diferentemente dos outros testes principais deste trabalho.

\subsubsection{Matriz: ecology2}

$\mathrm{Na}$ sequência, observe a Figura 4.16, contendo a representação dos elementos não nulos da matriz "ecology2".

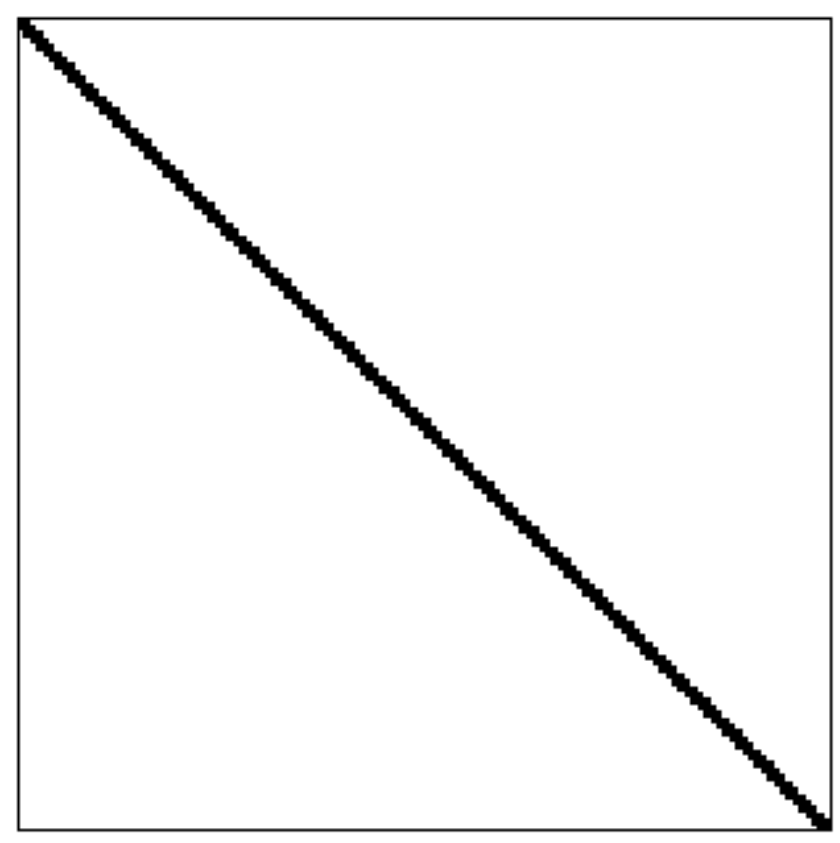

Figura 4.16 - Elementos não nulos da matriz "ecology2".

A estrutura da matriz "ecology2" assemelha-se muito às matrizes do item 4.4 deste mesmo capítulo, possuindo elementos muitos próximos à diagonal principal, formando diagonais muito densas paralelas à diagonal principal.

A matriz "ecology2" possui as características expostas na Tabela 4.13.

\begin{tabular}{|l|r|r|r|}
\hline Tabela 4.13 - Características da matriz "ecology2". \\
\hline Matriz & Ordem & Não Nulos & Densidade (\%) \\
\hline ecology2 & 999.999 & 4.995 .991 & 0,000499 \\
\hline
\end{tabular}

Como pôde ser observada, essa é uma das maiores matrizes utilizadas nos testes deste trabalho, além de ser considerada muito esparsa se comparada às demais matrizes também deste mesmo trabalho. 
Para os testes seguintes foram utilizados até 2048 processadores do supercomputador Hopper, considerando os tempos dos três solvers utilizados: SuperLU, MUMPS e PETSc. Os tempos gastos na resolução dos sistemas podem ser vistos na Tabela 4.14.

\begin{tabular}{|c|c|c|c|c|c|c|c|c|c|c|}
\hline Solver/Procs. & 4 & 8 & 16 & 32 & 64 & 128 & 256 & 512 & 1024 & 2048 \\
\hline PETSc (s) & 56,05 & 31,11 & |15,13 & 7,97 & "4,42 & 2,55 & 1,87 & 1,57 & 1,80 & 1,40 \\
\hline MUMPS (s) & 3,93 & 2,51 & 1,76 & 1,47 & 1,34 & 1,55 & 2,07 & \begin{tabular}{ll|}
4,14 \\
\end{tabular} & 10,82 & 18,77 \\
\hline SuperLU (s) & 7,74 & 5,99 & 5,19 & 6,62 & 8,63 & 6,68 & 13,68 & 11,41 & 29,16 & 23,35 \\
\hline
\end{tabular}

Mais uma vez os tempos iniciais do solver iterativo são muito superiores aos tempos apresentados pelos solvers diretos, porém com 512 processadores, o tempo mostrou-se muito próximo aos tempos do solver direto MUMPS, e com 2048 processadores o menor tempo de resolução foi obtido com o solver iterativo PETSc.

O solver SuperLU mostrou um desempenho inferior ao MUMPS, como já era esperado. O solver iterativo PETSc aproximou seus tempos de execução a partir de 32 processadores, vencendo o tempo mais rápido do SuperLU com apenas 64 processadores.

Antes de mais explicações a respeito deste teste, observe a Figura 4.17, contendo o gráfico das curvas dos tempos de execução dos solvers no ambiente paralelo deste trabalho.

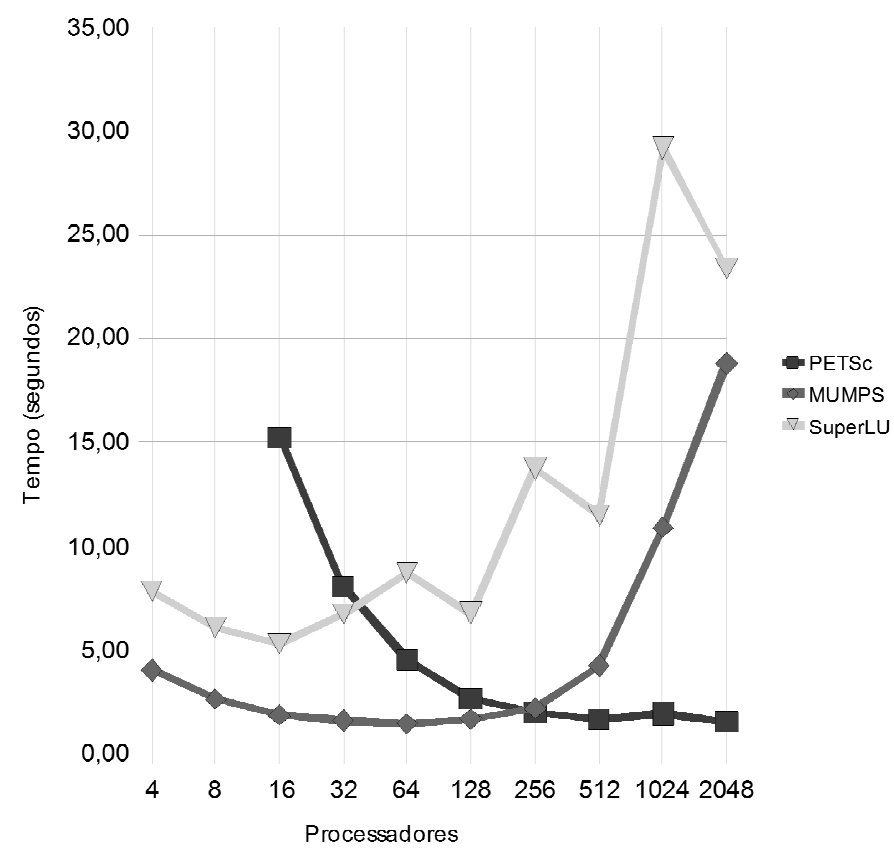

Figura 4.17 - Tempos de execução da matriz "ecology2". 
Considerando os dados da Tabela 4.14 e da Figura 4.17, pode-se observar que o solver iterativo PETSc teve um desempenho distante do solver direto MUMPS, somente com 128 processadores que o solver iterativo tornou-se competitivo com o solver direto.

Fica claro mais uma vez aqui a questão da escalabilidade do método dos gradientes conjugados, implementado pelo solver iterativo PETSc, fato já comentado no item anterior deste mesmo capítulo.

Como já comentado neste mesmo item, a matriz "ecology2" assemelha-se às matrizes do item 4.4, porém com uma dimensão (ordem) muito maior do que elas. Entretanto, o comportamento dos solvers foi diferente, pois quando a ordem da matriz aumentou nos testes do item 4.4, o solver iterativo PETSc teve um desempenho muito superior e, nesse caso, o solver direto MUMPS teve o melhor desempenho.

Outro detalhe da Figura 4.12 é que os tempos de execução do solver iterativo PETSc com 4 e 8 processadores foram omitidos, por serem muito distantes de quaisquer outros valores, como pode ser confirmado na Tabela 410.

\subsubsection{Matriz: apache2}

Observe a Figura 4.18, contendo a representação dos elementos não nulos da matriz "apache2".

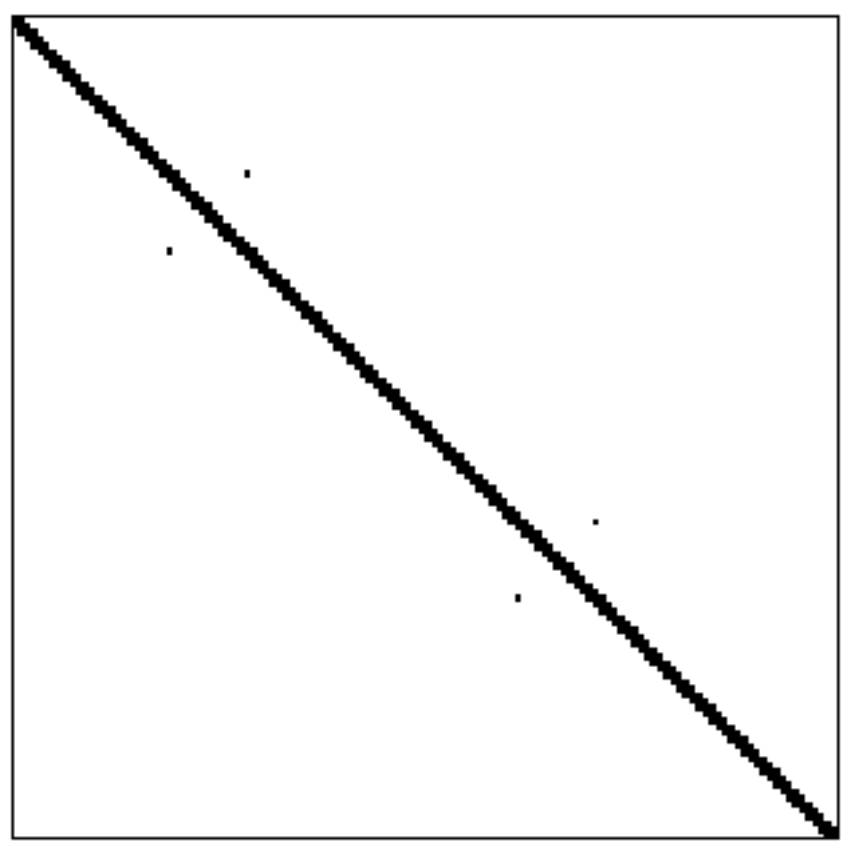

Figura 4.18 - Elementos não nulos da matriz "apache2". 
Note que a matriz "apache2" assemelha-se muito a matriz "ecology2", ilustrada anteriormente, com relação à estrutura dos elementos não nulos de ambas.

A matriz "apache2" possui as características expostas na Tabela 4.15.

\begin{tabular}{|l|r|r|r|}
\hline Tabela 4.15 - Características da matriz "apache2". \\
\hline Matriz & Ordem & Não Nulos & Densidade (\%) \\
\hline apache2 & 715.176 & 4.817 .870 & 0,000941 \\
\hline
\end{tabular}

Como pôde ser verificado na Tabela 4.15, a matriz "apache2" é muito mais densa do que sua semelhante, "ecology2", além de ser possível verificar na Figura 4.18 que existem alguns elementos distantes das diagonais densas paralelas a diagonal principal da matriz.

Os tempos de execução neste teste foram até 256 processadores, como pôde ser visto na Tabela 4.16 na próxima página.

Tabela 4.16 - Tempos de execução da matriz "apache2".

\begin{tabular}{|l||r||r|r|r|r|r||r|}
\hline Solver/Procs. & $\mathbf{4}$ & $\mathbf{8}$ & $\mathbf{1 6}$ & $\mathbf{3 2}$ & $\mathbf{6 4}$ & $\mathbf{1 2 8}$ & $\mathbf{2 5 6}$ \\
\hline \hline PETSc (s) & 21,73 & 12,59 & 7,15 & 4,11 & 2,11 & 1,45 & 1,21 \\
\hline \hline MUMPS (s) & 16,14 & 9,69 & 5,39 & 3,28 & 2,41 & 2,23 & 2,46 \\
\hline SuperLU (s) & 38,25 & 22,57 & 14,15 & 10,43 & 10,68 & 11,84 & 19,41 \\
\hline
\end{tabular}

Considerando os tempos da Tabela 4.16, pode ser observado que, tal qual o caso da matriz "ecology2", com um determinado número de processadores, no caso com 64, o solver iterativo PETSc passa a ser mais eficiente do que o solver direto MUMPS.

Além disso, com 256 processadores, o solver iterativo PETSc mostrou-se melhor do que solver direto MUMPS, diferentemente do caso da matriz "ecology2", em que o mesmo fato não ocorreu até o teste com 2048 processadores.

Para uma melhor compreensão do ocorrido, faz-se necessário observar a Figura 4.19, com um gráfico dos tempos de cada solver utilizado neste teste. 


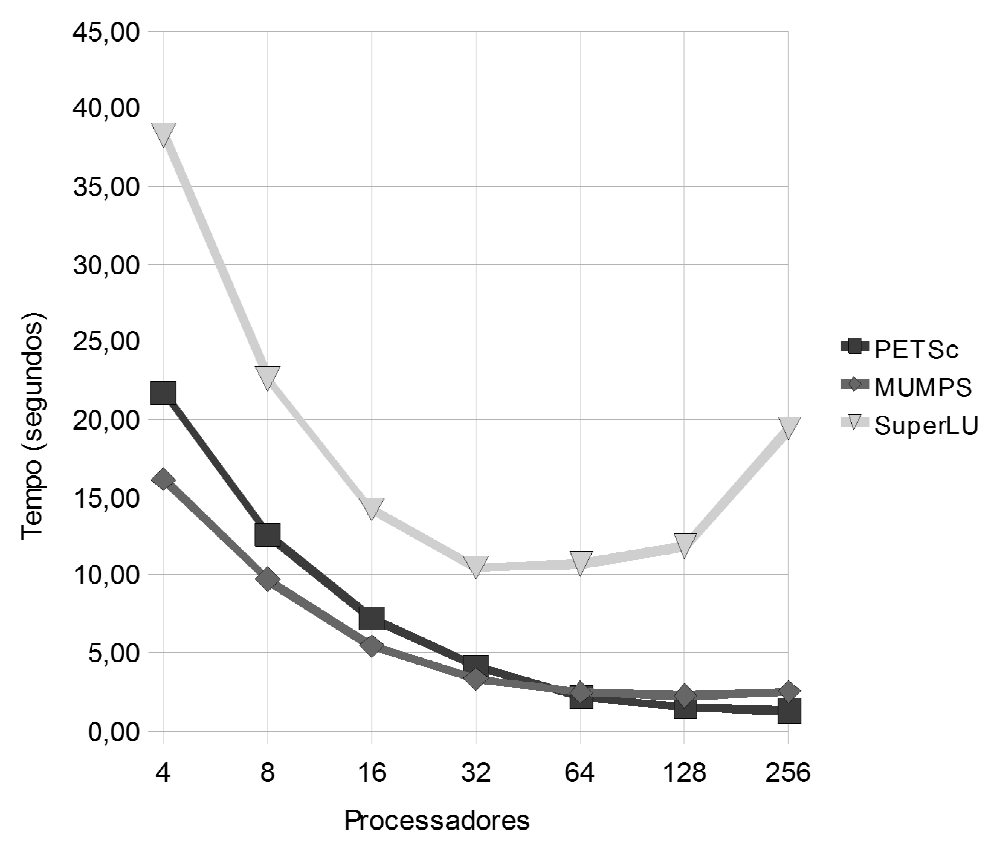

Figura 4.19 - Tempos de execução da matriz "apache2".

Na Figura 4.19 observa-se que as curvas do solvers são mais próximas, inclusive as cursas do PETSc e do MUMPS, cruzando-se com 64 processadores e desse ponto em diante o solver iterativo continua diminuindo o seu tempo de execução, enquanto o solver direto MUMPS vai aumentando seu tempo de execução [23], porém um pouco mais lentamente do que no exemplo realizado com a matriz "ecology2".

\subsubsection{Matriz: af_shell8}

Prosseguindo com os testes, observe a Figura 4.20, na próxima página, contendo a representação dos elementos não nulos da matriz "af_shell8". 


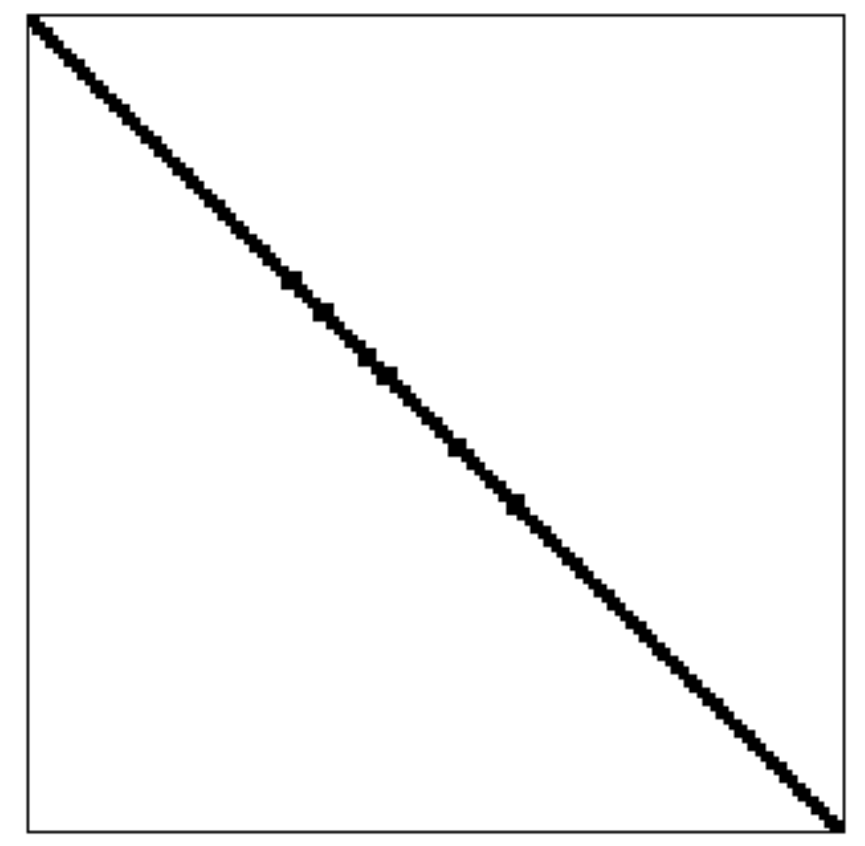

Figura 4.20 - Elementos não nulos da matriz "af_shell8".

A matriz da "af_shell8" é muito parecida com as matrizes "ecology2" e "apache2", no que diz respeito à estrutura dos elementos não nulos e observando a Tabela 4.17, pode-se ver a sua ordem, seus elementos não nulos e sua densidade.

Tabela 4.17 - Características da matriz "af shell8".

\begin{tabular}{|l|r|r|r|}
\hline Matriz & Ordem & Não Nulos & Densidade (\%) \\
\hline af_shell8 & 504.855 & 17.579 .155 & 0,00689 \\
\hline
\end{tabular}

Como pôde ser verificado na Tabela 4.17, a matriz "af_shell8" é muito mais densa do que suas semelhantes, as matrizes "ecology2" e "apache2".

Nesse caso, para os tempos de execução, foram novamente utilizados 2048 processadores, pois os testes tiveram um comportamento semelhante aos da matriz "ecology2", onde também foram utilizados 2048 processadores, como pode ser notado na Tabela 4.18.

Tabela 4.18 - Características da matriz "af_shell8".

\begin{tabular}{|l||r||r|r|r|r|r|r|r|r|r|}
\hline Solver/Procs, & $\mathbf{4}$ & $\mathbf{8}$ & $\mathbf{1 6}$ & $\mathbf{3 2}$ & $\mathbf{6 4}$ & $\mathbf{1 2 8}$ & $\mathbf{2 5 6}$ & $\mathbf{5 1 2}$ & $\mathbf{1 0 2 4}$ & $\mathbf{2 0 4 8}$ \\
\hline \hline PETSc (s) & 53,42 & 31,59 & 17,86 & 11,39 & 8,66 & 6,13 & 4,22 & 2,48 & 1,58 & 1,29 \\
\hline \hline MUMPS (s) & 7,23 & - & 3,40 & - & 2,47 & 2,65 & 3,23 & & 16,86 & - \\
\hline \hline SuperLU (s) & 10,74 & 6,96 & 4,86 & 3,95 & 4,02 & 4,84 & 7,42 & 6,35 & 13,01 & 11,87 \\
\hline
\end{tabular}

A primeira observação sobre a Tabela 4.18 é que o solver MUMPS apresentou dificuldades com 8, 32, 512 e 2048 processadores, não conseguindo executar suas rotinas de resolução de sistemas, sendo diagnosticado não ser uma 
questão de falta de memória RAM, pois o solver funcionou com 4 processadores, mas sim um erro do software e o diagnóstico de falha foge do escopo deste trabalho.

A Figura 4.21 ilustra as curvas de tempo dos solvers para testes que iniciam, mais uma vez, com 4 processadores, indo até 2048 processadores, sendo que os testes com 4 e 8 processadores do solver PETSC foram omitidos por conta de possuírem tempos muito altos, além dos tempos omitidos por erros de software, comentados no parágrafo anterior.

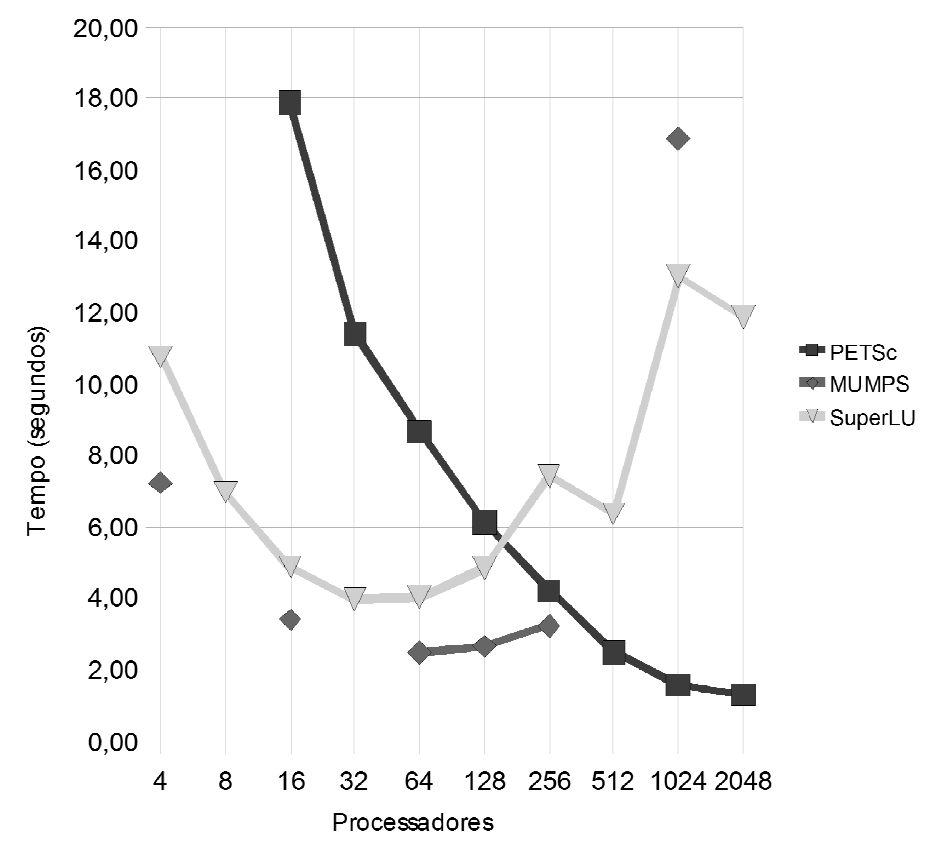

Figura 4.21 - Tempos de execução da matriz "af_shell8".

Como já era esperado, por conta dos testes com as matrizes "ecology2" e "apache2", o comportamento dos solvers paralelos foi similar, com 256 processadores o solver iterativo PETSc começou a mostrar-se competitivo e com 2048 processadores o melhor tempo foi obtido, fato idêntico ao ocorrido com a matriz "apache2".

O solver SuperLU demonstrou alternâncias a partir de 512 processadores, fato que começou a ocorrer na matriz "ecology2" com um número inferior de processadores, mas com um comportamento muito similar nos testes sequenciais (com mais processadores).

\subsubsection{Matriz: tmt_sym}

Prosseguindo com os testes, observe a Figura 4.22, contendo a representação dos elementos não nulos da matriz "tmt_sym". 


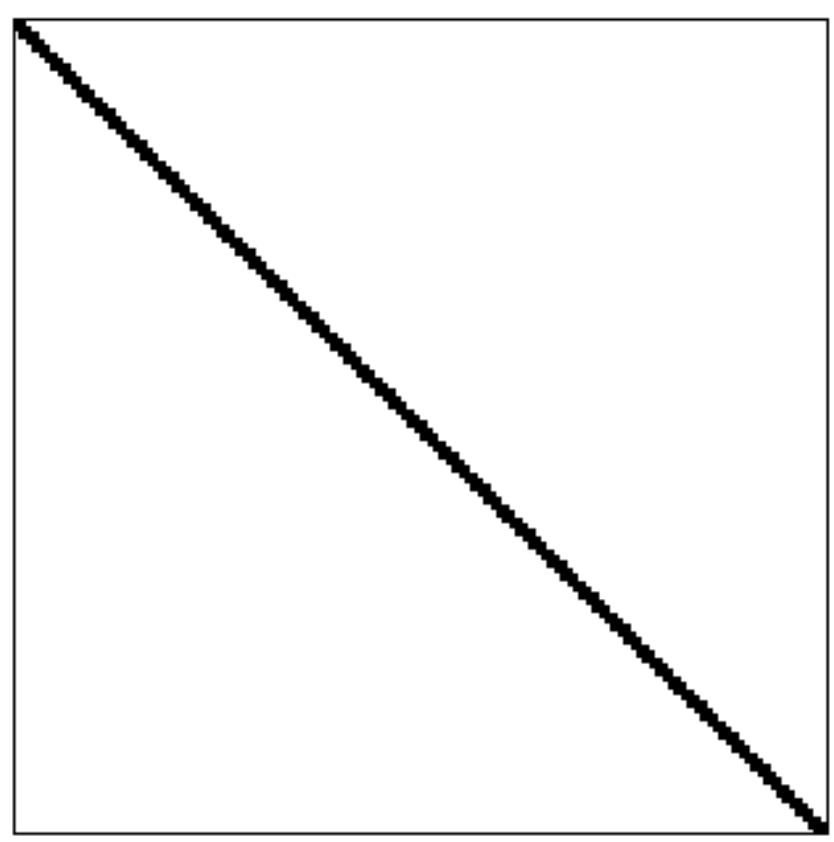

Figura 4.22 - Elementos não nulos da matriz "tmt_sym".

A matriz "tmt_sym" assemelha-se às matrizes "ecology2", "apache2" e "af_shell8", no que diz respeito a posição dos elementos não nulos presentes na mesma, tendo diagonais densas paralelas a diagonal principal.

Mais uma vez, faz-se necessário a Tabela 4.19 para verificar a dimensão da matriz "tmt_sym", a quantidade de elementos não nulos e sua densidade.

Tabela 4.19 - Características da matriz "tmt_sym".

\begin{tabular}{|c|c|c|c|}
\hline Matriz & Ordem & Não Nulos & Densidade (\%) \\
\hline tmt_sym & 726.713 & 5.080 .961 & 0,000962 \\
\hline
\end{tabular}

Observando a densidade da matriz "tmt_sym", pode-se verificar que essa matriz é igualmente densa a sua semelhante em estrutura de densidade, a matriz "apache2", inclusive possuindo densidades similares.

Com relação aos tempos de execução, mais uma vez foram utilizados nos testes de 4 e 2048 processadores, por conta do comportamento dos solvers, como pode ser observado na Tabela 4.20, na próxima página. 
Tabela 4.20 - Tempos de execução da matriz "tmt_sym".

\begin{tabular}{|l|r|r|r|r|r|r|r|r|r|r|}
\hline Solver/Procs, & $\mathbf{4}$ & $\mathbf{8}$ & $\mathbf{1 6}$ & $\mathbf{3 2}$ & $\mathbf{6 4}$ & $\mathbf{1 2 8}$ & $\mathbf{2 5 6}$ & $\mathbf{5 1 2}$ & $\mathbf{1 0 2 4}$ & $\mathbf{2 0 4 8}$ \\
\hline \hline PETSc (s) & 39,15 & 20,32 & 10,87 & 5,96 & 3,35 & 2,01 & 1,56 & 1,31 & 1,10 & 1,05 \\
\hline MUMPS (s) & 2,92 & 1,95 & 1,48 & 1,14 & 1,11 & 1,11 & 1,76 & 3,19 & 8,86 & 17,53 \\
\hline \hline SuperLU (s) & 4,19 & 4,19 & 5,42 & 4,40 & 5,30 & 6,08 & 8,16 & 8,84 & 24,33 & 26,24 \\
\hline
\end{tabular}

Assim, como já ocorreu nos testes anteriores, com as matrizes "ecology2", "apache2" e "af_shell8", a partir de um determinado número de processadores, o solver iterativo PETSc demonstrou melhor desempenho.

Nesse exemplo com 64 processadores, o solver iterativo PETSc já se mostrou competitivo, porém foi somente com 1024 processadores que o solver direto MUMPS foi vencido em termos do tempo, e o melhor resultado foi o de 2048 processadores com o solver iterativo PETSC.

Observando as curvas da Figura 4.23, os resultados ficam mais claros, sendo possível notar que as curvas de MUMPS e PETSc cruzam-se a partir de 256 processadores.

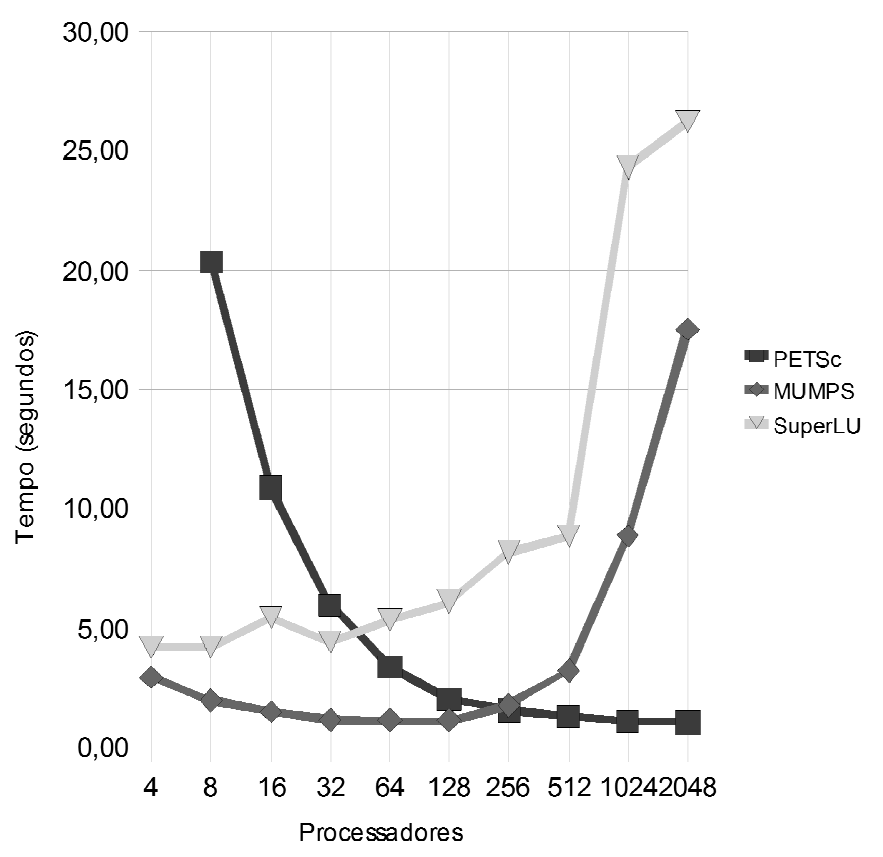

Figura 4.23 - Tempos de execução da matriz "tmt_sym".

$\mathrm{Na}$ figura anterior, somente o tempo de 4 processadores do solver iterativo PETSc foi omitido, para facilitar a visualização das curvas na figura.

\subsubsection{Matriz: af_1_k101}

Prosseguindo com os testes, observe a Figura 4.24, contendo a representação dos elementos não nulos da matriz "af_1_k101". 


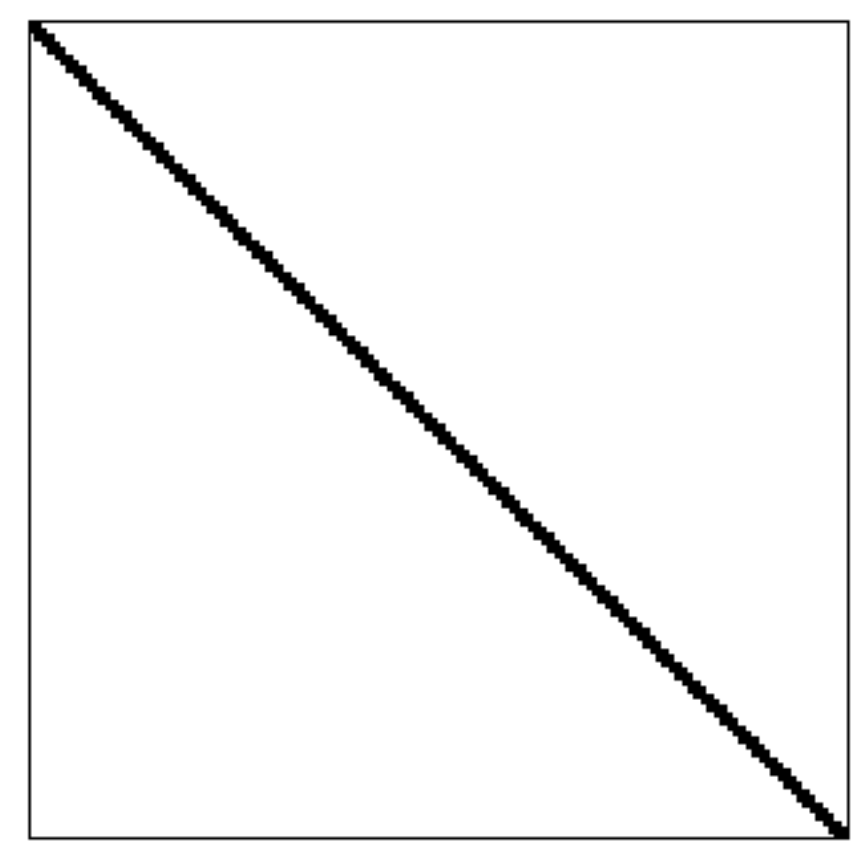

Figura 4.24 - Elementos não nulos da matriz "af_1_k101".

A matriz "af_1_k101" possui diagonais densas paralelas a diagonal principal, inclusive sendo considerada a matriz mais densa dos testes do item 4.6 deste trabalho, como pode ser verificado na Tabela 4.21, contendo a ordem da matriz, o número de elementos não nulos e sua densidade.

Tabela 4.21 - Características da matriz "af_1_k101".

\begin{tabular}{|l|r|r|r|}
\hline Matriz & Ordem & Não Nulos & Densidade (\%) \\
\hline af_1_k101 & 503.625 & 17.550 .675 & 0,00691 \\
\hline
\end{tabular}

A matriz "af_1_k101" assemelha-se muito a matriz "af_shell8" considerando a ordem, o número de elementos não nulos e, consequentemente, a densidade de ambas.

Para os testes com a matriz "af_shell8", foram utilizados até 2048 processadores, porém, para os testes com a matriz "af_1_k101", foram utilizados até 256 processadores, pois o comportamento dos solvers foi diferente nesse caso, como pode ser verificado na Tabela 4.22.

Tabela 4.22 - Tempos de execução da matriz "af_1_k101".

\begin{tabular}{|l|r|r||r|r|r|r|r|}
\hline Solver/Procs. & $\mathbf{4}$ & $\mathbf{8}$ & $\mathbf{1 6}$ & $\mathbf{3 2}$ & $\mathbf{6 4}$ & $\mathbf{1 2 8}$ & $\mathbf{2 5 6}$ \\
\hline \hline PETSc (s) & 1680,83 & 585,70 & 234,42 & 118,43 & 76,52 & 53,03 & 31,64 \\
\hline MUMPS (s) & 8,00 & 6,03 & 3,62 & 2,81 & 2,54 & 3,05 & - \\
\hline SuperLU (s) & 12,50 & 7,85 & 5,32 & 4,22 & 4,01 & 3,77 & 4,39 \\
\hline
\end{tabular}


Como verificado na Tabela 4.22, o comportamento dos solvers é bem distinto dos outros testes realizados anteriormente, considerando as características da matriz em questão, bem como o comportamento padrão dos solvers para determinados tipos de matrizes.

Primeiramente, o solver direto SuperLU, nesse caso, demonstrou tempos de resolução mais competitivos se comparados ao outro solver direto MUMPS, algo que não ocorreu em nenhum dos testes realizados anteriormente.

Outra questão a ser considerada, é o comportamento do solver iterativo PETSc, com tempos de resolução do sistema muito distantes dos outros dois solvers utilizados, algo que até ocorreu nos outros testes, porém somente com um número reduzido de processadores, geralmente entre 4 e 16 processadores.

A principal questão a ser considerada é que, quando o PETSc, e mesmo o SuperLU, foram aplicados a uma matriz com características muito semelhantes a essa, como pode ser notado nos testes com a matriz "af_shell8", o comportamento foi muito distinto.

As curvas da Figura 4.25 demonstram o ocorrido com os três solvers.

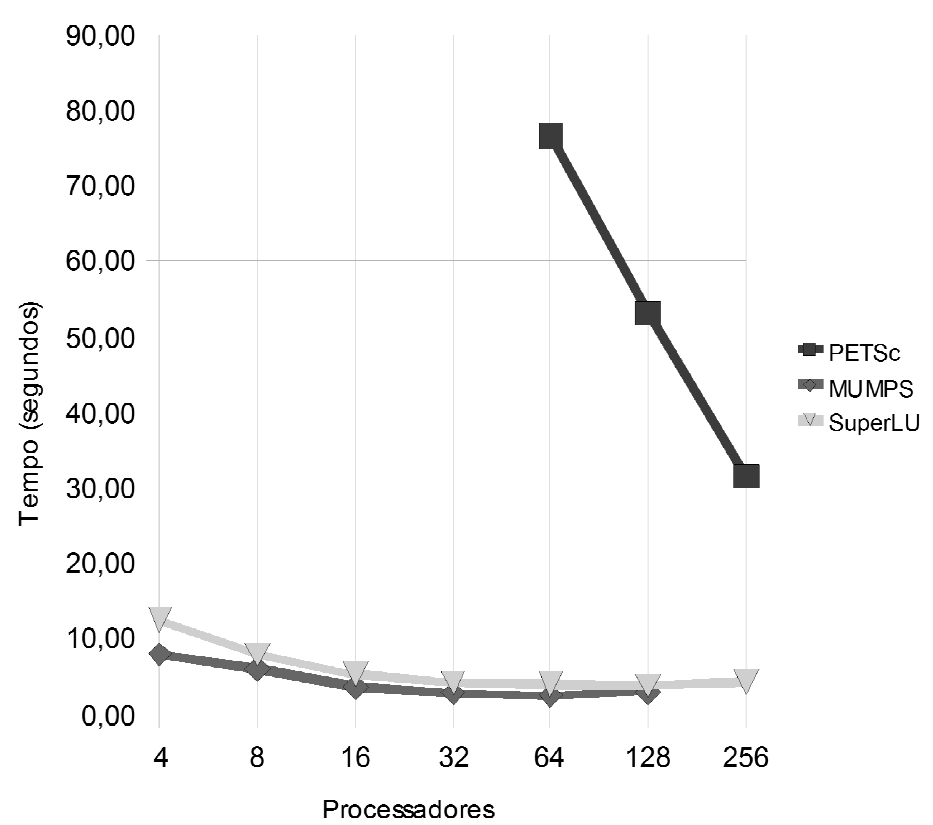

Figura 4.25 - Tempos de execução da matriz "af_1_k101".

Observando a figura anterior, pode-se notar que foi necessário omitir os maiores tempos de resolução do solver iterativo PETSc, para deixar a representação gráfica mais atrativa.

Outra questão a ser observada nesse teste é que o solver direto MUMPS não conseguiu resolver o sistema com 256 processadores, podendo ser uma falha de 
software ou ainda alguma questão envolvendo distribuição da memória, porém não foi possível um diagnóstico conclusivo. Mais uma vez essa questão não será tratada, por não se tratar do escopo deste trabalho.

\subsection{Speedup}

Em computação paralela o termo Speedup indica o quão rápido um algoritmo paralelo é se comparado ao mesmo código de programação, porém executando-se de forma sequencial [11].

O Speedup é calculado da seguinte forma:

$$
S p=T 1 / T p .
$$

Onde "Sp" indica o valor do Speedup para um determinado número de processadores "p". O valor "T1" indica o tempo de execução do código sequencial, ou seja, o de um único processador. O valor "Tp" indica o tempo de processamento para um determinado número de processadores, especificado por "p".

Note que o tempo pode ser medido na unidade em que o usuário preferir (milésimos de segundos, segundos, minutos, horas), porém, geralmente, é adotada a unidade de tempo de segundos para avaliar o desempenho do Speedup.

Para a divulgação de trabalhos em paralelo, principalmente quando os observadores são usuários novos, é comum a existência de gráficos utilizando o Speedup, provavelmente pelo sentido das curvas geradas, que vão para cima e para a direita.

\subsubsection{Speedup Linear}

Um valor de Speedup Linear, também chamado de Speedup Ideal, é obtido quando "Sp" é igual ao número de processadores utilizados no cálculo do presente Speedup, representado por " $p$ ".

Segundo [5], algoritmos com escalabilidade muito alta, ou muito boa, quando dobram o número de processadores utilizados no cálculo, também se dobra o valor aproximado do Speedup.

\subsubsection{Speedup Super Linear}

Esse fato é considerado incomum entre os códigos de programação paralela, 
o que faz com que os novos usuários de ambientes paralelos acreditem que dobrando o número de processadores, o Speedup será maior do que o dobro, ou seja, o tempo de execução do código é reduzido em menos da metade do tempo de execução sequencial.

Há várias razões que justifiquem a ocorrência de Speedup Super Linear, uma delas é a existência de uma memória cache com grande capacidade onde, em alguns casos, é possível alocar todos os dados do programa em execução na cache, tornando o acesso muito rápido.

Considere também que o controle de acesso à cache é de responsabilidade direta do processador, que atualmente possui autonomia para tomar tal decisão, não sendo possível dizer o que sairá da memória principal (RAM) e ficará na cache, essa decisão cabe inteiramente à lógica do próprio processador.

\subsubsection{Eficiência}

A eficiência de um algoritmo em paralelo é calculada utilizando-se da seguinte equação:

$$
E p=S p / p
$$

Onde "Ep" indica a eficiência para um determinado número de processadores, representado por "p". O valor de "Sp" corresponde ao valor do Speedup, também para um determinado número de processadores "p".

A eficiência é um valor tipicamente entre 0 (zero) e 1 (um), exceto no casos de speedup super linear, estimando o quão bem utilizados os processadores são ao realizar um determinado problema, considerando os gastos computacionais com comunicação e sincronização entre os processadores [11].

Nos algoritmos sequenciais, com Speedup Linear ou Ideal, o valor da eficiência é 1 (um). Em códigos de difícil paralelização, o valor da eficiência tende a 0 (zero).

Nos trabalhos de engenharia é mais comum observar gráficos de eficiência ao invés de Speedup, pois é mais fácil observar o comportamento do algoritmo em paralelo, além de aproveitar melhor a área do gráfico gerado. 


\subsubsection{Testes de Speedup e Eficiência}

Serão realizados aqui os testes relativos ao Speedup e a eficiência de cada um dos solvers utilizados no trabalho, para cada uma das matrizes pertencentes ao conjunto de Tim Davis [40].

\subsubsection{Speedup e Eficiência - Matriz: parabolic_fem}

A Figura 4.26 ilustra o comportamento dos três solvers, considerando o fator Speedup, com uma curva para cada um dos solvers: PETSc, MUMPS e SuperLU.

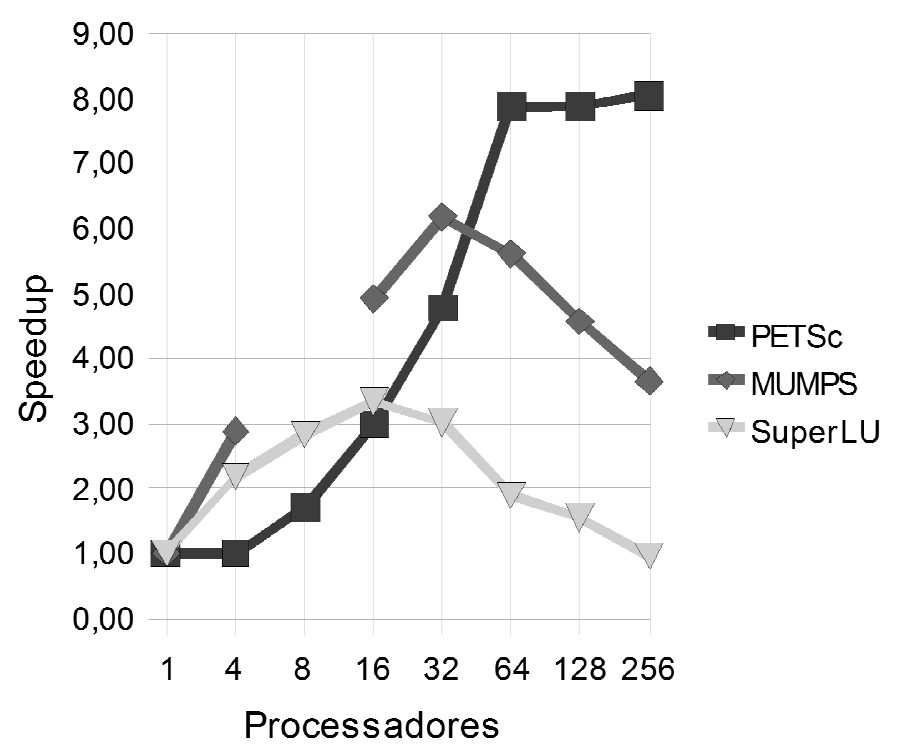

Figura 4.26 - Matriz "parabolic_fem" - Speedup dos solvers.

A curva representada pelo solver PETSc é a curva tradicional, vista em muitos trabalhos de divulgação da área de sistemas computacionais distribuídos, verificando um crescimento significativo nos primeiros agrupamentos de processadores e, em um determinado ponto esse crescimento tende a estabilizar-se por um certo número de agrupamentos. Deve ficar claro que em um determinado momento essa curva de Speedup provavelmente teve seus valores diminuindo, a questão é verificar quando isso ocorre.

Nas curvas dos solvers MUMPS e SuperLU isso fica evidente, pois com $32 \mathrm{e}$ 16 processadores, respectivamente, os valores de Speedup começam a reduzir. Note que o valor do teste com 8 processadores para o solver MUMPS não está presente, devido às razões comentadas anteriormente neste mesmo capítulo.

Para verificar a eficiência dos três solvers foi gerado um segundo gráfico, 
representado pela Figura 4.27, contendo as curvas de eficiências do PETSc, MUMPS e SuperLU.

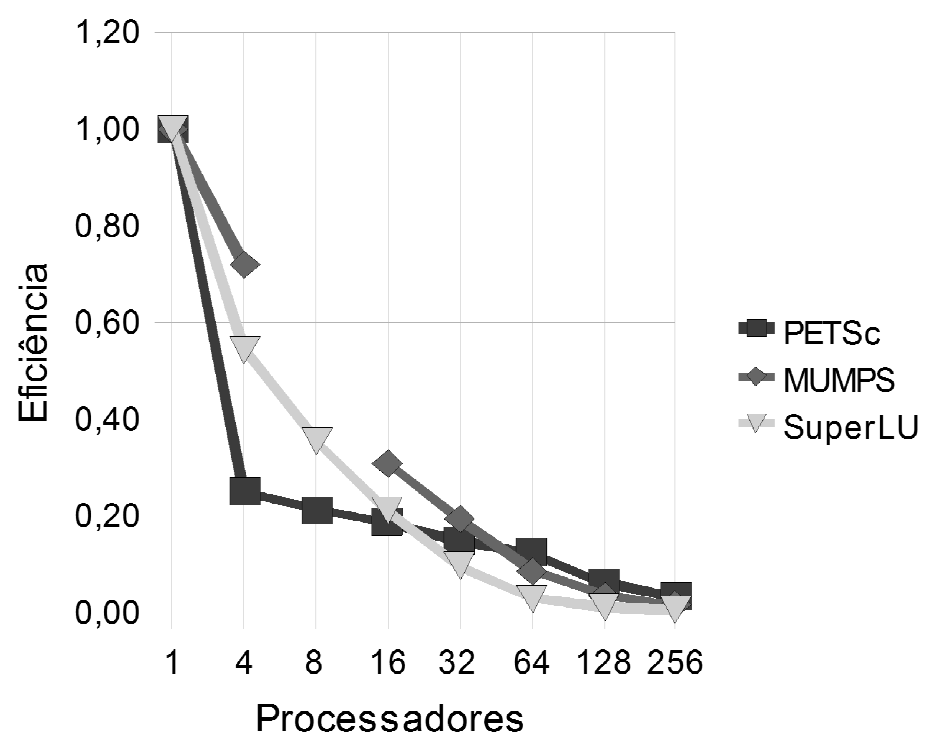

Figura 4.27 - Matriz "parabolic_fem" - Eficiência dos solvers.

Como já mencionado anteriormente no texto deste trabalho, os gráficos que medem a eficiência dos algoritmos paralelizados, geralmente, tendem a ser mais atrativos graficamente para os trabalhos de engenharia.

Observando as três curvas de eficiência, pode-se avaliar um comportamento muito similar dos três solvers. A curva do PETSc mantém uma eficiência em torno de 0,20 em $50 \%$ dos testes, mostrando que para os primeiros agrupamento de processadores, mais especificamente até 32 processadores, os solvers diretos mostraram ter mais eficiência.

\subsubsection{Speedup e Eficiência - Matriz: G3_circuit}

A matriz desse teste é a de maior ordem dentre as escolhidas para os testes deste trabalho. A Figura 4.28 contém a comparação do Speedup dos três solvers. 


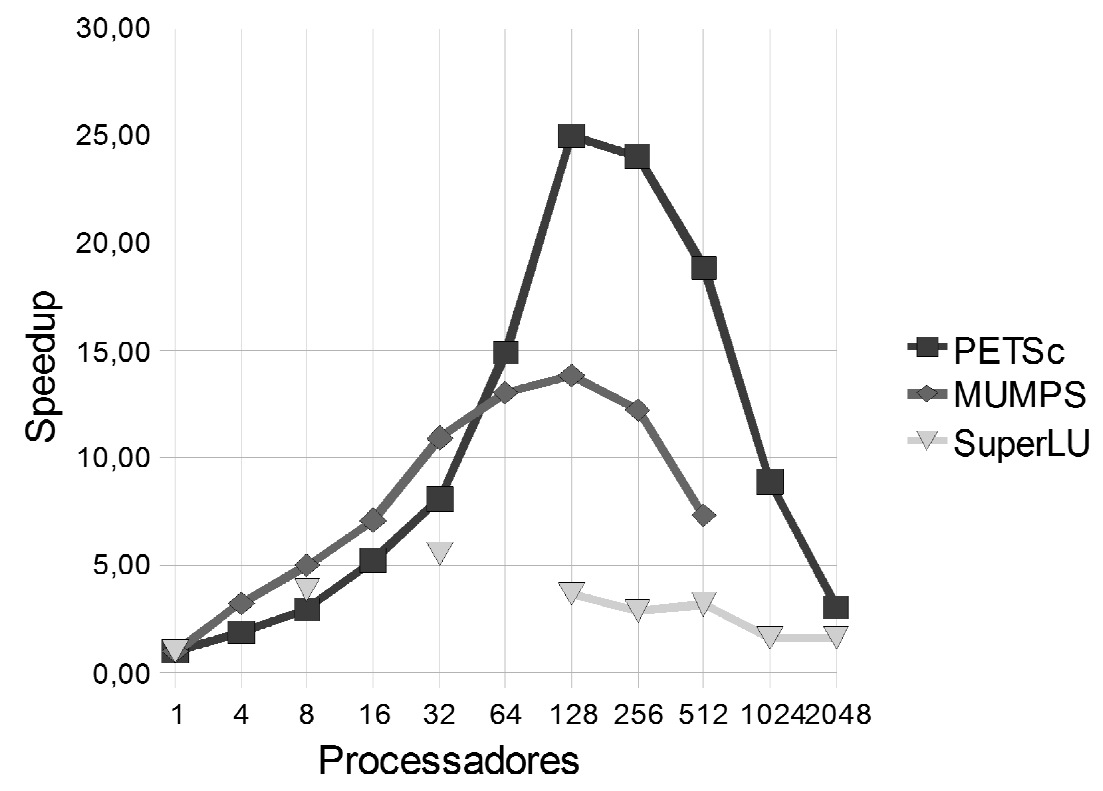

Figura 4.28 - Matriz "G3_circuit" - Speedup dos solvers.

Observe as semelhanças entre as curvas dos três solvers, note que para esse exemplo o comportamento do Speedup foi muito similar, com Speedup máximo com 128 processadores para os solvers PETSc e MUMPS e com 32 processadores para o solver SuperLU. Deve-se considerar também que, apesar das similaridades, os valores de Speedup do PETSc foram superiores, demonstrado a questão da escalabilidade do algoritmo desse software.

Outra questão a ser observada, é que os testes com 3, 16 e 64 processadores para o SuperLU não foram realizados, como já mencionado anteriormente neste mesmo capítulo, mas mesmo assim é possível verificar o comportamento do referido solver.

$\mathrm{Na}$ sequência pode-se observar a Figura 4.29, contendo as curvas de eficiência dos três solvers. 


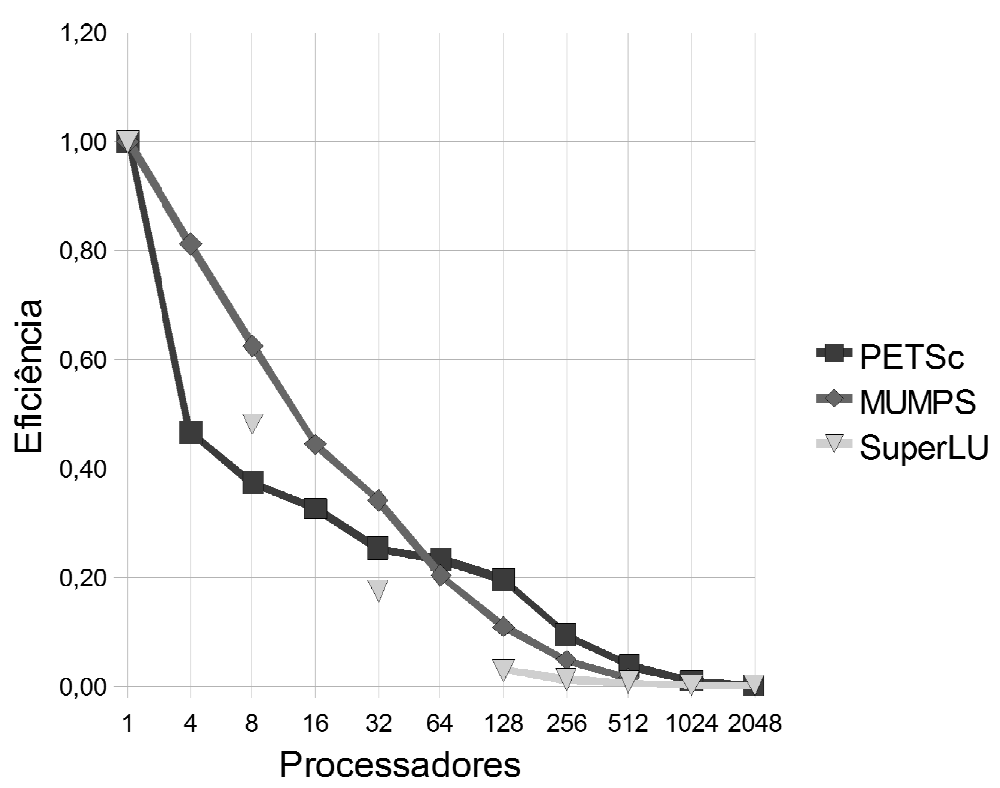

Figura 4.29 - Matriz "G3_circuit" - Eficiência dos solvers.

As curvas de eficiência dos três solvers são muito parecidas, exceto pelo fato de que a eficiência dos PETSc teve um valor estável em torno de 0,40 a 0,30, entre os testes com 8 a 64 processadores.

Os solvers diretos têm um comportamento de eficiência que pode ser classificado como mais drástico, pois a eficiência de ambos cai conforme o número de processadores aumenta, e tendem a zero quando chegam aos testes com agrupamentos de 256 processadores.

O solver iterativo consegue manter uma eficiência maior com agrupamentos de processadores, devido ao fator da escalabilidade do algoritmo utilizado no teste.

\subsubsection{Speedup e Eficiência - Matriz: thermal2}

A matriz "thermal2" será utilizada para os testes desse item, e as curvas dos três solvers estão ilustradas na Figura 4.30. 


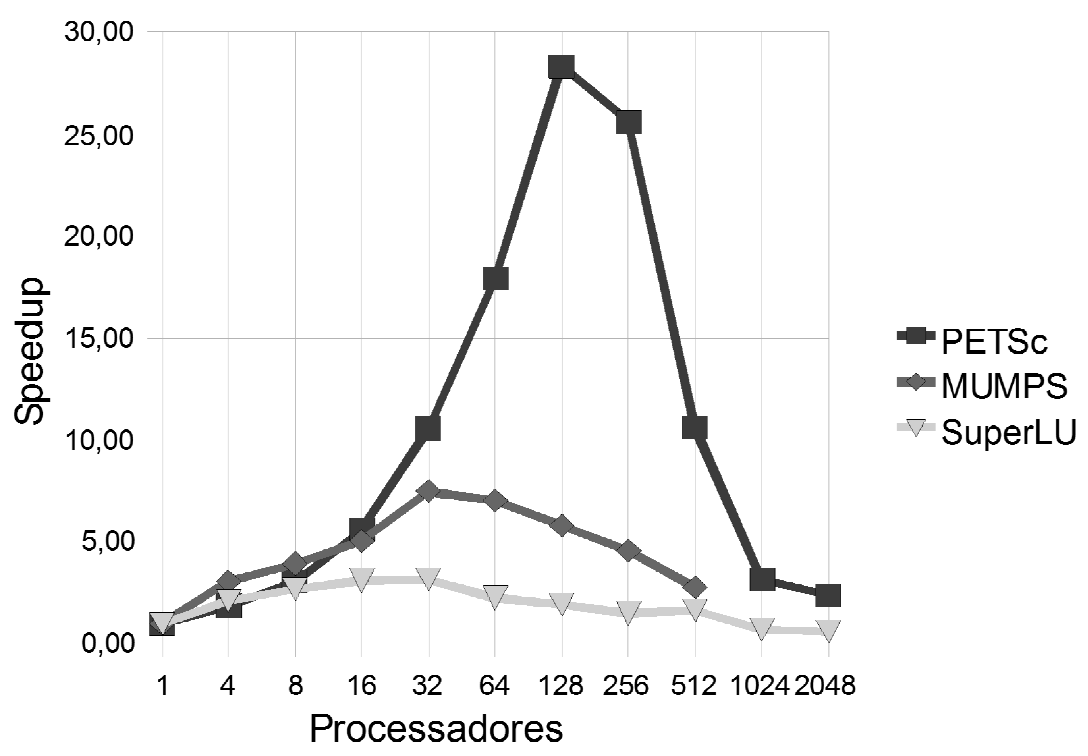

Figura 4.30 - Matriz "thermal2" - Speedup dos solvers.

Os valores de Speedup do solver iterativo, como já observado nos testes anteriores, são maiores dos que os solvers diretos, possuindo uma queda no valor do Speedup a partir de 256 processadores para o solver iterativo, e de 64 processadores para os solvers diretos.

Nesse exemplo, a curva de Speedup do PETSc não apresenta o comportamento tradicional, ou seja, sempre crescente para a direita conforme o número de processadores aumenta.

Observe agora a Figura 4.31, ilustrado a eficiência dos três solvers para o presente exemplo.

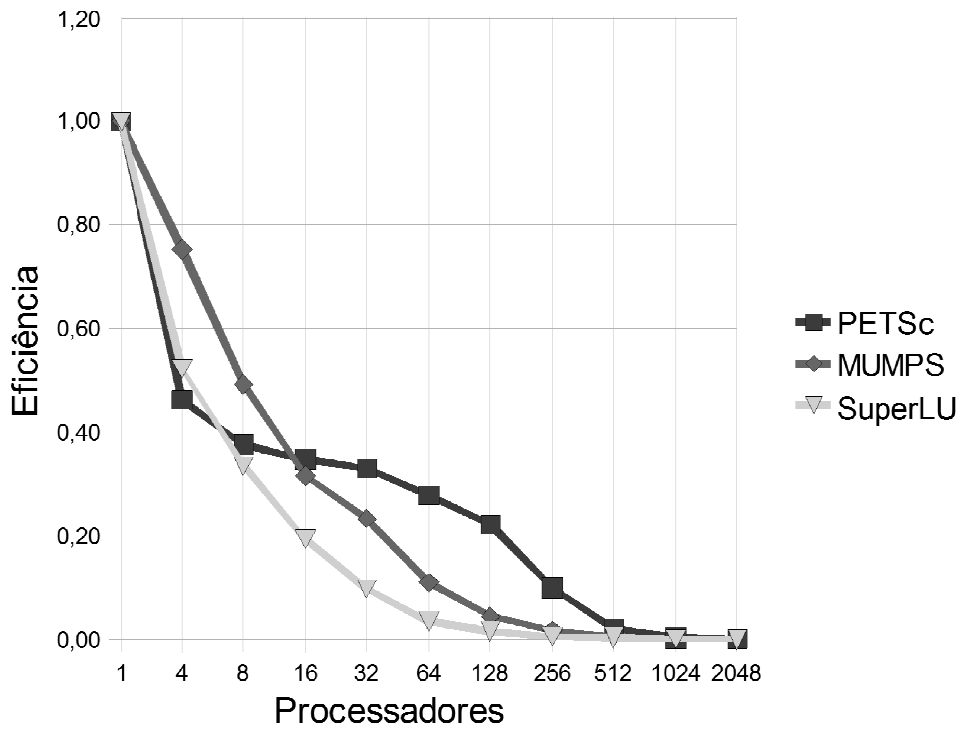

Figura 4.31 - Matriz "thermal2" - Eficiência dos solvers. 
A eficiência dos três solvers mostrou o comportamento já notado anteriormente, com o solver PETSc mostrando valores de eficiência próximos na faixa de agrupamento entre 8 e 64 processadores. Com 128 processadores em diante, o comportamento do solver iterativo é similar ao dos solvers diretos, com a curva tendendo a zero com o aumento de processadores.

\subsubsection{Speedup e Eficiência - Matriz: ecology2}

Para entender melhor o comportamento dos três algoritmos, serão apresentados os gráficos de Speedup e Eficiência para a matriz "ecology2".

Observe a Figura 4.32, onde estão representadas as curvas de Speedup dos três solvers: PETSC, MUMPS e SuperLU.

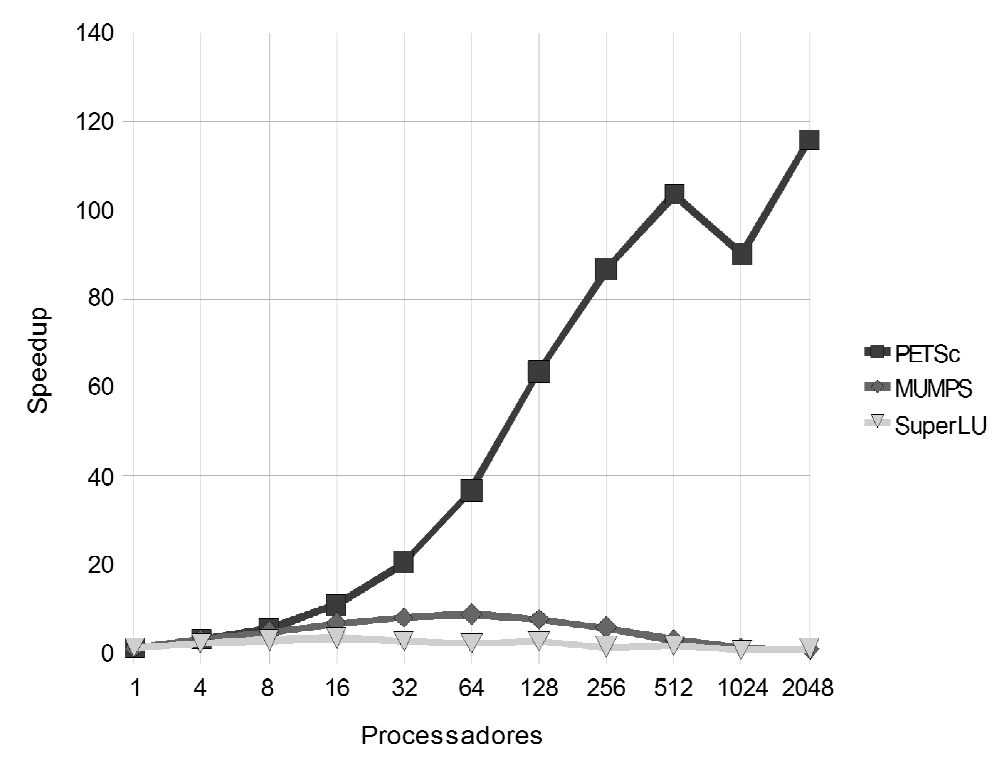

Figura 4.32 - Matriz "ecology2" - Speedup dos solvers.

A curva de Speedup do solver PETSc, se comparado à dos outros, demonstra o comportamento tradicional esperado pelos novos usuários, onde o Speedup aumenta conforme o número de processadores também aumenta.

Para observar melhor o comportamento dos outros dois solvers, é necessário a observação da Figura 4.33, contendo o Speedup dos solvers diretos, MUMPS e SuperLU. 


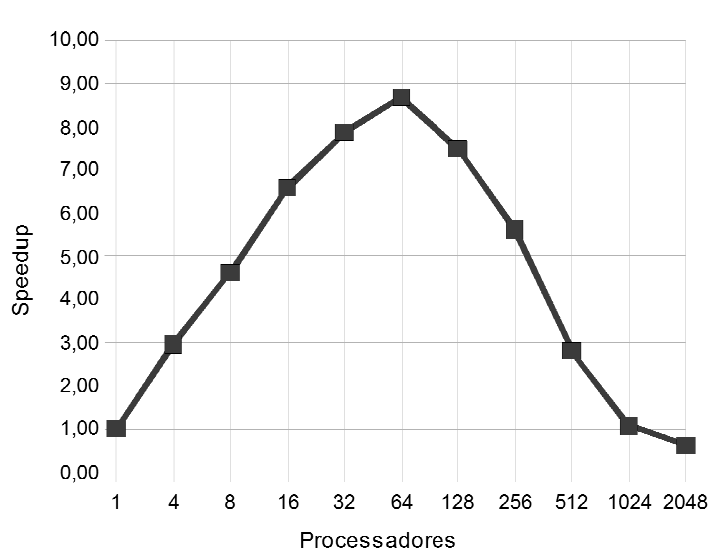

(a)

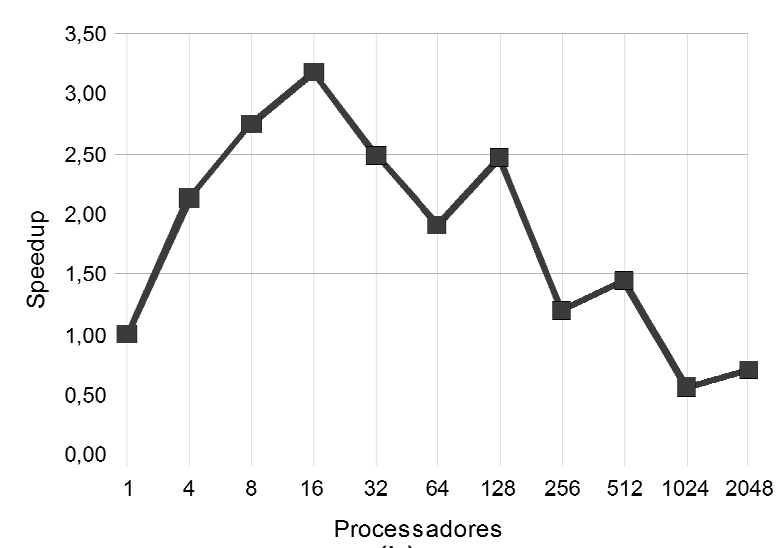

(b)

Figura 4.33 - Matriz "ecology2" - Speedup do solvers: MUMPS (a) e SuperLU (b).

Foi necessária a elaboração da figura anterior pelos valores assumidos por Speedup, muito distantes dos valores do solver PETSc. A curva do solver MUMPS, representada na Figura 4.33 (a) tem nitidamente, até o valor de 64 processadores, 0 comportamento esperado pelos usuários, ou seja, que o Speedup sempre aumente conforme se aumenta o número de processadores, porém, a partir de 128 processadores o comportamento é um tanto quanto diferente, e Speedup começa a diminuir, chegando ao ponto de ser mais lento do que um código sequencial, como pode ser observado no teste com 2048 processadores.

A Figura 4.33 (b) mostra a curva do solver SuperLU, que tem um comportamento interessante até 16 processadores, porém demonstrou que a performance paralela comparada à performance sequencial é muito instável, fazendo com que o usuário avalie se realmente é eficaz o paralelismo em certas casos.

O próximo teste que será realizado é o da comparação da eficiência entre os três solvers. Neste teste não será necessária a divisão em figuras separadas para representar as curvas, pois os valores estão compreendidos entre a faixa de zero a um.

Observe então a Figura 4.34, contendo as curvas de eficiência dos três solvers utilizados nesta pesquisa. 


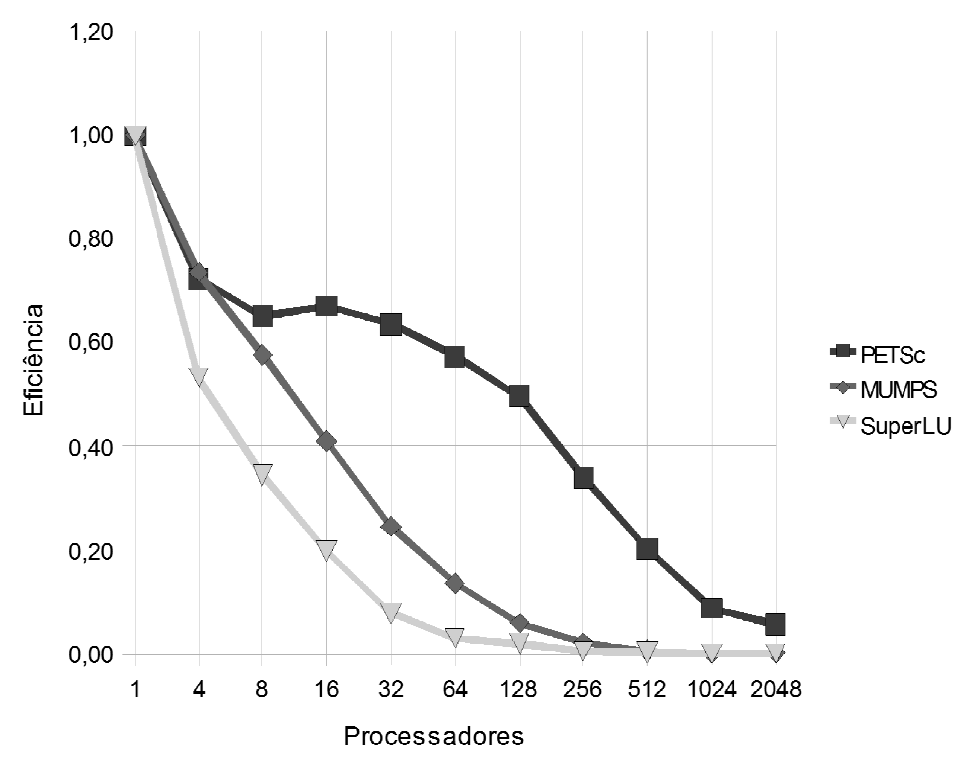

Figura 4.34 - Matriz "ecology2" - Eficiência dos solvers.

As curvas apresentadas na figura anterior mostram que o solver PETSC tem um algoritmo muito mais eficiente para o paralelismo, mostrando-se muito escalável até 128 processadores, com valor de eficiência próximo de 0,5, e é considerado um bom valor, principalmente ao comparar essa curva com as curvas do solver MUMPS e SuperLU, que mostram pouca eficiência a partir de 16 e 8 processadores, respectivamente.

\subsubsection{Speedup e Eficiência - Matriz: apache2}

Será analisado agora o comportamento do Speedup para a matriz "apache2", mais uma vez considerando os três solvers, como pode ser visto na Figura 4.35.

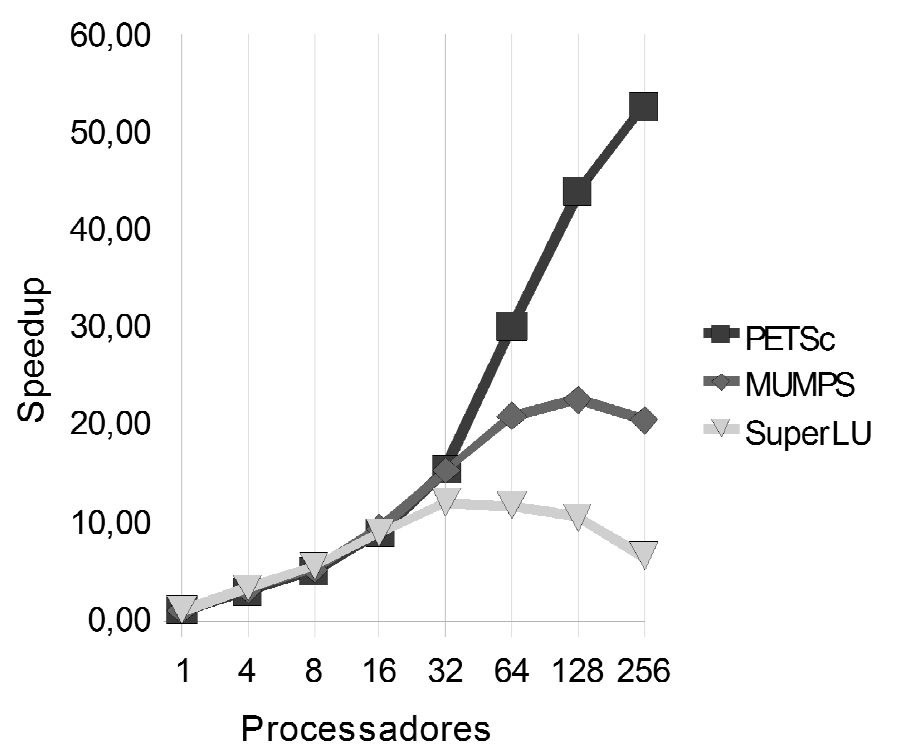

Figura 4.35 - Matriz "apache2" - Speedup dos solvers. 
A Figura 4.35 ilustra um comportamento mais homogêneo do Speedup, porém é somente pelo fato de terem sido utilizados no máximo 256 processadores, por conta dos testes com o MUMPS, que apresentaram falhas do software com 512, 1024 e 2048, como já foi descrito anteriormente.

Note que as três curvas possuem comportamento similar aos outros testes, só não tiveram uma queda tão evidente do Speedup para os solvers diretos pela ausência de testes com um número maior de processadores.

Observe a Figura 4.36, ilustrando a eficiência dos três solvers.

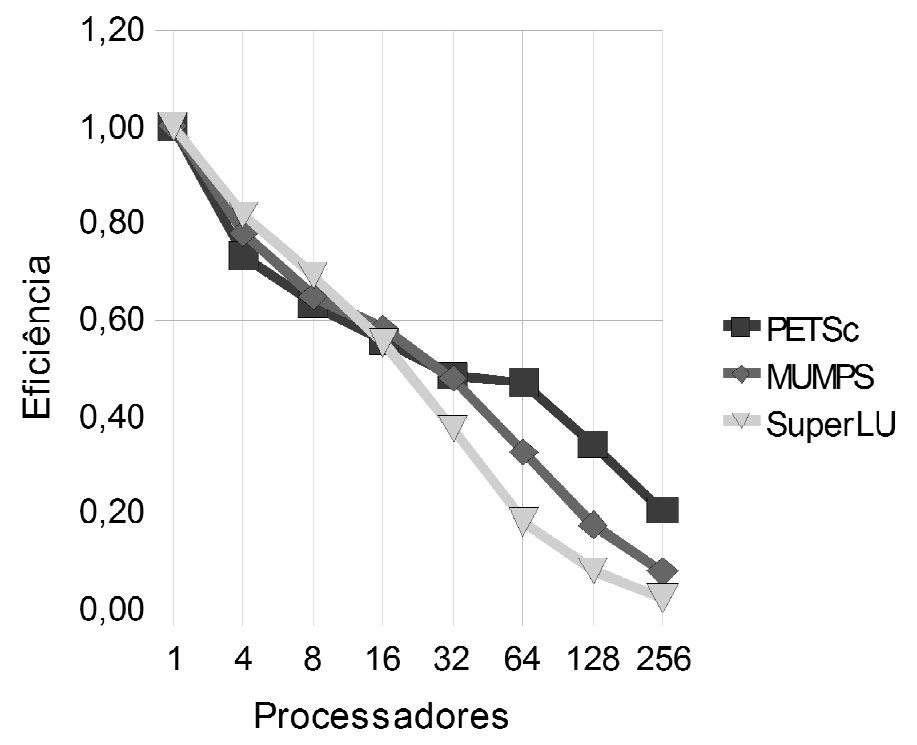

Figura 4.36 - Matriz "apache2" - Eficiência dos solvers.

O comportamento da eficiência dos três solvers foi similar aos comportamentos ilustrados nos testes anteriores, só não ocorreu a aproximação do valor zero por conta da ausência de testes com um número maior de processadores.

\subsubsection{Speedup e Eficiência - Matriz: af_shell8}

Observe agora os testes realizados coma matriz "af_shell8", com as curvas dos três solvers representadas na Figura 4.37. 


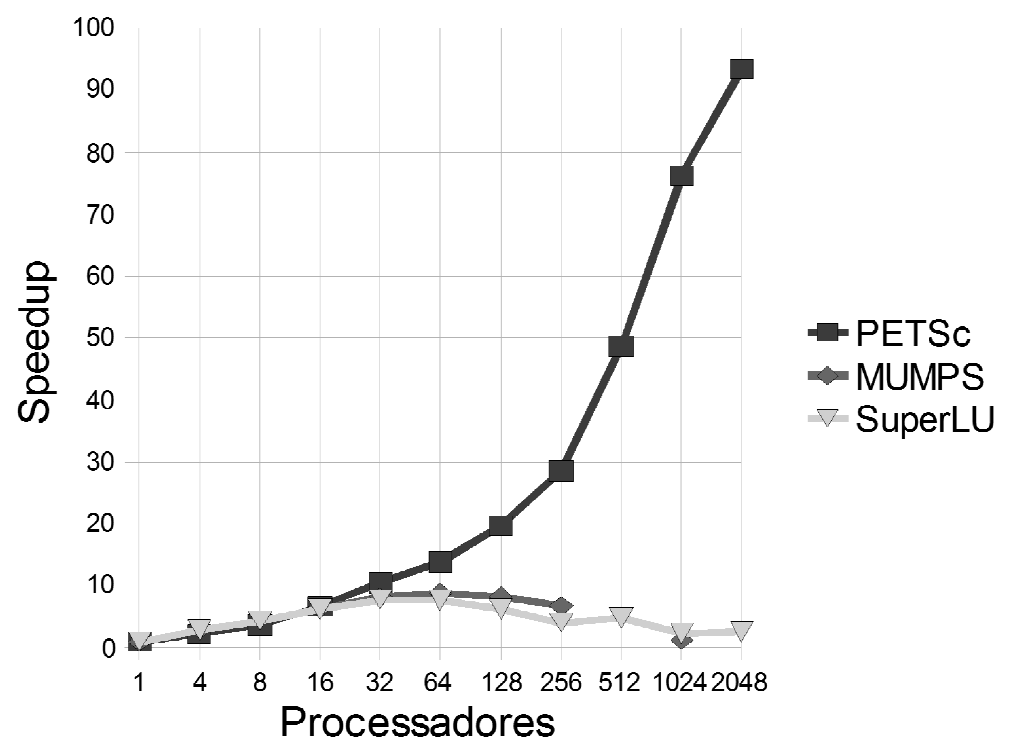

Figura 4.37 - Matriz "af_shell8" - Speedup dos solvers.

Mais uma vez tem-se a curva de Speedup do solver PETSc muito distante das curvas dos solvers diretos, deixando evidente a questão da escalabilidade. Assim como no exemplo anterior a este, faz-se necessário uma observação mais especifica entre os dois solvers diretos, ilustrada na Figura 4.38.

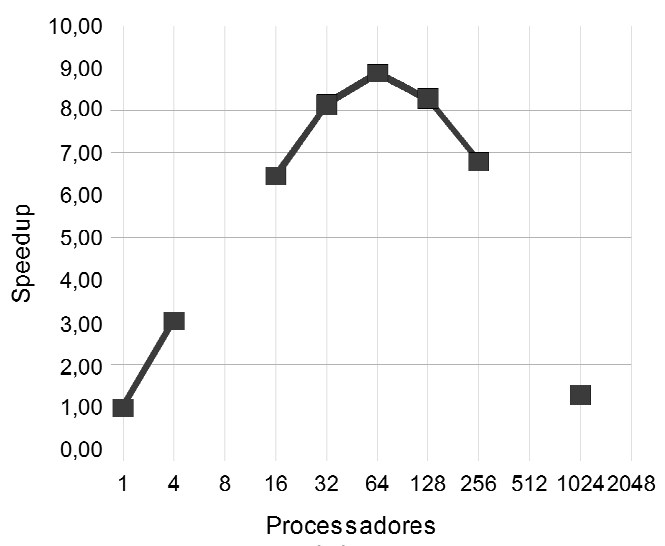

(a)

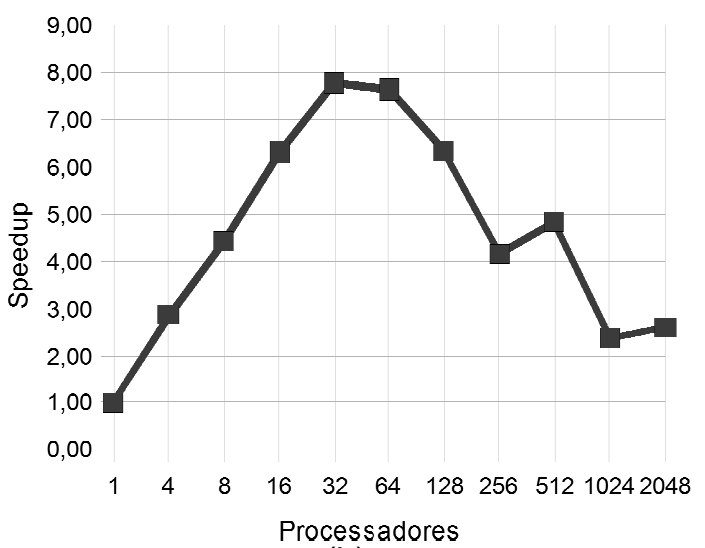

(b)

Figura 4.38 - Matriz "af_shell8" - Speedup do solvers: MUMPS (a) e SuperLU (b).

Observando a Figura 4.38 pode se notar que os testes do MUMPS com 8, 512 e 2048 processadores apresentaram falhas de software, fato já comentado anteriormente neste capítulo, porém é possível observar o comportamento da curva do solver, notando que ele segue o padrão das outras curvas vistas nos outros testes.

A curva do solver SuperLU apresenta uma certa discrepância nos testes com 512 e 2048 processadores, deixando a forma da curva um pouco diferente da maioria dos testes, assemelhando-se ao testes da matriz "ecology2". 
A Figura 4.39 ilustra as curvas de eficiência dos três solvers.

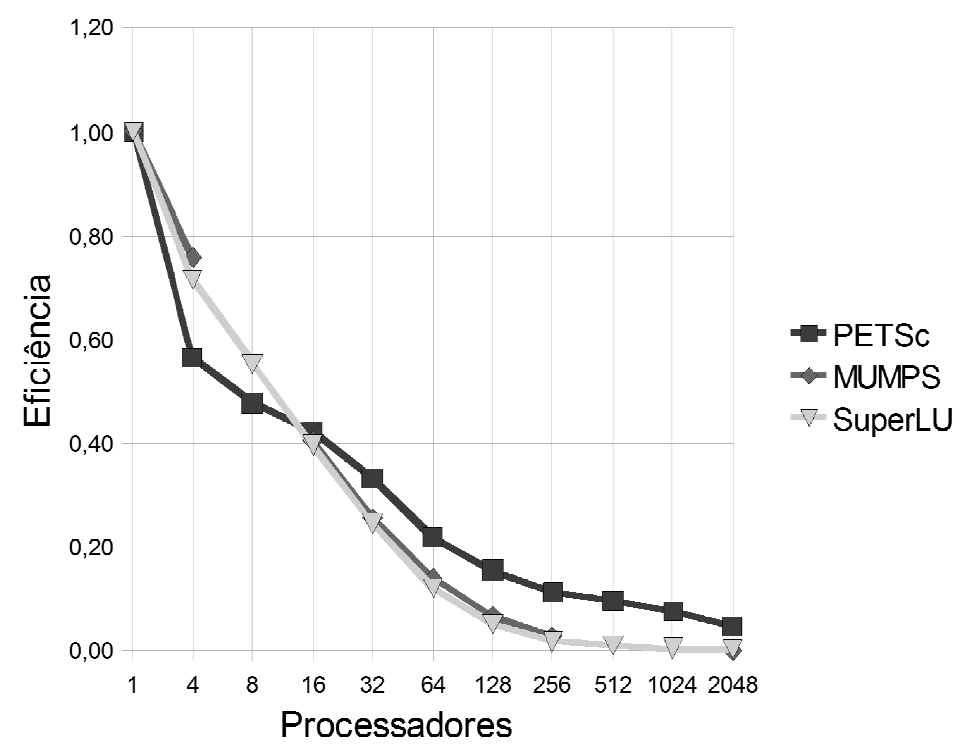

Figura 4.39 - Matriz "af_shell8" - Eficiência dos solvers.

Nesse caso, as três curvas de eficiência foram muito similares umas as outras, não ocorreu a estabilização da eficiência, com um valor considerável, por uma sequência de agrupamentos de processadores na curva do solver PETSc, fato que havia ocorrido anteriormente em diversos testes.

Mesmo assim, ainda é possível dizer que o solver iterativo PETSc tem uma eficiência maior do que os seus concorrentes diretos, MUMPS e SuperLU.

\subsubsection{Speedup e Eficiência - Matriz: tmt_sym}

Novamente exibidas as curvas de Speedup dos três solvers, agora para a matriz "tmt_sym", conforme pode ser observado na Figura 4.40. 


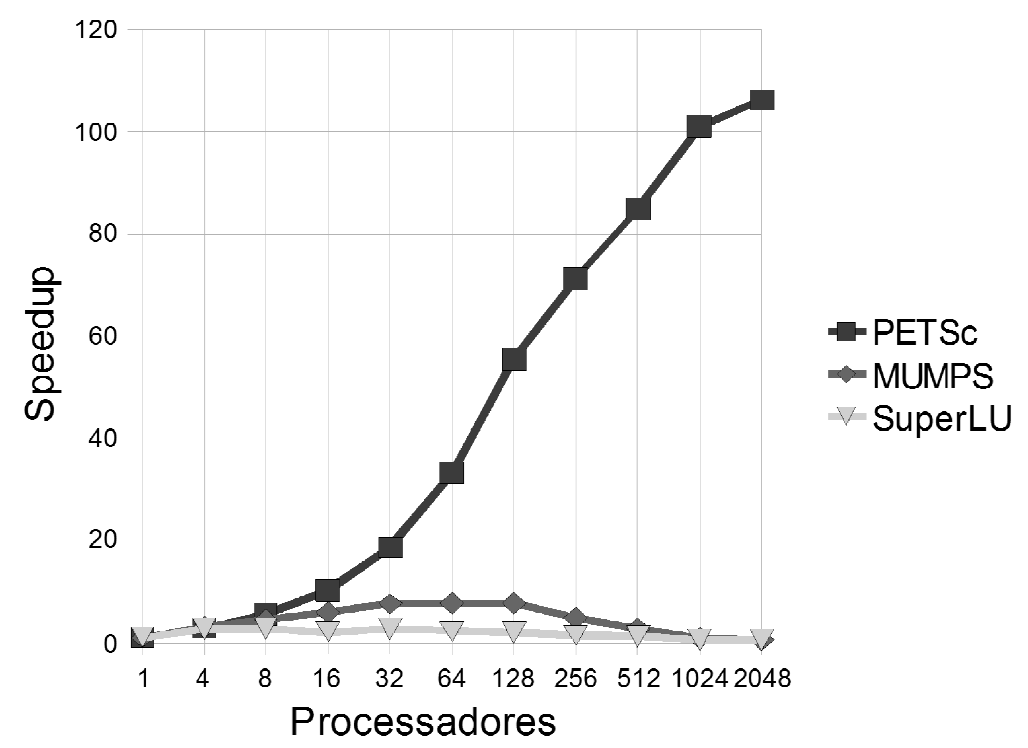

Figura 4.40 - Matriz "tmt_sym" - Speedup dos solvers.

Mais uma vez o comportamento dos três solvers seguiu o mesmo padrão, com o solver iterativo PETSc destacando-se pelos altos valores de Speedup, quando comparados aos valores de Speedup dos solvers diretos MUMPS e SuperLU.

Como prática adotada nos testes anteriores, observe as curvas de eficiência dos três solvers, ilustradas na Figura 4.41.

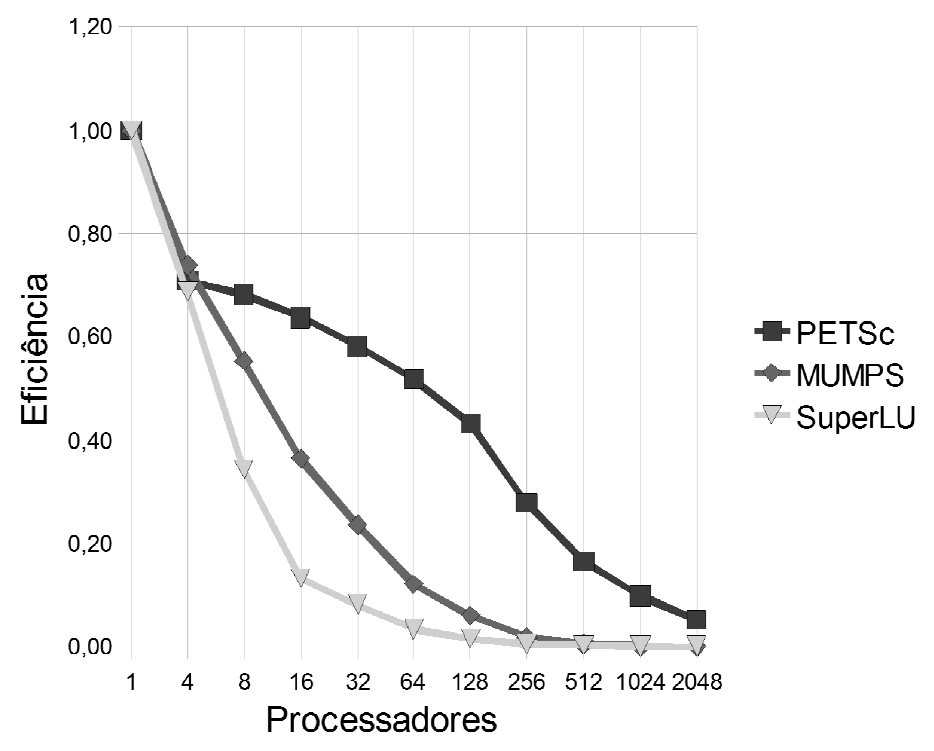

Figura 4.41 - Matriz "af_shell8" - Eficiência dos solvers.

As curvas de eficiência dos três solvers seguem um padrão já demonstrado em testes anteriores deste trabalho, onde ocorre uma estabilização do valor da eficiência do solver PETSc entre 0,50 e 0,60 nos testes de 16 a 128 processadores. 


\subsubsection{Speedup e Eficiência - Matriz: af_1_k101}

Os últimos testes de Speedup e eficiência foram realizados para a matriz "af_1_k101", assim como os testes de tempo dos processadores realizados em outro item deste mesmo capítulo.

Como era esperado, o comportamento para essa matriz foi bem diferente dos outros casos, conforme pode ser visto nas representações das curvas de Speedup da Figura 4.42.

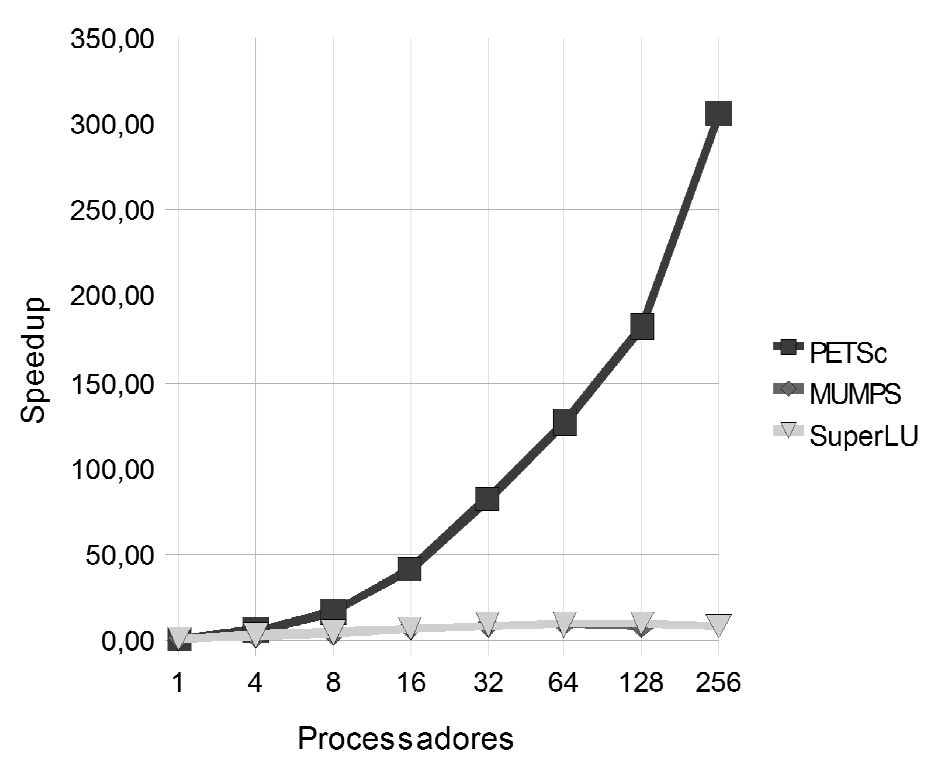

Figura 4.42 - Matriz "af_1_k101" - Speedup dos solvers.

Analisando as curvas de Speedup dos três solvers observa-se mais uma vez a distância dos valores de Speedup do solver PETSc para os solvers diretos, porém essa não é a principal questão a ser observada nesse gráfico.

Considerando os valores mais evidentes na figura, tome como ponto inicial de reflexão o teste com 16 processadores, que apresenta um Speedup de três vezes o esperado para um Speedup tradicional. Note que os valores passam da classificação de Speedup linear ou ideal, apresentando o que é denominado pela literatura de computação de alto desempenho, já mencionado anteriormente neste trabalho, de Speedup super linear.

Tal comportamento é raro, e pode ter ocorrido por diversos fatores, mais comumente por questões ligadas à arquitetura do computador, principalmente considerando os aspectos ligados à memória cache, como mencionado anteriormente. 
Nesse caso é difícil explicar o que ocorreu, pois o solver iterativo PETSc comportou-se dessa maneira somente neste teste.

Outra possibilidade a ser considerada é a maneira como os threads organizam-se [5], o que pode ter gerado tal comportamento, porém seria necessária uma análise mais profunda de questões de programação que compreendem, em um primeiro momento, tópicos ligados desde a concepção do sistema operacional até o desenvolvimento do próprio solver, não sendo em nenhum dos casos o escopo deste trabalho.

Observe a Figura 4.43, que ilustra a eficiência dos três solvers para este caso.

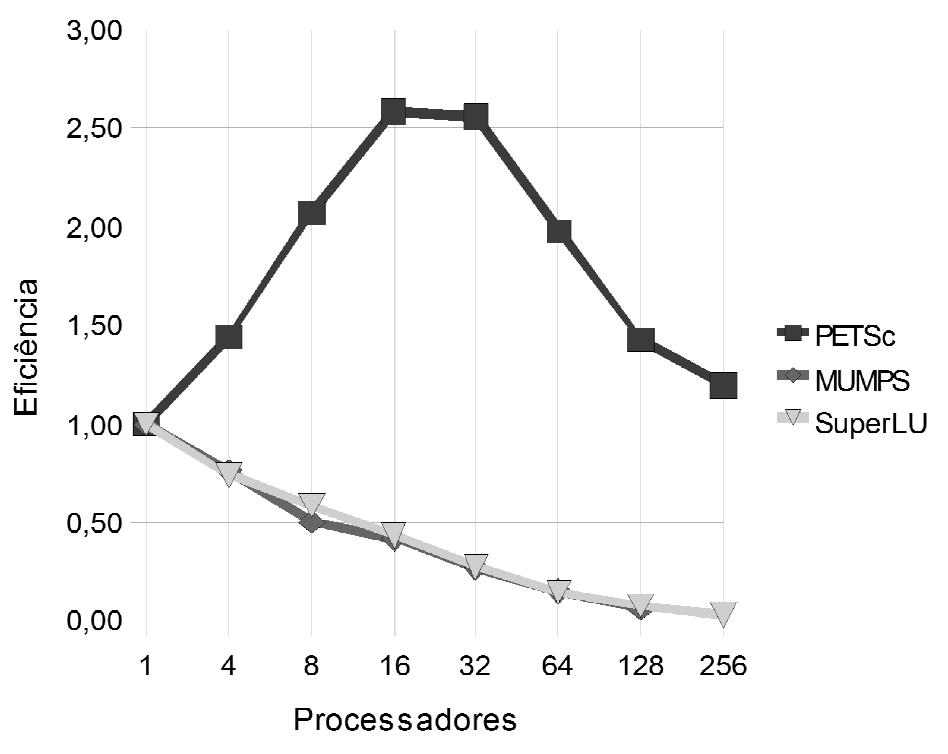

Figura 4.43 - Matriz "af_1_k101" - Eficiência dos solvers.

As curvas dos dois solvers diretos, MUMPS e SuperLU, apresentam um comportamento similar às curvas dos outros testes para esses mesmo solvers, porém o caso do solver iterativo PETSc é muito diferente dos outros.

Note que os valores iniciam-se no valor padrão inicial 1 e aumentam progressivamente até um valor em torno de 2,50, depois começam a diminuir, chegando a um valor aproximado de 1 no teste com 256 processadores.

A eficiência do solver PETSc para esse caso foi totalmente fora do padrão, atingindo valores atípicos e fora das expectativas dos testes de eficiência, que possuem valores geralmente compreendidos entre zero e um. 


\subsection{Testes de Volume MPI}

Baseando-se em alguns testes feitos por $\mathrm{Li}$ [23] e considerando-se o comportamento das rotinas MPI, foram planejados alguns testes similares, porém considerando a quantidade de tempo gasto com as rotinas MPI.

Note que esse tipo de avaliação permite verificar a questão da granularidade do código e sua escalabilidade.

Foram feitos testes para as matrizes principais do trabalho, utilizando o mesmo número de processadores dos testes realizados anteriormente.

Para realizar os procedimentos de medição das rotinas MPI, adotou-se o uso da ferramenta TAU [55], muito utilizado para instrumentar códigos que possuam rotinas MPI que precisam ser avaliadas de alguma forma.

Os testes realizados na pesquisa têm como objetivo verificar a porcentagem de tempo do código gasto com rotinas MPI e, neste trabalho, esse tipo de teste receberá a denominação de volume $\mathrm{MPI}$.

\subsubsection{Volume MPI - Matriz: parabolic_fem}

A primeira matriz que terá o volume de comunicação MPI medido é a "parabolic_fem", como pode ser observado na Figura 4.44.

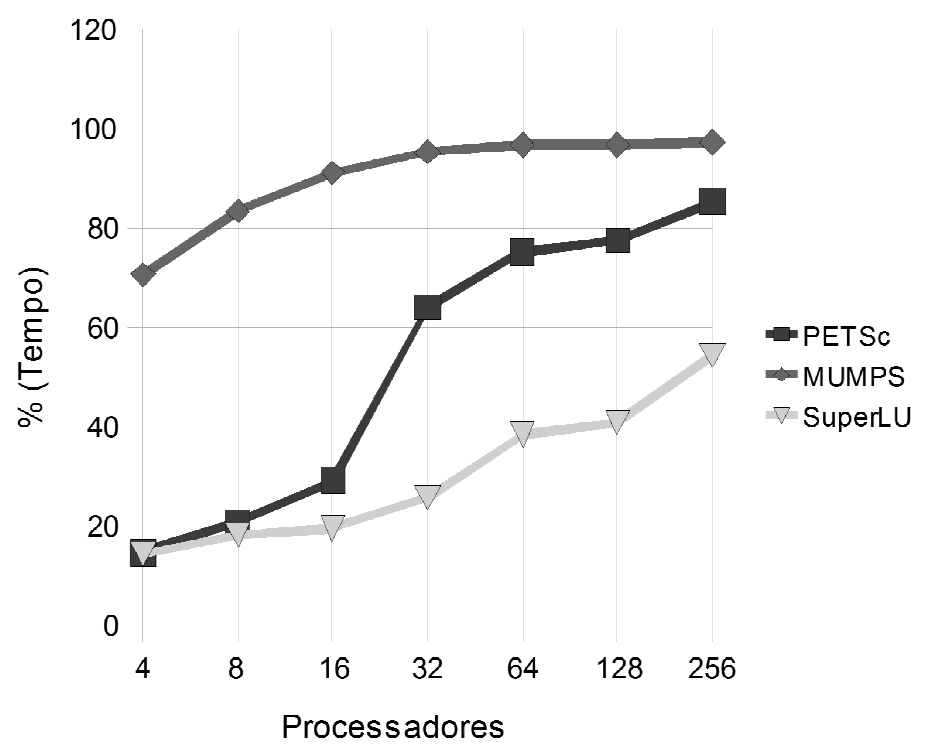

Figura 4.44 - Matriz "parabolic_fem" - Volume MPI.

Considerando a figura anterior, como pode ser notada na curva do solver direto MUMPS, a comunicação MPI é constante, demonstrando à baixa 
escalabidade do código, pois a granularidade do algoritmo é denominada fina. Nos testes com 32 processadores em diante, a comunicação mantêm-se em torno de $95 \%$.

Diferentemente do solver direto, o solver iterativo PETSc possui um algoritmo altamente escalável, a comunicação MPI é proporcional ao aumento do número de processadores, mostrando que o código possui granularidade denominada grossa, com diversos cômputos isolados.

O solver direto SuperLU possui um código também considerado escalável, aparentando existir um grande aproveitamento dos recursos locais da máquina, evitando a comunicação na rede. A questão, já comentada anteriormente, é que esse solver não é o ideal para as matrizes selecionadas para este trabalho.

\subsubsection{Volume MPI - Matriz: G3_circuit}

Considerando agora a matriz "G3_circuit, foi criada a Figura 4.45, com as curvas dos solvers utilizados neste trabalho.

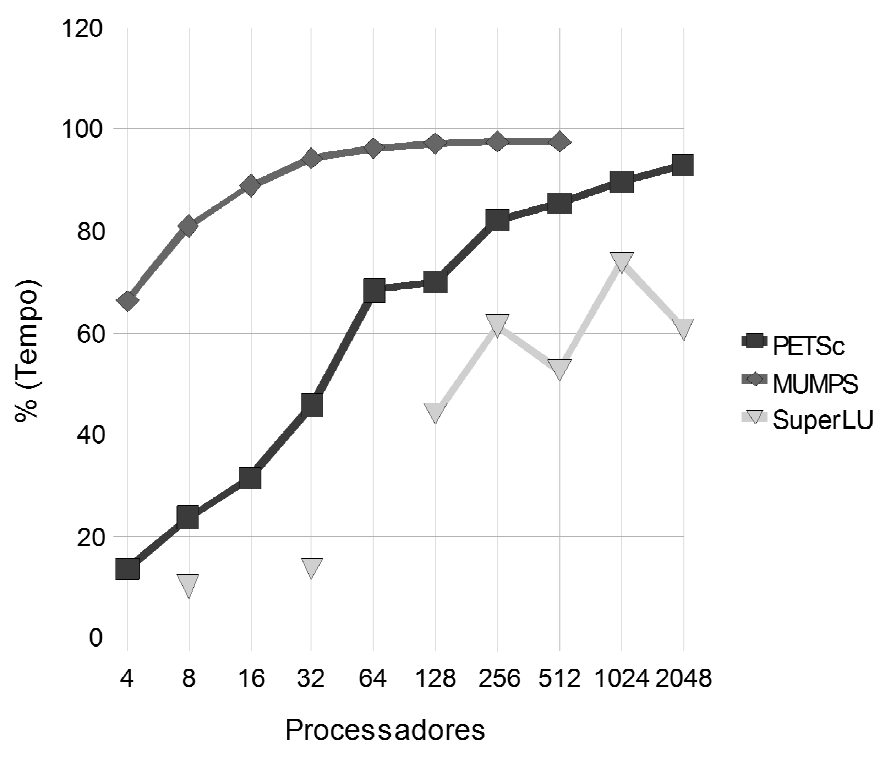

Figura 4.45 - Matriz "G3_circuit" - Volume MPI.

Para essa matriz foi utilizado um número maior de processadores, por conta da compatibilidade do solver direto MUMPS com tal volume de dados, fato discutido anteriormente neste mesmo capítulo tal fato.

O comportamento dos solvers PETSc e MUMPS demonstra ser parecido nos testes a partir de 256 processadores, ambos tendo um volume de rotinas MPI muito similar, provavelmente por não ser este um problema grande e então a 
granularidade do algoritmo torna-se mais fina.

O solver direto SuperLU demonstrou instabilidade nos testes com essa matriz, mostrando um uso de rotinas MPI sem um padrão bem definido, além do que não foi possível a realização dos testes com 4, 16 e 64 processadores, pelas razões discutidas anteriormente.

Lembre-se também que o solver direto MUMPS não conseguiu executar os testes com 1024 e 2048 processadores para essa matriz, fato também já explicado anteriormente neste mesmo capítulo.

\subsubsection{Volume MPI - Matriz: thermal2}

Para a matriz "thermal2", foram também utilizados agrupamentos maiores de processadores, como pode ser visto na Figura 4.46.

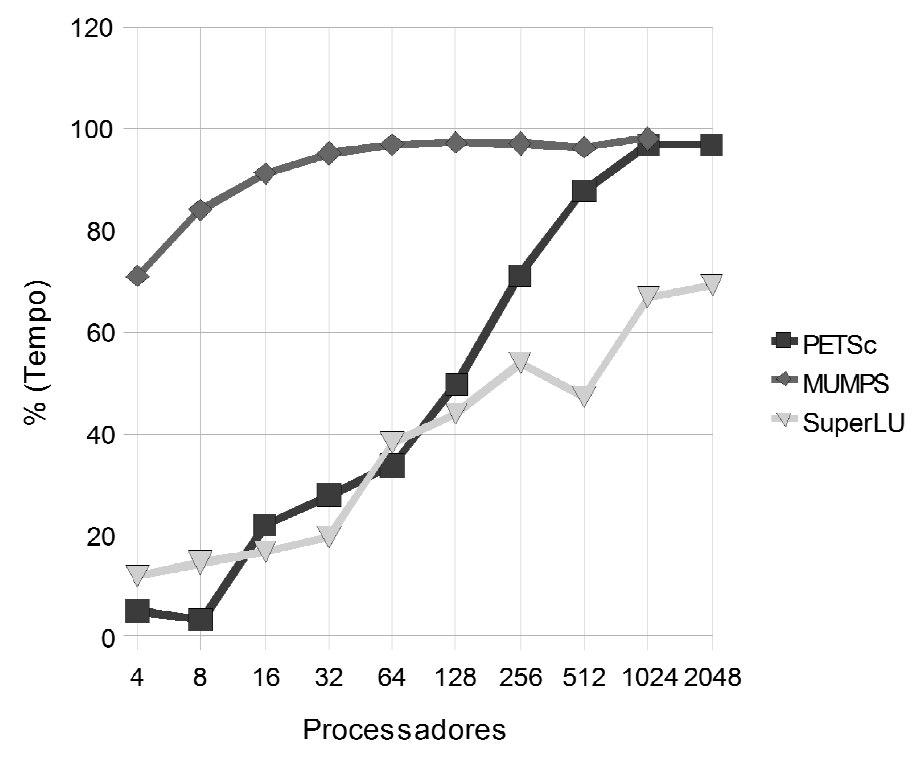

Figura 4.46 - Matriz "thermal2" - Volume MPI.

Para a matriz "thermal2", o solver iterativo PETSc mostrou-se mais escalável do que o exemplo anterior. Também teve a sua comunicação elevada, tal qual o solver MUMPS, nos testes a partir de 1024 processadores.

Um fato interessante e incomum também ocorreu com o solver iterativo PETSc, na situação do teste com 8 processadores do solver iterativo, tendo um volume MPI inferior ao teste com 4 processadores.

Com relação ao solver direto SuperLU, esse demonstrou uma escalabilidade muito maior do que a ocorrida com a matriz do exemplo anterior, além de um comportamento mais constante. 


\subsubsection{Volume MPI - Matriz: ecology2}

Seguindo o modelo dos testes anteriores, o volume de rotinas MPI para a matriz "ecology2" também foi gerado, como pode ser observado na Figura 4.47.

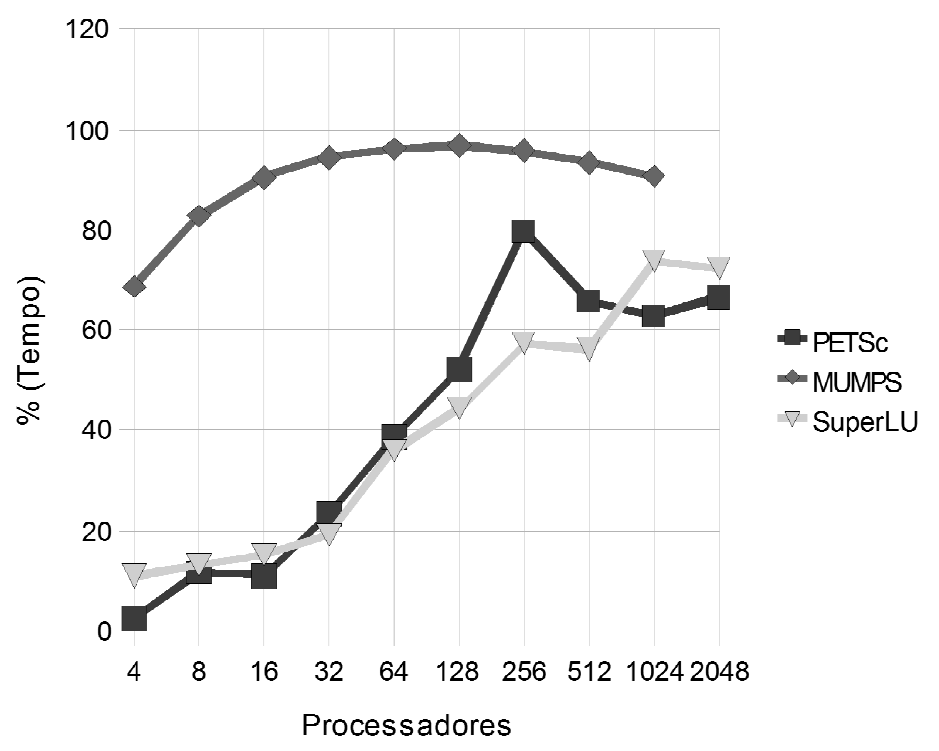

Figura 4.47 - Matriz "ecology2" - Volume MPI.

O solver direto MUMPS demonstrou o mesmo comportamento padrão esperado, diferente apenas pelo fato dos testes com agrupamentos a partir de 256 processadores diminuírem a quantidade de tempo gasto com rotinas MPI.

O solver iterativo PETSc mostrou o desempenho já esperado, porém, com 512 processadores começou a diminuir a comunicação MPI e estabilizou-se com relação ao volume MPI até os testes com 2048 processadores.

Observando a Figura 4.47, nota-se que o solver direto SuperLU comportou-se de forma muito semelhante ao solver iterativo PETSc, mas o fato de ter um comportamento de volume de rotinas MPI muito parecido, não indica que os tempos, speedup ou eficiência serão próximos.

\subsubsection{Volume MPI - Matriz: apache2}

A Figura 4.48 representa as curvas de volume MPI dos três solvers, com relação à matriz "apache2". 


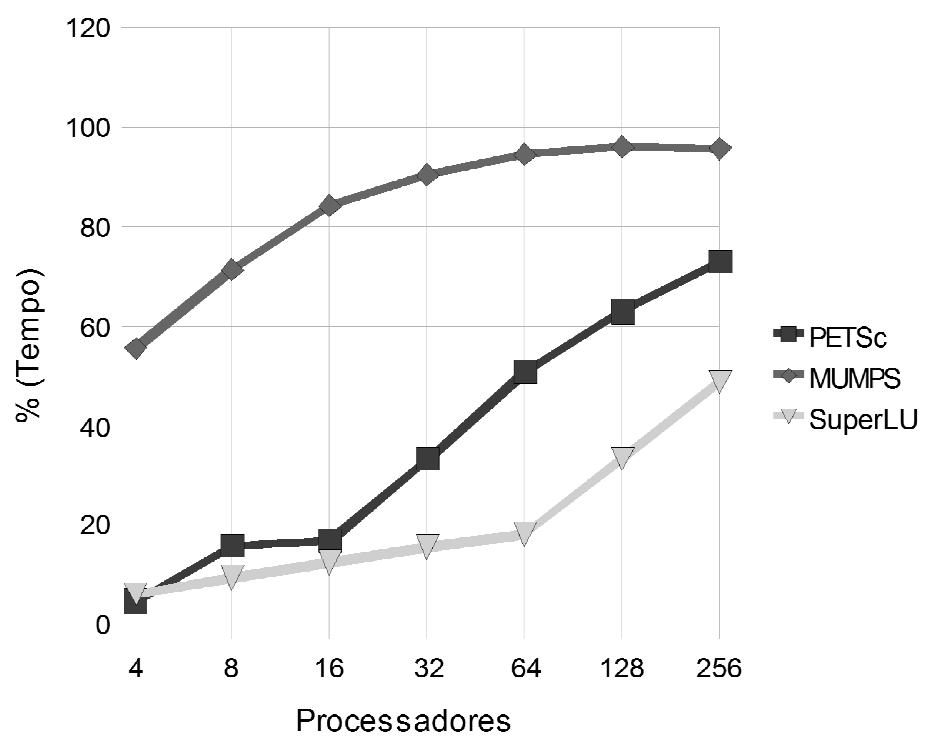

Figura 4.48 - Matriz "apache2" - Volume MPI.

Note que, também como nos outros testes, o solver direto MUMPS teve um comportamento com um grande volume de rotinas MPI. O solver iterativo PETSc mostrou mais uma vez que possui grande escalabilidade. O solver direto SuperLU mostrou mais uma vez sua escalabilidade, não tão alta quanto à do PETSc, porém muito mais escalável do que o MUMPS.

Para os testes dessa matriz, foram usados somente agrupamentos máximos de 256 processadores, por questões ocorridas com o solver MUMPS, já explicadas anteriormente neste trabalho.

\subsubsection{Volume MPI - Matriz: af_shell8}

O próximo teste com comportamento de volume de rotinas MPI ilustrado foi realizado com a matriz "af_shell8" e pode ser observado na Figura 4.49. 


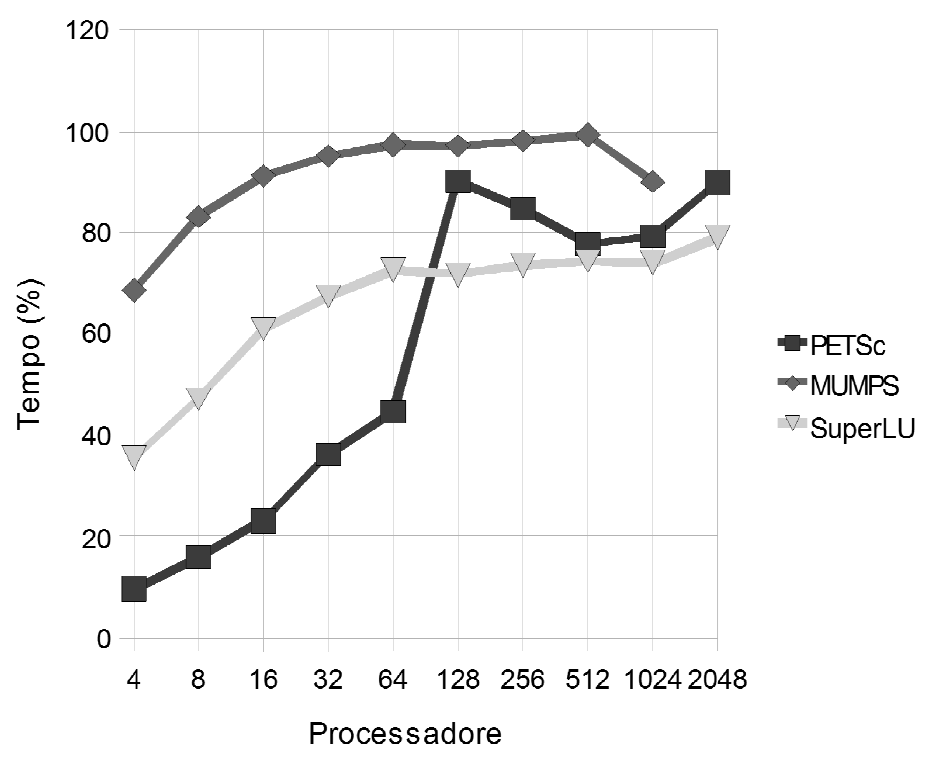

Figura 4.49 - Matriz "af_shell8" - Volume MPI.

Para esse caso, os solvers diretos MUMPS e SuperLU tiveram um comportamento similar, ilustrados por suas respectivas curvas. O MUMPS iniciou seus testes com volume em torno de $65 \%$ e depois se estabilizou com valores em torno de $90 \%$, nos testes a partir de 32 processadores. O solver SuperLU iniciou seus testes com volume em torno de $40 \%$ e posteriormente se estabilizou com valores em torno de $70 \%$, nos testes a partir de 32 processadores.

O solver iterativo PETSc mostrou mais uma vez a sua granularidade grossa, com extrema escalabilidade, ficando evidente na comparação do volume de dados dos testes com 64 e 128 processadores. Depois disso o algoritmo diminui sua comunicação de dados, tendo aumentado novamente nos testes com 2048 processadores.

\subsubsection{Volume MPI - Matriz: tmt_sym}

A próxima matriz analisada, denominada "tmt_sym", teve um comportamento muito similar ao dos outros testes, como pode ser observado na Figura 4.50, mais uma vez com as curvas de volume de rotinas MPI dos três solvers. 


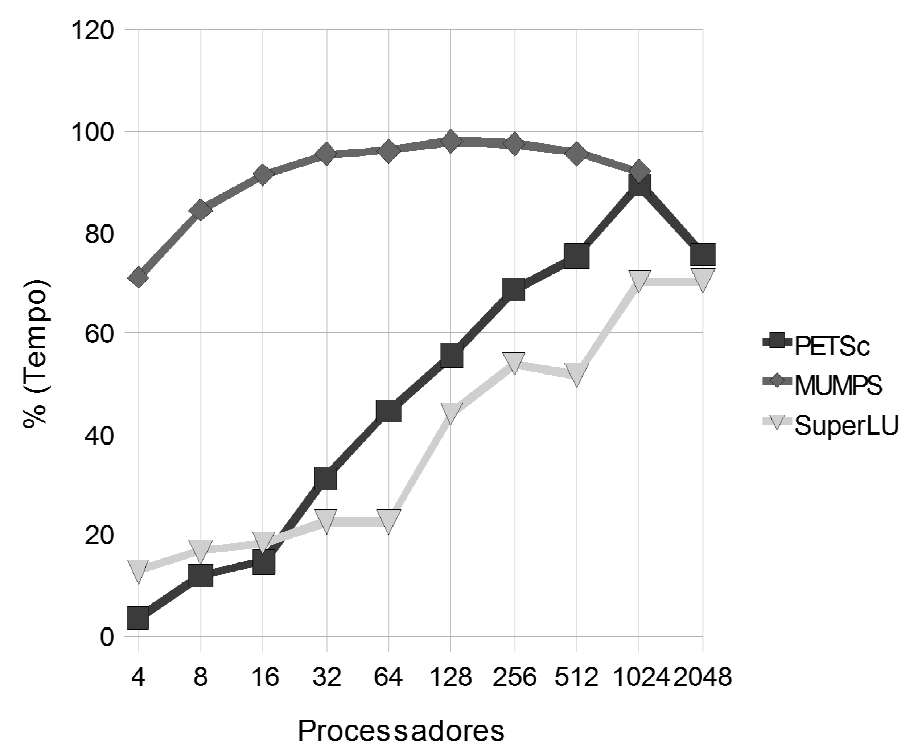

Figura 4.50 - Matriz "tmt_sym" - Volume MPI.

O comportamento do solver MUMPS foi o mesmo já visto anteriormente, sempre com uma porcentagem elevada do tempo gasto com as rotinas MPI, sendo que, nos testes com 2048 processadores, os testes a partir de 512 processadores tendem a diminuir a porcentagem de tempo gasto.

Assim como nos testes com a matriz "ecology2", os solvers PETSc e SuperLU mostraram um comportamento similar, sendo que o SuperLU gastou um pouco menos de tempo com as rotinas MPI do que o PETSc.

\subsubsection{Volume MPI - Matriz: af_1_k101}

O último teste realizado foi com a matriz "af_1_k101", que demonstrou resultados bem distintos das demais matrizes deste texto, como pode ser notados nos itens de testes anteriores deste mesmo capítulo.

Observe a Figura 4.51, mais uma vez, ilustrando as curvas de volume de dados MPI dos três solvers utilizados nesta pesquisa. 


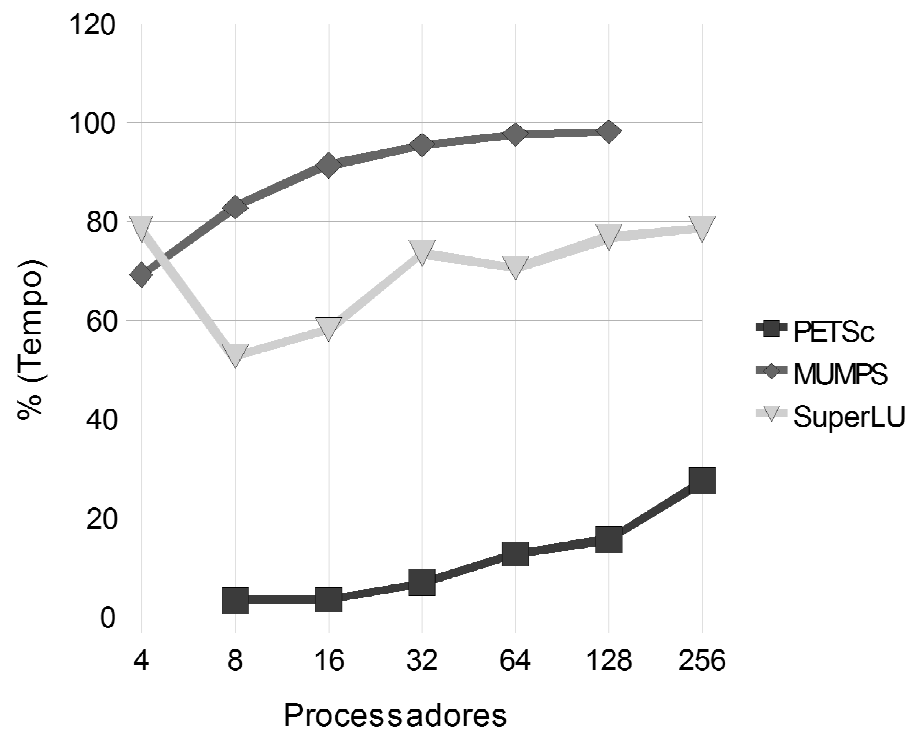

Figura 4.51 - Matriz "af_1_k101" - Volume MPI.

Esse caso precisa ser visto com cuidado, pois o comportamento dos solvers é muito diferente dos outros casos, exceto pelo MUMPS, que por todos os resultados obtidos até esse ponto deixou evidente seu comportamento homogêneo.

Com relação ao solver direto SuperLU, este apresentou volume de rotinas MPI elevado, e estabilizado em torno de $75 \%$ de tempo gasto com tais rotinas nos testes a partir de 32 processadores.

O solver PETSc mostrou uma baixíssima comunicação MPI, a granularidade de seu código pode ser considerada como extremamente fina, pois quase não foi possível notar a escalabilidade de seu algoritmo, por isso o tempo de resolução nesses casos ficou tão diferente dos demais testes.

\subsection{Testes de Rotinas MPI}

Prosseguindo com os testes relacionados ao comportamento MPI [23], foram feitos mais algumas comparações, considerando as três principais rotinas MPI que cada solver utiliza.

A Tabela 4.23 possui o nome das três rotinas mais utilizadas por cada solver, considerando o tempo gasto com cada uma delas. 
Tabela 4.23 - Principais rotinas MPI utilizadas por cada solver.

\begin{tabular}{|l|l|l|l|}
\hline Solver / Rotina & Rotina MPI 1 & Rotina MPI 2 & Rotina MPI 3 \\
\hline MUMPS & MPI_Bcast & MPI_Allreduce & MPI_Recv \\
\hline SuperLU & MPI_Bcast & MPI_Wait & MPI_Recv \\
\hline PETSc & MPI_Barrier & MPI_Allreduce & MPI_Recv \\
\hline
\end{tabular}

As figuras seguintes irão ilustrar a porcentagem de tempo gasta com cada uma das três respectivas rotinas de cada solver, considerando o tempo total de processamento de cada teste.

Mais uma vez o TAU [55] foi utilizado para realizar os procedimentos de medição das rotinas $\mathrm{MPI}$, como feito no item anterior a esse.

\subsubsection{Rotinas MPI - Matriz: parabolic_fem}

Considere agora a matriz "parabolic_fem" para os testes de medição das rotinas MPI utilizadas para o solver MUMPS, como pode ser observado na Figura 4.52 .

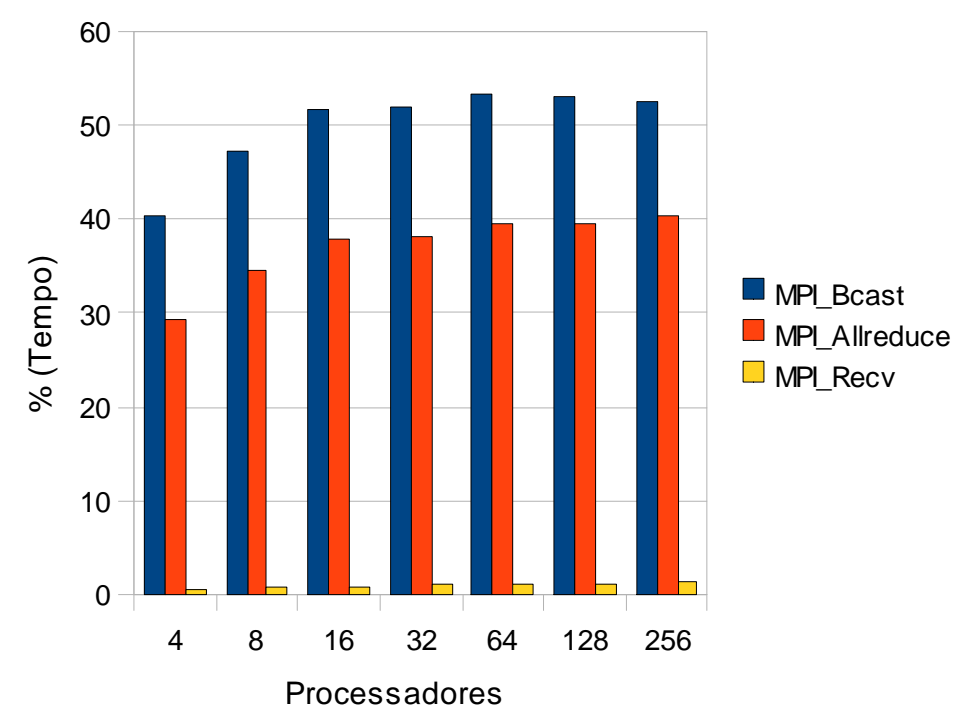

Figura 4.52 - Matriz "parabolic_fem" - Rotinas MPI do MUMPS.

Note que o solver MUMPS utiliza inicialmente $40 \%$ do tempo de processamento com a rotina MPI_Bcast, no teste com 4 processadores, aumentando progressivamente até pouco mais de 50\% no teste com 256 processadores. A rotina MPI_Allreduce também aumenta progressivamente o uso do tempo de processamento, inicialmente com 4 processadores, consumindo em torno de $30 \%$ do tempo total, e com 256 processadores em torno de $40 \%$. A rotina MPI_Recv mantém-se estável em torno de 1\% a 3\% nos testes realizados. 
$\mathrm{Na}$ figura anterior, fica evidente o excesso de tempo gasto pelas rotinas MPI_Bcast e MPI_Allreduce, que influenciam muito na performance do solver, pois tais rotina, geralmente, realizam a comunicação com todos os nós envolvidos no processamento, o que tende a influenciar negativamente na escalabilidade [56].

Observe agora a Figura 4.53, ilustrando os testes de rotinas MPI para o solver SuperLU.

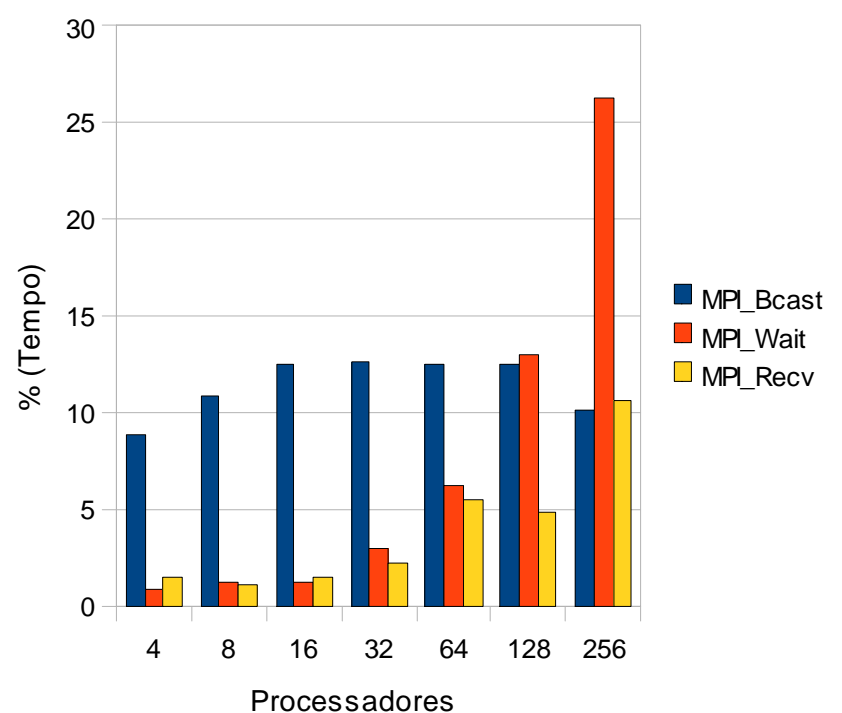

Figura 4.53 - Matriz "parabolic_fem" - Rotinas MPI do SuperLU.

Note que o solver SuperLU utiliza inicialmente pouco menos de $10 \%$ do tempo com a rotina MPI_Bcast, no teste com 4 processadores, aumentando progressivamente até $13 \%$ do tempo aproximadamente nos testes de 16 a 128 processadores, decaindo para $10 \%$ no teste final, com 256 processadores. A rotina MPI_Wait, inicialmente utilizando em torno de $2 \%$ do tempo de processamento com 4 processadores, também aumenta o consumo de tempo, chegando a mais de $10 \%$ do tempo no teste com 256 processadores. A rotina MPI_Recv consumia inicialmente em torno de $1 \%$ do tempo no teste com 4 processadores, porém no último teste, com 256 processadores, aumentou desproporcionalmente o uso do tempo, chegando a mais de $25 \%$ de consumo. Esse último teste serviu para mostrar que, para esse problema, o número de 256 processadores é desnecessário, sendo gasto um tempo desproporcional com a rotina MPI_Recv, considerando-se os testes anteriores do mesmo solver.

Nos testes demonstrados pela última figura, a rotina MPI_Bcast mostrou não gastar mais do que $13 \%$ do tempo, algo tolerável e que influencia positivamente na escalabilidade do solver, porém, no teste com 256 processadores, a rotina MPI_Wait 
consumiu muito tempo, em torno de $25 \%$ do total, e é uma rotina que também influencia na escalabilidade.

Como último teste para essa matriz, considere o solver PETSc e suas três rotinas MPI mais utilizadas, como pode ser visto na Figura 4.54.

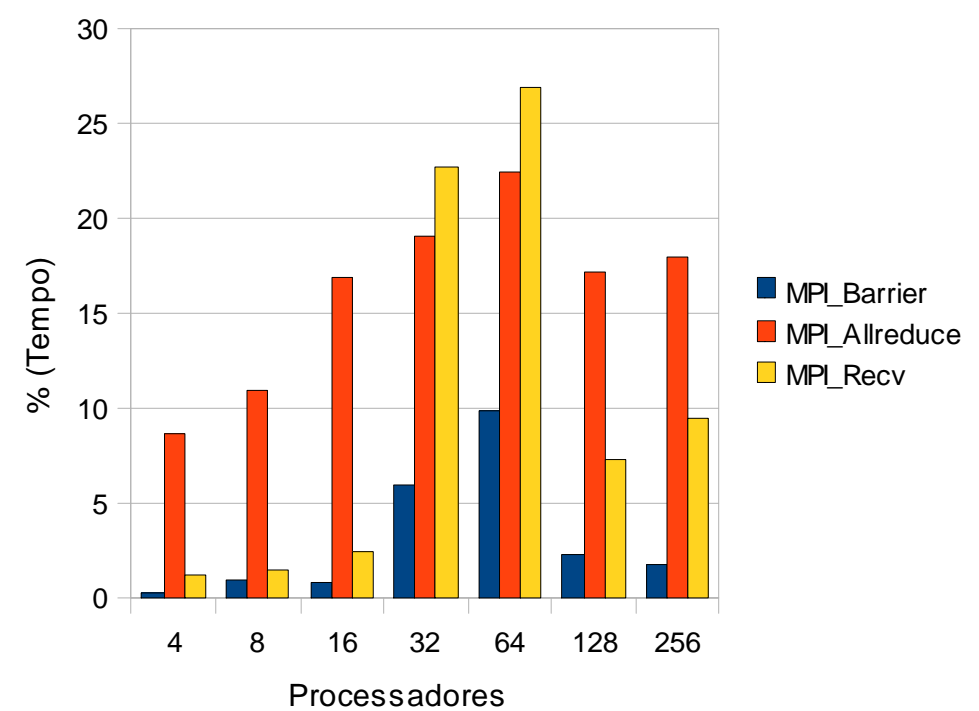

Figura 4.54 - Matriz "parabolic_fem" - Rotinas MPI do PETSc.

Observando os testes realizados com o PETSc, pode-se notar que o comportamento desse solver, considerando o uso das rotinas MPI, é pouco homogêneo. A rotina MPI_Barrier começa com um consumo de tempo no teste com 4 processadores pouco expressivo, com um valor menor do que $1 \%$, mas nos testes com 32 e 64, por exemplo, aumenta expressivamente o consumo do tempo. A rotina MPI_Allreduce inicia consumindo em torno de 8\% no primeiro teste com 4 processadores, porém chega a consumir em torno de $22 \%$ do tempo no teste com 64 processadores. A rotina MPI_Recv, similarmente a MPI_Barrier, inicia os testes com um consumo em torno de $1 \%$, mas chega a consumir em torno de $25 \%$ do tempo no teste com 64 processadores. O solver mostrou alta escalabilidade, adaptando-se positivamente à situação, pois o tempo começa a diminuir nos testes com 128 processadores, mostrando que não era mais necessária a quantidade de comunicação MPI que ocorreu no teste com 64 processadores, demonstrando ser 0 teste em que mais tempo foi gasto com rotinas MPI.

A rotina do solver PETSc que consome mais tempo em boa parte dos testes realizados é a rotina MPI_Allreduce, que pode influenciar negativamente em sua performance, dificultando a escalabilidade, porém ela não consome mais do que 
$22 \%$ do tempo total no teste com 64 processadores, mas nos outros testes, acaba consumindo em média somente $15 \%$ do tempo total.

\subsubsection{Rotinas MPI - Matriz: G3_circuit}

Nesse teste será considerada a matriz "G3_circuit", realizando a medição das rotinas MPI do solver MUMPS (Figura 4.55).

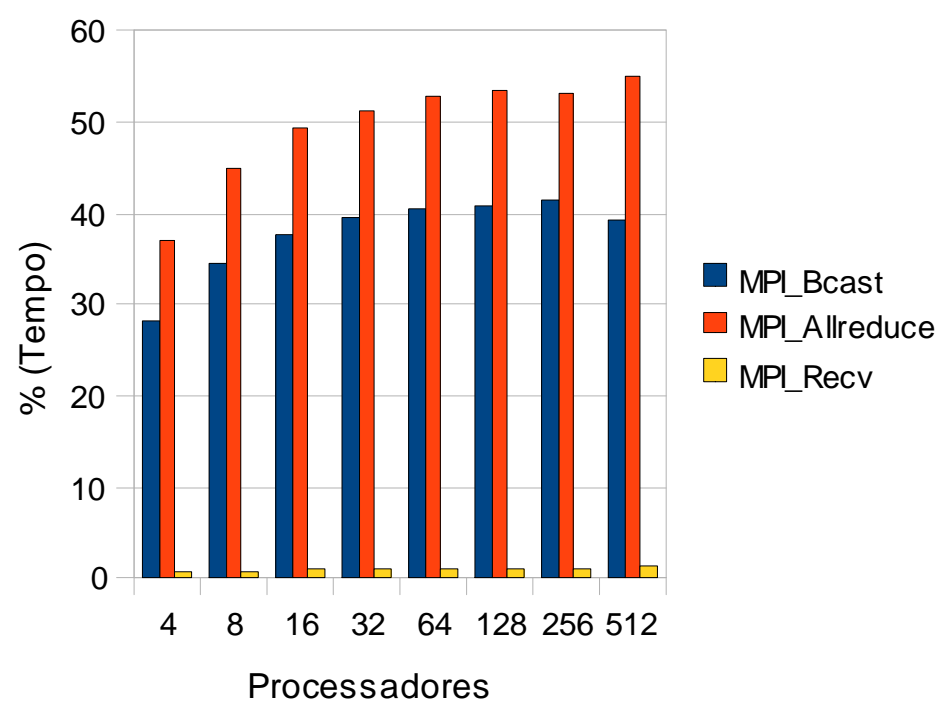

Figura 4.55 - Matriz "G3_circuit" - Rotinas MPI do MUMPS.

O comportamento do solver MUMPS é muito similar com o aumento do número de processadores, como pode ser notado na figura anterior. Com relação as rotinas, MPI_Bcast começa com um consumo de $30 \%$ do tempo de processamento no teste com 4 processadores e aumenta progressivamente até valores em torno de $40 \%$ nos testes com 32, 64, 128, 256 e 512 processadores. A rotina MPI_Allreduce também aumenta o consumo do tempo de processamento, com um tempo inicial um pouco menor do que $40 \%$ com 4 processadores, atingindo mais de $50 \%$ do tempo no teste com 512 processadores. Já a rotina MPI_Recv mantém o consumo em torno de $1 \%$ desde o primeiro teste com 4 processadores até o último teste com 512 processadores.

Com relação à escalabilidade, cabem os mesmos comentários dos testes com a matriz do item anterior, o excesso de tempo gasto com as rotinas MPI_Bcast e MPI_Allreduce pode prejudicar a escalabilidade do código.

O próximo teste contempla o solver SuperLU e aborda a quantidade de rotinas MPI para a matriz "G3_circuit”, como pode ser visto na Figura 4.56. 


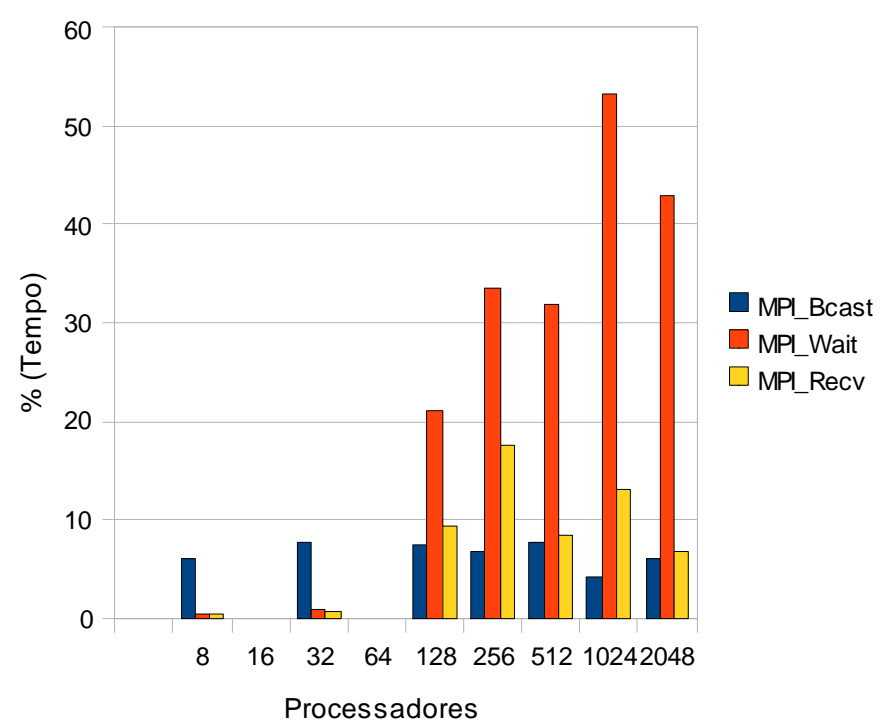

Figura 4.56 - Matriz "G3_circuit" - Rotinas MPI do SuperLU.

Como pode ser notado na figura anterior, os testes com o solver SuperLU não funcionaram com 4, 16 e 64 processadores, fato já comentado anteriormente neste mesmo trabalho. Além disso no teste com 8 e 32 processadores, a comunicação MPI é muito pequena, aparentemente o paralelismo mostrou-se pouco eficiente, ainda assim os problemas couberam na memória principal. A rotina MPI_Bcast mostrou-se estável, consumindo em torno de pouco menos de $10 \%$ do tempo de execução com 8 processadores. A rotina MPI_Wait iniciou com $20 \%$ de consumo do tempo total com 128 processadores e chegou ao consumo máximo de tempo de pouco mais de $50 \%$ com 1024 processadores, desconsiderando os tempos com $8 \mathrm{e}$ 32 processadores. A rotina MPI_Recv iniciou com menos de $1 \%$ no teste com 8 processadores e chegou a um pico de quase $20 \%$ no teste com 256 processadores.

O solver SuperLU mostrou mais adaptabilidade à estrutura da matriz, pois 0 comportamento das rotinas MPI mudou, comparando-se com o teste anterior, porém muito tempo foi gasto com a rotina MPI_Wait, o que pode influenciar negativamente na escalabilidade.

A Figura 4.57 ilustra os testes de rotinas MPI para o solver PETSc. 


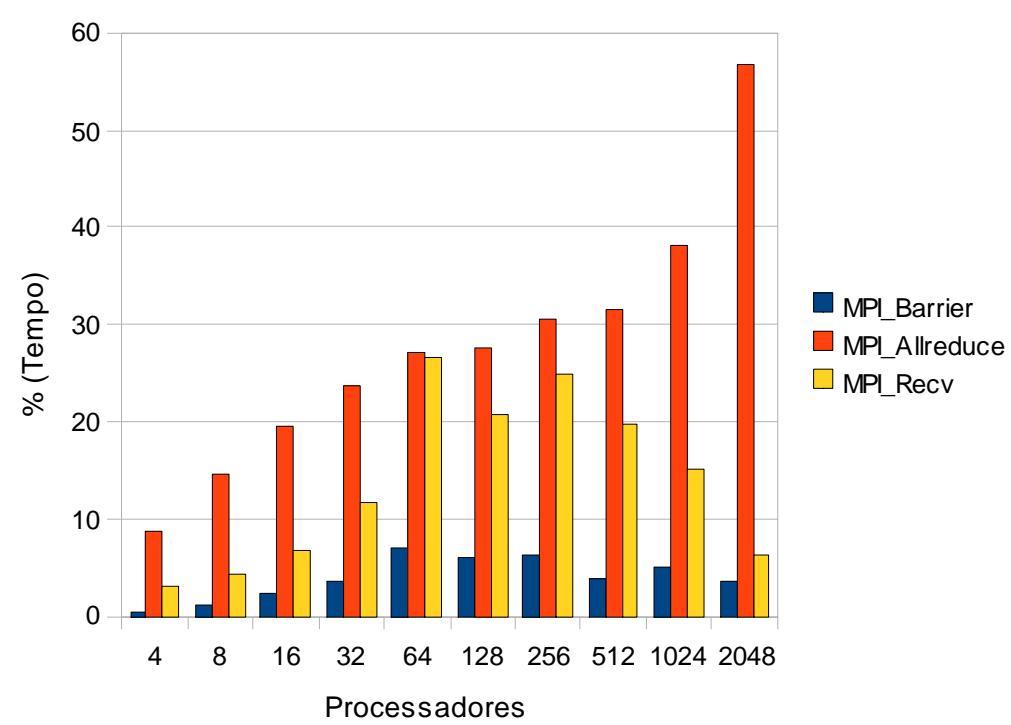

Figura 4.57 - Matriz "G3_circuit" - Rotinas MPI do PETSc.

O solver PETSc mais uma vez ilustra um comportamento heterogêneo, indicando sua escalabilidade. A rotina MPI_Barrier inicia com um consumo de tempo em torno de $1 \%$ no teste com 4 processadores e atinge o seu pico em torno de $6 \%$ no teste com 64 processadores. A rotina MPI_Allreduce inicia com consumo de tempo um pouco menor de $10 \%$ no teste com 4 processadores e, com uma curva crescente, atinge o pico de quase $60 \%$ de consumo do tempo no teste com 2048 proecessadores. A rotina MPI_Recv inicia com um consumo em torno de $3 \%$ no teste com 4 processadores e atinge seu tempo máximo em torno de $27 \%$ no teste com 64 processadores.

Muito similiar ao comportamento obtido no teste com a matriz "parabolic_fem", o solver PETSc, apesar da escalabidade característica dos solvers iterativos, tente a aumentar muito o tempo gasto com a rotina MPI_Allreduce, chegando a quase 60\% no teste com 2048 processadores, o que influenciou negativamente, ao menos para esse caso, a escalabilidade do solver.

\subsubsection{Rotinas MPI - Matriz: thermal2}

Considere agora a matriz "thermal2", partindo para a Figura 4.58, que ilustra o comportamento das rotinas MPI no solver MUMPS. 


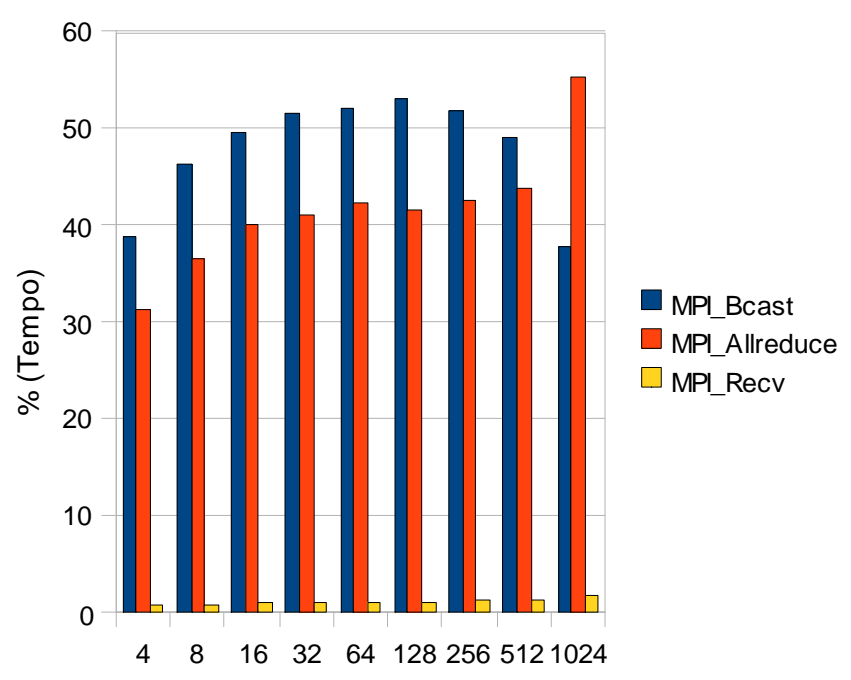

Figura 4.58 - Matriz "thermal2" - Rotinas MPI do MUMPS.

Considerando a figura anterior, pode-se observar um comportamento muito similar do solver MUMPS para os testes com a matriz "thermal2". A rotina MPI_Bcast obteve um valor máximo de aproximadamente $53 \%$ de consumo de tempo no teste com 128 processadores. A rotina MPI_Allreduce obteve um valor de aproximadamente 55\% no teste com 1024 processadores. A rotina MPI_Recv manteve-se estável, consumindo não mais do que $3 \%$ do tempo total de processamento.

Os comentários sobre escalabilidade feitos nos testes anteriores também aplicam-se aos testes com a matriz "thermal2".

A próxima figura (Figura 4.59) ilustra o comportamento das rotinas MPI para o solver SuperLU.

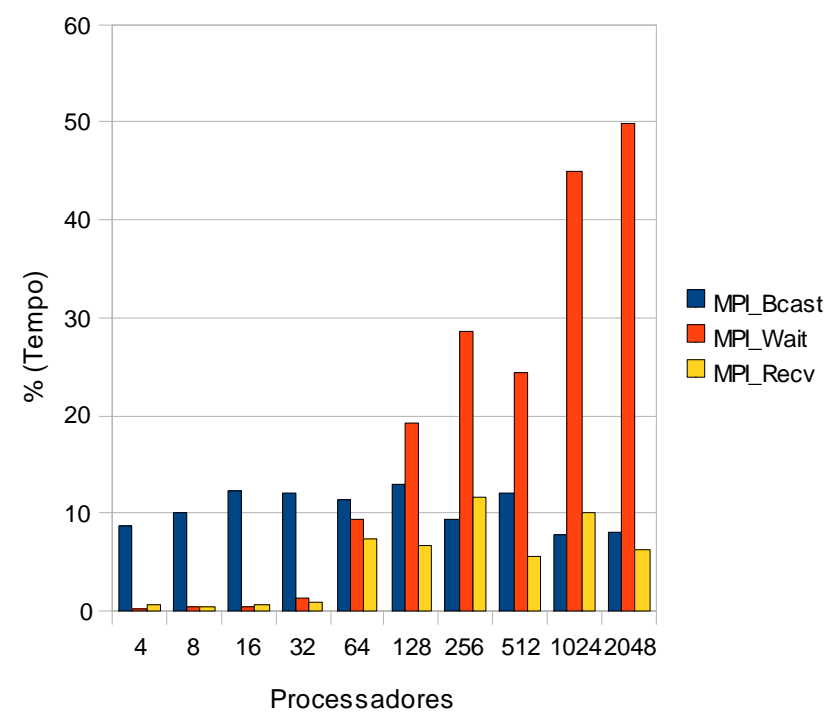

Figura 4.59 - Matriz "thermal2" - Rotinas MPI do SuperLU. 
Note que o solver SuperLU teve um comportamento similar aos testes com a matriz "G3_circuit". A rotina MPI_Bcast não passou de 12\% de tempo consumido no teste com 128 processadores. A rotina MPI_Wait atingiu um pico de $50 \%$ no teste com 2048 processadores. A rotina MPI_Recv não passou de $11 \%$ de consumo do tempo. A escalabilidade mostrou-se similiar ao exemplo com a matriz "G3_circuit".

A Figura 4.60 ilustra o comportamento das rotinas MPI para o solver PETSc.

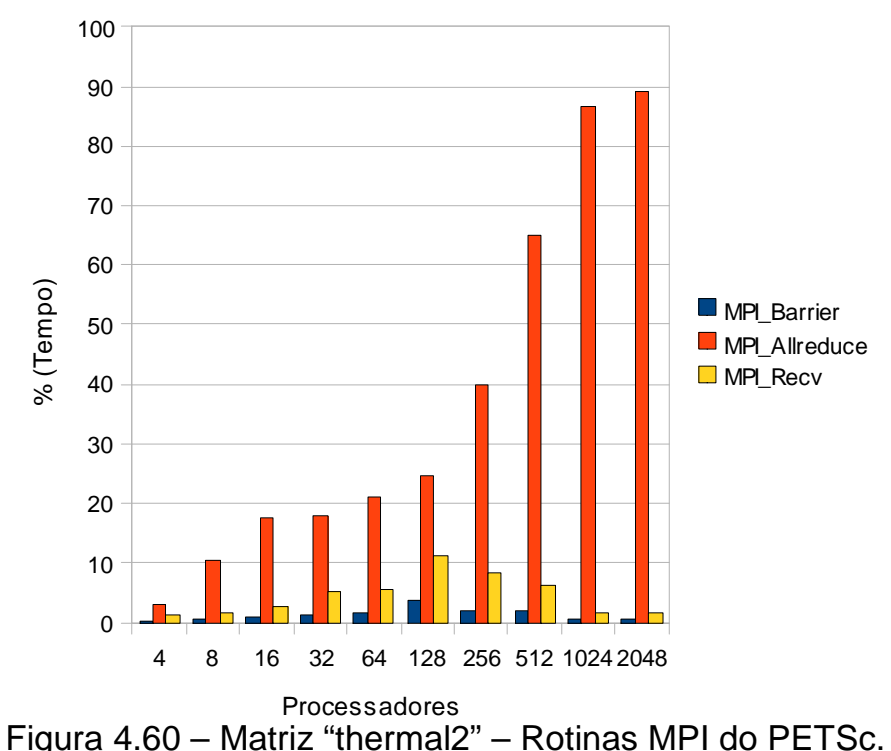

O solver PETSc mostrou um comportamento similiar ao teste com a matriz "G3_circuit". A rotina MPI_Barrier não passou de 3\% de consumo de tempo no teste com 128 processadores. A rotina MPI_Allreduce, por outro lado, atingiu $90 \%$ de consumo de tempo no teste com 2048 processadores. A rotina MPI_Recv não ultrapassou $11 \%$ de consumo de tempo, também no teste com 128 processadores.

O excesso de tempo gasto com a rotina MPI_Allreduce mostrou que, a partir de uma determinada quantidade de processadores [57], o paralelismo passa a não ter mais vantagem para esse caso, mesmo o algoritmo sendo altamente escalável. Essa questão já foi discutida anteriormente nos testes de speedup e eficiência.

\subsubsection{Rotinas MPI - Matriz: ecology2}

A Figura 4.61 ilustra os testes realizados com a matriz "ecology2", considerando o solver MUMPS. 


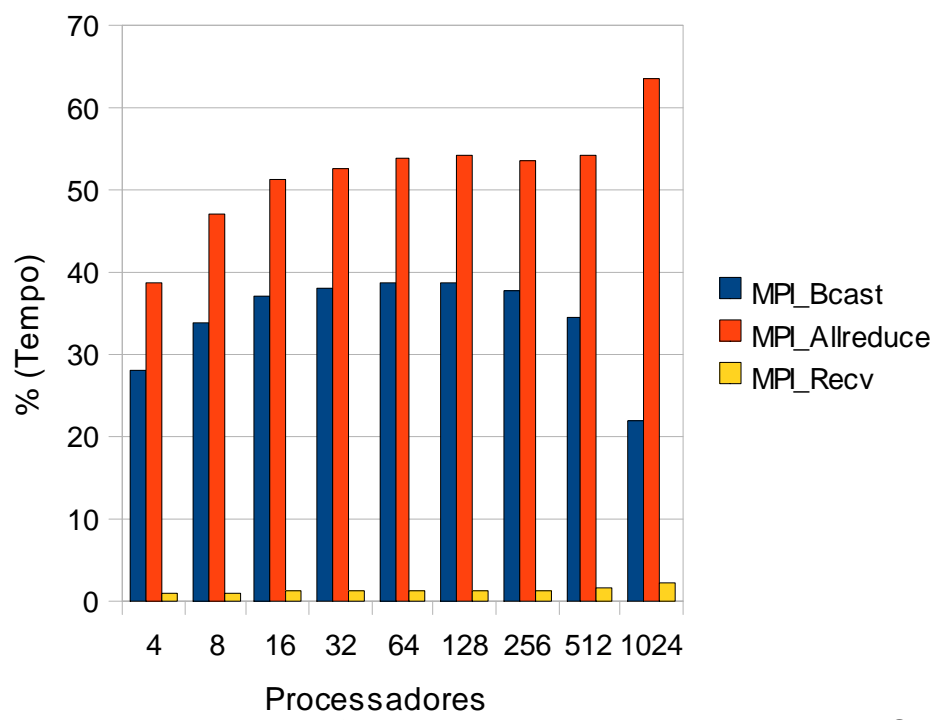

Figura 4.61 - Matriz "ecology2" - Rotinas MPI do MUMPS.

Da mesma maneira que os testes anteriores, o MUMPS mostrou um excesso de tempo gasto com as rotinas MPI_Bcast e MPI_Allreduce, sendo que as duas efetuam comunicação com o grupo de processos envolvidos no processamento. $A$ rotina MPI_Bcast consumiu quase $40 \%$ de tempo no teste com 64 processadores. A rotina MPI_Allreduce consumiu mais de $60 \%$ no teste com 1024 processadores. A rotina MPI_Recv manteve-se estável, não passando de $3 \%$ de tempo consumido nos testes realizados.

Como já foi dito, o padrão de comportamento é mantido por esse solver, em alguns momentos tendo muito tempo consumido pela rotina MPI_Bcast e em outros pela rotina MPI_Allreduce.

Observe agora os testes com o solver SuperLU, ilustrados na Figura 4.62.

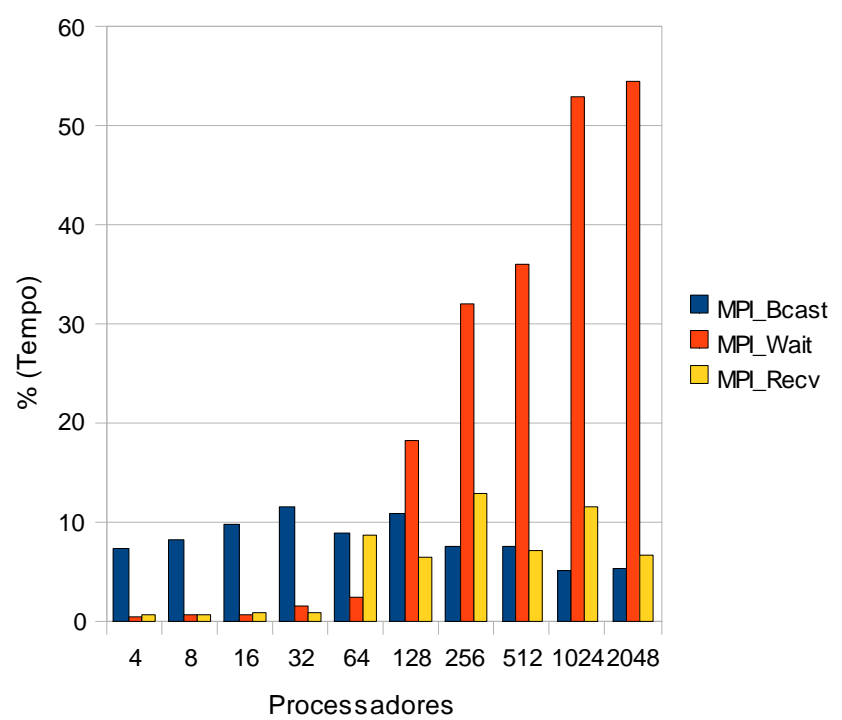

Figura 4.62 - Matriz "ecology2" - Rotinas MPI do SuperLU. 
O comportamento do solver SuperLU para a matriz "ecology2" é muito similar aos testes realizados anteriormente. A rotina MPI_Bcast não consumiu mais do que $12 \%$ de tempo no teste com 32 processadores. A rotina MPI_Wait teve um pico de quase 55\% no teste com 2048 processadores. A rotina MPI_Recv não passou de $13 \%$ de consumo de tempo no teste com 256 processadores.

Como tem se mostrado evidente, a cada teste de medição de tempo gasto com as rotinas MPI, para o conjunto de matrizes utilizados até então, o solver SuperLU mostra um determinado comportamento até os testes com 32 processadores, desse ponto em diante o comportamento do solver muda consideravelmente, passando a gastar mais tempo com o sincronismo, através da rotina MPI_Wait, do que com o MPI_Bcast.

A próxima figura (Figura 4.63) ilustra o comportamento do solver PETSc.

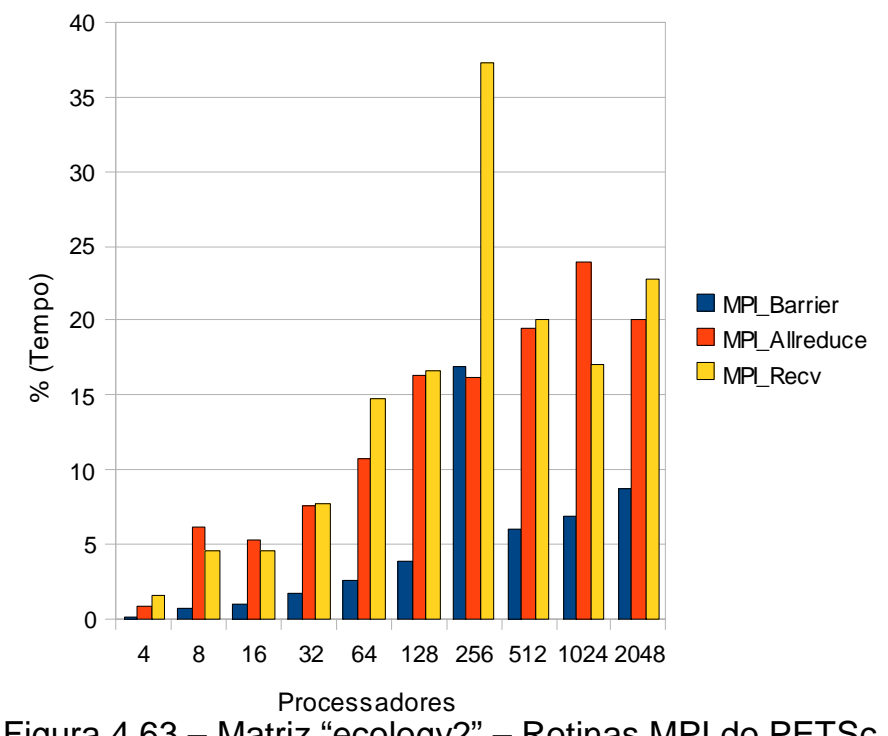

Figura 4.63 - Matriz "ecology2" - Rotinas MPI do PETSc.

O solver PETSc apresenta um comportamento similar ao dos outros testes. A rotina MPI_Barrier consumiu pouco mais de $16 \%$ no teste com 256 processadores. A rotina MPI_Allreduce consumiu em torno de $24 \%$ do tempo no teste com 1024 processadores. A rotina MPI_Recv consumiu aproximadamente $37 \%$ do tempo no teste com 256 processadores.

Quando se compara esse teste com os testes realizados com as matrizes anteriores, observa-se que o PETSc tem um comportamento similar, mas não tão idêntico quanto ao MUMPS, por exemplo. Nesse caso a rotina MPI_Barrier chegou a $16 \%$, fato incomum no testes anteriores. O mesmo ocorreu com MPI_Recv, obtendo 
$37 \%$ com o mesmo número de processadores. Por ser o único caso para essa matriz, o teste com 256 foge do padrão de comportamento do solver.

\subsubsection{Rotinas MPI - Matriz: apache2}

O próximo exemplo de teste do MUMPS é com a matriz "apache2" como pode ser visto na Figura 4.64.

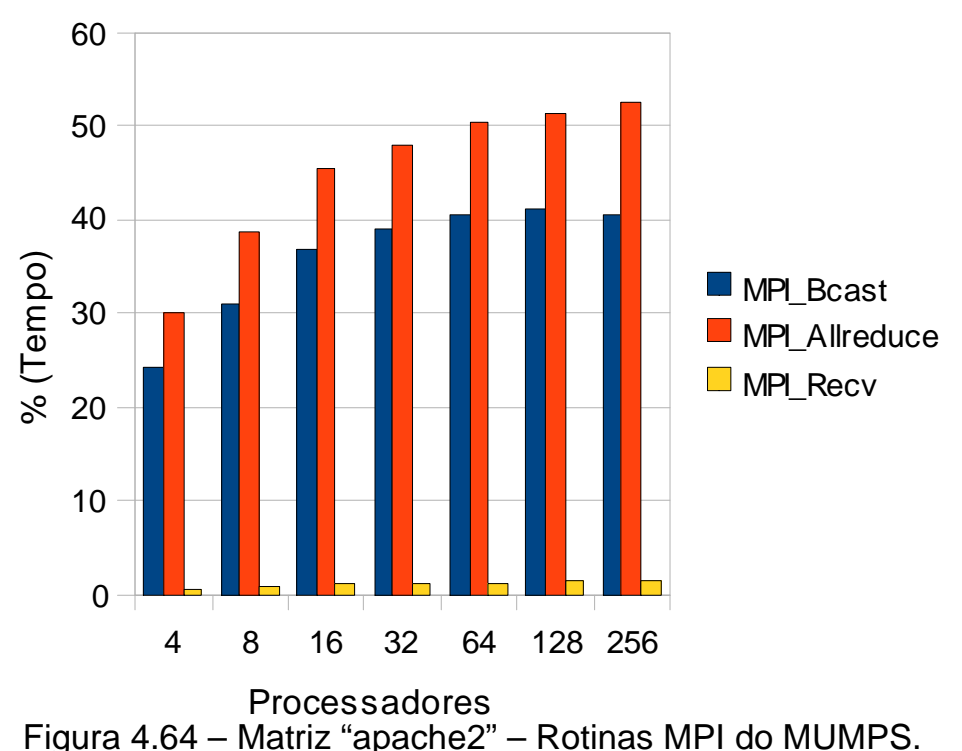

As rotinas MPI do solver MUMPS comportaram-se de maneira tradicional para os testes com a matriz "apache2". A rotina MPI_Bcast não consumiu mais do que $42 \%$ de tempo no teste com 128 processadores. A rotina MPI_Allreduce atingiu um pico máximo de $52 \%$ de consumo de tempo no teste com 256 processadores. A rotina MPI_Recv não ultrapassou 3\% de consumo de tempo ao longo dos testes.

Para esse teste não se observou nenhum comportamento diferente dos anteriores que pudesse influenciar de alguma outra forma na escalabilidade, considerando que a granularidade do algorimo é sempre a mesma.

Mais uma vez, será observado agora o comportamento do solver SuperLU para a mesma matriz, ilustrado na Figura 4.65. 


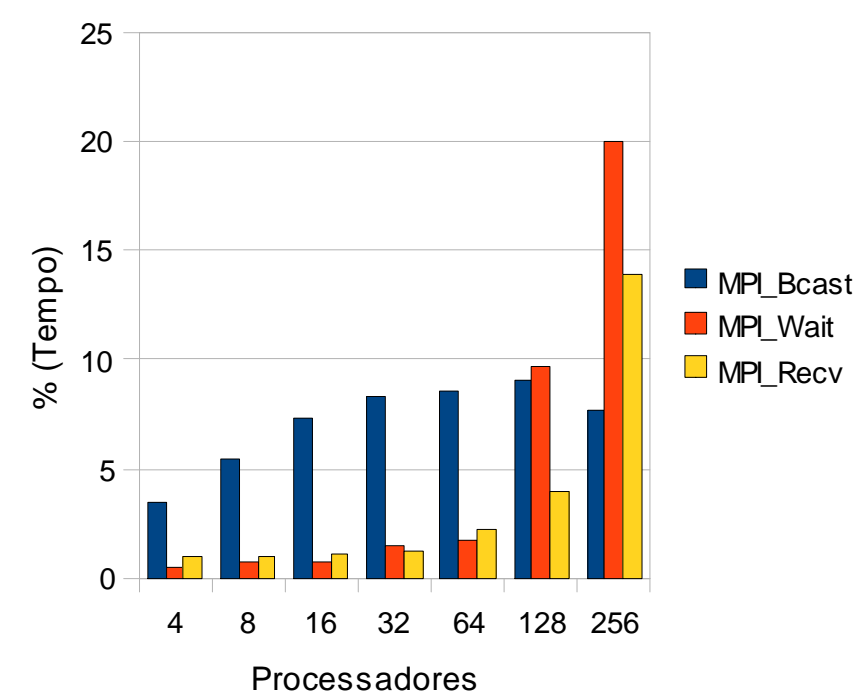

Figura 4.65 - Matriz "apache2" - Rotinas MPI do SuperLU.

O comportamento do solver SuperLU novamente demonstrou o mesmo padrão observado anteriormente. A rotina MPI_Bcast não ultrapassou $8 \%$ de consumo do tempo no teste com 128 processadores. A rotina MPI_Wait demonstrou seu pico de $20 \%$ de consumo de tempo no teste com 256 processadores. A rotina MPI_Recv não ultrapassou a barreira de $13 \%$ de consumo de tempo no teste com 256 processadores.

O solver SuperLU mostrou-se estável com relação ao seu comportamento de escalabilidade, alterando-o no teste com 256 processadores, fato já observado anteriormente. A ordem de grandez dos sistemas lineares que estão sendo resolvidos provavelmente estão influenciando nessa mudança de comportamento.

O solver PETSc é o último a ter seu comporamento analisado para essa matriz, conforme pode ser observado na Figura 4.66.

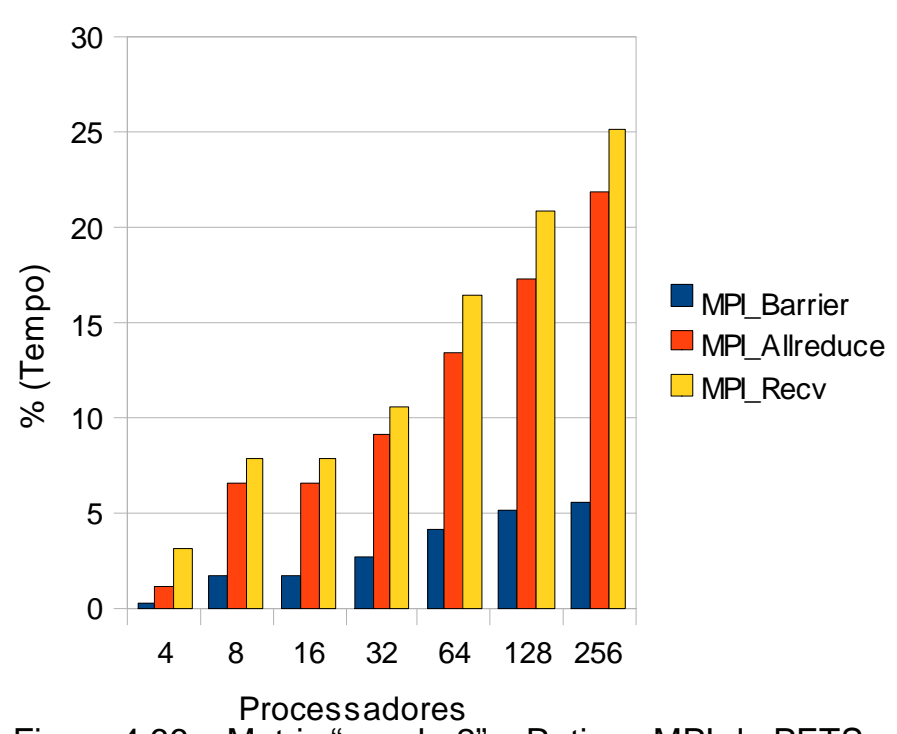

Figura 4.66 - Matriz "apache2" - Rotinas MPI do PETSc. 
O solver PETSc mostrou seu comportamento padrão mais uma vez. A rotina MPI_Barrier não ultrapassou $6 \%$ de consumo de tempo no teste com 256 processadores. A rotina MPI_Allreduce não ultrapassou $22 \%$ de consumo de tempo no teste com 256 processadores. A rotina MPI_Recv consumiu pouco mais de $25 \%$ de tempo, também no teste com 256 processadores.

Nada de novo foi observado com relação ao solver PETSc, considerando-se a escalabilidade ou a granularidade.

\subsubsection{Rotinas MPI - Matriz: af_shell8}

A próxima matriz para os testes com o solver MUMPS é a "af_shell8", como pode ser visto na Figura 4.67.

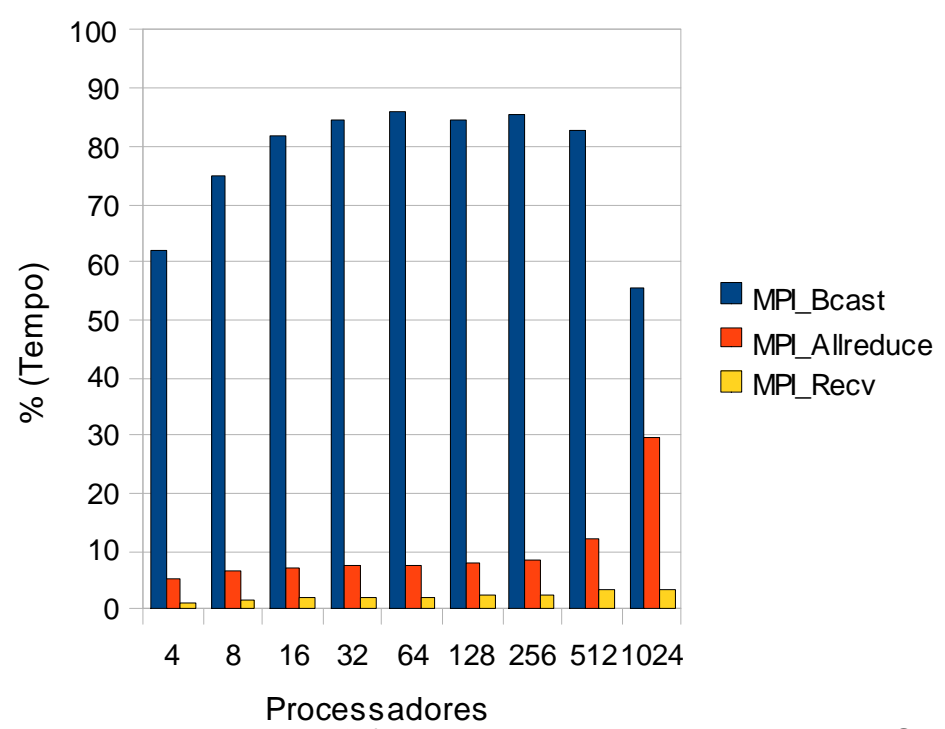

Figura 4.67 - Matriz "af_shell8" - Rotinas MPI do MUMPS.

Para essa matriz, o MUMPS mostrou-se um pouco diferente com relação aos testes anteriores, considerando-se a rotina MPI_Allreduce. A rotina MPI_Bcast atingiu um pico de $85 \%$ de consumo de tempo no teste com 64 processadores. A rotina MPI_Allreduce mostrou-se muito diferente, considerando-se os outros testes, pois em quase todos os testes não atingiu nem $10 \%$ de consumo de tempo, exceto pelo teste com 1024 processadores, com um consumo de tempo de $30 \%$. A rotina MPI_Recv não passou dos 3\% de consumo de tempo.

Diferentemente dos testes anteriores do solver MUMPS, esse não demonstrou tanto uso da rotina MPI_Allreduce, o que em tese contribui para uma melhor performance [57], por outro lado muito tempo foi gasto com a rotina MPI_Bcast. 
O próximo teste é com o solver SuperLU, ilustrado na Figura 4.68.

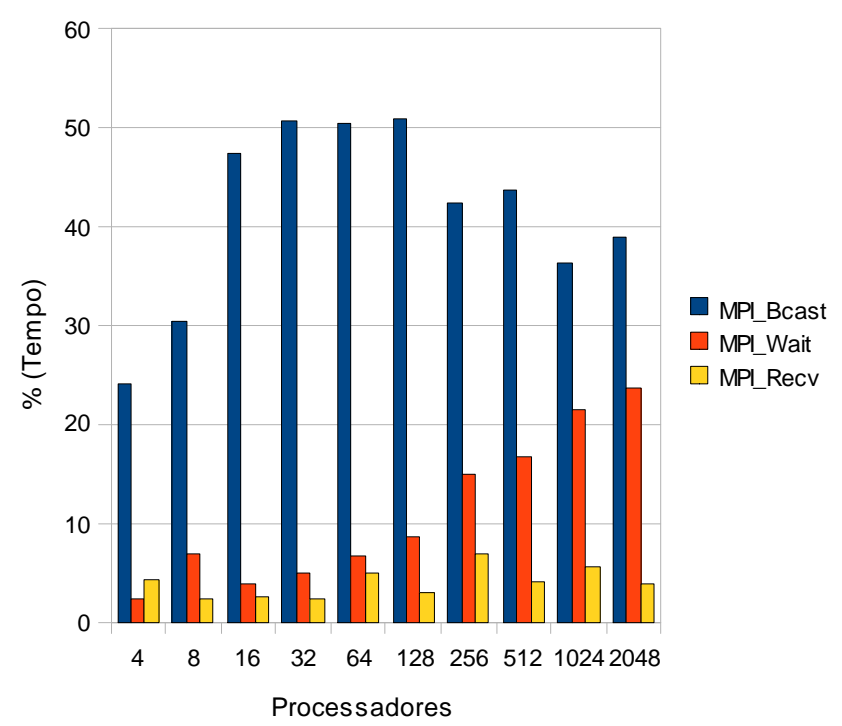

Figura 4.68 - Matriz "af_shell8" - Rotinas MPI do SuperLU.

O comportamento do solver SuperLU mostrou-se também diferente para essa matriz. A rotina MPI_Bcast chegou a passar de $50 \%$ de consumo de tempo, ao passo que nos testes com as outras matrizes o valor raramente passava de $10 \%$. A rotina MPI_Wait atingiu um pico de $23 \%$ no teste com 2048 processadores. A rotina MPI_Recv não ultrapassou $7 \%$ de consumo do tempo no teste com 256 processadores.

Para esse teste o SuperLU gastou muito tempo com as rotinas MPI_Bcast e MPI_Wait, o que pode contribuir negativamente para a escalabilidade [57].

A Figura 4.69 ilustra os testes de rotinas MPI do solver PETSc.

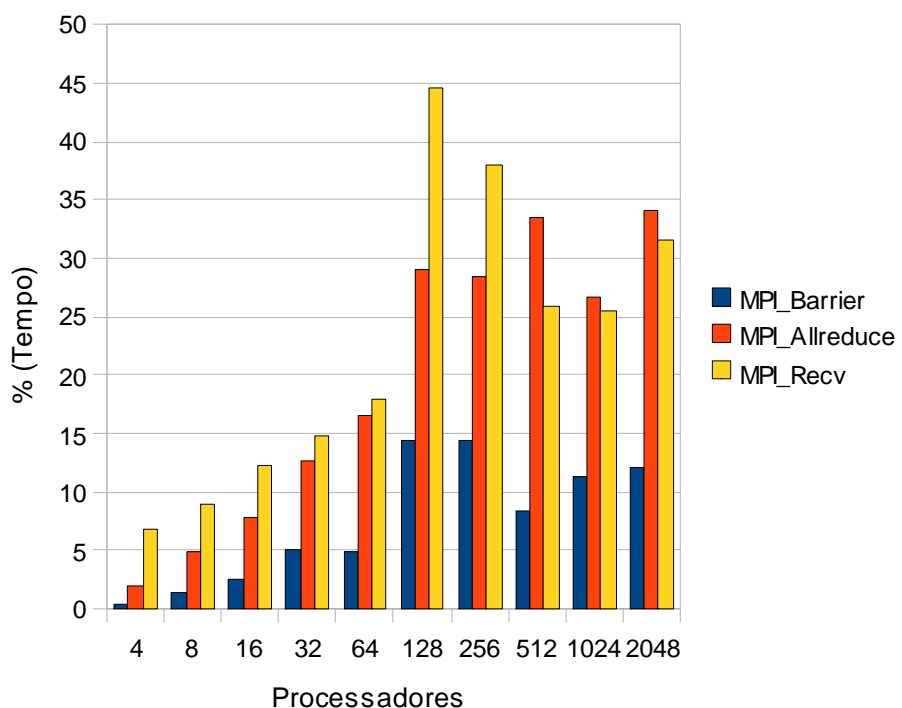

Figura 4.69 - Matriz "af_shell8" - Rotinas MPI do PETSc. 
O PETSc mostrou um comportamento muito similar aos outros testes, exceto por alguns detalhes que serão descritos na sequência. A rotina MPI_Barrier inicou os testes consumindo não mais do que $5 \%$ de tempo, tendo dois picos de $14 \%$ dos testes com 128 e 256 processadores, porém, nos testes a partir de 512 processadores, voltou a aumentar progressivamente. A rotina MPI_Allreduce comportou-se de maneira similar, tendo um pico de quase 34\% no teste com 2048 processadores. A rotina MPI_Recv teve um pico de $44 \%$ no teste com 128 processadores.

O solver PETSc mostrou um comportamento característico, aumentando progressivamente 0 tempo consumindo por suas rotinas MPI_Barrier e MPI_Allreduce, fato que ocorreu em quase todos os outros testes anteriores.

\subsubsection{Rotinas MPI - Matriz: tmt_sym}

A Figura 4.70 ilustra os testes realizados com a matriz "tmt_sym", considerando o solver MUMPS.

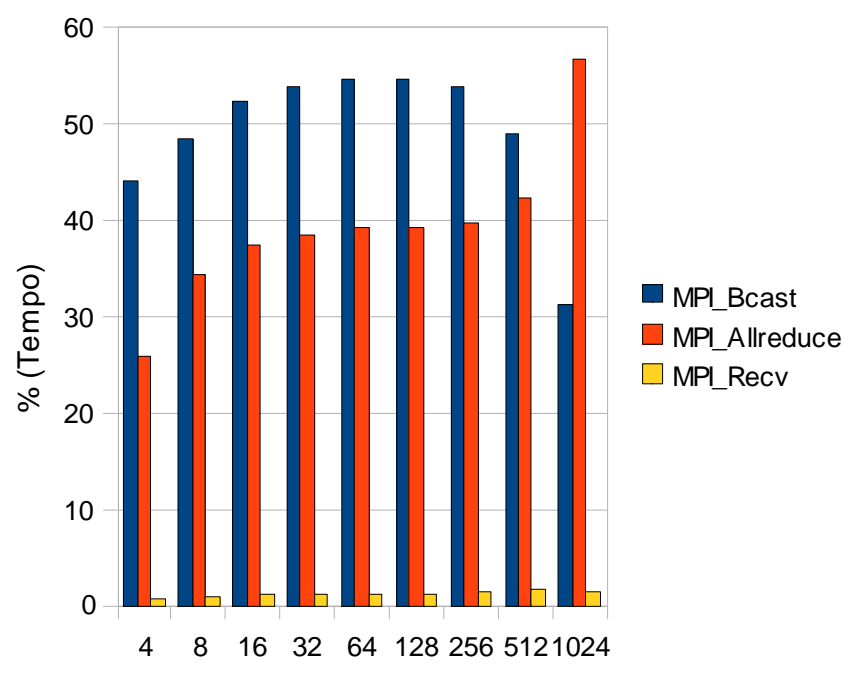

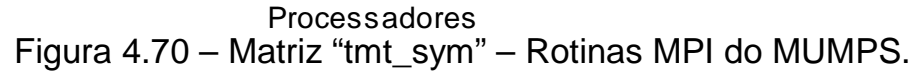

O comportamento do solver MUMPS seguiu o esperado, baseando-se claro nos testes anteriores. A rotina MPI_Bcast não passou de 55\% de consumo de tempo no teste com 64 processadores. A rotina MPI_Allreduce também seguiu o padrão de consumo de tempo, exceto pelo pico de $57 \%$ de consumo de tempo no teste com 1024 processadores. A rotina MPI_Recv mostrou-se estável, não consumindo mais do que $3 \%$ de tempo. 
Para os testes com a matriz "tmt_sym", não há nada a acrescentar com relação à questão da escalabilidade ou granularidade que não tenha sido dito anteriormente.

A Figura 4.71 ilustra os testes de rotinas MPI realizados com o solver SuperLU.

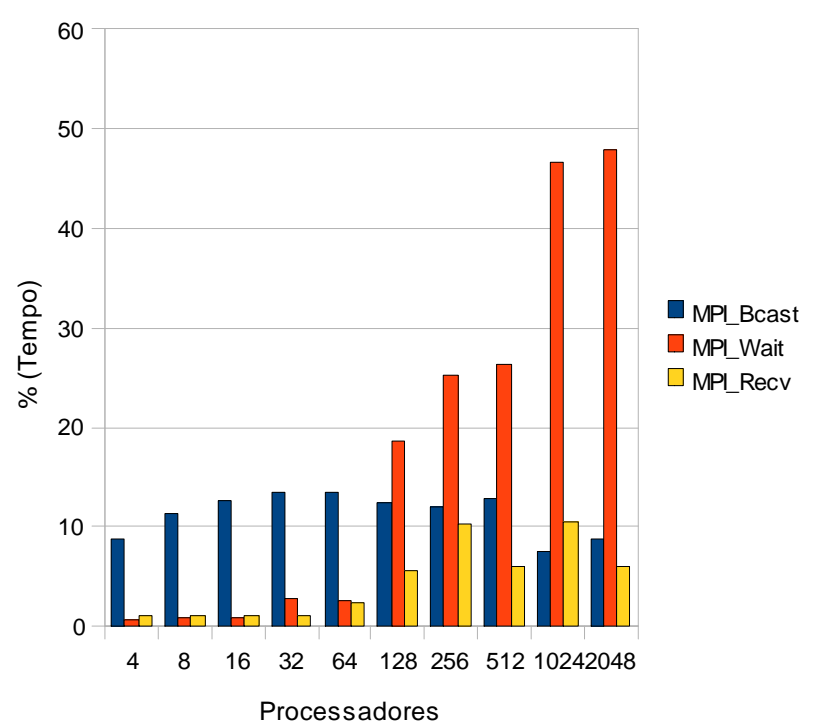

Figura 4.71 - Matriz "tmt_sym" - Rotinas MPI do SuperLU.

O solver SuperLU também mostrou resultados já conhecidos pelos testes realizados anteriormente com as outras matrizes. A rotina MPI_Bcast não passou de $14 \%$ de consumo de tempo no teste com 64 processadores. A rotina MPI_Wait seguiu seu padrão baixo até o teste com 128 processadores, onde a porcentagem de consumo de tempo elevou-se até atingir um pico de $48 \%$ de consumo de tempo no teste com 2048 processadores. A rotina MPI_Recv não passou de $11 \%$ de consumo de tempo no teste com 1024 processadores.

O comportamento do SuperLU repetiu-se para esse caso, ou seja, o MPI_Wait manteve-se baixo até o teste com 64 processadores, desse ponto em diante o consumo dessa rotina passa a aumentar, por questões de sincronismo de processo, mostrando que o algoritmo tem uma granularidade não tão grossa ou que o problema não é grande o suficiente para um bom aproveitamento do solver em questão.

A próxima figura (Figura 4.72) ilustra o comportamento do solver PETSc. 


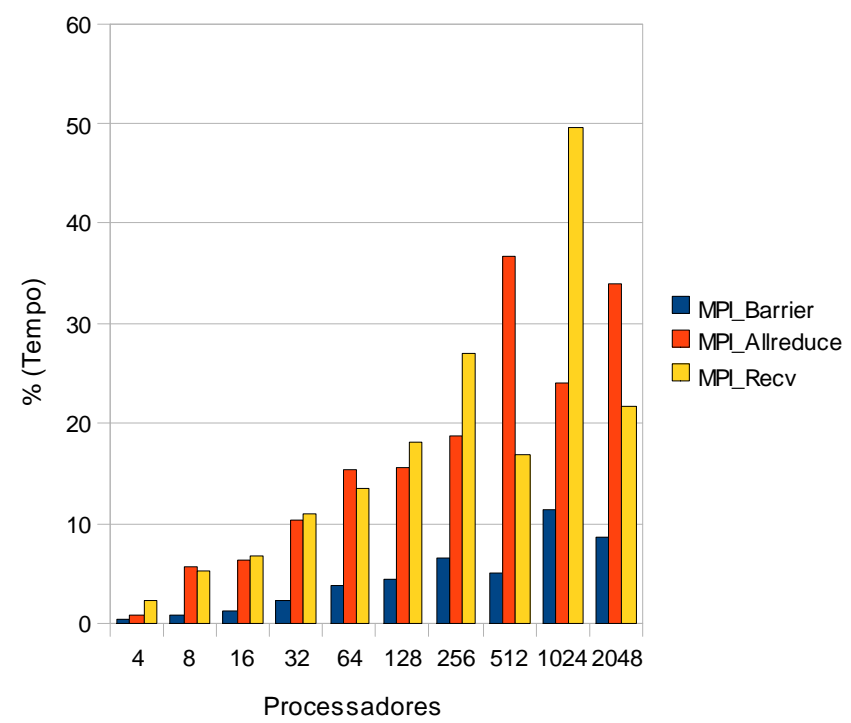

Figura 4.72 - Matriz "tmt_sym" - Rotinas MPI do PETSc.

Para os testes de rotinas MPI com o PETSc, o mesmo ocorrido diversas vezes anteriormente, repetiu-se aqui. A rotina MPI_Barrier não passou de $12 \%$ de consumo de tempo no teste com 1024 processadores. A rotina MPI_Allreduce aumenta o consumo de tempo progressivamente, exceto pelos testes com $1024 \mathrm{e}$ 2048 processadores, atingindo o pico de $37 \%$ no teste com 512 processadores. A rotina MPI_Recv também aumenta progressivamente o consumo de tempo, exceto pelos testes com 512 e 2048 processadores, atingindo o consumo máximo de 49\% do tempo no teste com 1024 processadores.

Pode-se dizer que a escalabilidade do solver manteve-se bem até o teste com 256 processadores, após esse ponto ele manteve-se instável, provavelmente não pela granularidade de seu código que tradicionalmente é grossa, mas sim pela ordem do problema, não havendo mais necessidade de aumentar o número de processadores a partir do ponto de 256 processadores.

\subsubsection{Rotinas MPI - Matriz: af_1_k101}

A Figura 4.73 ilustra os testes realizados com a matriz "tmt_sym", considerando o solver MUMPS. 


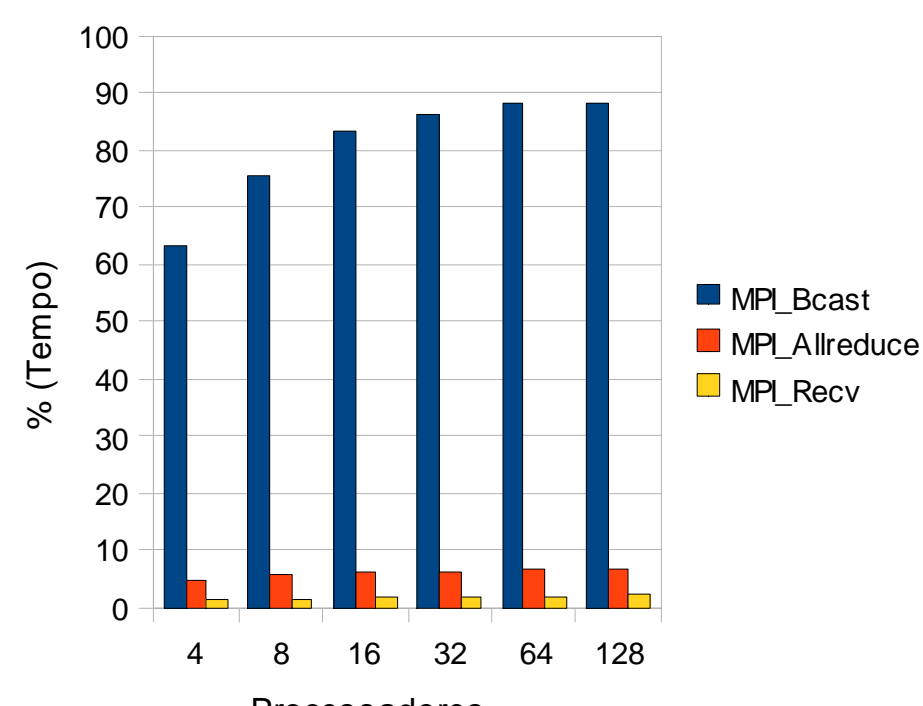

Figura 4.73 - Matriz "af_1_k101" - Rotinas MPI do MUMPS.

O comportamento do solver MUMPS não foi o padrão ocorrido em quase todos os testes anteriores, nesse caso, boa parte do tempo foi consumido por uma única rotina. A rotina MPI_Bcast chegou a consumir quase $90 \%$ do tempo total no teste com 64 processadores. A rotina MPI_Allreduce, diferentemente dos outros casos, não consumiu mais do que $8 \%$ do tempo total também no teste com 64 processadores. A rotina MPI_Recv pouco tempo consumiu, não passando de $3 \%$.

O MUMPS consumiu muito tempo enviando informações com a rotina MPI_Bcast, mas não teve trocas posteriores com as reduções de informações com a rotina MPI_Allreduce, o que mostra a existência de granularidade alta, mas também mostra a provável sobrecarga de alguns processadores.

A Figura 4.74 exibe o comportamento das rotinas MPI para o solver SuperLU.

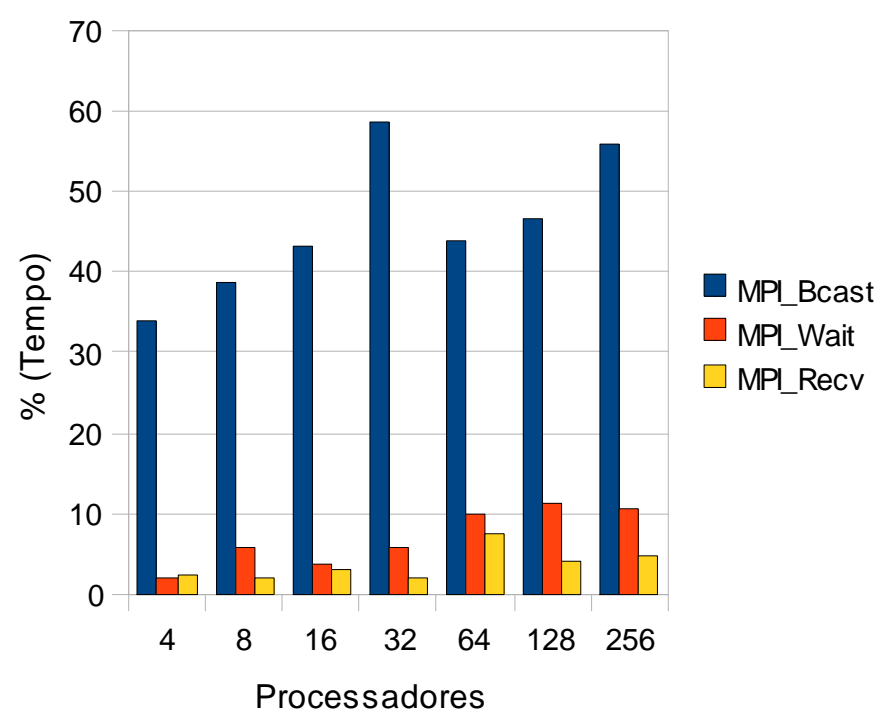

Figura 4.74 - Matriz "af_1_k101" - Rotinas MPI do SuperLU. 
O solver SuperLU teve um comportamento totalmente diferente nesse teste comparando-se com os testes das matrizes anteriores. A rotina MPI_Bcast consumiu no mínimo $33 \%$ do tempo no teste com 4 processadores e $58 \%$ no teste com 32 processadores. A rotina MPI_Wait não passou de $12 \%$ de consumo de tempo no teste com 128 processadores. A rotina MPI_Recv não passou de $8 \%$ no teste com 64 processadores.

O comportamento do SuperLU com a matriz "af_1_k101" foi realmente diverso do restante, a rotina MPI_Bcast jamais assumiu tais valores nos testes anteriores, considerando-se esse padrão crescente e de porcentagem de consumo de tempo elevada em todos os testes. Além disso a rotina MPI_Wait consumiu pouquíssimo tempo comparando-se com os testes anteriores. Com base nisso pode-se dizer que os dados foram distribuídos, porém devem ter ficado isolados em alguns processadores, consumindo tempo excessivo e, em alguns momentos, saturandoos, pois os testes com essa matriz demonstraram lentidão, como pode ser constatado anteriormente neste trabalho.

O próximo teste ilustra o comportamento do solver PETSc (Figura 4.75).

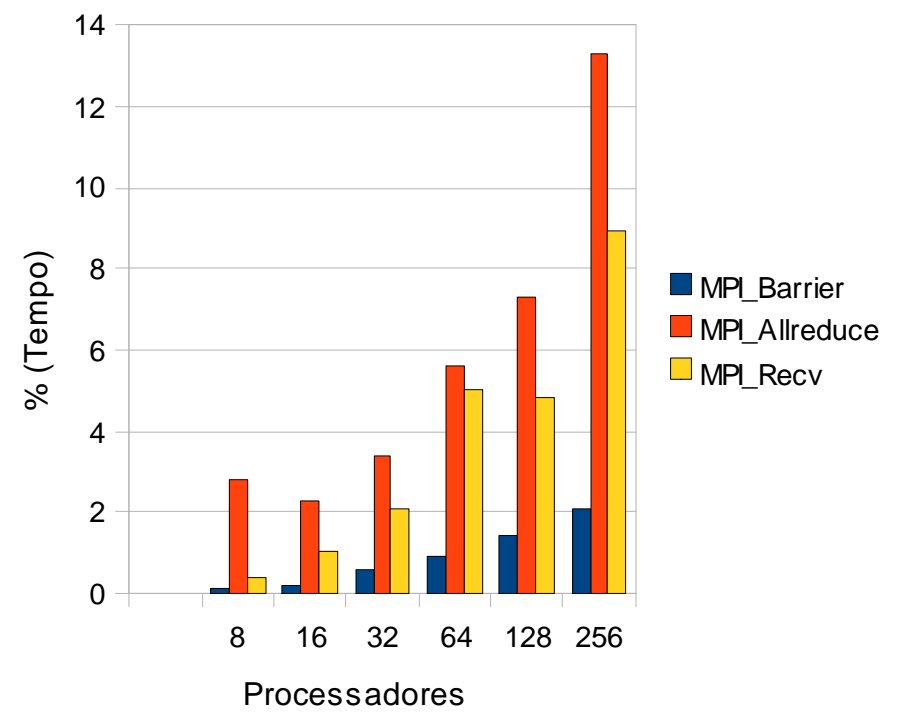

Figura 4.75 - Matriz "af_1_k101" - Rotinas MPI do PETSc.

O PETSc mostrou um comportamento das rotinas MPI muito similar ao dos testes anteriores, exceto pela questão do tempo consumido, fato esse que será discutido na sequência. A rotina MPI_Barrier não chegou a consumir nem 3\% do tempo no teste com 256 processadores. A rotina MPI_Allreduce teve um pico de quase $14 \%$, também no teste com 256 processadores. A rotina MPI_Recv teve um consumo máximo de $9 \%$ do tempo também no teste com 256 processadores. 
Apesar da similaridade do gráfico de barras, ao acompanhar as porcentagens dos valores obtidos, pode-se notar que os valores são bem inferiores se comparandos aos testes anteriores, de onde se pode concluir que a comunicação é baixíssima e alguns processadores ficam sobrecarregados com os cálculos. Para esse exemplo o solver PETSc mostrou pouca escalabilidade. 


\section{Conclusões}

O presente trabalhou ilustrou ao longo de seu desenvolvimento diversos aspectos da programação paralela ou distribuída aplicada à resolução de sistemas de equações lineares.

O trabalhou iniciou-se com uma discussão sobre questões essencialmente computacionais relacionadas com ambientes de programação paralela, como detalhes da arquitetura de computadores, sistemas operacionais e, ainda, esclarecendo como programar em ambientes paralelos de memória distribuída, utilizando uma biblioteca de troca de mensagens (MPI).

Posteriormente, foram feitas explanações matemáticas sobre duas possibilidades de se resolver um sistema de equações lineares: os métodos diretos e os métodos iterativos. Além disso, foram apresentadas três bibliotecas computacionais bem conhecidas para resolver sistemas de equações em ambientes computacionais de alto desempenho.

Por fim, um conjunto de matrizes com as mesmas características das geradas pelo método dos Elementos Finitos foi escolhido no banco de matrizes da Universidade da Flórida para realizar diversos testes com as bibliotecas já mencionadas.

Foram realizados quatro tipos de testes: speedup, eficiência, volume MPI e rotinas $\mathrm{MPI}$. Os dois primeiros testes são bem conhecidos na literatura. $O$ teste de volume MPI mostrou quanto tempo é gasto com rotinas MPI e o teste de rotinas MPI mostrou as três rotinas MPI que consumiram mais tempo em cada uma das três bibliotecas utilizadas nesta pesquisa.

Com relação às contribuições apresentadas neste trabalho, pode-se dizer que a abordagem de solvers paralelos com uma das máquinas mais rápidas do mundo não havia sido realizada no Departamento de Engenharia de Estruturas e Geotécnica da Escola Politécnica da USP. Pode-se acrescentar também que o teste de rotinas MPI, que permite avaliar as três principais rotinas e entender um pouco mais a respeito do comportamento do solver, também não foi encontrado na literatura internacional.

Esta pesquisa também gerou material de consulta para que outros pesquisadores, mesmo sem formação computacional específica, possam utilizar os solvers em ambientes paralelos sem grandes dificuldades, fornecendo as bases 
necessárias, caracterizando um trabalho da área conhecida como Engenharia Computacional.

O presente trabalho pode, possivelmente, ser complementado com uma das seguintes possibilidades:

- Implementar as bibliotecas dos solvers paralelos estudados no PEFSYS, software utilizado por diversos alunos que realizam suas pesquisas no Departamento de Engenharia de Estruturas e Geoténica da EPUSP;

- Continuar os estudos e testes com ambientes de alto desempenho utilizando processadores gráficos (GPU).

Espera-se futuramente colocar em prática as duas possibilidades citadas anteriormente, contribuindo para a evolução dos programas desenvolvidos pelos pesquisadores do departamento, adequando tais softwares aos ambientes de alto desempenho encontrados na atualidade. 


\section{Referências}

[1] FOSTER, I. Designing and Building parallel programs: concepts and tools for parallel software engineering. Addison Wesley : USA, 1994.

[2] STALLINGS, W. Computer Organization and architetcture: designing for performance. Prentice Hall : New Jersey, 1999.

[3] CAMATA, J. J. Estratégias Computacionais de Alto Desempenho Aplicadas ao Método dos Elementos Finitos. Tese de Doutadorado em Engenharia Civil : Rio de Janeiro, 2011.

[4] LIMA, O. F., PASARO, A., ABE, N. M., CALDEIRA, A. D. Resolução de Sistemas de Equações Lineares em um Cluster Beowulf. Disponível em: <http://www.efa.ieav.cta.br/lev/projeto/believe/desemp/cnmac_artigo.html>. Acessado em: 12 Fevereiro 2012.

[5] TANenbaum, A. S., SteEn, M. V. Sistemas distribuídos: princípios e paradigmas, $2^{a}$ ed. Pearson Prentice Hall : São Paulo, 2007.

[6] TANENBAUM, A. S., WOODHULL, A. S. Sistemas Operacionais: projeto e implementação, $3^{\mathrm{a}}$ ed. Bookman : Porto Alegre, 2008.

[7] LAWRENCE Berkeley National Laboratory, 2011. Disponível em: $<$ http://www.lbl.gov/>. Acessado em: 21 Dezembro 2012.

[8] UNIVERSIDADE Federal de Juiz de Fora. Graduação em Engenharia Computacional, 2012. Disponível em: <http://www.ufjf.br/engcomputacional/>. Acessado em: 21 Dezembro 2012.

[9] WeBeR, R. F. Arquitetura de Computadores Pessoais, $2^{\mathrm{a}}$ ed. Artmed : Porto Alegre, 2008.

[10] FLYNN, M. Some Computer Organization and Their Effectiveness. IEEE Transactions on Computers 1972; 21. 
[11] JAQUIE, K. R. L. Extensão da Ferramenta de Apoio à Programação Paralela (F.A.A.P.) para Ambientes Paralelos Virtuais. Dissertação de Mestrado : São Carlos, 1999.

[12] MASSETO, F. I., SATO, L. M., LI, K. A novel strategy for building interoperable MPI environment in heterogeneous high performance systems. The Journal of Supercomputing 2012; 60:87-116.

[13] GALVIN, P. B., SILBERSCHATZ, A., GAGNE, G. Fundamentos de sistemas operacionais - $6^{\underline{a}}$ edição. LTC : Rio de Janeiro, 2004.

[14] INTEL CORPORATION. Intel 64 and IA 32 Architectures Software Developer's Manual, vol. 1. Denver, 2006.

[15] INTEL CORPORATION. Intel 64 and IA 32 Architectures Optimization Reference Manual. Denver, 2006.

[16] SNIR, M., OTTO, S., LEDERMAN, S. H., WALKER, D., DONGARRA, J. J. MPI The Complete Reference, vol. I. Massachusetts Institute of Technology : Massachusetts, 1996.

[17] ARENALES, S., DAREZZO, A. Cálculo Numérico: aprendizagem com apoio de software. Thomson : 2008.

[18] RUGGIERO, M. A. G., LOPES, V. L. R. Cálculo Numérico: aspectos teóricos e computacionais - 2ª Edição. Makron Books : 1996.

[19] PETTOFREZZO, A. J. Matrices and Transformations. Dover Publications : New York, 1978.

[20] FRANKLIN, J. N. Matrix Theory. Dover Publications : New York, 2000.

[21] CIMERMAN, M. Resolução de Sistemas Lineares via Métodos Iterativos com Pré-Condicionadores - Aplicação em Problemas de Engenharia de Estruturas. Dissertação de Mestrado : São Paulo, 1996. 
[22] APARECIDO, J. B., SOUZA, N. Z., CAMPOS-SILVA, J. B. Data structure and the pre-conditioned cojugate gradient method for solving large sparse linear systems with symmetric positive definite matrix. XXXII Iberian-Latin-American Congress on Computational Methods in Engineering 2011.

[23] AMESTROY, P. R., DUFF, I. S., L'EXCELLENT, J., LI, X. S. Analysis and Comparison of Two General Sparse Solvers for Distributed Memory Computers. ACM Transactions on Mathematical Software 2001; 27:388-421.

[24] LAWSON, C. L., HANSON, R. J., KINCAID, D., KROGH, F. T. Basic Linear Algebra Subprograms for FORTRAN usage. ACM Trans. Math. Soft. 1979.

[25] PIMENTA, P. M., FERREIRA, A. B., GONÇAlVES, F. R., NIGRO, P. S. B. Software Reverse Engineering Techniques applied to Optimization of Linear Equations Systems Solvers. XXXII Iberian-Latin-American Congress on Computational Methods in Engineering 2011:299.

[26] DONGARRA, J. J., DU CROZ, J., HAMMARLINGS, S., HANSON, R. J. An extended set of FORTRAN Basic Linear Algebra Subprograms. ACM Trans. Math. Soft. 1988.

[27] DONGARRA, J. J., DU CROZ, J., DUFF, I. S., HANSON, R. J. A set of Level 3 Basic Linear Algebra Subprograms. ACM Trans. Math. Soft. 1990.

[28] ANDERSON, E., BAI, Z., BISCHOF, C., BLACKFORD, L. S., DEMMEL, J., DONGARRA, J. J., DU CROZ, J., GREENBAUM, A., HAMMARLING, S., MCKENNEY, A., SORENSEN, D. LAPACK Users' Guide, 3rd edition ed. SIAM : Philadelphia, 1999.

[29] LAPACK GROUP. Lapack Homepage, 2012. Disponível em: <http://www.netlib.org/lapack/>. Acessado em: 10 Julho 2012.

[30] LI, X. S., DEMMEL, J. W., GILBERT, J. R. SuperLU Users Guide. 2011.

[31] LI, X. S., SHAO, M. A Supernodal approach to incomplete LU factorization with partial pivoting. ACM Transactions on Mathematical Software 2011; 37.

[32] PIMENTA, P. M., MARQUES, O. A., FERREIRA, A. B. Performance Analysis of 
Parallel Software for Solving Systems of Linear Equations. $X$ World Congress on Computational Mechanics 2012:268.

[33] GRIGORI, L., DEMMEL, J. W., LI, X. S. Parallel Symbolic Factorization for Sparse LU with Static Pivoting. SIAM J. Scientific Computing 2007; 29:12891314.

[34] DUFF, I., GRIMES, R., LEWIS, J. User's Guide for the Harwell-Boeing Sparse Matrix Collection. CERFACS 1992.

[35] AMESTROY, P. R., BUTTARI, A., GUERMOUCHE, A., L'EXCELLENT, J., UCAR, B. Multifrontal Massively Parallel Solver User's Guide. Université de Toulouse, Toulouse 2011.

[36] Marques OA, Drummond LA. An Overview of the Advanced CompuTational Software (ACTS) Collection. ACM TOMS 2005; 31:282-301.

[37] DEVLOO, P. R. B. Object Oriented Tools for Scientific Computing. Engineering with Computers 2000; 16:63-72.

[38] MARQUES, O. A., DRUMMOND, L. A. The DOE ACTS Information Center. Disponível em: <http://acts.nersc.gov>. Acessado em: 20 Fevereiro 2012.

[39] BALAY, S., BROWN, J., BUSCHELMAN, K., EIJKHOUT, V., GROUPP, W., KAUSHIK, D., KNEPLEY, M., MCINNES, L. C., SMITH, B., ZHANG, H. PETSC Users Manual - Revision 3.3. Argonne National Laboratory 2012.

[40] DAVIS, T. University of Florida Sparse Matrix Collection, 2000. Disponível em: <http://www.cise.ufl.edu/research/spase/matrices>. Acessado em: 1 Fevereiro 2012.

[41] FIEDLER, M. Special matrices and their applications in Numerical Mathematics, 2nd ed. Dover Publications : New York, 2008.

[42] ISAACSON, E., KELLER, H. B. Analysis of Numerical Methods. Dover Publications : New York, 1994. 
[43] YOUNG, D. M. Iterative Solution of Large Linear Systems. Dover Publications : New York, 2003.

[44] STEPHENSON, G. An introduction to matrices, sets and groups for science students. Dover Publications : New York, 1986.

[45] SALVETTI, D. D. Elementos de Cálculo Numérico, 2ª ed. Companhia Editora Nacional : São Paulo, 1976.

[46] BITTENCOURT, M. L., FEIJÓ, R. A. Análise Comparativa de Métodos Diretos e Iterativos para a Solução de Sistemas de Equações. Revista Internacional de Métodos Numéricos para Cálculo y Diseño en Ingeniería 1997.

[47] GOLUB, G. H., LOAN, C. F. V. Matrix Computation, Third ed. The John Hopkins University Press : Baltimore, 1996.

[48] FELIPPA, C. A. Chapter 26 - Introduction to Finite Element Methods. In Solving FEM Equations. University of Colorado, 2010.

[49] MANGUOGLU, M. A General Sparse Sparse Linear System Solver and Its Application in OpenFOAM. Partnership for Advanced Computing in Europe 2012.

[50] POSCHMANN, P., KOMZSIK, L., MAYER, S., BABIKOV, P., BABIKOVA, M. Direct Or Iterative - A Dilemma For The User

[51] ASENJO, R., BANDERA, G., TRABADO, G. P., ZAPATA, E. L. Iteractive and Direct Sparse Solvers on Parallel Computers. Euroconference: Supercomputation in Nonlinear and Disordered Systems: Algorithms, Applications and Architectures 1996.

[52] JAMIL, N. A Comparison of Direct and Indirect Solvers for Linear Systems of Equations. Int. J. Emerg. Sci 2012.

[53] POLIZZI, E., SAMEH, A. A. A parallel hybrid banded system solver: the SPIKE algorithm. Parallel Computing 2006; 32:177-194.

[54] POLIZZI, E., SAMEH, A. A. SPIKE: A parallel environment for solving banded 
linear systems. Parallel Computing 2007; 36:113-120.

[55] SHENDE, S., MALONY, A. D., SPEAR, W., BIERSDORFF, S., MILLSTEIN, S. TAU Performance System Tutorial. University of Oregon 2011.

[56] KUMAR, V., NANJUNDIAH, R., THAZHUTHAVEETIL, M. Impact of message compression on the scalability of an atmospheric modeling application on clusters. Parallel Computing 2008; 34:1-16.

[57] MAMIDALA, A. R., KUMAR, R., DE, D., PANDA, D. K. MPI Collectives on Modern Multicore Clusters: Performance Optimizations and Communication Characteristics. Cluster Computing and the Grid - CCGRID 2008:130-137. 


\section{Apêndice A - Operacionalizando a estrutura paralela}

O ambiente paralelo, como já foi dito anteriormente, precisa de um sistema operacional compatível com a estrutura física disponível e, apto a executar procedimentos pertinentes ao ambiente paralelo.

Nessa linha de sistemas operacionais, o Linux tem sido adotado de maneira ampla pelas instituições públicas, pois é um sistema operacional livre, sem custos e com uma vasta disponibilidade de ferramentas gratuitas para esse ambiente.

Existem várias distribuições Linux criadas para operar ambientes paralelos ou distribuídos, e uma delas é o Pelican Linux, adotado ao longo deste anexo como ferramenta para demonstrar o que pode ser feito dentro dessa área.

\section{A.1 Inicializando o sistema servidor}

Primeiramente, deve-se adotar um computador como sendo o principal, também chamado de master nos materiais dessa área. Esse computador poderá ser, além de master, o chamado front end, que é a máquina com a qual o usuário irá interagir com o cluster.

Colocando o CD de inicialização do sistema Pelican Linux nesse computador principal, após carregar o sistema será exibida a tela representada pela Figura A.1. 


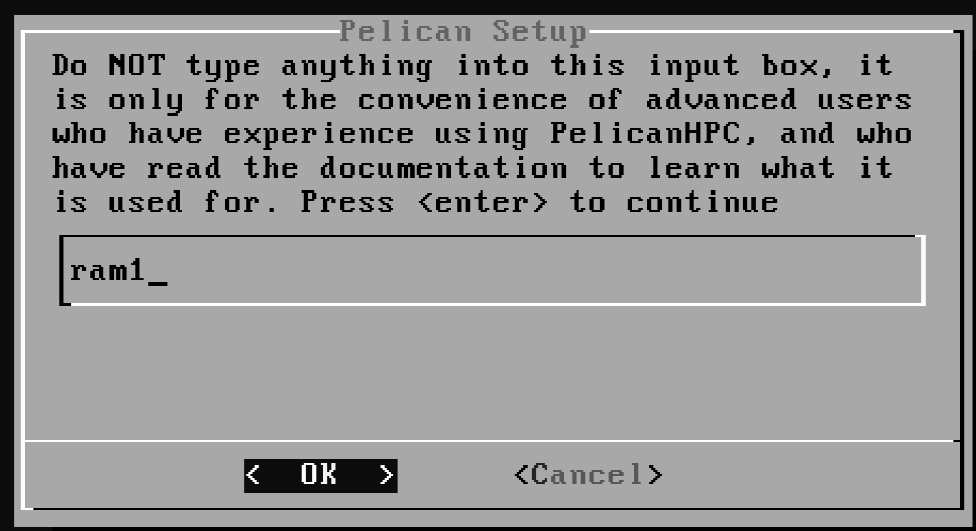

Figura A.1 - Primeira tela de setup do Pelican Linux.

Essa tela tem um box com um valor inicial "ram1" e esse valor não precisa ser alterado, exceto em situações de personalização do ambiente paralelo que não serão discutidas neste anexo. Teclando ENTER, será exibida a próxima tela, representada pela Figura A.2.

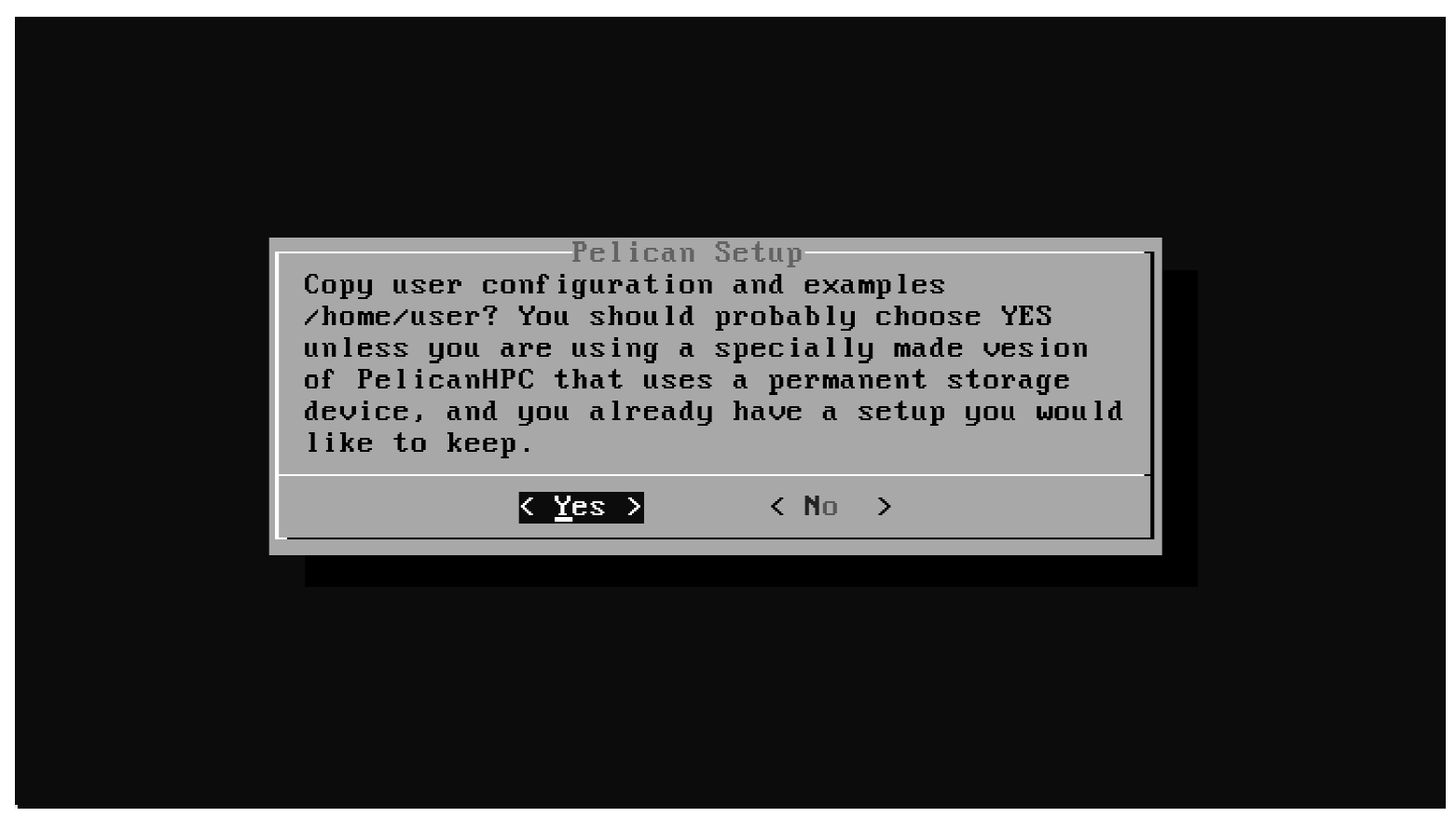

Figura A.2 - Segunda tela de setup do Pelican Linux.

A Figura A.2 ilustra uma tela em que o sistema irá copiar na memória RAM a 
estrutura básica de operacionalização do cluster e os diretórios básicos de usuário, portanto, se o usuário do sistema possui uma estrutura personalizada já disponibilizada anteriormente por configurações manuais, a escolha correta aqui seria "No".

No entanto, como o processo está sendo feito do início, o ideal é selecionar a opção "Yes" para que o ambiente e os exemplos sejam todos devidamente alocados na memória RAM.

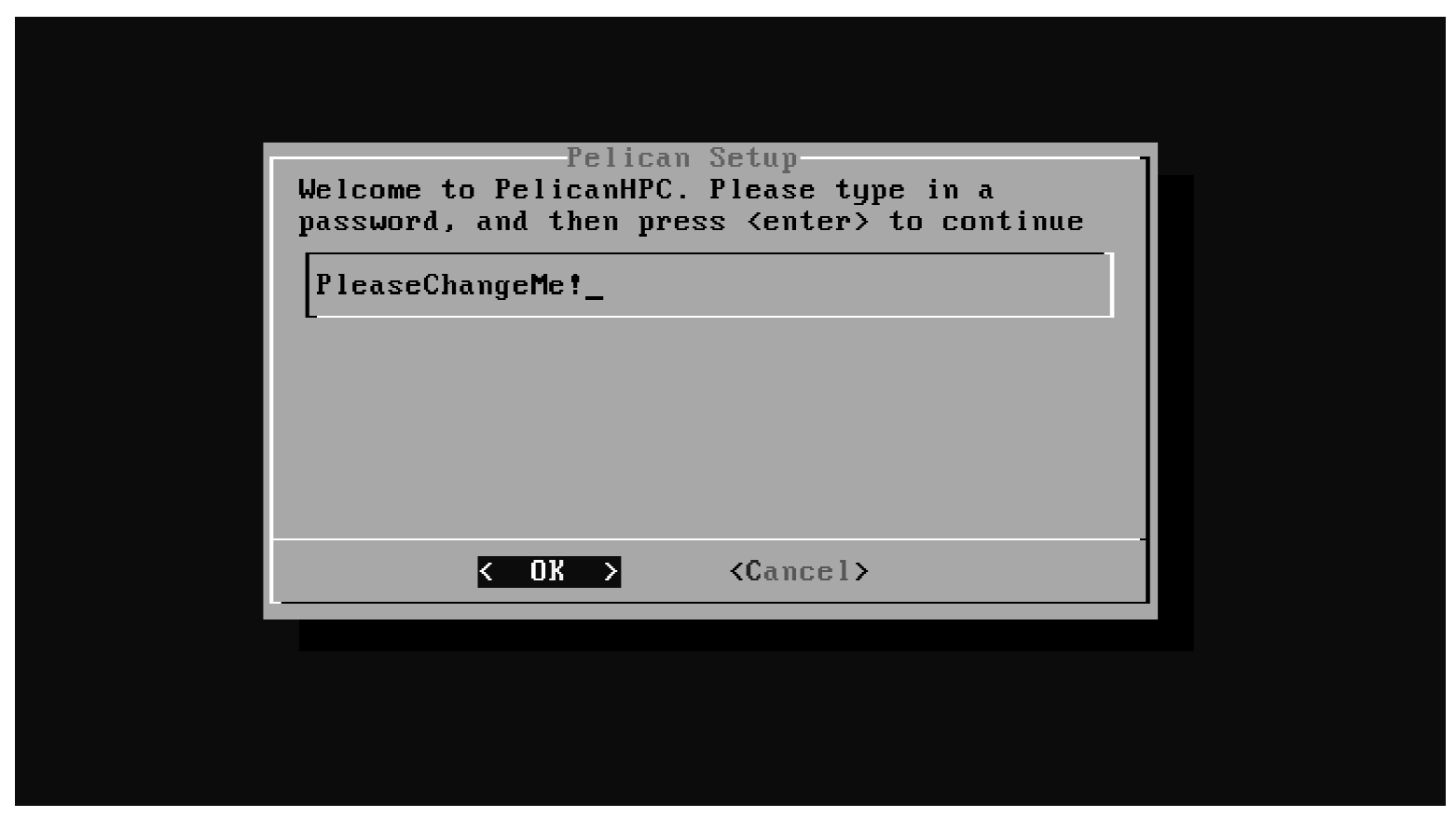

Figura A.3 - Alteração de senha de "user" do Pelican Linux.

A Figura A.3 solicita que se insira uma senha de uso do usuário "user", que será necessária quando for preciso interagir mais profundamente com as configurações do sistema Pelican Linux.

Após esses passos, será exibida uma tela do modo "Shell" do Linux, ou seja, a interação do usuário somente por modo de texto via linha de comandos, como pode ser observado na Figura A.4. 


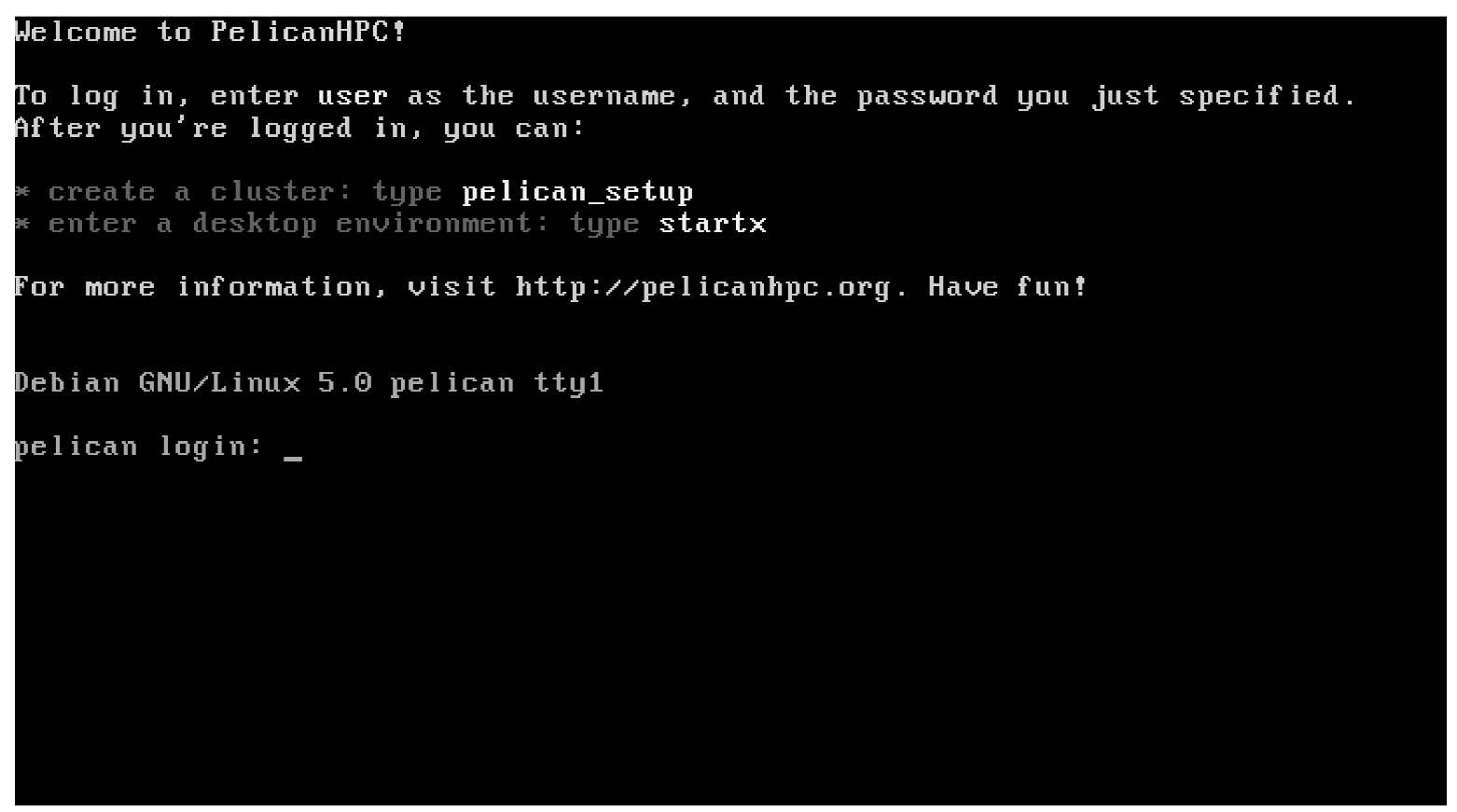

Figura A.4 - Alteração de senha de "user" do Pelican Linux.

Agora, é necessário inserir o usuário "user" no Shell e depois a senha cadastrada anteriormente para efetuar o login no sistema. Após isso, o comando "pelican_setup" deverá ser digitado e teclado ENTER para dar andamento às configurações do sistema, como pode ser visto na Figura A.5.

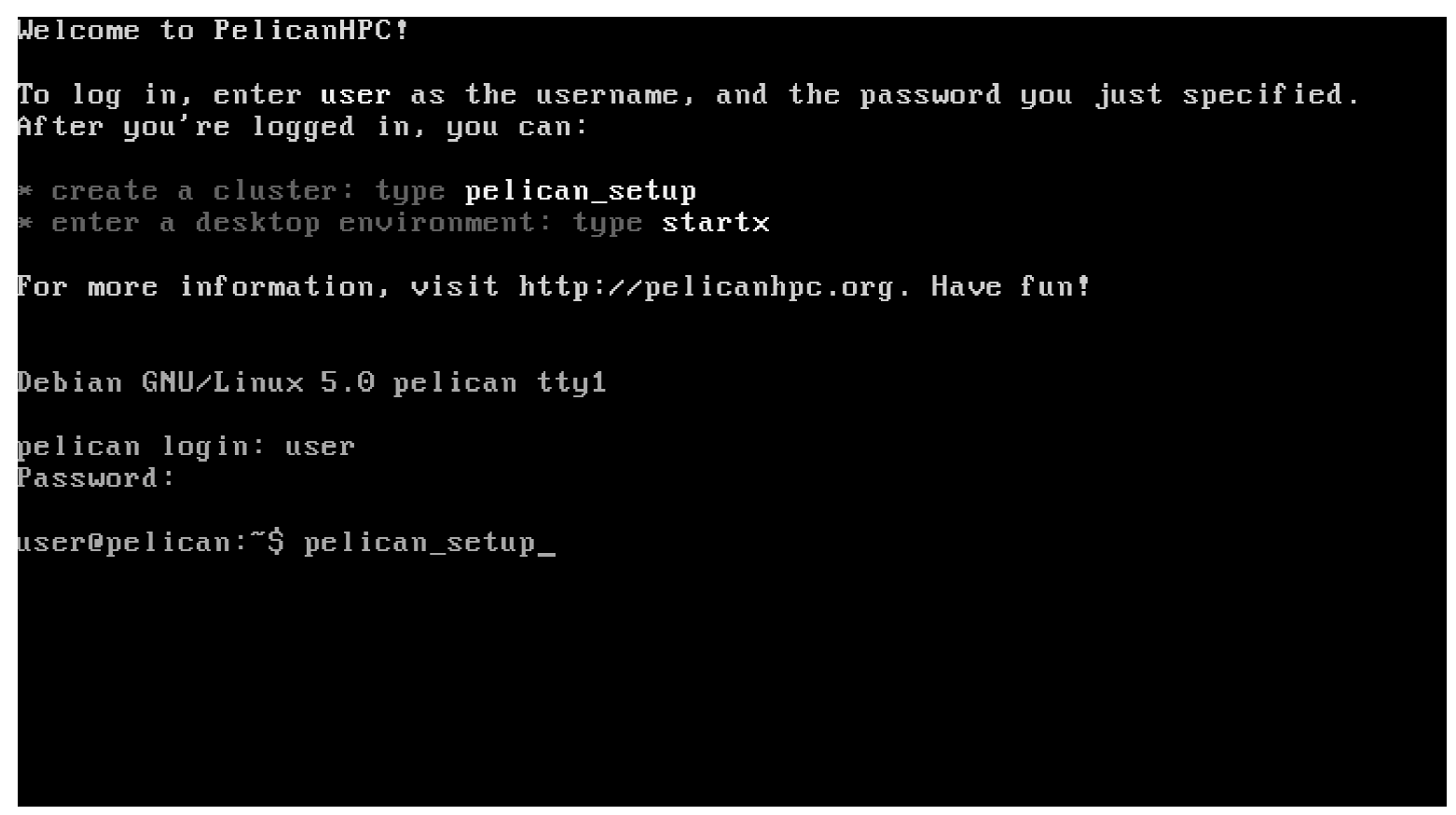

Figura A.5 - Login no sistema e digitação do comando "pelican_setup".

Após o comando, será exibida uma nova tela alertando sobre o processo de 
inicialização de endereçamento automático de rede (DHCP) pelo servidor Pelican Linux, o qual poderá entrar em conflito com outro servidor que tenha a mesma funcionalidade, caso a estrutura de rede que esteja sendo utilizada seja compartilhada a outra estrutura de rede local ao alcance desta (Figura A.6).

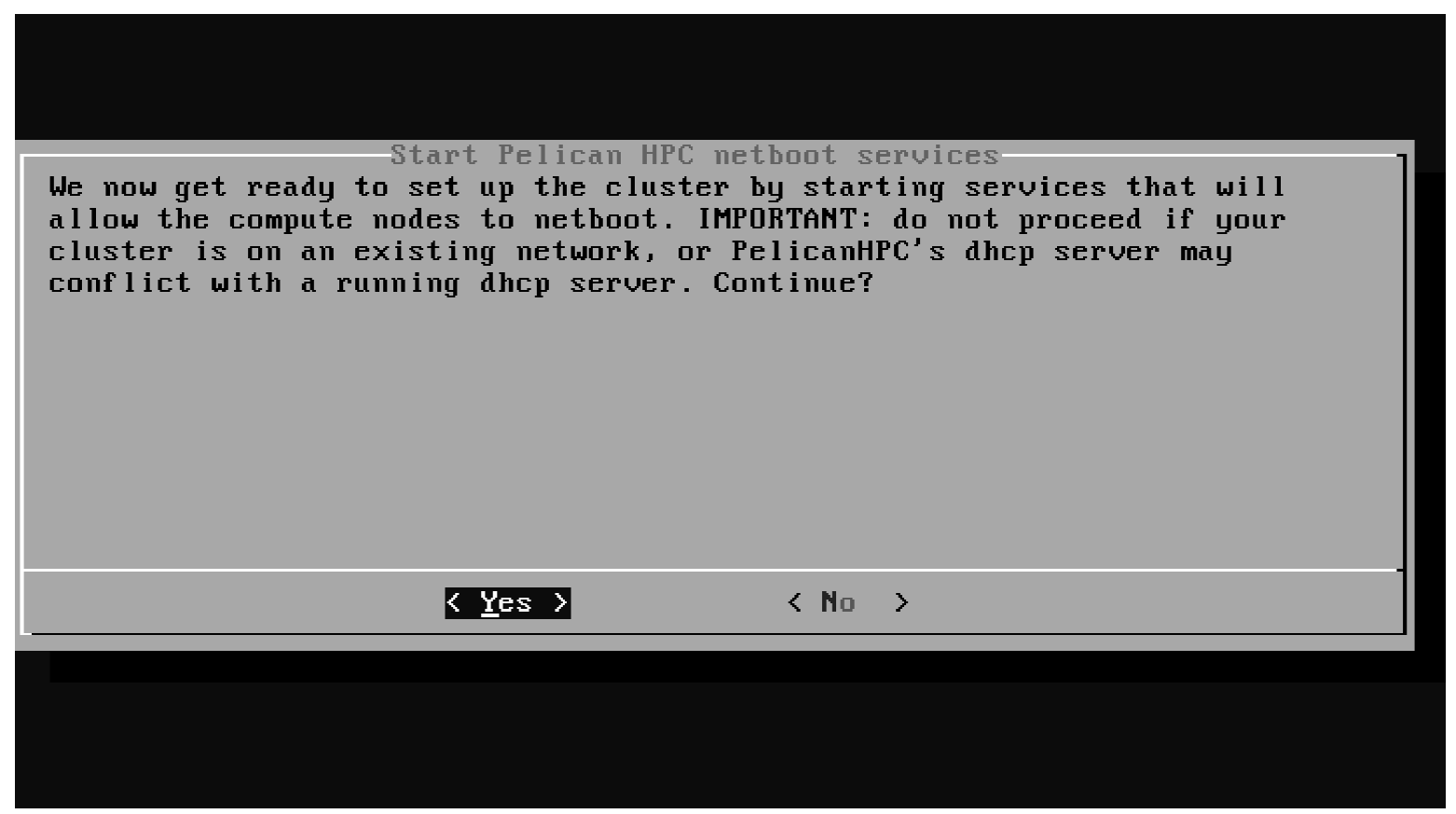

Figura A.6 - Alerta de inicialização de serviço de DHCP do Pelican Linux.

Agora é necessário que as outras máquinas ligadas na mesma estrutura física de rede do computador servidor sejam inicializadas, para que elas possam carregar o sistema operacional via rede, inclusive com as configurações de rede definidas pelo próprio Pelican Linux.

A Figura A.7 possui uma confirmação para localização dos nós escravos, mas ela só deverá ser dada, selecionando "Yes" e dando ENTER, somente após ligar todos os escravos da rede e todos terem carregado o sistema. 
Time to bring the compute nodes into the cluster. If you are resizing a running cluster, be aware that continuing will interrupt any running MPI jobs. Cont inue?

Figura A.7 - Solicitação para "escanear" o os nós sejam ligados.

\section{A.2 Inicializando o sistema escravo}

Como já foi dito anteriormente, existe agora a necessidade de carregar o sistema nos computadores escravos da rede, também chamado de nós escravos, ou simplesmente nós.

Esses computadores deverão ter sido configurados para efetuar o boot ou inicialização do sistema pela interface de rede presente em cada um deles, e tal configuração poderá ser feita no Setup da BIOS de cada um dos nós.

Se o nó escravo possuir um monitor, poderá ser observado que, logo ao buscar o boot pela rede, será exibida uma tela similar à da Figura A.8, onde a interface de rede localiza um servidor na rede disponibilizando uma imagem de sistema operacional. 


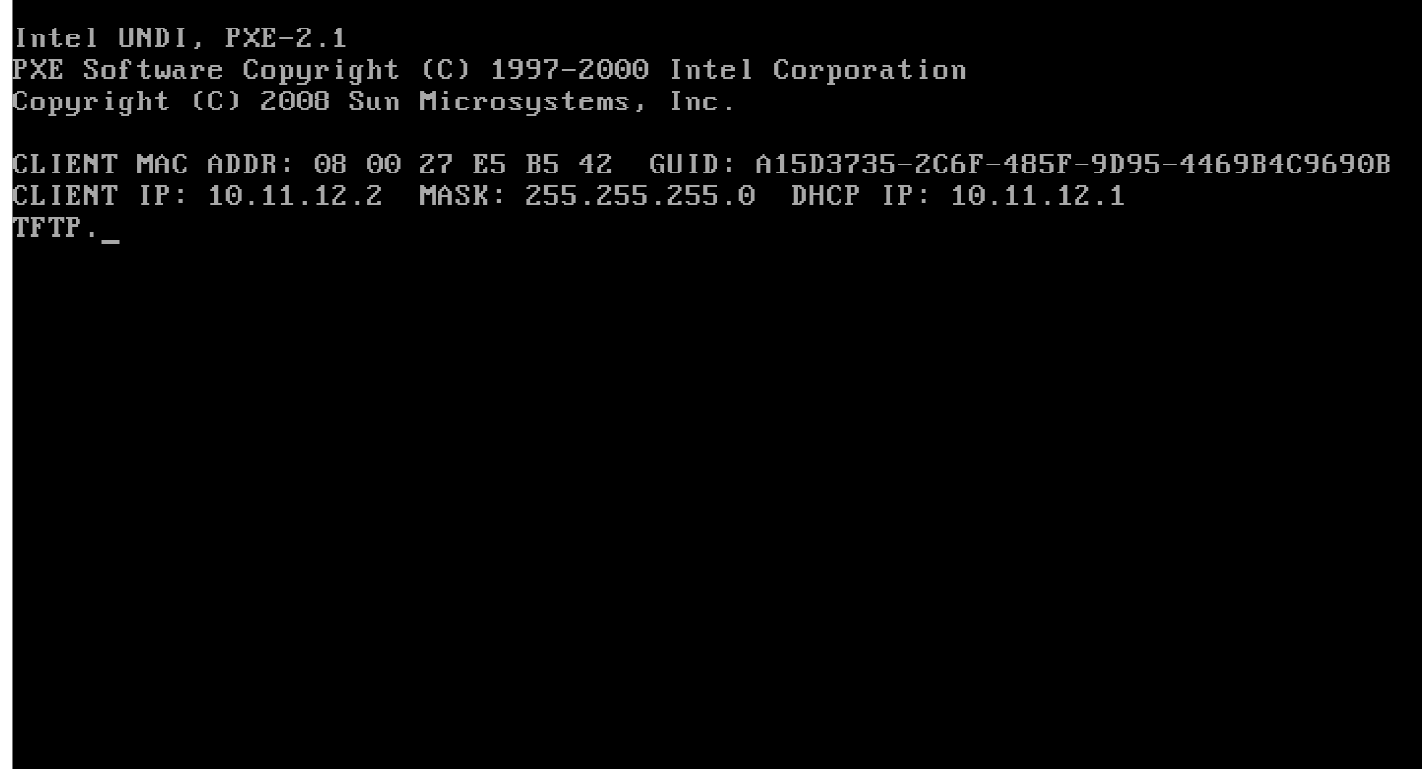

Figura A.8 - Boot de um dos nós do cluster.

Não existe a necessidade de qualquer interação direta do usuário com os nós do cluster, pois o sistema é carregado automaticamente após localizar a imagem do sistema operacional disponível pela rede através do servidor Pelican.

Novamente, se o nó escravo possuir um monitor, após alguns minutos (o tempo pode variar de acordo com o hardware) será exibida a tela da Figura A.9.

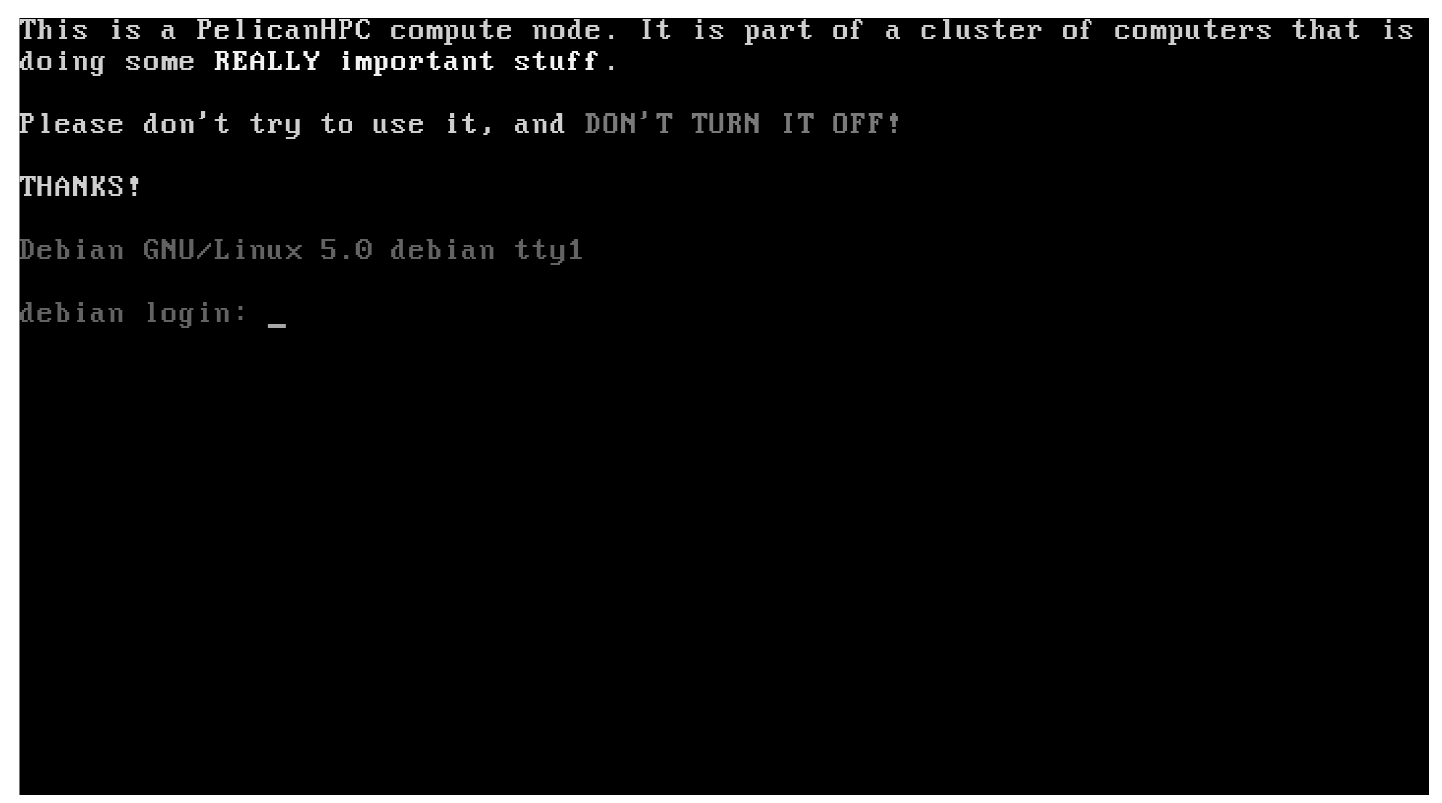

Figura A.9 - Tela principal de um nó escravo. 


\section{A.3 Localizando os nós escravos no servidor}

O sistema paralelo precisa reconhecer os nós escravos que foram ligados e que tiverem o sistema Pelican carregado, para isso deve-se voltar, no servidor, ao ponto de parada da Figura A.7, selecionando "Yes" e teclando ENTER.

O nó servidor irá agora localizar todos os nós presentes na mesma estrutura física de rede e que já carregaram o sistema operacional Pelican, como pode ser visto na Figura A.10.

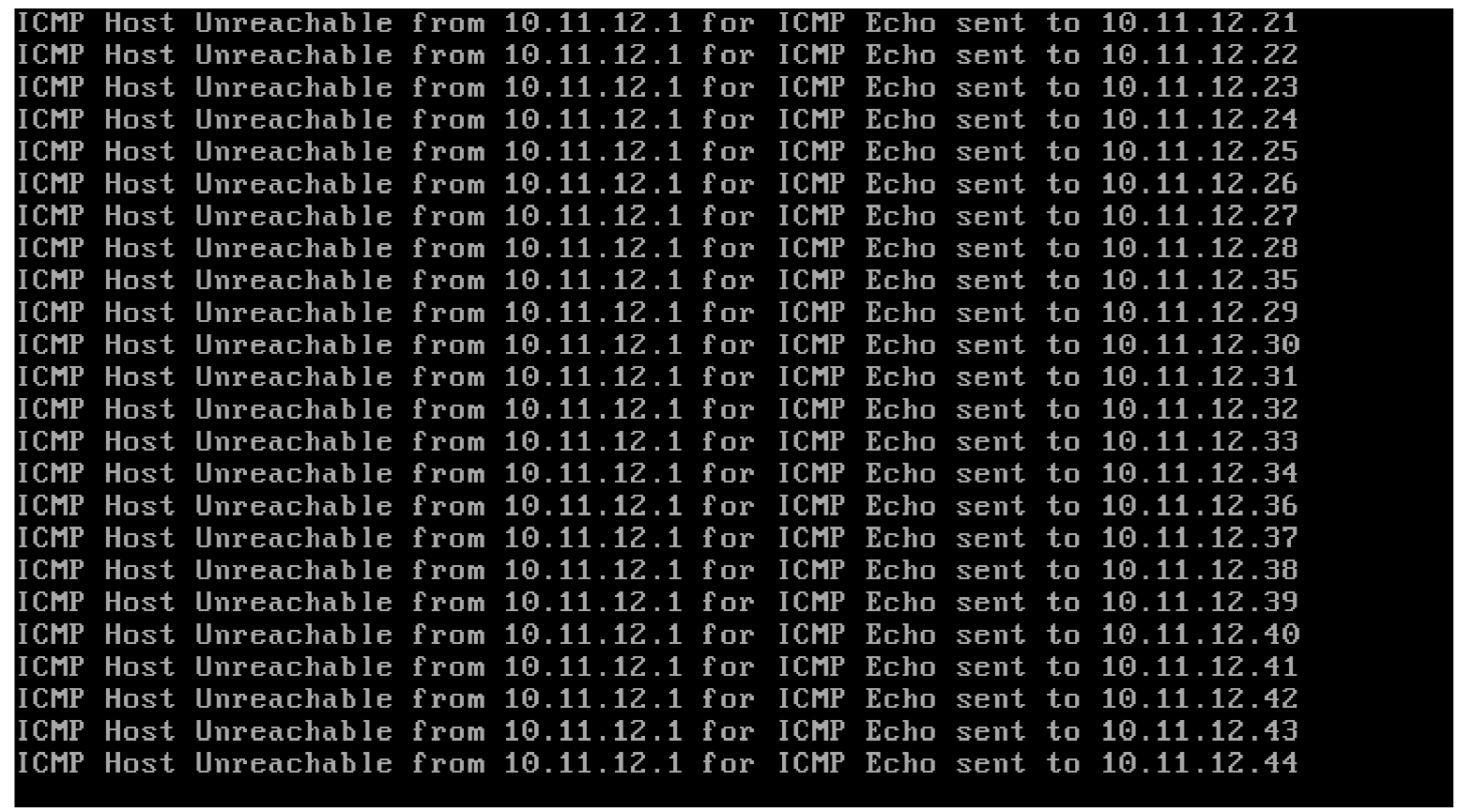

Figura A.10 - O nó servidor buscando os nós escravos.

Se observar com cuidado a Figura A.10, pode-se notar o envio de pacotes de echo ICMP, os quais solicitam uma resposta de recebimento por cada um dos endereços dos nós pertencentes à estrutura do cluster.

A próxima figura, denominada Figura A.11, mostra a tela do servidor já com o número de nós identificados por ela e aguardando uma confirmação de finalização do processo, selecionando "Yes" e teclando ENTER. Caso a opção "No" seja selecionada, o servidor irá tentar localizar novos nós escravos. 


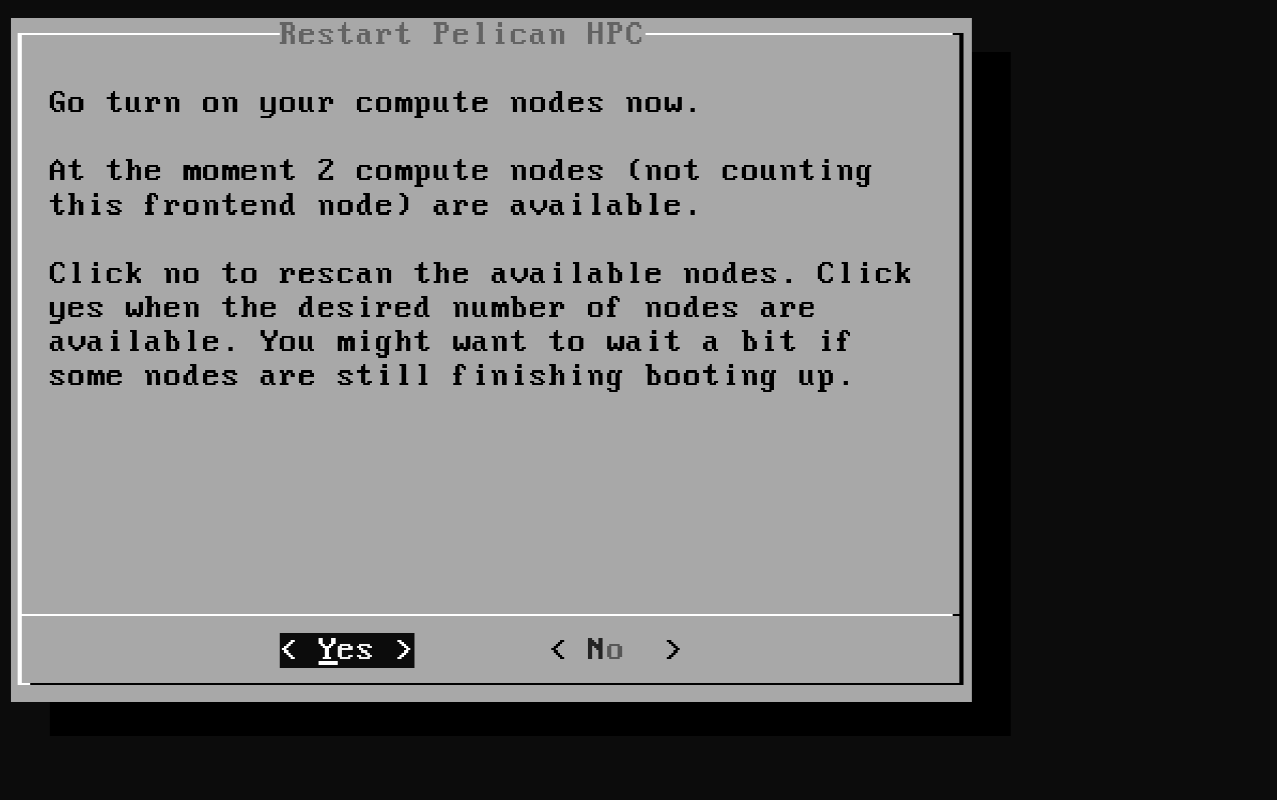

Figura A.11 - Confirmação da localização dos nós da rede.

A tela final, após o script de configuração do cluster, será exibida como na Figura A.12 e, então, basta teclar "ENTER" para voltar ao Shell do servidor, finalizando o processo inicializado pelo comando "pelican_setup".

Restart Pelican HPC
Your cluster of 3 nodes is (probably)
lamboted. If there was a problem, just re-run
the script.
The nodes in the cluster are listed in the
file $r$ tmp/bhosts. If you add or remove
compute nodes, re-run this script
(pelican_restart_hpc) wheneuer you like.
K ok >

Figura A.12 - Tela final do comando "pelican_setup". 